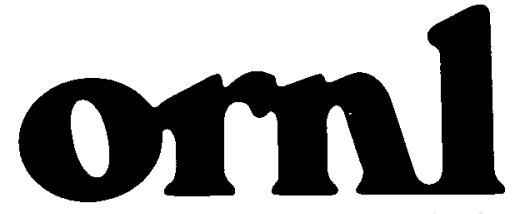

OAK RIDGE

NATIONAL

LABORATORY

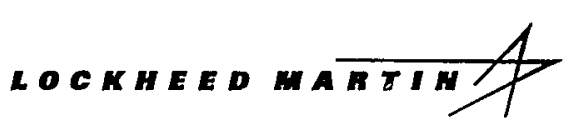

RECEIVED

NOV 291999

OSTI
Durability-Based Design Criteria for a Chopped-Glass-Fiber Automotive Structural Composite

\author{
J. M. Corum \\ R. L. Battiste \\ W. Ren \\ M. B. Ruggles
}


This report has been reproduced from the best available copy.

Reports are available to the public from the following source.

National Technical Information Service

5285 Port Royal Road

Springfield, VA 22161

Telephone 703-605-6000 (1-800-553-6847)

TDD 703-487-4639

Fax 703-605-6900

E-mail orders@ntis.fedworld.gov

Web site http://www.ntis.gov/ordering.htm

Reports are available to U.S. Department of Energy (DOE) employees, DOE contractors, Energy Technology Data Exchange (ETDE) representatives, and Intemational Nuclear Information System (INIS) representatives from the following source.

Office of Scientific and Technical Information

P.O. Box 62

Oak Ridge, TN 37831

Telephone 423-576-8401

Fax 423-576-5728

E-mail reports@adonis.osti.gov

Web site http://www.osti.gov/products/sources.htm!

Reports produced after January 1, 1996, are generally available via the DOE Information Bridge. Web site http:/hww.doe.gov/bridge

This report was prepared as an account of work sponsored by an agency of the United States Government. Neither the United States Government nor any agency thereof, nor any of their employees, makes any warranty, express or implied, or assumes any legal liability or responsibility for the accuracy, completeness, or usefulness of any information, apparatus, product, or process disclosed, or represents that its use would not infringe privately owned rights.

Reference herein to any specific commercial product, process, or service by trade name, trademark, manufacturer, or otherwise, does not necessarily constitute or imply its endorsement, recommendation, or favoring by the United States Government or any agency thereof. The views and opinions of authors expressed herein do not necessarily state or reflect those of the United States Government or any agency thereof. 


\section{DISCLAIMER}

Portions of this document may be illegible in electronic image products. Images are produced from the best available original document. 
ORNL/TM-1999/182

Engineering Technology Division

\title{
DURABILITY-BASED DESIGN CRITERIA FOR A CHOPPED- GLASS-FIBER AUTOMOTIVE STRUCTURAL COMPOSITE
}

\author{
J. M. Corum \\ R. L. Battiste \\ W. Ren \\ M. B. Ruggles
}

November 1999

\author{
Prepared by the \\ OAK RIDGE NATIONAL LABORATORY \\ Oak Ridge, Tennessee 37831-6285 \\ managed by \\ LOCKHEED MARTIN ENERGY RESEARCH CORP. \\ for the \\ U.S. DEPARTMENT OF ENERGY \\ under contract DE-AC05-96OR22464
}


$\ldots+\ldots$,

,

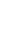




\section{CONTENTS}

ABSTRACT.

1. INTRODUCTION.

1.1 BACKGROUND.

1.2 MATERIALS/PROCESS DESCRIPTIONS ................................................... 1-2

1.2.1 Reference Material .......................................................................... $1-2$

1.2.2 Verification Material..................................................................... $1-3$

1.3 LOADINGS AND ENVIRONMENTS ……….......................................... $1-4$

1.4 OUTLINE OF REPORT ...................................................................... $\quad 1-5$

1.5 DEFINITONS USED IN PART 1............................................................. $1-5$

PART 1. DESIGN CRITERIA

2. ELASTIC AND CREEP PROPERTIES FOR DESIGN ANALYSIS .......................... 2-1

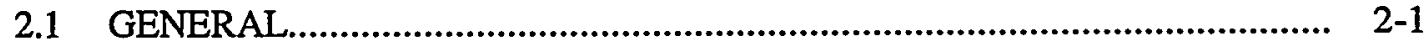

2.2 ELASTIC CONSTANTS FOR DESIGN........................................................ 2-1

2.2.1 Effect of Temperature...................................................................... 2-1

2.2.2 Environmental Effects ................................................................. 2-1

2.2.3 Prior Loading Effects........................................................................... 2-1

2.3 CREEP PROPERTIES FOR DESIGN ................................................... 2-2

2.3.1 Basic Creep Equation............................................................................ 2-3

2.3.2 Effect of Temperature ......................................................................... 2- 2-3

2.3.3 Environmental Effects........................................................................ 2-3

2.3.4 Isochronous Stress-Strain Curves...................................................... 2-5

Appendix 2.A. TIME-DEPENDENT BENDING OF CANTILEVER BEAMS................... 2. 2-9

3. BIAXIAL STRENGTH CRITERION-MAXIMUM PRINCIPAL STRESS............... 3-1

4. DESIGN ALLOWANCES FOR STATIC LOADINGS............................................ 4-1

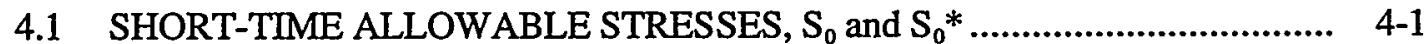

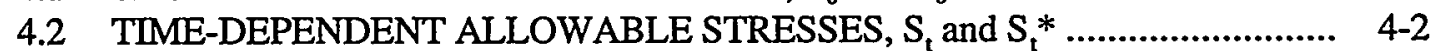

4.3 TREATMENT OF MEMBRANE AND BENDING STRESSES ........................ . 4-6

4.4 TREATMENT OF INCREMENTS OF SUSTAINED LOADS ......................... 4. 4-6

5. DESIGN LIMITS FOR CYCLIC LOADINGS ................................................... $5-1$

5.1 BASIC FATIGUE DESIGN CURVES........................................................... $5-1$

5.2 EFFECTS OF TEMPERATURE ........................................................... $\quad 5-2$

5.3 ENVIRONMENTAL EFFECTS................................................................. $5-2$

5.4 TREATMENT OF VARYING STRESS AMPLITUDES.................................... $5-2$

5.5 FATIGUE EVALUATION PROCEDURE...................................................... 5-3

6. DAMAGE TOLERANCE DESIGN FOR LOW-ENERGY

IMPACTS AND OTHER DEFECTS ............................................................. 6

6.1 GENERAL REQUIREMENTS ................................................................. 6-1

6.2 EFFECTS OF CIRCULAR HOLES......................................................... 6-1

6.3 DETERMINATION OF IMPACT DAMAGE AREAS .................................. 6-2

6.4 DETERMINATION OF STRENGTH AND STIFFNESS DEGRADATION..... 6-2

7. SUMMARY AND COMPARISON WITH REFERENCE COMPOSITE..................... 7-1

7.1 ELASTIC AND CREEP PROPERTIES FOR DESIGN ANALYSIS .................. 7-1

7.2 BIAXIAL STRENGTH CRITERION …………........................................ 7-2

7.3 DESIGN ALLOWABLE STRESSES FOR STATIC LOADINGS..................... $\quad 7-2$

7.4 LIMITS FOR CYCLIC LOADINGS ............................................................. 
7.5 DAMAGE TOLERANCE EVALUATION ................................................. $7-4$

7.6 SIMPLIFIED SUMMARY OF DESIGN RULES ....................................... $7-5$

PART 2. BACKGROUND DATA AND MODELS

8. BASIC TENSILE, COMPRESSIVE, AND IN-PLANE SHEAR PROPERTIES......... 8-1

8.1 INTRODUCTION............................................................................. $8-1$

8.2 MOISTURE SORPTION ................................................................... 8-2

8.3 TENSILE PROPERTIES ....................................................................... 8-5

8.3.1 Room-Temperature Behavior ....................................................... 8-5

8.3.2 Temperature Effects..................................................................... 8-7

8.3.3 Environmental Effects.............................................................. 8-11

8.4 COMPRESSIVE PROPERTIES ....................................................... 8-13

8.4.1 Room-Temperature Behavior ............................................... 8-13

8.4.2 Temperature Effects............................................................... 8-14

8.4.3 Environmental Effects ............................................................... 8-14

8.5 IN-PLANE SHEAR PROPERTIES ................................................ 8-18

8.5.1 Room-Temperature Behavior ..................................................... 8-18

8.5.2 Temperature Effects.................................................................. 8-18

8.5.3 Environmental Effects................................................................ 8-21

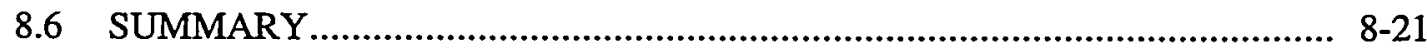

9. FLEXURE AND SHORT-BEAM SHEAR PROPERTIES .................................... 9-1

9.1 OUT-OF-PLANE FLEXURE PROPERTIES ............................................... 9-1

9.1.1 Room-Temperature Behavior ......................................................... 9-1

9.1.2 Temperature Effects................................................................ 9-1

9.1.3 Environmental Effects................................................................ 9-2

9.2 SHORT-BEAM SHEAR

9.2.1 Room-Temperature Behavior .................................................. 9-2

9.2.2 Moisture Effects .................................................................... $9-2$

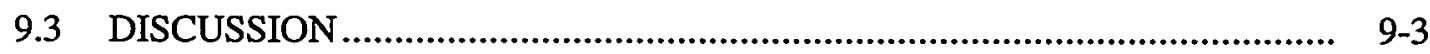

10. BIAXIAL FLEXURE TESTS AND STRENGTH CRITERION ............................ 10-1

10.1 INTRODUCTION ............................................................................... 10-1

10.2 BIAXIAL STRENGTH CRITERION .............................................. 10-2

10.3 TEMPERATURE EFFECTS.......................................................... 10-6

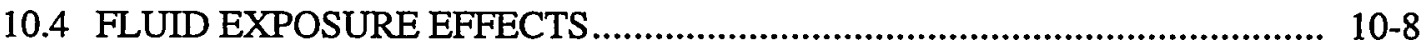

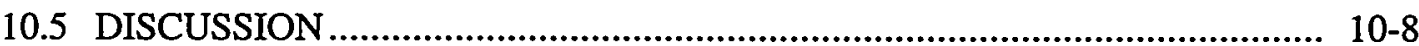

11. EFFECTS OF STRESS CONCENTRATIONS.............................................. 11-1

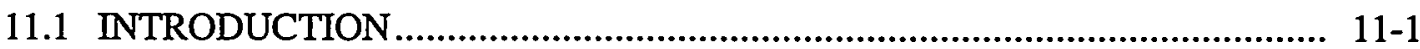

11.2 BACKGROUND—STRESS CONCENTRATION FACTORS

FOR CIRCULAR HOLES .................................................................. 11-1

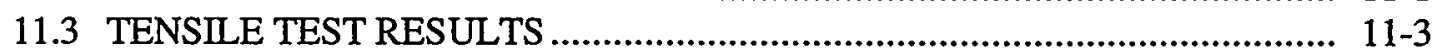

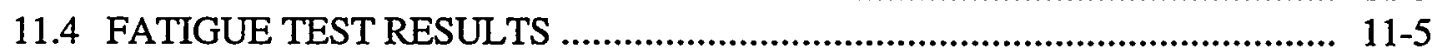

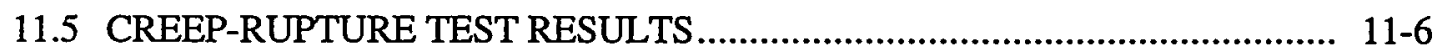

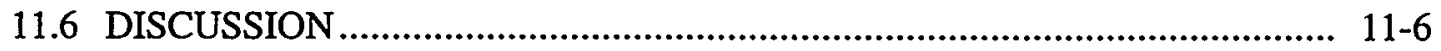

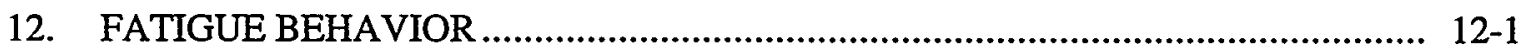

12.1 INTRODUCTION ............................................................................ 12-1

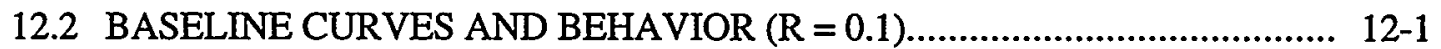

12.3 ENVIRONMENTAL EFFECTS.......................................................... 12-5

12.4 BLOCK LOADING EFFECTS (CUMULATIVE DAMAGE) ........................ 12-12

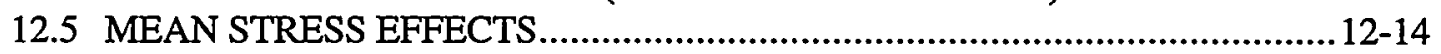

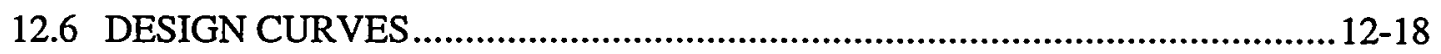




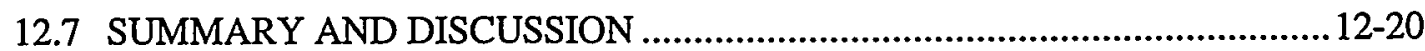

13. CREEP DEFORMATION........................................................................... 13-1

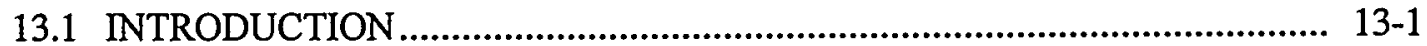

13.2 BASELINE CREEP DEFORMATION ……………..................................... 13-2

13.2.1 Creep Deformation Data in Air with 50\% Relative Humidity at Room Temperature Under Tension .................................................. 13-2

13.2.2 Linearity, Data Reduction, and Model Development ............................. 13-2

13.3 TEMPERATURE EFFECTS IN AIR............................................................ 13-5

13.3.1 Creep Compliance at Various Temperatures .......................................... 13-5

13.3.2 Creep Deformation Models for Various Temperatures............................ 13-8

13.3.3 Tertiary Creep at $120^{\circ} \mathrm{C}$.................................................................. 13-8

13.4 ENVIRONMENTAL EFFECTS...................................................................13-11

13.4.1 Creep Compliance in Various Environments .......................................13-11

13.4.2 Creep Deformation Models for Various Environments ...........................13-12

13.5 COMPRESSIVE CREEP DEFORMATION .................................................13-14

13.5.1 Compressive Creep Compliance and Model in Air/50\%/RH

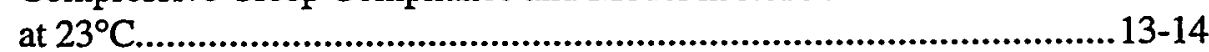

13.5.2 Compressive Creep Compliance and Model in Water at $23^{\circ} \mathrm{C}$.................13-16

13.6 SUMMARY AND DISCUSSION ...................................................................13-16

14. CREEP RUPTURE ............................................................................... 14-1

14.1 INTRODUCTION....................................................................... 14-1

14.2 TENSILE BEHAVIOR ......................................................................... 14-1

14.2.1 Failure in Air with 50\% RH at Room Temperature ............................. 14-1

14.2.2 Temperature Effects in Air................................................................ 14-2

14.2.3 Environmental Effects.............................................................. 14-5

14.3 COMPRESSIVE BEHAVIOR ................................................................14-10

14.3.1 Failure in Air with 50\% RH at Room Temperature ...............................14-10

14.3.2 Temperature Effects in Air .............................................................14-10

14.3.3 Environmental Effects......................................................................14-12

14.4 SUMMARY AND DISCUSSION ................................................................14-15

15. PRIOR LOAD EFFECTS ................................................................................. 15-1

15.1 INTRODUCTION................................................................................... 15-1

15.2 EFFECT OF PRIOR SHORT-TIME STATIC LOADS ..................................... 15-1

15.3 EFFECT OF PRIOR FATIGUE CYCLES................................................... 15-2

15.4 EFFECT OF PRIOR CREEP DEFORMATION .............................................. 15-4

15.5 SUMMARY AND DISCUSSION ........................................................... 15-5

16. DAMAGE TOLERANCE ....................................................................... 16-1

16.1 INTRODUCTION .................................................................................... 16-1

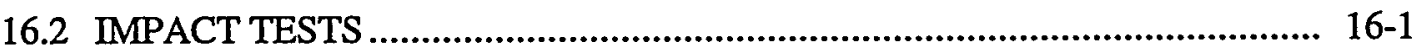

16.2.1 Baseline Results ........................................................................ 16-1

16.2.2 Moisture Effects......................................................................... 16-4

16.2.3 Brick-Drop Tests........................................................................ 16-6

16.3 DEGRADATION OF PROPERTIES......................................................... 16-6

16.4 SUMMARY AND DISCUSSION ...............................................................16-12

17. REFERENCES.......................................................................................... 17-1 


\title{
DURABILITY-BASED DESIGN CRITERIA FOR A CHOPPED- GLASS-FIBER AUTOMOTIVE STRUCTURAL COMPOSITE
}

\author{
J. M. Corum \\ R. L. Battiste \\ W. Ren \\ M. B. Ruggles
}

\begin{abstract}
This report provides recommended durability-based design criteria for a chopped-glassfiber reinforced polymeric composite for automotive structural applications. The criteria closely follow the framework of an earlier criteria document for a continuous-strand-mat (CSM) glassfiber reference composite. Together these design criteria demonstrate a framework that can be adapted for future random-glass-fiber composites for automotive structural applications.

Both criteria documents were developed as a part of a U.S. Department of Energy Advanced Automotive Materials project entitled "Durability of Lightweight Composite Structures." The project is closely coordinated with the Automotive Composites Consortium (ACC). Both the initial CSM reference composite and the chopped-fiber verification composite were chosen and provided by ACC.

This document is in two parts; Part 1 provides the design criteria, while Part 2 provides the underlying experimental data and models. The durability issues addressed include the effects of cyclic and sustained loadings, temperature, fluid environments, and low-energy impacts (e.g., tool drops and roadway kickups) on deformation, strength, and stiffness. Guidance for design analysis, time-independent and time-dependent allowable stresses, rules for cyclic loadings, and damage-tolerance design guidance are provided.
\end{abstract}

\section{INTRODUCTION}

\subsection{BACKGROUND}

This report is the second one providing durability-based design criteria for automotive structures made of random-glass-fiber polymeric composites. The first report, which was in two parts, addressed a reference composite consisting of a urethane-based matrix reinforced with a glass-fiber continuous-strand mat (CSM).1,2 This second report addresses a second composite, a urethane-based matrix, reinforced with a chopped-glass-fiber mat preformed by the $\mathrm{P} 4$ process. This second material is referred to as the verification material, in that it was intended to verify that the overall design criteria framework, developed for the reference composite, could be adapted to other similar candidate automotive structural composites.

Both reports are based on experimental characterization and modeling carried out as a part of the U.S. Department of Energy (DOE) project entitled "Durability of Lightweight Composite Structures for Automotive Applications" at the Oak Ridge National Laboratory (ORNL). The project is closely coordinated with the Automotive Composites Consortium (ACC). Both the 
reference and verification composites were chosen and supplied by ACC in the form of 3.2-mm-thick plaques.

The primary project goal is to develop experimentally based, durability-driven design guidelines to assure the long-term (15-year) integrity of polymeric composite automotive structures. Durability issues include the potentially degrading effects that both cyclic and sustained loadings, exposure to automotive fluids, temperature extremes, and low-energy impacts from such things as tool drops and roadway kickups can have on structural strength, stiffness, and dimensional stability.

While the project focus has now shifted to carbon-fiber composites, this report and Refs. 1 and 2 are the result of an initial emphasis on glass-fiber composites. One other report ${ }^{3}$ completes the primary documentation of the results of the glass-fiber composite work. Reference 3 provides recommended minimum test requirements and suggested test methods for establishing the durability properties and characteristics of future candidate random-glass-fiber polymeric composites for automotive structural applications. The recommendations and suggestions are based on experience and results developed under the Durability Project. The report is intended as an aid to suppliers offering new glass-fiber composites for automotive applications and to testing organizations that are enlisted to characterize the composites.

\subsection{MATERIALS/PROCESS DESCRIPTIONS*}

This report follows closely the scope and outline of Refs. 1 and 2, and while its primary focus is on the chopped-fiber verification composite, frequent comparisons are made throughout with the results presented in Refs. 1 and 2 for the reference composite. The following information will differentiate these two materials with respect to their chemical make-up and processing histories.

\subsubsection{Reference Material}

The first material, identified as the reference material, received the most extensive characterization and was the primary source of the models and guidelines. This composite material has a resin matrix composed of a urethane-based material produced by the Dow Chemical Company and identified as Spectrim MM364. The reinforcement is a CSM product produced by Vetrotex International and identified as Unifilo U750.

Chemically, the resin matrix in this material is an isocyanurate. In this chemical structure, the basic urethane chemical components, polyol and polymeric isocyanate, are catalyzed in a manner to produce cyclic, isocyanurate, structures that produce the desired high-temperature resistance in the finished composite. The catalyst, which produces this cyclic structure, is diphenylmethane diisocyanate, referred to as DABCO. The matrix is produced via the Structural Reaction Injection Molding (SRIM) process in which the two reactive streams, polyol and polymeric isocyanate, are pumped at high pressure into an impingement mixing chamber to quickly produce a uniform mixture of the components. The reacting mixture is then pumped into a closed mold containing the reinforcement. The reaction time necessary to transform the liquid chemical reactants into the solid resin matrix is of the order of $30 \mathrm{~s}$.

The Vetrotex Unifilo U750 reinforcement consists of continuous strands of E-glass combined with a polyester powdered binder to produce a swirl mat architecture. The material is

\footnotetext{
${ }^{*}$ Contributed by E. M. Hagerman, Automotive Composites Consortium/General Motors.
} 
available on continuous rolls of varying widths. The glass is produced with a basic silane size that, along with the polyester binder, is present at an $8 \%$ level. The specific version used in these experiments was U750-450-138. The product is claimed to be compatible with polyester, vinylester, epoxy and urethane resin systems. Each sheet of this product is actually comprised of three separate layers of glass to produce the surfaces and a core. The individual layers differ in glass strand geometry and configurations and produce easy resin flow-through and wet-out during molding operations.

The mold used in these experiments was a simple "picture frame mold" in which a steel shim of the thickness of the desired molded part was placed between two flat steel plates. This shim contained a square center cut-out of 610 by $610 \mathrm{~mm}$, the dimensions of the plaque to be produced. The upper steel plate incorporated a sprue or connection to the output of the SRIM machine. The mold was mounted in a 150 -ton hydraulic press. The procedure for molding the reference material consisted of five steps. First, the glass preform, consisting of five plies of the specific U750 product was cut to the 610 - by $610-\mathrm{mm}$ exact dimensions of the mold. Second, the preform was placed into the cavity produced by the lower steel mold plate and the cut-out shim. Third, the press was closed and full tonnage applied. Fourth, the resin from the SRIM machine was injected at high pressure into the preform through the sprue located in the center of the upper mold plate. The resin then flowed through the preform constrained in the mold. And finally, after a 2.5 -min cure time, the press opened, and the molded plaque was removed. The final step was a $1-\mathrm{h}$ postcure at $150^{\circ} \mathrm{C}$.

The resulting composite had an average fiber content of $25.0 \mathrm{vol} \%(41.4 \mathrm{wt} \%)$.

\subsubsection{Verification Material}

The matrix of the verification material was produced by the Bayer Corporation and identified as Baydur 420 IMR, where IMR denotes "internal mold release." Chemically, the matrix resin is also a urethane-based material but differs in its basic chemical structure. While polyols and polymeric isocyanates similar to the reference material are used, in this case an amine coreactant replaces the DABCO component and produces a cross-linked urea-urethane basic structure instead of the cyclic isocyanurate. The urea component contributes to the heat resistance of the final composite structure. Identical SRIM equipment is used as before. With the urea-urethane systems, the time required for the liquid to solid transformation is of the order of $15-20 \mathrm{~s}$.

Preforms for the verification material were produced using the $\mathrm{P} 4$ process recently developed by Owens-Corning in Battice, Belgium. In these preforms, 50-mm-long chopped glass fibers were used in place of the CSM used with the reference material. The E-glass material, RO7EX1, was specifically developed for the P4 process. The process consists of chopping the fibers and blowing them onto a screen of the same dimensions as the final part to be produced. The fibers are held in place by air being drawn through the screen. Two types of glass were used in the preparation of these preforms. The first was a fine, $600-t e x(\mathrm{~g} / 1000 \mathrm{~m})$ strand chopped to $\sim 10-\mathrm{mm}$ length and applied at $40 \mathrm{-g} / \mathrm{m}^{2}$ areal density. The purpose of this layer was to form a barrier to prevent powdered binder from penetrating the preform in subsequent stages of the preform fabrication. The second type was the structural glass at 2400 tex chopped to $50-\mathrm{mm}$ length and applied at a much heavier areal density, $2135 \mathrm{~g} / \mathrm{m}^{2}$. When sufficient fibers were in place, a powdered binder was blown into the preform and heated air used to melt and cure the binder. The binder used was a thermoset unsaturated polyester material referred to as Cray Valley Stratyl P 81 A2 and was present at the 5\% level. Finally, cool air was blown through the preform 
to set the binder. In this way, a preform containing the proper areal density of glass in the proper geometric configuration was produced.

A more sophisticated mold was used in the molding of the verification material plaques. A "shear-edge mold" replaced the picture-frame mold used previously. The primary difference is that in the shear-edge configuration, the upper mold half telescopes into the lower mold half. In this way, the composite material being molded carries the full molding pressure from the press. In the previous picture-frame mold the molding pressure was carried principally by the outer periphery of the shim. Visual inspection of plaques of the reference and verification materials shows a very rough surface with much glass read through on the reference material surface and a much smoother surface on the verification material plaques. These observations relate directly to the mold design. With both materials, appreciable shrinkage occurs during the chemical reaction. In the shear-edge mold, the upper mold half follows the chemical shrinkage through the telescoping action of the mold halves. In the picture-frame mold, the molding pressure is supported by the shim; as the shrinkage occurs, the composite contracts away from the smooth mold surfaces and leaves the observed glass read through and roughness. In addition, the new mold includes an efficient mold vacuum system that produces up to $710 \mathrm{~mm}$ of vacuum. The vacuum reduces the void content of the molded plaques.

The molding procedure for the verification material differed in that the resin injection procedure was used. The glass preforms, as delivered, were of the proper areal density and required no plying-up or cutting to dimension as was described in the CSM preforming procedure. These P4 preforms were, however, composed of the two distinct layers of differing glass types. This condition constitutes an unbalanced laminate that produces warpage in the composite plaques. To counter this, an additional $0.5-\mathrm{mm}$ layer of thin veil material was added into the bottom of the mold before the preform was introduced. A commercial veil material from Nico Corporation was used for this purpose. In the resin-injection procedure, after the preform is loaded into the mold, the mold is left open $\sim 10-15 \mathrm{~mm}$. Resin is injected into this opening, and then the press fully closed. This allows the resin to first flow, with little resistance, across the upper surface of the preform and then under closing pressure flow into the thickness direction of the preform. This procedure results in less disturbance of the glass orientation and produces a more uniform void free distribution of resin through the glass preform. Again, a 2.5-min cure time was allowed before the mold was opened and the part ejected. Final postcure was $120^{\circ} \mathrm{C}$ for $1 \mathrm{~h}$.

The verification material had an average fiber content of 28.9 vol \% (46.4 wt \%).

Thirty-six plaques of the chopped-fiber verification material were used in the durability characterization reported herein. The plaques were numbered B1 through B36 by ORNL, with each designation corresponding to a more descriptive designation used by ACC. The ORNL plaque numbers are frequently referenced in this report.

\subsection{LOADINGS AND ENVIRONMENTS}

From a durability standpoint, it is assumed here that an automobile with a composite structure must last for 15 years $(131,500 \mathrm{~h})$ and 150,000 miles. It is further assumed that during the 15 years, the vehicle will actually be operated between 3000 and $5000 \mathrm{~h}$ (at an average speed of 30 to $50 \mathrm{mph}$ ). 
The design temperature range is assumed to vary from a minimum of $-40^{\circ} \mathrm{C}$ to a maximum of $120^{\circ} \mathrm{C}$, with the higher temperatures occurring only during operation.

In addition to functional stiffness and deformation requirements, structures must support and resist a variety of live and dead loads. During operation, for example, live loads might include a combination of pothole impact, hard turn, and maximum acceleration. Dead loads during the 15-year life would include those from the weight of the vehicle or, more importantly, sustained loads in the bed of a light truck.

Structures will also be subjected to common vehicle fluids and operating atmospheres, and design limits must take the resulting property degradation into account. The effects of a variety of fluids and moisture conditions were examined in the case of the reference composite. Based on the findings there, the fluids examined here were reduced primarily to distilled water and windshield washer fluid (a methanol/water mix).

\subsection{OUTLINE OF REPORT}

This report is divided into two parts, in a manner analogous to the arrangement used in Refs. 1 and 2. Part 1, which consists of six chapters, provides detailed rules and guidelines for (1) the properties to be used in structural analysis, (2) design allowables for static loadings,

(3) design rules for cyclic loadings, and (4) damage tolerance design for low-energy impacts. A final Part 1 chapter summarizes the chopped-fiber composite criteria and compares the allowables with the corresponding values for the reference CSM composite.

Part 2, which consists of nine chapters, provides the experimental data and models on which the criteria of Part 1 are based. Those readers wishing to understand the behavioral characteristics of the chopped-fiber composite should read Part 2 prior to reading Part 1. Part 2 has chapters on basic properties, biaxial strength, stress concentration effects, fatigue, creep and creep rupture, prior load effects, and impact.

\subsection{DEFINITIONS USED IN PART I}

$\begin{array}{ll}\text { a } & \text { Hole diameter } \\ \mathrm{E} & \text { Elastic modulus } \\ \mathrm{E}_{\mathrm{t}} & \text { Time-dependent "pseudoelastic modulus" } \\ \mathrm{G} & \text { Shear modulus }[\mathrm{E}=2 \mathrm{G}(1+\mathrm{v})] \text { for an isotropic material } \\ \mathrm{K} & \text { Temperature-dependent factor on allowable bending stress } \\ \mathrm{m} & \text { Mass of impacting object } \\ \mathrm{n} & \text { Number of applied fatigue cycles of a given stress } \\ \mathrm{N}_{\mathrm{d}} & \text { Number of allowable design cycles for a given stress } \\ \mathrm{P} & \text { Calculated membrane stress components at a point in the plane of a plate or shell } \\ \mathrm{Q} & \text { structure } \\ \mathrm{R} & \text { Calculated bending stress components at a point } \\ \mathrm{S} & \text { Ratio of minimum to maximum stress in a fatigue cycle } \\ \mathrm{S}_{\mathrm{a}} & \text { Maximum principal stress derived from stress components at a point } \\ \mathrm{S}_{\mathrm{max}} & \text { Maximum stress in a fatigue cycle } \\ \mathrm{S}_{0} & \text { Basic short-time allowable stress (time } \mathrm{t}=0 \text { ) } \\ \mathrm{S}_{\mathrm{t}} & \text { Time-dependent allowable stress }\end{array}$


$\mathrm{S}_{0} * \quad$ Short-time allowable stress applicable to biaxial stresses

$\mathrm{S}_{\mathrm{t}}{ }^{*} \quad$ Time-dependent allowable stress applicable to biaxial stresses

$\mathrm{S}_{\mathrm{r}} \quad$ Minimum creep-rupture strength at a given time

SCF Stress concentration factor

$\mathrm{t} \quad$ Time at a given stress

$\mathrm{T}_{\mathrm{d}} \quad$ Allowable design time at a given stress

UTS Ultimate tensile strength

$v \quad$ Velocity of impacting object

w Plate width

$\varepsilon \quad$ Normal strain

$\varepsilon^{c} \quad$ Normal creep strain

$\sigma \quad$ Normal stress

$\sigma_{\mathrm{r}} \quad$ Average creep-rupture strength at a given time

$\bar{\sigma} \quad$ Applied stress in plate with hole

$\bar{\sigma}_{\infty} \quad$ Applied stress in infinitely wide plate with hole

$\checkmark$ Poisson's ratio 


\section{Part 1}

DESIGN CRITERIA 


\section{ELASTIC AND CREEP PROPERTIES FOR DESIGN ANALYSIS}

\subsection{GENERAL}

Although local and plaque-to-plaque variations occur, tests reported in Chap. 8 indicate that, on average, the $\mathrm{P} 4$ chopped-glass-fiber composite is isotropic in the plane of the plaques. This means that the elastic and creep properties given in this chapter are assumed to be identical in all directions in the plane of the plaque.

\subsection{ELASTIC CONSTANTS FOR DESIGN}

For an orthogonally anisotropic material that is isotropic in one plane, there are five independent elastic constants-two associated with the plane of the isotropy and three associated with the direction normal to that plane. Here, the in-plane constants are taken as the modulus of elasticity, E, and Poisson's ratio, v. The in-plane shear modulus, G, is then given by

$$
\mathrm{G}=\frac{\mathrm{E}}{2(1+v)} \text {. }
$$

Data reported in Chap. 8 confirm that this relation holds for the P4 chopped-fiber composite.

The recommended average room-temperature elastic modulus and Poisson's ratio values are $E=11.8 \mathrm{GPa}$, and $v=0.32$. These basic values should be adjusted in accordance with the recommendations of the following three subsections.

\subsubsection{Effect of Temperature}

Poisson's ratio increases slightly with increasing temperature (see Chap. 8). The modulus of elasticity, on the other hand, decreases linearly as the temperature increases from -40 to $120^{\circ} \mathrm{C}$ (see Chap. 8). This decrease is shown in Fig. 2.1 as a multiplication factor on the above roomtemperature value of $11.8 \mathrm{GPa}$. Values of both Poisson's ratio and stiffness are tabulated in Table 2.1.

\subsubsection{Environmental Effects}

As described in Chap. 8, two reference fluid environments where chosen to bound practical effects. The first is a presoak of $1000 \mathrm{~h}$ in room-temperature distilled water. The second is a 100 -h presoak in windshield washer fluid (70\% methanol/30\% distilled water). A stiffness multiplication factor of 0.91 covers both degrading conditions.

\subsubsection{Prior Loading Effects}

As described in Chap. 15, prior loadings, whether short-time static, cyclic, or long-time sustained, produce microstructural damage that is manifest as a reduction in stiffness. These reductions should be accounted for in design analyses. Recommended reduction factors, taken from Sect. 15.5, are tabulated below.

\begin{tabular}{lcc} 
Prior load & & $\begin{array}{c}\text { Stiffness } \\
\text { multiplication factor }\end{array}$ \\
\cline { 3 - 3 } Short-time static & & 0.96 \\
Fatigue cycling & & 0.88 \\
Long-term sustained & & 0.87
\end{tabular}




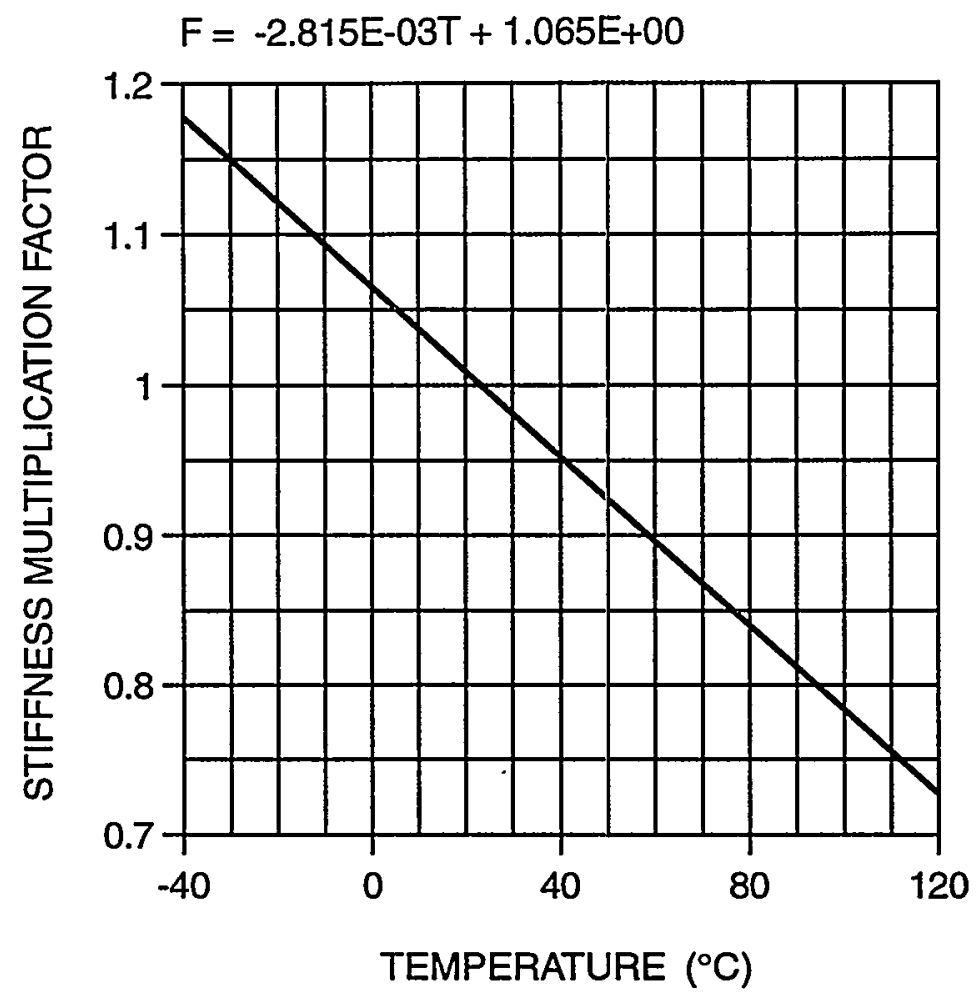

Fig. 2.1. Multiplication factor for determining elastic stiffness at a given temperature from room-temperature value. This factor also holds for tensile strength.

Table 2.1. Stiffness, E, and Poisson's ratio, v, at various temperatures

\begin{tabular}{ccc}
\hline Temperature $\left(\mathrm{C}^{\circ}\right)$ & Stiffness $(\mathrm{GPa})$ & $v$ \\
\hline-40 & 13.9 & 0.31 \\
23 & 11.8 & 0.32 \\
50 & 10.9 & 0.33 \\
120 & 8.6 & 0.34 \\
\hline
\end{tabular}

In each of these cases, the value shown corresponds to maximum allowable design prior loading conditions. The prior short-time static load corresponds to the maximum allowable, $\mathrm{S}_{0}$ (see Chap. 4); the prior cycling corresponds to $5 \%$ of the cyclic life, which is the design limit (see Chap. 5); and the duration of the long-term sustained load corresponds to the allowable design time (see Chap. 4).

\subsection{CREEP PROPERTIES FOR DESIGN}

In the case of long-term sustained loadings-either those associated with the 3000- to 5000-h operating life of an automobile or the nominally 15-year overall life-creep deformations may become an important consideration and need to be accounted for in design analyses. This can be done at one of three levels of sophistication: 
- using a time-dependent "pseudoelastic modulus" in an elastic analysis,

- using a creep equation in an inelastic (elastic-creep) analysis, or

- using a damage-based constitutive model derived for the material that can predict the effects of changing load levels as well as recovery strains upon unloading.

Guidance for the first two are given in the following sections. The recommended constitutive model is described in Ref. 4.

\subsubsection{Basic Creep Equation}

The recommended creep equation is derived in Chap. 13 from the results of creep tests at various stresses. It was found to apply to both tensile and compressive stresses, and presumably, with an appropriate biaxial relation, such as the common $\mathrm{J}_{2}$ creep theory, to biaxial stresses as well.

The room-temperature, ambient air, creep strain is given by

$$
\varepsilon^{c}=9.59 \times 10^{-4} \sigma \mathrm{t}^{0.141}
$$

where $\varepsilon^{c}$ is the time-dependent creep strain in percent, $\sigma$ is stress in $\mathrm{MPa}$, and $\mathrm{t}$ is time in hours. The linear relation of Eq. (2.1) holds reasonably well up to a stress of $125 \mathrm{MPa}$. Figure 2.2 shows the creep curves predicted by Eq. (2.1).

As was the case for the elastic modulus, creep strains are affected by temperature and fluid environments. These effects are described in the following two subsections. Unlike the elastic modulus case, however, prior loads appear to have no effect on subsequent creep strains.

\subsubsection{Effect of Temperature}

The effect of temperature on creep is to multiply the creep strains predicted by Eq. (2.1) by a simple factor, which is shown in Fig. 2.3 for the automotive design temperature range and given in Table 2.2 for selected temperatures. The right-hand column in Table 2.2 gives the approximate stress level above which the creep response becomes nonlinear with stress and Eq. (2.1) is no longer accurate.

While tensile and compressive creep are equal at room temperature, this may not be the case at elevated temperatures. No elevated temperature compressive creep strain data were generated, but it is expected that compressive creep will increase faster than tensile creep. Thus, care should be taken to avoid hot structures in regions of compressive stress.

\subsubsection{Environmental Effects}

Creep multiplication factors were developed in Chap. 13 for the two reference fluid environments-a $1000-\mathrm{h}$ presoak in distilled water and a $100-\mathrm{h}$ presoak in windshield washer fluid. After the presoaks, the creep tests were performed with the specimens immersed in the fluid. The resulting multiplication factors are

\begin{tabular}{lc}
\multicolumn{1}{c}{ Fluid } & $\begin{array}{c}\text { Creep-strain } \\
\text { multiplication factor }\end{array}$ \\
\hline Distilled water & 1.79 \\
Windshield washer fluid & 2.23
\end{tabular}




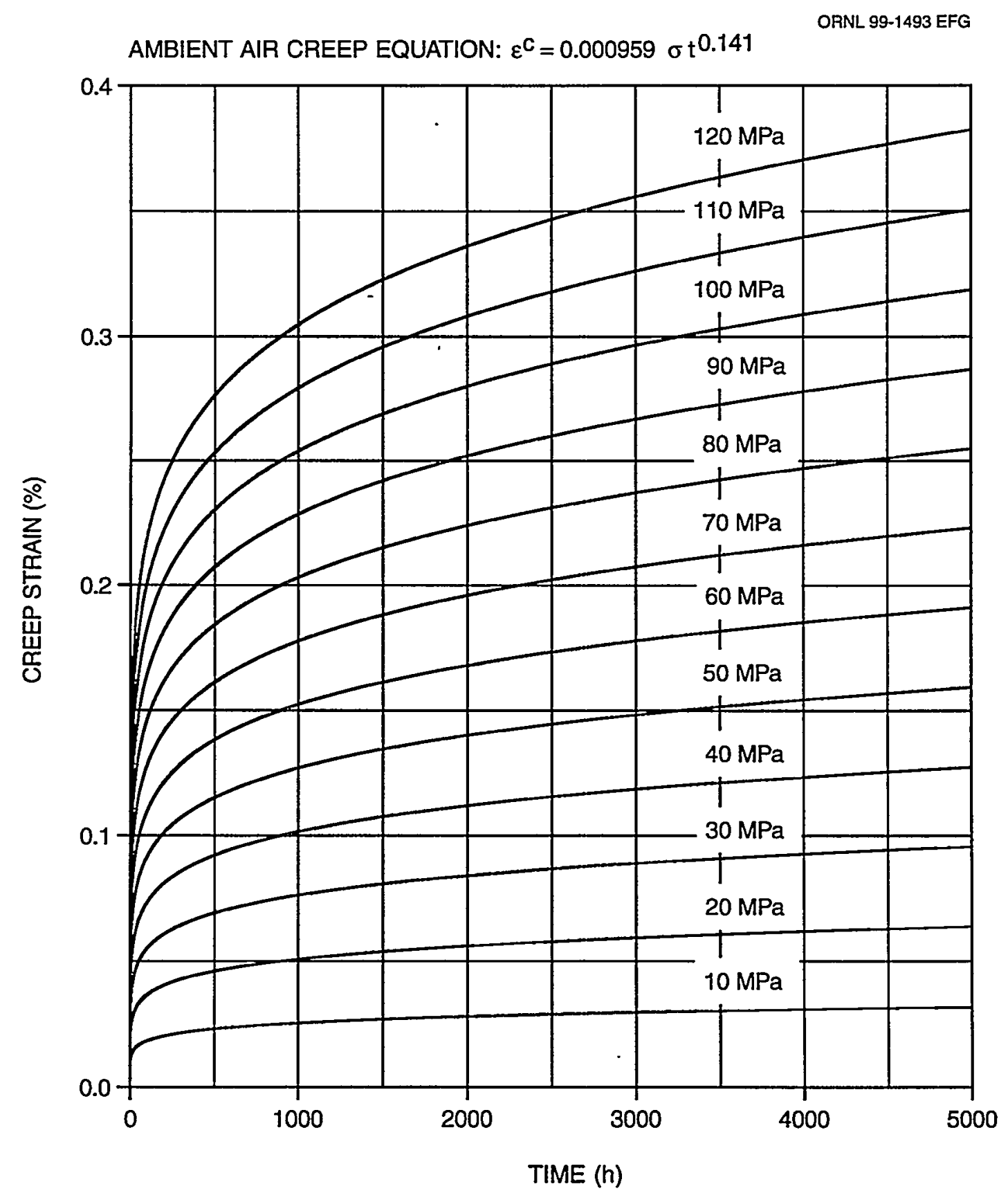

Fig. 2.2. Time-dependent creep strain curves for room-temperature ambient air conditions (nominally $50 \%$ RH). 


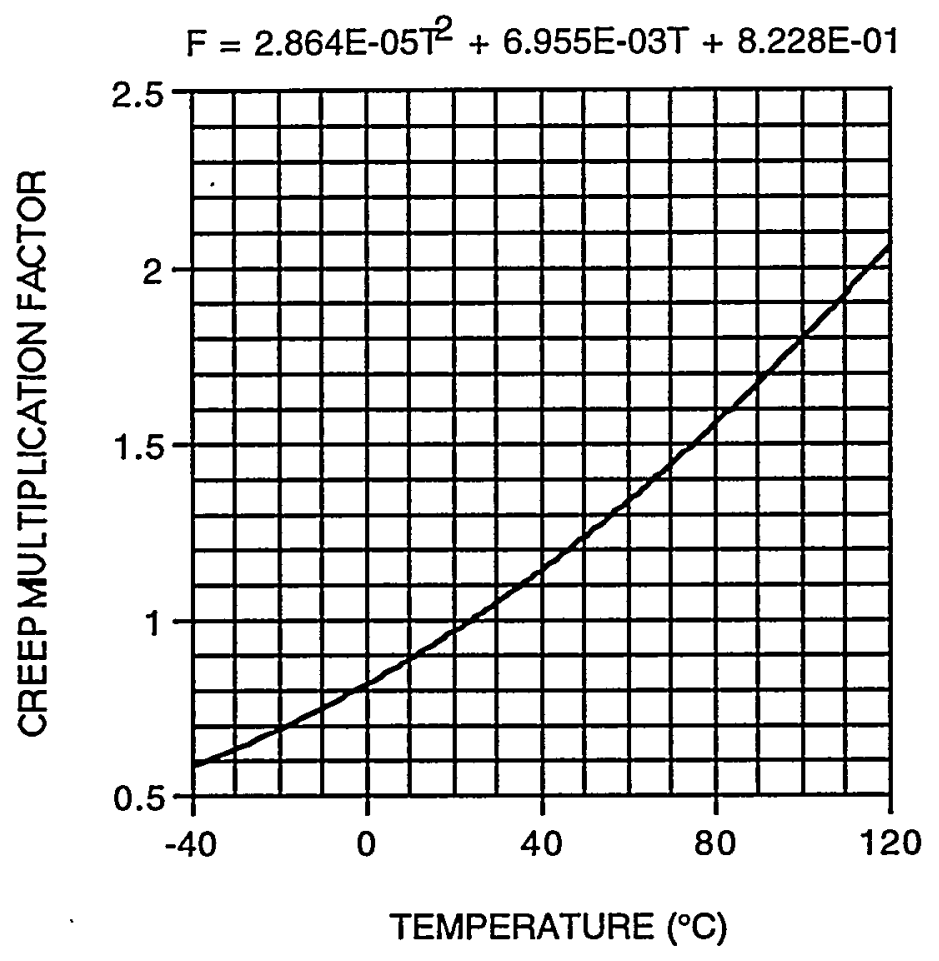

Fig. 2.3. Creep strain multiplier for temperature effects.

Table 2.2. Temperature multiplication factors for creep strain

\begin{tabular}{ccc}
\hline Temperature $\left(\mathrm{C}^{\circ}\right)$ & Creep factor & Limit of linearity $(\mathrm{MPa})$ \\
\hline-40 & 0.59 & 150 \\
23 & 1.00 & 125 \\
50 & 1.24 & 100 \\
120 & 2.07 & 75 \\
\hline
\end{tabular}

To bound the effects of fluids, the creep strains predicted by Eq. (2.1) should be multiplied by one of the above factors, as appropriate.

Compressive creep data presented in Chap. 13 for specimens presoaked in distilled water at $50^{\circ} \mathrm{C}$ for 3 months (an extreme condition) indicate that subsequent room-temperature creep in water is the same as in tension. In light of these results, it is recommended that the above factors be used for compression and for biaxial stress states.

\subsubsection{Isochronous Stress-Strain Curves}

The use of isochronous stress-strain curves, which show the total strain at a given time resulting from a constant applied stress, were introduced in Ref. 1 as a way to approximately predict creep deformations in a structure. When one of these curves, corresponding to a specific 
time, is used in an elastic-plastic analysis, the creep deformation occurring during that time period can often be predicted reasonably well.

Isochronous curves for the P4 chopped-fiber composite are shown in Fig. 2.4. An equation is also provided. The curve labeled "tensile" is the short-time $(0 \mathrm{~h})$ stress-strain curve. The 131,000-h curve shows the total strain that would accumulate at a given stress level over the 15 -year life of an automobile. The creep strain over 15 years is about half again as much as the "instantaneous" loading strain.

The table inset in Fig. 2.4 gives values of the time-dependent "pseudoelastic modulus," $\mathrm{E}_{\mathrm{t}}$, corresponding to each isochronous curve. This modulus is the slope of the initial linear portion of each curve. Use of the modulus for a given time in an elastic analysis is a further simplification in estimating creep deformations corresponding to a given time.

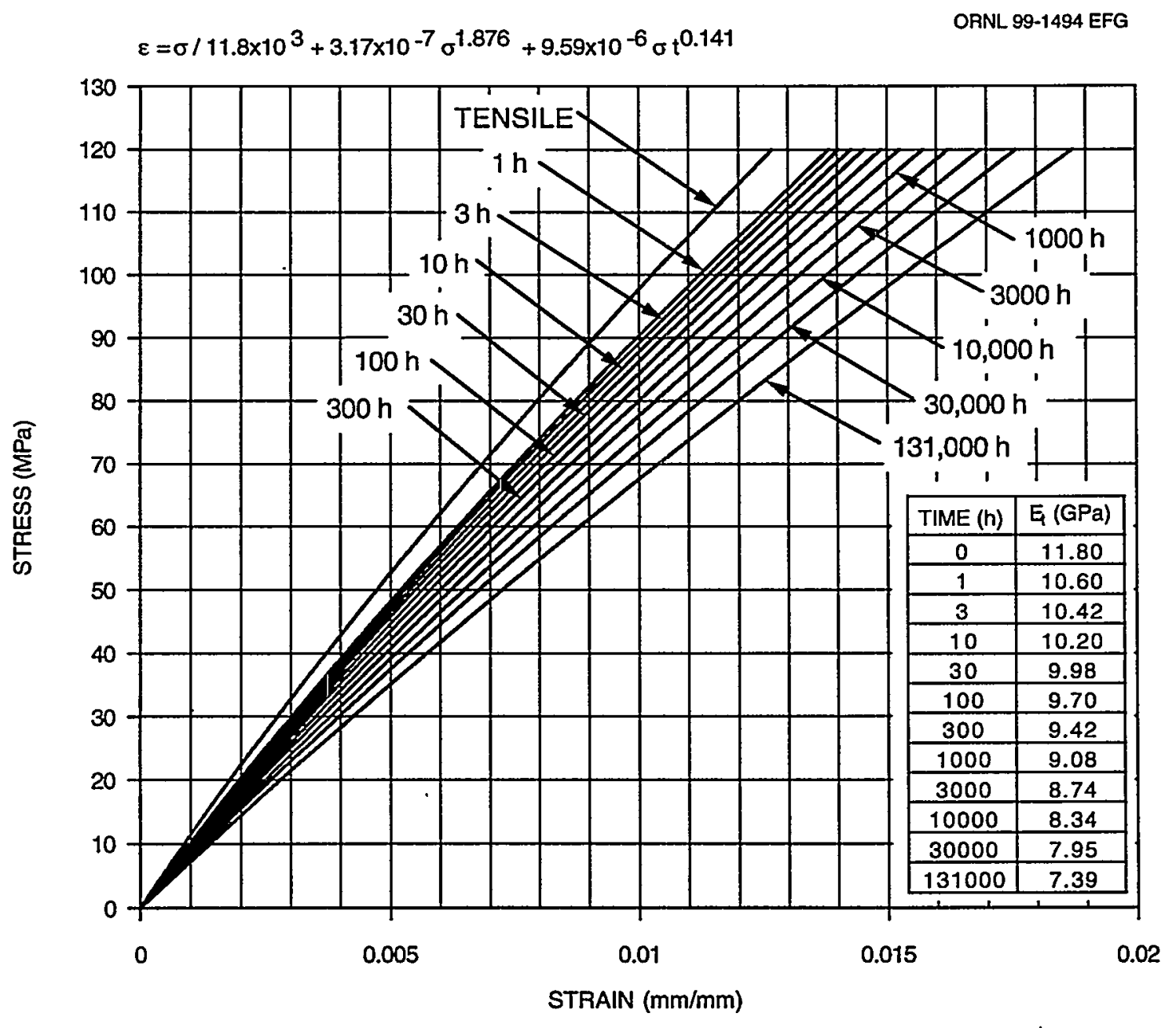

Fig. 2.4. Isochronous stress-strain curves for room-temperature ambient air. 
Temperature and environmental effects can be readily incorporated into the timedependent modulus values by using the following relationship:

$$
\mathrm{E}_{\mathrm{t}}=\mathrm{EE}_{\mathrm{c}} /\left(\mathrm{E}+\mathrm{E}_{\mathrm{c}}\right)
$$

Here, $\mathrm{E}$ is the elastic modulus and

$$
\mathrm{E}_{\mathrm{c}}=\frac{\sigma}{\varepsilon^{\mathrm{c}}}=\frac{1}{\mathrm{At}^{\mathrm{n}}}
$$

where $A$ and $n$ are the constants in the creep law [Eq. (2.1)]. The temperature, environmental, and prior loading multiplication factors presented earlier in Sect. 2.2 for elastic stiffness can be directly used to adjust $E$ in Eq. (2.2). The creep quantity $E_{c}$ is the inverse of creep strain, so the inverse of the creep temperature and environmental multiplication factors given in Subsects. 2.3.2 and 2.3.3 should be used to adjust $\mathrm{E}_{\mathrm{c}}$ in Eq. (2.2).

The utility of using the above time-dependent modulus values in an elastic analysis to predict time-dependent structural deformations has been experimentally demonstrated and verified in a series of cantilever beam tests. These are described in Appendix 2.A to this chapter, where comparisons of measured and predicted time-dependent deflections are presented.

*Derived from expressing the total time-dependent strain as the sum of the elastic strain and the timedependent creep strain. 


\section{Appendix 2.A. TIME-DEPENDENT BENDING OF CANTILEVER BEAMS}

Isochronous stress-strain curves and associated time-dependent "pseudoelastic modulus" values, which can be used in an elastic analysis to predict time-dependent structural deformations, were presented in Sect. 2.3.4. The purpose of this appendix is to illustrate how well this approach can work by comparing predictions with measured time-dependent deflections from tests of cantilever beam specimens.

Figure 2.A.1 is a schematic of the test. The elastic deflection at the load is given by

$$
\delta=\frac{4 \mathrm{P} \ell^{3}}{\mathrm{Ebh}^{3}}\left(1-\mathrm{v}^{2}\right),
$$

where, in our case, $P=24.74 \mathrm{~N}$, and the nominal beam dimensions are $\ell=102 \mathrm{~mm}, \mathrm{~b}=25 \mathrm{~mm}$, and $\mathrm{h}=3.2 \mathrm{~mm}$. Poison's ratio, $v$, is 0.32 . To predict deflections at various times, $\mathrm{t}, \mathrm{E}$ is replaced by $E_{t}$ from the isochronous creep curves.

Figures 2.A.2 and 2.A.3 show results of two representative tests. In the case of Beam $2 b$ (Fig. 2.A.3), recovery upon unloading was measured, and it was predicted by simply subtracting the originally predicted time-dependent creep. In both cases, actual specimen cross-section dimensions were used, and the $E_{\mathrm{t}}$ values form Fig. 2.4 were multiplied by the ratio of the actual specimen stiffness (measured in pretest stiffness checks) to the average chopped-fiber composite stiffness value of $11.8 \mathrm{GPa}$. As discussed in Chap. 13, this normalization tends to minimize the effects of specimen-to-specimen differences.

The comparisons are very good, which demonstrates the potential utility of this simplified approach for predicting creep deformations in automotive structures. The fact that timedependent creep at the stress levels of design interest is essentially linear with stress is partly responsible for the good agreement.
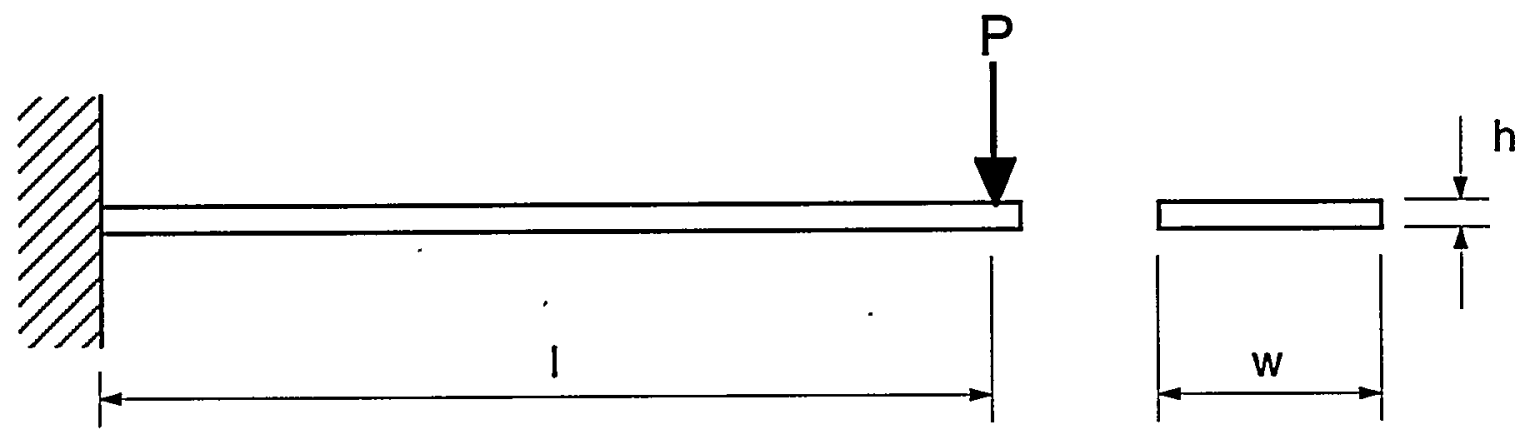

Fig. 2.A.1. Schematic of cantilever beam creep test. 


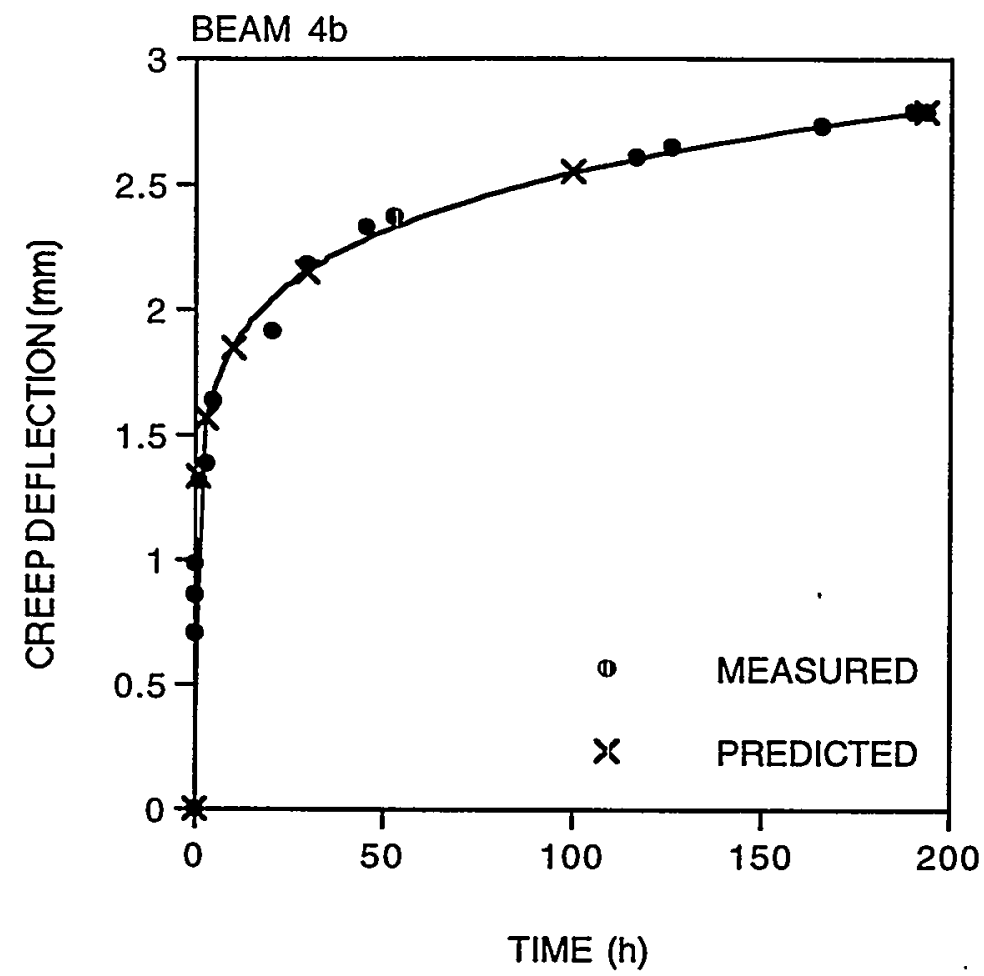

Fig. 2.A.2. Comparison of measured and predicted (curve) time-dependent creep deflections for Beam $\mathbf{4 b}$.

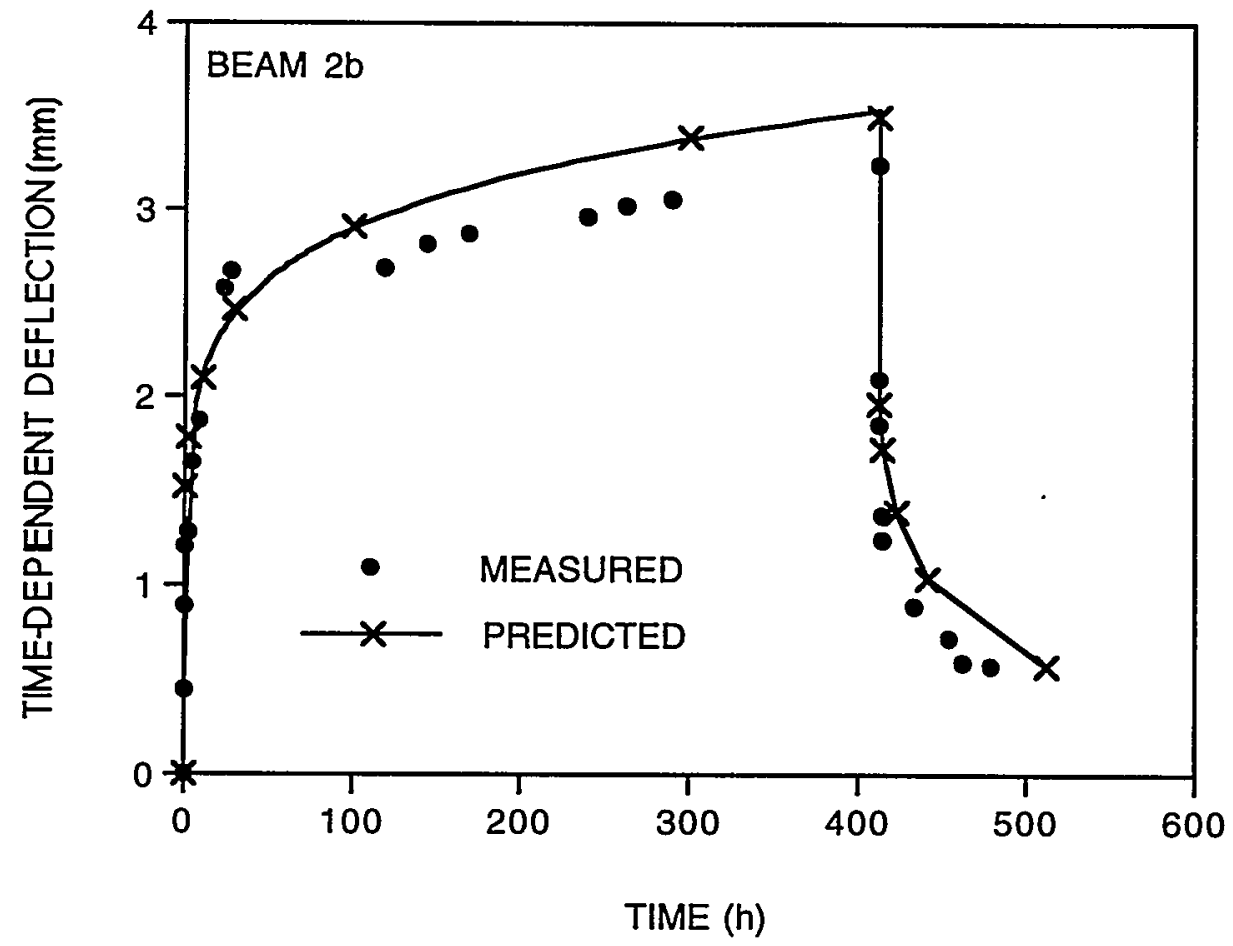

Fig. 2.A.3. Comparison of measured and predicted (curves) creep and recovery for Beam 2b. 


\section{BIAXIAL STRENGTH CRITERION-MAXIMUM PRINCIPAL STRESS}

The allowable stresses recommended in the next two chapters are based largely on uniaxial test results. For design, it is convenient to represent the biaxial stress states in a thin composite structure by a single quantity that can be compared to the allowable stresses. A simple biaxial strength criterion is required for this. Tests to evaluate and choose an appropriate criterion are described in Chap. 10.

Of the candidate criteria considered in Chap. 10, the simplest-the maximum stress criterion-was found to best represent short-time, room-temperature, ambient air failure data (see Fig. 10.6). Hence, that is the criterion adopted here. ${ }^{*}$ To use it, the maximum principal stress at each point in a structure is simply compared to the allowable stress values.

As explained in Chap. 10, failures under biaxial stresses at elevated temperatures and after exposure to fluid environments cause complications. Ideally, the strength reduction factor for a given temperature or environment would be the same for all stress states. This is not the case. The approach adopted in the following chapters is to have allowable stresses for uniaxial tensile stress states. At room temperature in ambient air, these same allowables apply to arbitrary biaxial stress states as well. However, at elevated temperatures and after fluid exposure, additional reduction factors are placed on the allowables to bound the increased degradation associated with other stress states. The maximum principal stress criterion is still used, but the uniaxial tension allowable stress is lowered.

\footnotetext{
*While the tests in Chap. 10 are limited to short-time static conditions, the chosen biaxial strength criterion is assumed to also apply to fatigue and creep-rupture failures.
} 


\section{DESIGN ALLOWABLES FOR STATIC LOADINGS}

\subsection{SHORT-TIME ALLOWABLE STRESSES, $\mathrm{S}_{0}{\text { AND } \mathrm{S}_{0}}^{*}$}

The basic short-time allowable stress is based on the minimum room-temperature UTS, which is defined in Chap. 8 as the "B-basis stress" used in MIL-HDBK-17.5 This minimum room-temperature value for the $\mathrm{P} 4$ chopped-glass-fiber composite is based on statistical treatment of $n=94$ UTS values, such that the survival probability at the minimum stress is $90 \%$ at a confidence level of $95 \%$. The room-temperature minimum UTS was calculated to be $149 \mathrm{MPa}$.

The basic time-independent allowable stress, $S_{0}$, is defined as two-thirds UTS $\min$. At room-temperature, $S_{0}$ thus becomes $S_{0}=99 \mathrm{MPa}$.

Values for other temperatures can be determined using the multiplication factors plotted in Fig. 2.1 (the factors there, taken from Chap. 8, apply to both elastic stiffness and tensile strength). Values of $S_{0}$ at various temperatures are given in Table 4.1.

For elevated temperatures, the $S_{0}$ values in Table 4.1 apply only to uniaxial tension. As explained in Chap. 10, a further stress reduction is required at $50^{\circ}$ and $120^{\circ} \mathrm{C}$ to account for the greater effect of temperature on stress states other than pure tension. The bounding multiplication factor at $50^{\circ} \mathrm{C}$ is 0.75 , and at $120^{\circ} \mathrm{C}$, it is 0.46 . Thus, the governing stress allowable for a general stress state at $50^{\circ} \mathrm{C}$ is $0.75 \times 99=74 \mathrm{MPa}$, and at $120^{\circ} \mathrm{C}$, it is $0.46 \times 99=45 \mathrm{MPa}$. These latter values, applicable to arbitrary biaxial stress states, are denoted by $\mathrm{S}_{0} *$. This is the short-time biaxial stress limit at each point in a structure.

An additional reduction factor is applied to account for fluid effects. For tensile, compressive, and shear stresses, the appropriate bounding strength multiplication factor on $S_{0}$ is 0.91 (see Chap. 8). For biaxial stress states, the appropriate factor on $S_{0} *$ is 0.84 (see Chap. 10).

Prior loads, as discussed in Chap. 15 , also reduce subsequent short-time strength. Prior fatigue cycling, up to the allowable number of cycles, reduces the subsequent UTS by $1.6 \%$, and prior creep, up to the allowable, reduces the UTS an additional $3.6 \%$. The total bounding multiplication factor to account for prior loads is thus $0.984 \times 0.964=0.95$.

The allowable stresses- $S_{0}$ for uniaxial tension and $S_{0} *$ for arbitrary biaxial stress states-with the bounding environmental multiplication factors and prior loading reductions factored in are given in Table 4.2.

Table 4.1. Basic $S_{0}$ and $S_{0} *$ allowable stresses

\begin{tabular}{ccc}
\hline $\begin{array}{c}\text { Temperature } \\
\left({ }^{\circ} \mathrm{C}\right)\end{array}$ & $\mathrm{S}_{0}{ }^{a}$ & $\mathrm{~S}_{0} * b$ \\
$(\mathrm{MPa})$ & $(\mathrm{MPa})$ \\
\hline-40 & 117 & 117 \\
23 & 99 & 99 \\
50 & 91 & 74 \\
120 & 72 & 45 \\
\hline$a_{\text {Applicable to uniaxial tension. }}$ & \\
$b_{\text {Applicable to arbitrary biaxial stress states. }}$
\end{tabular}


Table 4.2. $S_{0}$ and $S_{0} *$ values degraded by environment and prior cyclic loadings

\begin{tabular}{ccc}
\hline $\begin{array}{c}\text { Temperature } \\
\left({ }^{\circ} \mathrm{C}\right)\end{array}$ & $\begin{array}{c}\mathrm{S}_{0} \\
(\mathrm{MPa})\end{array}$ & $\begin{array}{c}\mathrm{S}_{0} * \\
(\mathrm{MPa})\end{array}$ \\
\hline-40 & 101 & 93 \\
23 & 86 & 79 \\
50 & 79 & 59 \\
120 & 62 & 36 \\
\hline
\end{tabular}

While test data for every combination of stress state, temperature, and environment were not available for formulating the allowable stresses in Tables 4.1 and 4.2, it is believed that the data base was sufficiently comprehensive to lead to a reliable design.

\subsection{TIME-DEPENDENT ALLOWABLE STRESSES, $\mathrm{S}_{\mathrm{t}}$ AND $\mathrm{S}_{\mathrm{t}}$ *}

For sustained loadings, creep-rupture stress is the basis for time-dependent allowable stresses, provided that $S_{0}$, or $S_{0} *$, is not lower than the creep-rupture-derived values. The following design margin is used:

$$
0.8 \mathrm{~S}_{\mathrm{r}}
$$

where $S_{\mathrm{r}}$ is the minimum creep-rupture strength. Values of the allowable stress $0.8 \mathrm{~S}_{\mathrm{r}}$ are developed and tabulated in Chap. 14 from the results of tensile and compressive creep-rupture tests at various temperatures and in various environments.

Like the case of the short-time failures addressed in the previous section, tensile and compressive creep-rupture strengths are the same at room temperature, but at $120^{\circ} \mathrm{C}$ - the only other temperature at which compressive data were obtained-the compressive strength is significantly below the tensile strength. No biaxial creep-rupture data are available. Thus some assumptions will be required in this section to generate a complete set of time-dependent allowable stresses applicable to biaxial loadings.

For uniaxial tension-and compression at room temperature-the time-dependent allowable stress, $S_{t}$, is defined as

$$
\mathrm{S}_{\mathrm{t}} \leq\left\{\begin{array}{l}
\mathrm{S}_{0} \\
0.8 \mathrm{~S}_{\mathrm{r}}
\end{array} .\right.
$$

Values of $S_{t}$ without environmental or prior load effects are tabulated in Table 4.3 and plotted in Fig. 4.1(a).

For arbitrary biaxial loadings, the time-dependent allowable stress is denoted by $\mathrm{S}_{\mathrm{t}} *$ and is defined as

$$
\mathrm{S}_{\mathrm{t}}{ }^{*} \leq\left\{\begin{array}{l}
\mathrm{S}_{0}^{*} \\
0.8 \mathrm{~S}_{\mathrm{r}}^{*}
\end{array}\right.
$$


Table 4.3. Basic $S_{t}$ allowable stresses (applicable only to uniaxial tension and to biaxial stresses at room temperature)

\begin{tabular}{crrccccc}
\hline \multirow{2}{*}{$\begin{array}{c}\text { Temperature } \\
\left({ }^{\circ} \mathrm{C}\right)\end{array}$} & $0 \mathrm{~h}$ & $10 \mathrm{~h}$ & $1000 \mathrm{~h}$ & $3000 \mathrm{~h}$ & $5000 \mathrm{~h}$ & 1 year & 15 years \\
\cline { 2 - 7 } & 117 & 100 & 94 & 92 & 91 & 91 & 87 \\
-40 & 99 & 99 & 94 & 92 & 91 & 91 & 87 \\
23 & 91 & 91 & 91 & 91 & 91 & 91 & 87 \\
50 & 72 & 72 & 72 & 70 & 69 & $a$ & $a$ \\
120 & & &
\end{tabular}

$a_{\text {Unrealistic condition. }}$

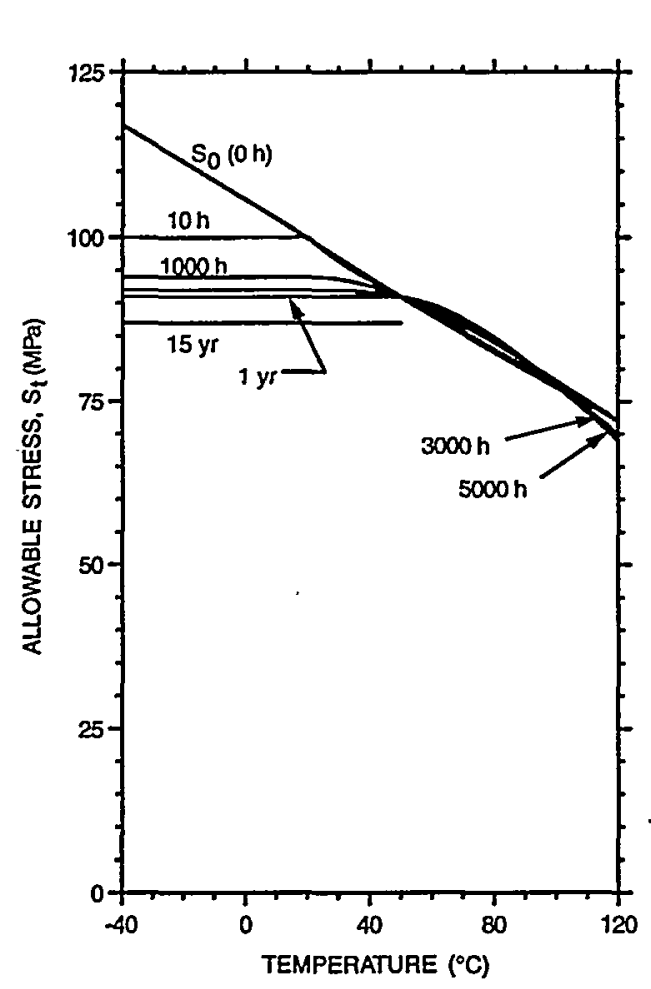

a. $S_{t}$ (unaxial tension)

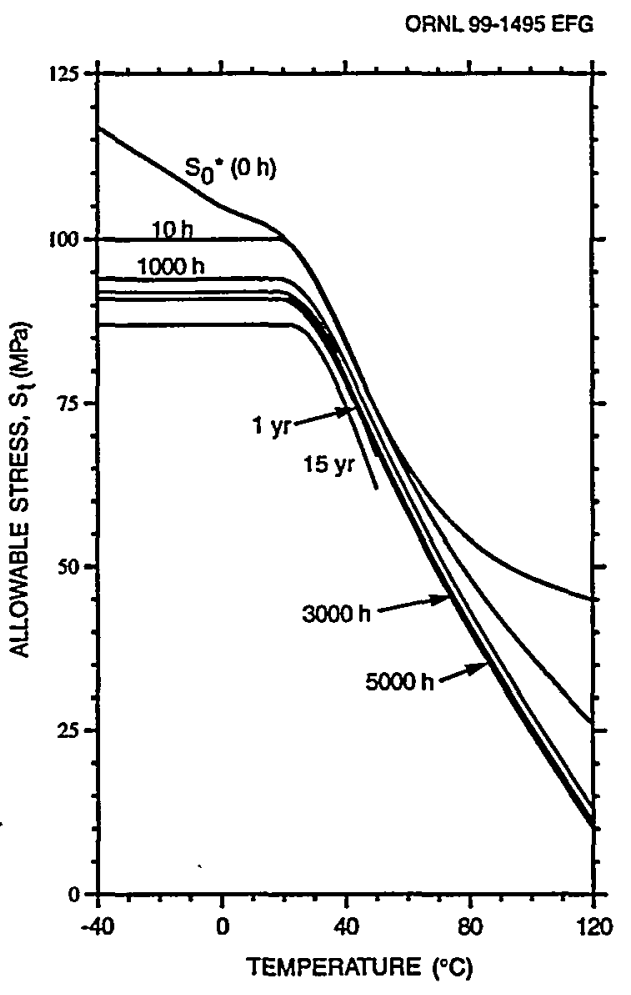

b. $\mathbf{S}_{\mathbf{t}}^{*}$ (biaxial)

Fig. 4.1. Basic allowable stresses without environmental and prior load effects.

Here, $\mathrm{S}_{\mathrm{r}} *$ should be the bounding minimum-creep-rupture strength under compressive and biaxial loadings. However, the only nonuniaxial-tension data available are the compressive results, mentioned above, at room temperature and $120^{\circ} \mathrm{C}$. The former are equal to the tensile values at room temperature. Two assumptions must be made. First, it is assumed that, using the maximum principal stress criterion, the compressive creep-rupture strength bounds all of the biaxial stress states. ${ }^{*}$ Second, it is assumed that compressive creep-rupture values at $50^{\circ} \mathrm{C}$ can be conservatively estimated by linearly interpolating between the room-temperature and $120^{\circ} \mathrm{C}$ values. The $-40^{\circ} \mathrm{C}$ values are taken to be the same as at room temperature.

${ }^{*}$ This was the case for short-time loadings at $120^{\circ} \mathrm{C}$ (see Fig. 10.8). 
The resulting values of $S_{t}{ }^{*}$, without environmental or prior load effects, are tabulated in Table 4.4 and plotted in Fig. 4.1(b).

The task now is to construct tables analogous to Tables 4.3 and 4.4 but with the degrading effects of fluid environments and prior loading effects included. This has already been done for $S_{0}$ and $S_{0} *$ (the 0-h values) in Table 4.2. Further, it is concluded in Chap. 15 that only prior cyclic loads reduce subsequent creep-rupture strength. The effect, while relatively small, varies from a reduction of $4.4 \%$ at $10 \mathrm{~h}$ to $5.1 \%$ at 15 years.

Table 14.4 gives stress reduction multiplication factors for fluid effects. The pertinent values to be used here are given below in Table 4.5. Comparison of these values with those in Chap. 14 (Table 14.4) shows that they were developed from tensile tests. The only compressive creep-rupture tests in a fluid were in water at 23 and $50^{\circ} \mathrm{C}$ following a $50^{\circ} \mathrm{C}$ presoak for 3 months. In both cases the effect of this extreme presoak, intended to saturate the specimens, was the same in both tension and compression. On this basis, it was concluded that the factors in Table 4.5 can be assumed to apply to compression as well as to tension. Because the water exposure case bounds the windshield washer factors, only the former will be used to reduce allowable stresses. Further, the maximum reduction will be cut off at 0.60 . The factors to be used are shown shaded in Table 4.5.

Table 4.6 for $S_{t}$ and Table 4.7 for $S_{t}{ }^{*}$ were developed using the prior load and environmental reduction factors discussed above. The allowables are plotted in Fig. 4.2. Use of these tables should conservatively account for prior loads and bound any realistic environmental effects.

Table 4.4. Basic $\mathrm{S}_{\mathrm{t}}$ * allowable stresses (applicable to arbitrary biaxial stress states)

\begin{tabular}{crrccccc}
\hline \multirow{2}{*}{$\begin{array}{c}\text { Temperature } \\
\left({ }^{\circ} \mathrm{C}\right)\end{array}$} & $0 \mathrm{~h}$ & $10 \mathrm{~h}$ & $1000 \mathrm{~h}$ & $3000 \mathrm{~h}$ & $5000 \mathrm{~h}$ & 1 year & 15 years \\
\cline { 2 - 8 } & 117 & 100 & 94 & 92 & 91 & 91 & 87 \\
-40 & 99 & 99 & 94 & 92 & 91 & 91 & 87 \\
23 & 74 & 74 & 71 & 69 & 68 & $67^{a}$ & $62^{a}$ \\
50 & 45 & 26 & 13 & 11 & 10 & & \\
120 & 8 & 8 &
\end{tabular}

$a_{\text {Extrapolated. }}$

Table 4.5. Fluid stress reduction multiplication factors

\begin{tabular}{|c|c|c|c|c|c|c|}
\hline Environment/stress & $10 \mathrm{~h}$ & $1000 \mathrm{~h}$ & $3000 \mathrm{~h}$ & $5000 \mathrm{~h}$ & 1 year & 15 years \\
\hline $\begin{array}{l}23^{\circ} \mathrm{C} \text { distilled water, } \\
1000 \text {-h presoak at } 23^{\circ} \mathrm{C} / \mathrm{T} \& \mathrm{C}^{a}\end{array}$ & 0.75 & 0.64 & 0.61 & 0.60 & 0.59 & \\
\hline $\begin{array}{l}23^{\circ} \mathrm{C} \text { windshield wash, }{ }^{b} \\
100 \text {-h presoak at } 23^{\circ} \mathrm{C} / \mathrm{T} \& \mathrm{C}\end{array}$ & 0.82 & 0.70 & 0.67 & 0.66 & 0.65 & \\
\hline
\end{tabular}


Table 4.6. $S_{t}$ allowable stresses (applicable to uniaxial tension) degraded by environment and prior cyclic loads

\begin{tabular}{|c|c|c|c|c|c|c|c|}
\hline \multirow{2}{*}{$\begin{array}{c}\text { Temperature } \\
\left({ }^{\circ} \mathrm{C}\right)\end{array}$} & \multicolumn{7}{|c|}{ Allowable stress (MPa) } \\
\hline & $\mathrm{Oh}$ & $10 \mathrm{~h}$ & $1000 \mathrm{~h}$ & $3000 \mathrm{~h}$ & $5000 \mathrm{~h}$ & 1 year & 15 years \\
\hline-40 & 101 & 72 & 57 & 53 & 52 & 52 & 50 \\
\hline 23 & 86 & 71 & 57 & 53 & 52 & 52 & 50 \\
\hline 50 & 79 & 66 & 56 & 53 & 52 & 52 & 50 \\
\hline 120 & 62 & 52 & 44 & 41 & 39 & & \\
\hline
\end{tabular}

Table 4.7. $\mathrm{S}_{\mathrm{t}} *$ allowable stresses (applicable to arbitrary biaxial stress states) degraded by environment and prior cyclic loads

\begin{tabular}{cccccccc}
\hline \multirow{2}{*}{$\begin{array}{c}\text { Temperature } \\
\left({ }^{\circ} \mathrm{C}\right)\end{array}$} & $0 \mathrm{~h}$ & $10 \mathrm{~h}$ & $1000 \mathrm{~h}$ & $3000 \mathrm{~h}$ & $5000 \mathrm{~h}$ & 1 year & 15 years \\
\cline { 2 - 8 } & 93 & 72 & 57 & 53 & 52 & 52 & 50 \\
-40 & 79 & 71 & 57 & 53 & 52 & 52 & 50 \\
23 & 59 & 53 & 43 & 40 & 39 & 38 & 35 \\
50 & 36 & 19 & 8 & 6 & 6 & & \\
120 & 07
\end{tabular}

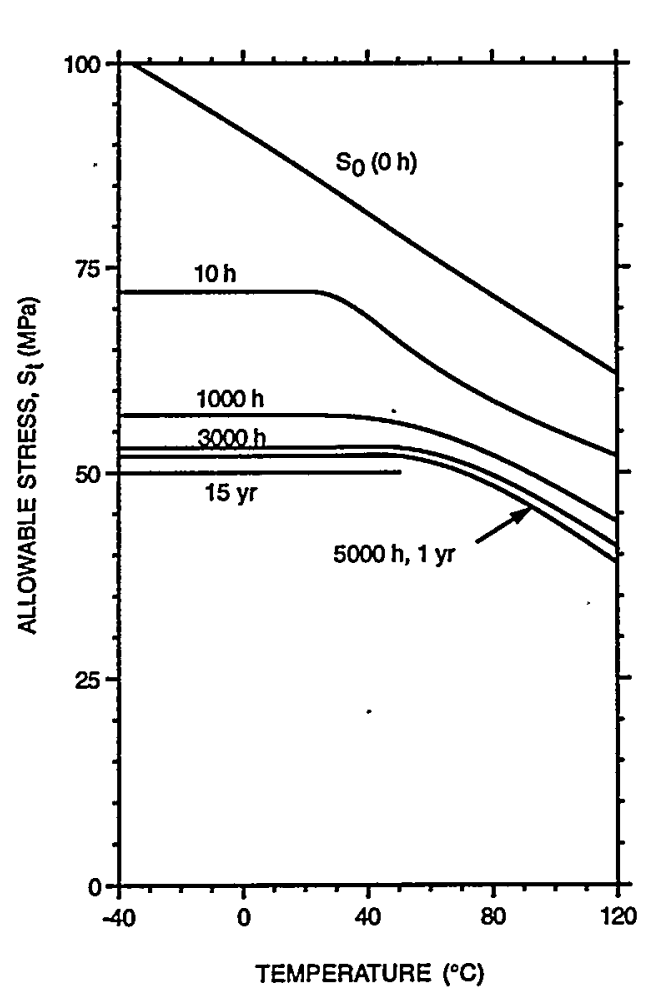

a. $S_{t}$ (uniaxial tension)

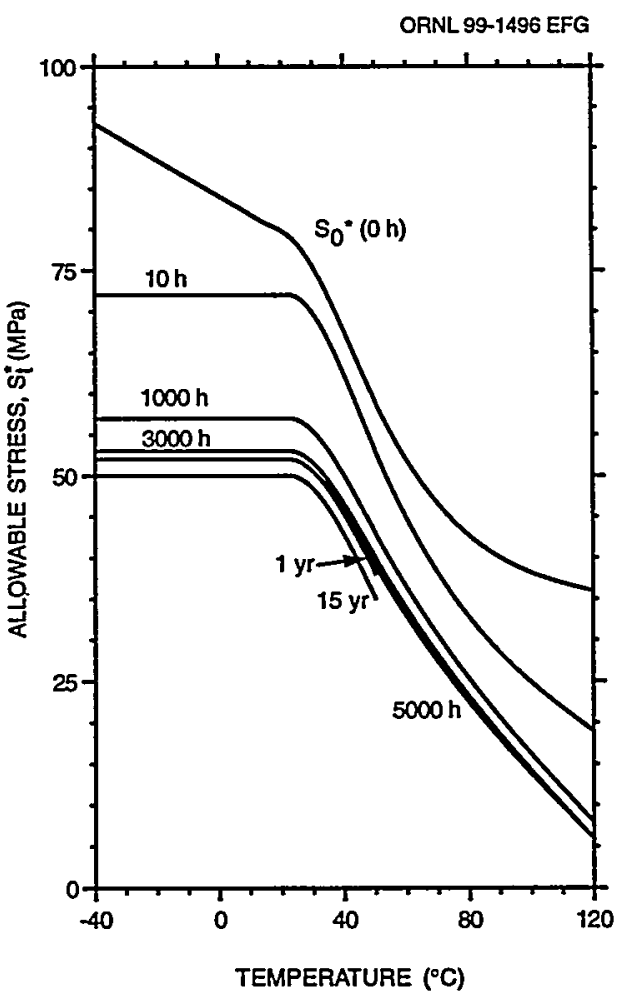

b. $S_{t}^{*}$ (biaxial)

Fig. 4.2. Allowable stresses with reductions to account for environmental and prior load effects. 


\subsection{TREATMENT OF MEMBRANE AND BENDING STRESSES}

The $S_{0}$ and $S_{t}$ (or $S_{0}{ }^{*}$ and $S_{t}{ }^{*}$ ) allowable stresses given in the previous section establish limits on allowable in-plane membrane stresses, $P$. For out-of-plane bending away from structural discontinuities, the membrane plus bending stresses, $\mathrm{P}+\mathrm{Q}$, are limited to

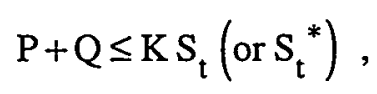

where $\mathrm{K}$ is temperature dependent, with values tabulated below:

\begin{tabular}{ccc}
$\mathrm{T}\left({ }^{\circ} \mathrm{C}\right)$ & & $\mathrm{K}$ \\
\hline-40 & & 1.5 \\
23 & & 1.5 \\
50 & & 1.5 \\
120 & & 1.2
\end{tabular}

The flexure tests on which the $\mathrm{K}$ factors are based are discussed in Chap. 9.

Geometric discontinuities include corners and bends. Here; the fiber distribution across the thickness of a composite plate or shell structure is likely to be less uniform. Even more importantly, when the inside surface of reentrant bends is in tension, a new failure mode (i.e., delaminations) can be introduced (see Chap. 15 of Ref. 2). In these cases, the membrane plus bending stresses are limited as follows:

$$
\mathrm{P}+\mathrm{Q} \leq 0.8 \mathrm{~S}_{\mathrm{t}}^{*}
$$

\subsection{TREATMENT OF INCREMENTS OF SUSTAINED LOADS}

For changing stress levels, the time-fraction summation method should be used to assess cumulative damage. The sum of the use fractions associated with the primary plus bending stresses for all increments of loading should not exceed a value of 1.0:

$$
\sum_{i}\left(\frac{t}{T_{d}}\right)_{i} \leq 1.0 .
$$

Here, $t_{i}$ is the specified duration of a given load increment $i$, and $T_{d_{i}}$ is the allowable time for the stress associated with that load increment. 


\section{DESIGN LIMITS FOR CYCLIC LOADINGS}

\subsection{BASIC FATIGUE DESIGN CURVES}

Room-temperature, ambient-air design fatigue curves are shown in Fig. 5.1. As described in Sect. 12.6, these curves are derived from fatigue failure curves by first placing a margin of 20 on cycles to failure and then multiplying stress by an additional reduction factor of 0.84 . The latter factor is the ratio of the minimum to average UTS. It provides an extra margin against data scatter, and it helps limit stiffness reductions due to cycling to values closer to the desired $10 \%$.

The choice of the proper curve to use depends on the mean stress. If the mean stress is tensile, then the curve labeled "positive mean" should be used. For the common case of cycling between zero and a maximum tensile stress, $S_{\max }$, this design curve would be used, with $S_{\mathbf{a}}$ the alternating stress, being equal to $1 / 2 S_{\max }$. For completely reversed cycling (zero mean stress) or for a compressive mean stress, the curve labeled "zero and negative mean" should be used. The reasoning that led to the choice of these two curves is discussed in Sect. 12.5.

In the absence of definitive biaxial fatigue test data, it is assumed that principal stresses govern fatigue failures, just as in the case of short-time static loadings. For conservatism, it should be assumed that if either principal mean stress component is positive, then the positive mean curve should be used, i.e., the zero and negative mean curve should only be used when both mean stress components are negative. Further, in the case of zero mean stress, the zero and negative mean curve should only be used if both principal stress components are positive at one extreme of the cycle and negative at the other.

ORNL 99-1497 EFG

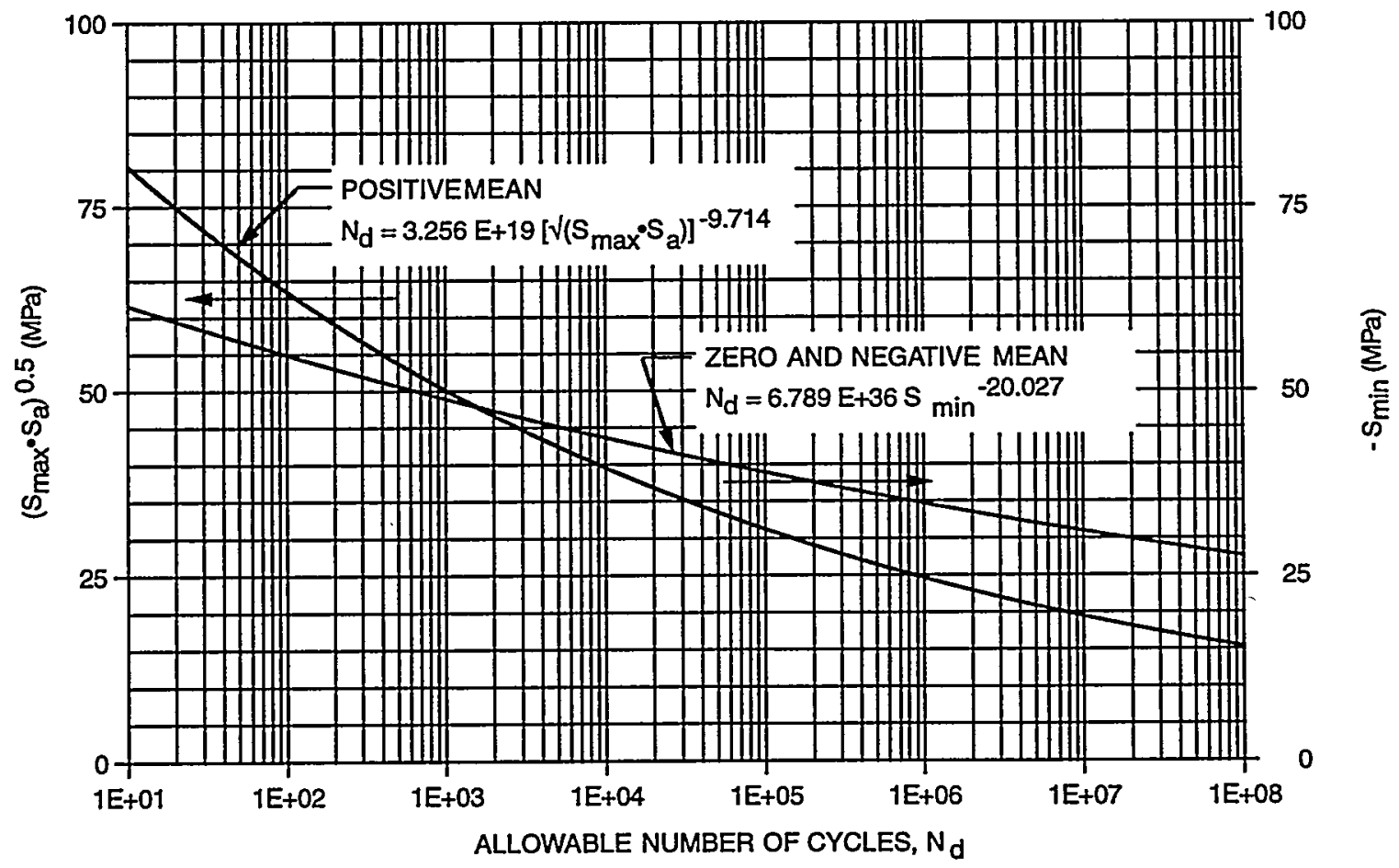

Fig. 5.1. Room-temperature design fatigue curves. The appropriate curve to use depends on the sign of the mean stress. 


\subsection{EFFECTS OF TEMPERATURE}

The design fatigue curves in Fig. 5.1 are for room temperature. For other temperatures, fatigue strength multiplication factors that are developed in Sect. 12.2 should be used. The factors are repeated here in Table 5.1.

These factors were derived from tension-tension fatigue data. In the absence of other data, it is assumed that they apply to other uniaxial and biaxial cyclic conditions as well.

Table 5.1. Fatigue strength factors to account for temperature

\begin{tabular}{ccccc}
\hline \multirow{2}{*}{$\begin{array}{c}\text { Temperature } \\
\left({ }^{\circ} \mathrm{C}\right)\end{array}$} & $10^{2}$ & $10^{4}$ & $10^{6}$ & $10^{8}$ \\
\cline { 2 - 5 } & 1.21 & 1.04 & 0.90 & 0.77 \\
-40 & 1.00 & 1.00 & 1.00 & 1.00 \\
23 & 0.93 & 0.96 & 1.00 & 1.03 \\
50 & 0.68 & 0.76 & 0.86 & 0.96 \\
120 & & & & \\
\hline
\end{tabular}

\subsection{ENVIRONMENTAL EFFECTS}

Fluid effects on fatigue are discussed in Sect. 12.3. Just as was done for the allowable stresses for static loadings, two practical bounding fluid exposures will be used:

- $1000-\mathrm{h}$ presoak in room-temperature distilled water, and

- $100-h$ presoak in room-temperature windshield washer fluid.

The fatigue tests were performed in the fluid in both cases.

The fatigue strength multiplication factors are tabulated in Table 5.2. Values greater than 1.00 are reduced to 1.00 in the table. To bound all environmental effects, the water values are recommended.

Table 5.2. Fatigue strength factors for two bounding fluid environments

\begin{tabular}{lcccc}
\hline \multirow{2}{*}{ Environment } & \multicolumn{4}{c}{ Cycles } \\
\cline { 2 - 5 } & $10^{2}$ & $10^{4}$ & $10^{6}$ & $10^{8}$ \\
\hline Water, 1000-h presoak & 0.75 & 0.82 & 0.89 & 0.97 \\
Windshield washer fluid, & 0.90 & 0.95 & 1.00 & 1.00 \\
100-h presoak & & & & \\
\hline
\end{tabular}

\subsection{TREATMENT OF VARYING STRESS AMPLITUDES}

For varying stress amplitudes, Miner's rule should be used to account for cumulative fatigue damage (see Sect.12.4). For a design to be acceptable, the fatigue damage should satisfy the following relation: 


$$
\sum_{i}\left(\frac{n}{N_{d}}\right)_{i} \leq 1.0,
$$

where $n_{i}$ is the number of specified cycles of cycle type $i$ and $N_{d_{i}}$ is the number of designallowable cycles for cycle $i$ determined from one of the design fatigue curves (Fig. 5.1) adjusted to correspond to the maximum temperature of the cycle and to account for environment.

\subsection{FATIGUE EVALUATION PROCEDURE}

The following fatigue analysis procedure should be used. For each cycle type i, determine for each point in the structure the maximum principal stress and, at a different time in the cycle, the minimum principal stress. The algebraic difference between these two values yields the maximum possible stress range. The mean stress is the average of the two values, and the amplitude is one-half the stress range.

The guidance given at the end of Sect. 5.1 above should be used to determine which of the design fatigue curves in Fig. 5.1 to use. The chosen curve should be adjusted by the factors in Table 5.1 to correspond to the maximum temperature of the cycle. Further, environmental factors from Table 5.2 should be used as appropriate. 


\section{DAMAGE TOLERANCE DESIGN FOR LOW-ENERGY IMPACTS AND OTHER DEFECTS}

\subsection{GENERAL REQUIREMENTS}

A two-part design assessment approach is recommended.

1. Assume the presence of a 6.4-mm-diam circular hole in the worst possible location of the structure, and demonstrate, through analysis or use of experimental data and models, that the structure maintains its integrity. This evaluation will ensure that the structure can tolerate minor impacts and structural flaws at least up to a size of $6.4 \mathrm{~mm}$ in diameter or length, no matter where they are located. Guidance for this evaluation is provided in the next section.

2. For specific low-energy impacts such as roadway kickups, tool drops, and load drops in a pickup truck box, the procedures described in Sects. 6.3 and 6.4 may be used to assess damage tolerance for damage areas larger than that corresponding to a 6.4-mm-diam hole.

\subsection{EFFECTS OF CIRCULAR HOLES}

Results of tensile, tensile fatigue, and tensile creep-rupture tests of specimens with circular holes are presented in Chap. 11 of Part 2. A key finding is that the effective stressconcentration factor (SCF) is not nearly as high as theoretically predicted. Furthermore, the smaller the hole, the smaller the effective SCF. Figure 6.1, which can be used for design

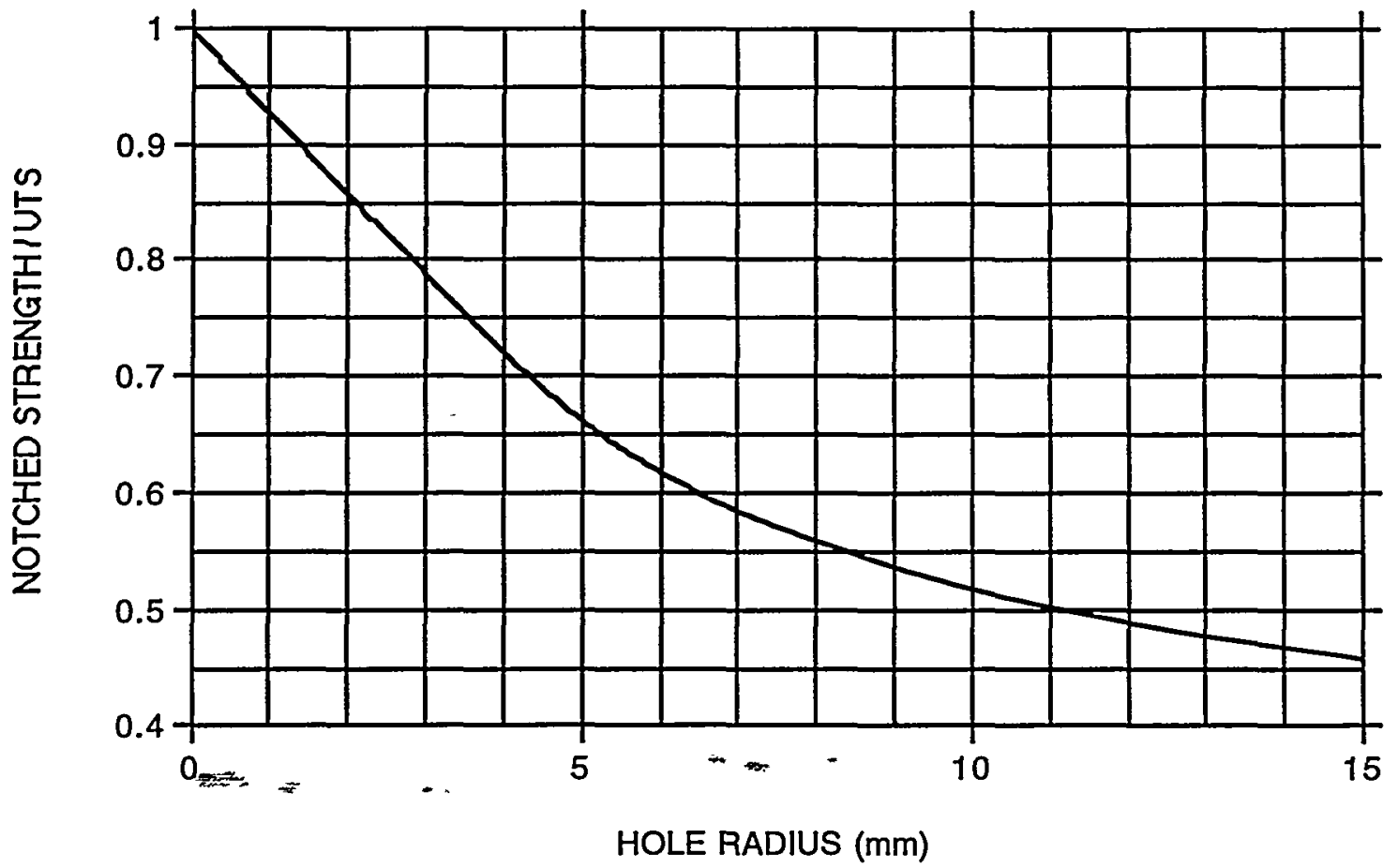

Fig. 6.1. Strength reduction factor for a circular hole in an infinitely wide, uniaxially loaded plate. 
evaluations, is a correlation, due to Whitney and Nuismer, ${ }^{6}$ of tensile strength vs hole size. The ordinate gives the strength of an infinitely wide, uniaxially loaded plate with a hole as a fraction of the strength with no hole-the UTS. For the standard 6.4-mm-diam hole, the reduction is 0.78 from Fig. 6.1, compared to a theoretical reduction of 0.33 .

While Fig. 6.1 is for an infinitely wide plate, real structures will have sections where the width to hole diameter is relatively small. In those cases, the following equation, from Chap. 11, can be used to determine the applied failure-causing stress, $\bar{\sigma}$, in a finite-width plate that corresponds to an applied failure-causing stress, $\bar{\sigma}_{\infty}$, in an infinitely wide plate:

$$
\frac{\bar{\sigma}}{\bar{\sigma}_{\infty}}=\frac{3(1-\mathrm{a} / \mathrm{w})}{2+(1-\mathrm{a} / \mathrm{w})^{3}},
$$

where $w$ is the plate width, and $a$ is the hole diameter.

It can be assumed that Fig. 6.1, derived from tensile test results, can be used for tensile fatigue and tensile creep-rupture strengths as well. The basis for this is that tensile, fatigue, and creep-rupture tests of 25.4-in.-wide specimens with 6.4-mm-diam holes all showed about the same strength reduction.

While no compressive hole data exist, it is expected that Fig. 6.1 can be used for compressive stress states as well.

To reliably predict stiffness reductions in structures with circular holes, finite element analyses should be employed. In addition to stiffness effects, the analyses will predict stresses that can be compared with the allowable stresses. However, the peak predicted stresses should be adjusted downward using Fig. 6.1 and Chap. 11 as guides.

\subsection{DETERMINATION OF IMPACT DAMAGE AREAS}

For a given impacting object (e.g., roadway kickup or dropped tool) of mass, m, impacting the structure with a velocity, $v$, in the most highly stressed location, away from structural discontinuities, the impact damage area should be determined from the "design" curve in Fig. 6.2. The design curve is the upper bound of data generated from air-gun and pendulum impact tests on clamped 203-mm-diam by 3.2-mm-thick circular plates. Development of this design curve and its applicability to real events, such as bricks dropped in a pickup box, are discussed in Chap. 16 of Part 2. Also, it is shown in Chap. 16 that the curve covers the standard fluid environment effects (specimens presoaked in distilled water for $1000 \mathrm{~h}$ at room temperature actually exhibited less damage than unsoaked specimens).

Once the impact damage area has been estimated, the procedures recommended in Sect. 6.4 can be used to assess the likely effect on properties and structural integrity.

\subsection{DETERMINATION OF STRENGTH AND STIFFNESS DEGRADATION}

The procedures recommended here depend, more or less, on the assumption that an impact damage area can be conservatively represented by a circular hole of equivalent area. The effects of circular holes are discussed in Chap. 11 of Part 2, while the effects of impact damage are discussed in Chap. 16. 


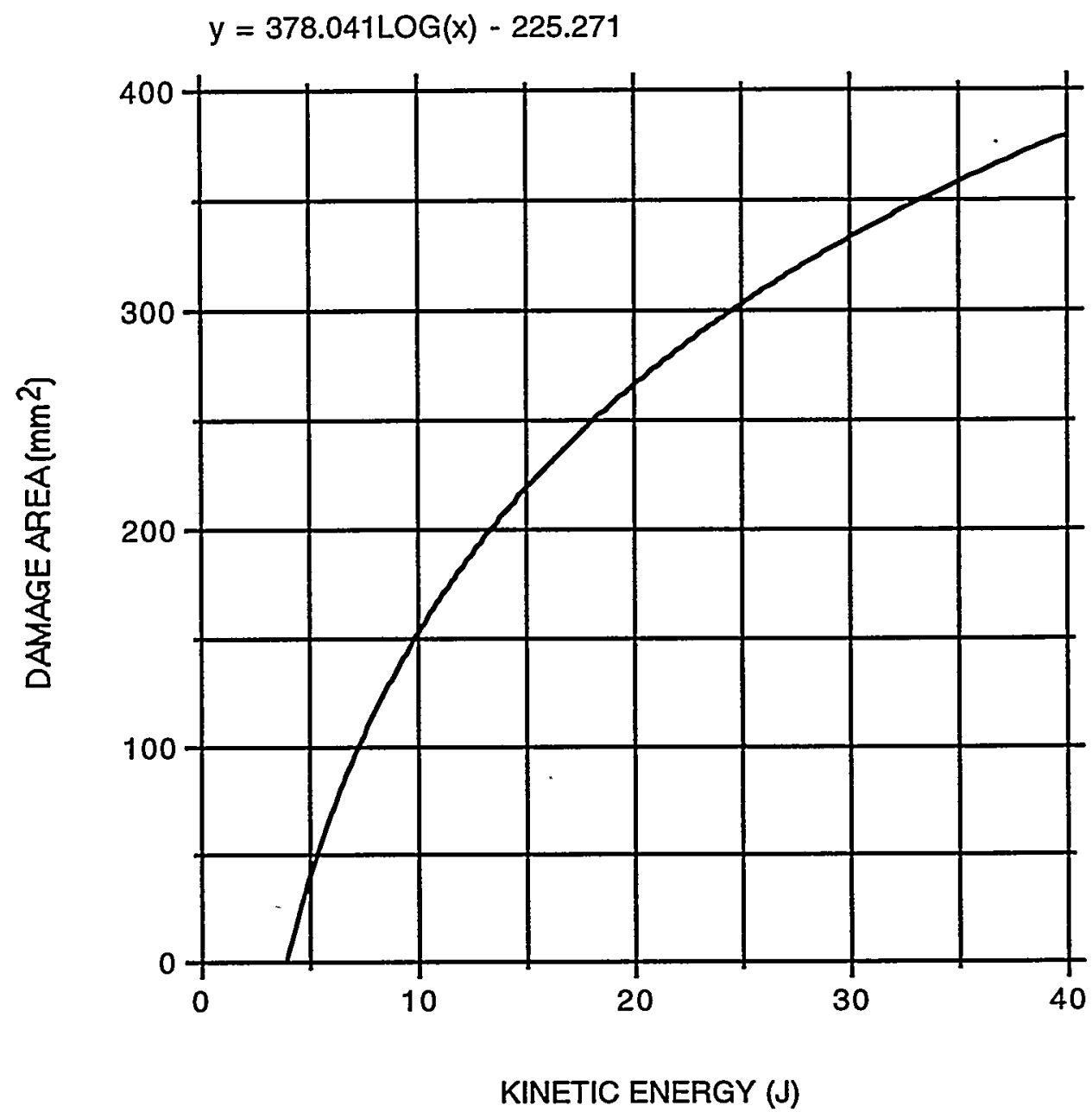

Fig. 6.2. Design curve for determining impact damage area. Kinetic energy is onehalf the impacting body's mass times its velocity squared $\left(1 / 2 \mathrm{~m} \mathrm{v}^{2}\right)$.

Damage areas can either be factored into the structural evaluation as a circular hole, or the degradation in strength can be estimated as specified in the following paragraph. If the equivalent circular hole approach is used, local peak stresses above a certain level can be ignored, as discussed in Sect. 6.2. Structural stiffness degradation can best be estimated, conservatively, by the equivalent circular hole method.

For a given predicted damage area, the degradation in compressive strength can be estimated using Fig. 6.3. These curves were derived from test data obtained from 25.4-mmwide specimens cut from impacted plates. They show the strength of specimens containing the damage area relative to the strength in undamaged regions. For modest amounts of damage, up to an equivalent circular hole of about $20 \mathrm{~mm}$ in diameter, tensile and tensile fatigue strengths are not reduced by the damage, presumably because the unbroken fibers continue to carry load. The compressive strength, and presumably fatigue strength for cycles that go into compression, is significantly reduced. 


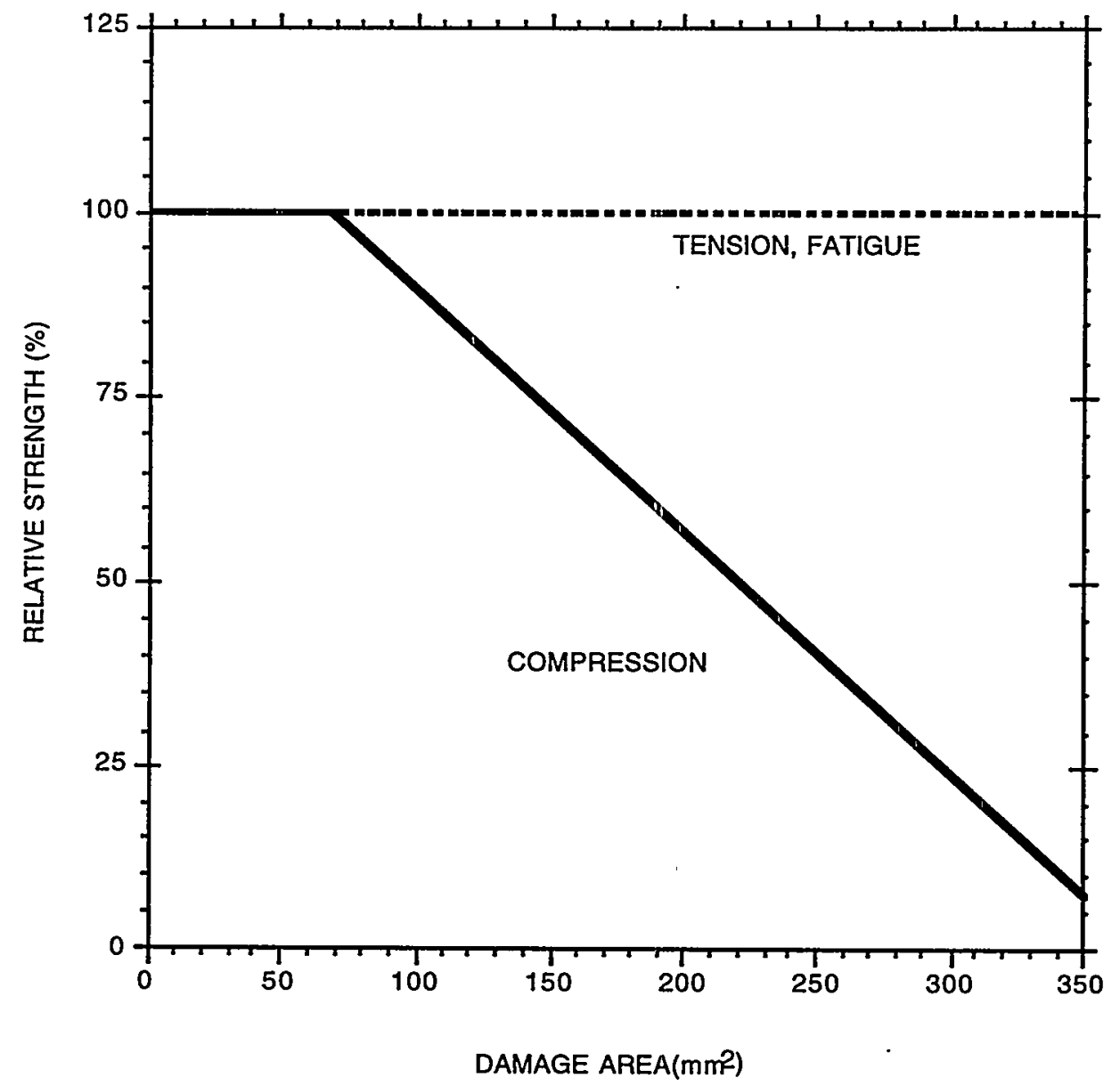

Fig. 6.3. Strength degradation as a function of damage area. This figure applies directly only to a $25.4-\mathrm{mm}$-wide specimen.

In using Fig. 6.3 to estimate strength reductions, it should be kept in mind that the curves are for 25.4-mm-wide specimens. To approximately convert the results to an infinitely wide plate or to other finite widths, Eq. (6.1) can be used. 


\section{SUMMARY AND COMPARISON WITH REFERENCE COMPOSITE}

This chapter briefly summarizes the detailed criteria presented in the previous chapters for the P4 chopped-glass-fiber/Baydur 420 IMR composite and highlights major differences between these criteria and those given in Ref. 1 for the reference CSM glass-fiber composite. In the final section of the chapter, the criteria are reduced to a simplified table of allowable stresses in the form of reduction factors on the room-temperature, ambient air, UTS value. Where appropriate, reference composite values are shown in parentheses to facilitate direct comparisons between the two materials.

\subsection{ELASTIC AND CREEP PROPERTIES FOR DESIGN ANALYSIS}

Both the chopped-fiber and reference composites were assumed to be isotropic in the plane of the plaques. While this is essentially true for the current composite, the reference composite stiffness varied by about $18 \%$ between the two principal material directions. The elastic properties of the chopped-fiber composite are tabulated in Table 7.1, with the reference composite values given in parentheses.

The chopped-glass-fiber composite elastic modulus values are about $25 \%$ higher than the reference composite values, and they are slightly less temperature sensitive. The recommended bounding stiffness reduction multiplication factor to account for fluid effects in the chopped-fiber composite is 0.91 ( 0.83 for the reference composite). Prior loads reduce the stiffness in both composites. For the chopped-fiber material, a factor of 0.96 ( 0.93 for the reference composite) accounts for prior static loads; $0.88(0.90)$ accounts for prior cyclic loads; and $0.87(1.00)$ accounts for prior creep.

The creep response of both composites is described by a simple power law in time; in the design range the response is linear with stress. Representative values of creep strain/unit stress are shown in Table 7.2 for comparative purposes. The reference composite exhibits higher creep $(22 \%$ more at $5000 \mathrm{~h})$.

For both materials a simple constant multiplier on room-temperature creep strains adequately describes creep at other temperatures. The multipliers are tabulated in Table 7.3. Here the reference composite creep is slightly less sensitive to temperature.

In both cases fluid effects were also bounded by simple multiplication factors on creep strains. For the chopped-fiber composite, two factors were given:

- distilled water: 1.79 (1.60), and

- windshield washer fluid: $2.23(1.50)$.

Table 7.1. Elastic constants for design

\begin{tabular}{ccc}
\hline $\begin{array}{c}\text { Temperature } \\
\left({ }^{\circ} \mathrm{C}\right)\end{array}$ & $\begin{array}{c}\text { Elastic modulus } \\
(\mathrm{GPa})\end{array}$ & $\begin{array}{c}\text { Poisson's } \\
\text { ratio }\end{array}$ \\
\hline-40 & $13.9(11.5)$ & $0.31(\mathrm{NA})^{a}$ \\
23 & $11.8(9.4)$ & $0.32(0.31)$ \\
120 & $8.6(6.1)$ & $0.34(\mathrm{NA})$ \\
\hline
\end{tabular}

$a_{\mathrm{NA}}=$ not available. 
Table 7.2. Creep strain values at room temperature

\begin{tabular}{cc}
\hline $\begin{array}{c}\text { Time } \\
(\mathrm{h})\end{array}$ & $\begin{array}{c}\text { Creep strain } \\
\text { per unit stress } \\
(1000 \times \% / \mathrm{MPa})\end{array}$ \\
\hline 100 & $18(18)^{a}$ \\
1000 & $25(28)$ \\
3000 & $30(35)$ \\
5000 & $32(39)$ \\
\hline
\end{tabular}

$a_{\text {Reference composite values from Ref. } 1 .}$

Table 7.3. Creep multiplication factors

\begin{tabular}{cl}
\hline $\begin{array}{c}\text { Temperature } \\
\left({ }^{\circ} \mathrm{C}\right)\end{array}$ & Creep factor \\
\hline-40 & $0.59(0.65)^{a}$ \\
23 & $1.00(1.00)$ \\
120 & $2.07(1.88)$ \\
\hline
\end{tabular}

$a_{\text {Reference composite values from Ref. } 1 .}$

Thus, just as was the case for temperature, the chopped-fiber composite creep is more sensitive to fluid environments than was the reference composite.

\subsection{BIAXIAL STRENGTH CRITERION}

The maximum principal stress criterion adequately represents the room-temperature short-time failure data for the chopped-fiber composite. In contrast, the maximum shear stress criterion was best for the reference composite. These criteria are identical in quadrants one and three; in quadrants two and four, the maximum shear stress criterion is more limiting than the maximum stress criterion.

Elevated temperatures and fluid environments introduce complications in that those stress states where the matrix dominates behavior are degraded more than those where the behavior is fiber dominated. The maximum principal stress criterion is still used, but additional reduction factors are placed on the allowables to bound the increased degradation.

\subsection{DESIGN ALLOWABLE STRESSES FOR STATIC LOADINGS}

The basic time-dependent allowable stress quantity for the chopped-fiber composite is the same as that used in Ref. 1 for the reference composite:

$$
S_{t} \leq\left\{\begin{array}{l}
S_{0} \\
0.8 S_{r}
\end{array} .\right.
$$


Here, $S_{t}$ is the time-dependent allowable; $S_{0}$ is the short-time (time-independent) allowable; and $S_{\mathrm{r}}$ is the minimum creep-rupture strength corresponding to time t. Representative values are tabulated in Table 7.4. The chopped-fiber composite allowables are considerably higher than the corresponding reference composite values, especially at the elevated temperature and longer times.

At $-40^{\circ} \mathrm{C}$ and room temperature in ambient air, the values in Table 7.4 are the allowable stresses that limit the maximum principal stresses in a structure. At higher temperatures, the values only apply to uniaxial tensile stresses; the additional reduction factors discussed in Sect. 7.2 are used for other stress states. To facilitate this, a modified allowable stress, $\mathrm{S}_{\mathrm{t}}^{*}$, is defined. In terms of $\mathrm{S}_{\mathrm{t}}{ }^{*}$, the $120^{\circ} \mathrm{C}$ values in Table 7.4 become $45 \mathrm{MPa}$ and $10 \mathrm{MPa}$ at $0 \mathrm{~h}$ and $5000 \mathrm{~h}$, respectively. The other values remain unchanged.

The values of $\mathrm{S}_{\mathrm{t}}{ }^{*}$ are drastically reduced at $120^{\circ} \mathrm{C}$. The practical ramification of this is that structures subjected to compressive or biaxial stresses must be shielded from elevated temperatures.

The $S_{t}$ and $S_{t}$ * allowables must be reduced further, where appropriate, to account for fluid environments and prior load effects. The fluid factors depend on whether the stress state is uniaxial or biaxial. Values for 0 and $5000 \mathrm{~h}$ are tabulated in Table 7.5. The values in parentheses are from Ref. 1 for the reference composite. It should be pointed out that in the case of fluid effects on the reference composite, biaxial data were not available, so it was assumed that the uniaxial reduction factors applied to any stress state.

Fluid degradation effects are a little less for the chopped-fiber composite than for the reference composite. Prior load effects are slightly larger.

Table 7.4. $S_{t}$ values in air $(\mathrm{MPa})$

\begin{tabular}{cccc}
\hline $\begin{array}{c}\text { Temperature } \\
\left({ }^{\circ} \mathrm{C}\right)\end{array}$ & $0 \mathrm{~h}$ & $5000 \mathrm{~h}$ & 15 years \\
\hline-40 & $117(97)^{a}$ & $91(74)$ & $87(71)$ \\
23 & $99(80)$ & $91(74)$ & $87(71)$ \\
120 & $72(52)$ & $69(40)$ & \\
\hline
\end{tabular}

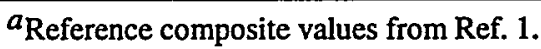

Table 7.5. Fluid and prior load reduction factors

\begin{tabular}{lcc}
\hline & $0 \mathrm{~h}$ & $5000 \mathrm{~h}$ \\
\hline Fluid effects & & \\
$\quad$ Uniaxial & $0.91(0.83)$ & $0.60(0.51)$ \\
$\quad$ Compressive and biaxial & $0.84(0.83)$ & $0.60(0.51)$ \\
Prior load effects & $0.95(0.98)$ & $0.95(0.97)$ \\
\hline
\end{tabular}




\subsection{LIMITS FOR CYCLIC LOADINGS}

Two design fatigue curves are used for the chopped-fiber composite. One, derived from tension-tension fatigue tests and using the stress parameter $\sqrt{\left(S_{\max } \cdot S_{a}\right)}$, where $S_{a}$ is the alternating stress, is for cycles with a positive mean stress. The other, derived from fully reversed fatigue tests and using the minimum cyclic stress, $S_{\min }$, as the stress parameter, is for cycles having a zero or negative mean stress. Both curves have a margin of 20 on cycles to failure and an additional multiplication reduction factor of 0.84 on stress to approximately account for the difference between average and minimum strengths.

While the fatigue evaluation procedure for the reference composite (Ref. 1) used the same two basic fatigue curves, the additional reduction factor of 0.84 on stress was not used, and the treatment of mean stresses used there was different. A modified Goodman relation was adopted for the reference composite. That relation did not adequately describe the mean stress effects in the chopped-fiber composite- - thus the use of the parameter $\sqrt{\left(\mathrm{S}_{\max } \cdot \mathrm{S}_{\mathrm{a}}\right)}$.

Table 7.6 tabulates allowable maximum cyclic stress values for a cycle alternating between zero and the tensile maximum $(R=0)$. The corresponding reference composite values from Ref. 1 are given in parentheses. Although the average tensile fatigue strength of the chopped-fiber composite is higher than that of the reference composite (see Fig. 12.2 in Part 2), the multiplier of 0.84 on stress added to the chopped-fiber design curves makes the roomtemperature allowable cyclic stresses for the two materials about equal. The variation of highcycle fatigue strength with temperature is significantly different for the two composites.

For fluid effects on fatigue, the case of distilled water with a 1000-h presoak is the bounding condition. At $10^{2}$ cycles, the multiplier is $0.75(0.95)$. At $10^{8}$ cycles, it is $0.97(0.81)$. The numbers in parentheses are the corresponding reference composite factors from Ref. 1.

Miner's rule for assessing varying cyclic stress amplitudes was adopted for the choppedfiber composite, just as it was for the reference composite.

Table 7.6. Allowable maximum stress for tension $(R=0)$ cycling

\begin{tabular}{ccc}
\hline \multirow{2}{*}{$\begin{array}{c}\text { Temperature } \\
\left({ }^{\circ} \mathrm{C}\right)\end{array}$} & \multicolumn{2}{c}{ Stress (MPa) } \\
\cline { 2 - 3 } & $10^{2}$ cycles & $10^{8}$ cycles \\
\hline-40 & $114(116)$ & $18(29)$ \\
23 & $95(96)$ & $23(24)$ \\
120 & $64(63)$ & $22(15)$ \\
\hline
\end{tabular}

\subsection{DAMAGE TOLERANCE EVALUATION}

The two-part design assessment procedure recommended for assessing impact damage and other flaws is essentially the same as that used in Ref. 1 for the reference composite. First, a 6.4-mm-diam circular hole in the worst possible location of the structure should be assumed and its effect on strength and stiffness evaluated using analysis or experimental data. That part of 
calculated local stress concentration factors greater than an experimentally determined, hole-sizedependent value can be ignored.

For specific low-energy impacts such as roadway kickups, tool drops, and load drops in a pickup box, experimentally derived correlations are given for (1) conservatively estimating the damage area from the mass and velocity of the impacting object and (2) determining, from the estimated damage area, the resulting degradation in strength. In contrast to the reference composite for which tensile strength was most degraded, only the compressive strength was degraded in the chopped-fiber composite.

Table 7.7 tabulates the predicted damage for four representative combinations of impactor mass and velocity. Relative to the reference composite, the chopped-fiber composite is less damaged by the larger mass and somewhat more damaged by the smaller mass.

Table 7.7. Damage areas predicted from design curve (Fig. 6.2)

\begin{tabular}{ccc}
\hline $\begin{array}{c}\text { Mass } \\
(\mathrm{kg})\end{array}$ & $\begin{array}{c}\text { Velocity } \\
(\mathrm{m} / \mathrm{s})\end{array}$ & $\begin{array}{c}\text { Damage area } \\
\left(\mathrm{mm}^{2}\right)\end{array}$ \\
\hline 11.52 & 1.5 & $195(303)^{a}$ \\
11.52 & 2.0 & $290(532)$ \\
0.0227 & 33.8 & $195(155)$ \\
0.0227 & 45.1 & $290(245)$ \\
\hline
\end{tabular}

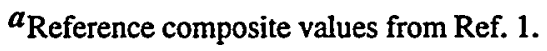

\subsection{SIMPLIFIED SUMMARY OF DESIGN RULES}

As a way of further summarizing and simplifying the rules, Table 7.8 gives key allowable stress values for various conditions as a percentage of the average room-temperature UTS of $177 \mathrm{MPa}$. Corresponding values for the reference composite, derived from Ref. 1, are given in parentheses.

Often in the past, a strain limit of 0.3 to $0.4 \%$ has been used for design of automotive composite structures to cover all effects. For the chopped-fiber composite, this corresponds to 20 to $27 \%$ of the average room-temperature UTS (19 to $26 \%$ for the reference composite). Comparison of these values with the allowables in Table 7.8 shows that the strain limits are adequate except for the extreme areas of the table (high temperature, long times, high cycles). They are, however, overly conservative in many other cases. The limits given in Part 1 of this report put the design allowables on a more rational and defensible basis, and they avoid the over- and underconservation associated with the simplified approach. 
Table 7.8. Key allowable stresses, expressed as a percentage of average room-temperature UTS ${ }^{a}$

\begin{tabular}{|c|c|c|c|c|}
\hline \multirow{2}{*}{$\begin{array}{c}\text { Stress } \\
\text { allowable }\end{array}$} & \multicolumn{2}{|c|}{$\begin{array}{c}\text { Without environmental and } \\
\text { prior load effects }\end{array}$} & \multicolumn{2}{|c|}{$\begin{array}{c}\text { With environmental and prior } \\
\text { load effects }\end{array}$} \\
\hline & $\begin{array}{c}\text { Room } \\
\text { temperature }\end{array}$ & $120^{\circ} \mathrm{C}$ & $\begin{array}{c}\text { Room } \\
\text { temperature }\end{array}$ & $120^{\circ} \mathrm{C}$ \\
\hline $\mathrm{S}_{0}$ & $56(54)^{b}$ & $41(36)$ & $49(45)$ & $35(29)$ \\
\hline $\mathrm{S}_{0} *$ & $56(\mathrm{NA})^{c}$ & 25 (NA) & 45 (NA) & 20 (NA) \\
\hline \multicolumn{5}{|l|}{$S_{t}$} \\
\hline $5000 \mathrm{~h}$ & $51(51)$ & $39(27)$ & $29(25)$ & $22(22)$ \\
\hline 15 years & $49(48)$ & - & $28(23)$ & - \\
\hline \multicolumn{5}{|l|}{$S_{t}^{*}$} \\
\hline $5000 \mathrm{~h}$ & 51 (NA) & $6(\mathrm{NA})$ & 29 (NA) & 3 (NA) \\
\hline 15 years & 49 (NA) & - & 28 (NA) & - \\
\hline \multicolumn{5}{|l|}{$S_{\max }(R=0)$} \\
\hline $10^{2}$ cycles & $54(65)$ & $36(43)$ & $41(46)$ & - \\
\hline $10^{8}$ cycles & $13(16)$ & $12(10)$ & $13(11)$ & - \\
\hline
\end{tabular}


Part 2

\section{BACKGROUND DATA AND MODELS}




\title{
8. BASIC TENSILE, COMPRESSIVE, AND IN-PLANE SHEAR PROPERTIES
}

\author{
M. B. Ruggles
}

\subsection{INTRODUCTION}

The material used in this study was $\mathrm{P} 4$ chopped-fiber reinforcement in a Baydur $420 \mathrm{IMR}$ resin. The glass fiber reinforced material closely represents the ACC Focal Project II truck box material. Thirty-six plaques were used. The glass preforms were made in one step (one layer) and were intended to be isotropic in the plane of the plaque. To check this premise, the stiffnesses of 30 plaques, received in the first batch, were measured in two directions as shown in Fig. 8.1.* (An additional six plaques were from a second batch received after the deflection tests had been completed.) Each plaque was simply supported on two sides, as shown in the sketch below, and subjected to a light load in the center. The resulting center deflection was measured. The plaque was then rotated $90^{\circ}$ and the test repeated. The measured deflections were a measure of isotropy.

The average deflection difference in the two directions for all the plaques was only $0.5 \%$. The largest individual difference was $9 \%$, with most values being considerably less. Of the plaques, 18 were weaker in the $0^{\circ}$ direction, and 12 were weaker in the $90^{\circ}$ direction. From these measurements, it was concluded that there is no consistent strong or weak direction. All test specimens were cut in the $0^{\circ}$ direction.

All of the tensile-type specimens were untabbed and dogboned. ${ }^{3}$ To assure that dogboning to a specimen width of $20.3 \mathrm{~mm}$ did not introduce a consistent change in properties relative to those that would be obtained from a 25.4-mm-wide straight-sided specimen, the stiffness of 11 straight-sided specimens was measured; the specimens were then dogboned and the stiffness measured again. Overall, the average for all 11 specimens remained the same, 11.2 GPa. From this it was concluded that the dogboned specimens provide representative properties.

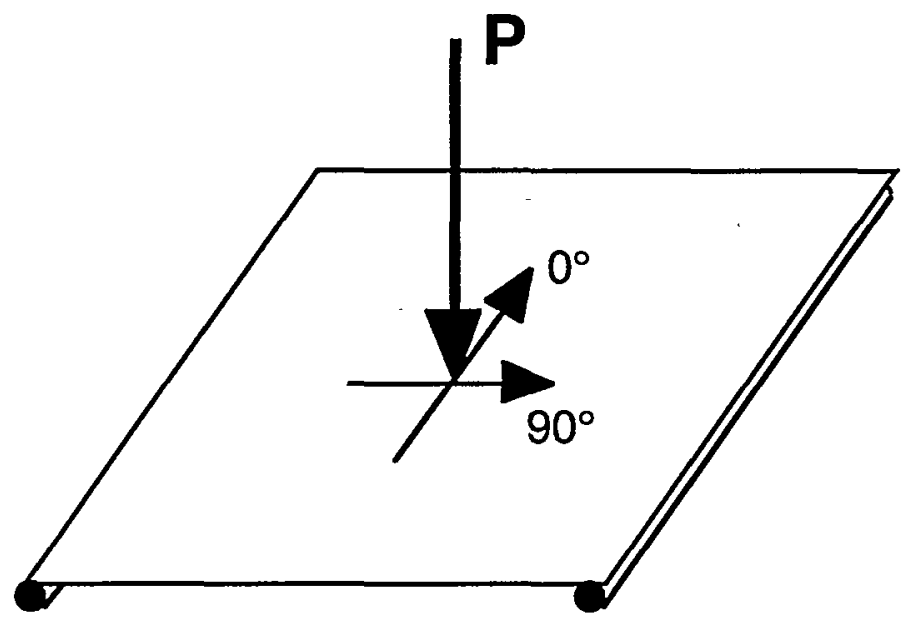

Fig. 8.1. Schematic of plaque bend tests.

*Tests performed by R. L. Battiste, ORNL. 


\subsection{MOISTURE SORPTION}

Investigations of the effects of moisture exposure on tensile properties were conducted with the purpose of establishing correlations between exposure time, weight change, and property changes. A broad range of exposure conditions was chosen to provide a better understanding of moisture effects.

Two groups of specimens were exposed to $50^{\circ} \mathrm{C}$ distilled water. One group was immersed in the "as-received" condition. Another group was predried for $915 \mathrm{~h}$ in vacuum at $50^{\circ} \mathrm{C}$, which resulted in an average weight loss of $0.41 \%$. The study included exposure times of up to $6168 \mathrm{~h}$. Percent weight change as a function of the square root of exposure time is shown in Fig. 8.2. Weight change is calculated with reference to weight at the time of immersion. As expected, weight gain due to moisture intake is significantly more rapid for predried specimens. Furthermore, the data scatter for the predried specimens is smaller. This observation is readily explained by the fact that moisture content in predried specimens is considerably more uniform than that in as-received specimens. Also note that for both predried and "as-received" specimens the weight increases, reaches a maximum (after about three months of exposure), then starts to decrease, probably due to binder and/or matrix loss. Following exposure of $6168 \mathrm{~h}$, six specimens immersed in the as-received condition were dried in vacuum at $50^{\circ} \mathrm{C}$ for $2016 \mathrm{~h}$. The average weight loss was $2.53 \%$. The average weight loss of as-received specimens dried for $912 \mathrm{~h}$ was $0.41 \%$. In both cases weight change is calculated with respect to the weight in the as-received condition. The lower weight of the specimens exposed for $6168 \mathrm{~h}$ and then dried for $2016 \mathrm{~h}$ further indicates that material loss may have taken place during exposure.

Effects of exposure in $50^{\circ} \mathrm{C}$ distilled water on tensile properties are summarized in Table 8.1, where the average values of percent change in strength and stiffness are given for

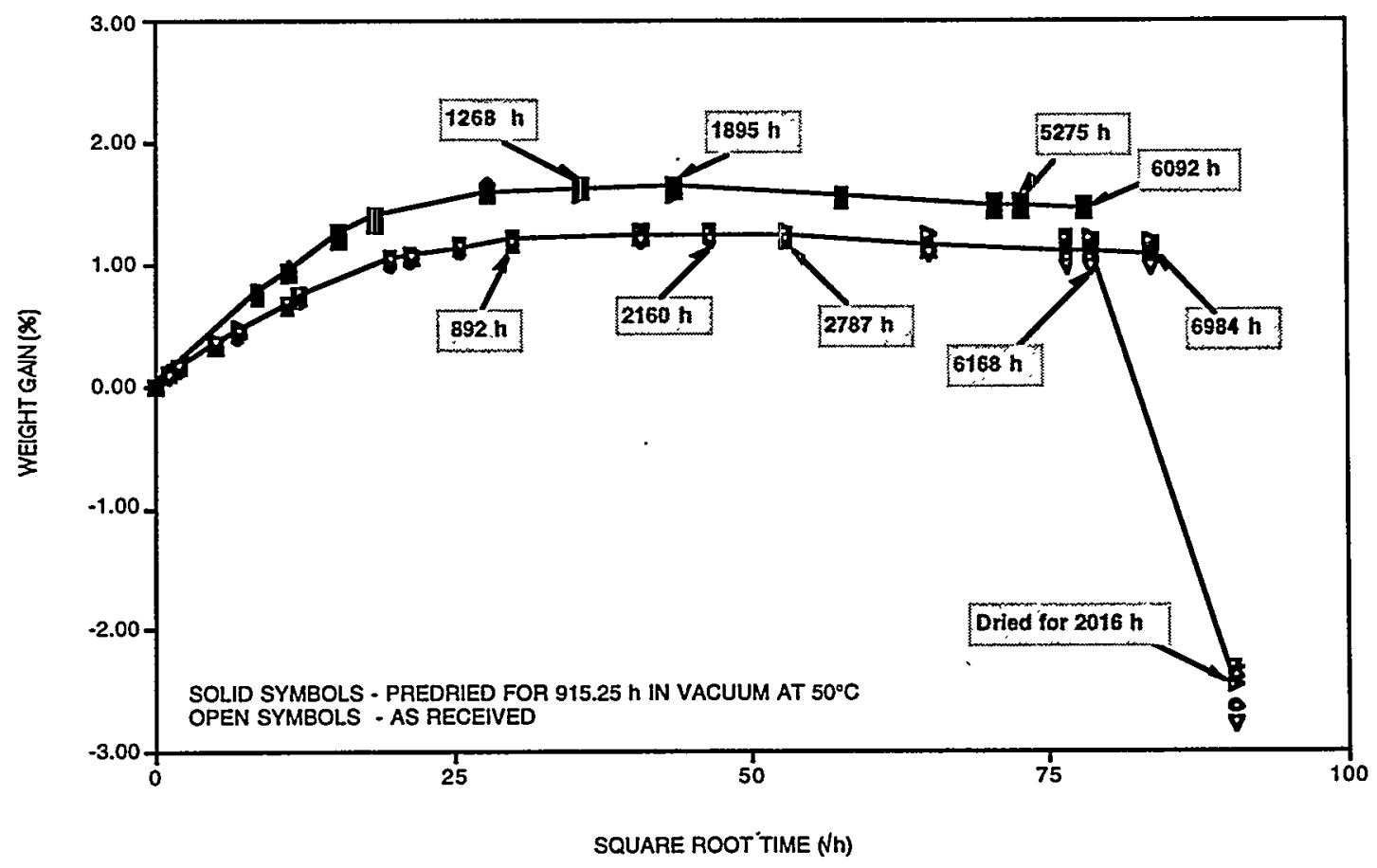

Fig. 8.2. Percent weight change due to exposure in $50^{\circ} \mathrm{C}$ distilled water. 
Table 8.1. Effect of exposure in $50^{\circ}$ distilled water on tensile strength and stiffness

\begin{tabular}{ccc}
\hline $\begin{array}{c}\text { Exposure time } \\
(\mathrm{h})\end{array}$ & $\begin{array}{c}\text { Change in stiffness } \\
(\%)\end{array}$ & $\begin{array}{c}\text { Change in strength } \\
(\%)\end{array}$ \\
& As-received specimens \\
892 & -5.97 & -21.1 \\
2160 & -9.53 & -31.4 \\
2787 & -13.1 & -34.3 \\
6768 & -13.9 & -40.1 \\
6984 & -13.9 & -44.5 \\
& Predried specimens & \\
1268 & -9.52 & -26.3 \\
1895 & -12.0 & -37.4 \\
5275 & -15.2 & -47.6 \\
6092 & -15.0 & -47.0 \\
As-received specimens exposed for 6168 h and dried for $2016 \mathrm{~h}$ \\
$6168 / 2016$ & -2.16 & -22.8 \\
\hline
\end{tabular}

different exposure times (each average is based on at least six specimens). Note that, most likely, material loss was occurring all along. For exposure times greater than $2160 \mathrm{~h}$, weight loss became greater than weight gain. Therefore property changes are partly due to the leaching out of the material.

Furthermore, it is seen that as-received specimens exposed for $6168 \mathrm{~h}$ and then dried for $2016 \mathrm{~h}$ have almost regained the original stiffness (stiffness loss now is only $2.16 \%$ ). Strength loss, however, still remains significant at $22.8 \%$.

Effects of moisture exposure on stiffness and strength are illustrated in Figs. 8.3 and 8.4. Shown in Fig. 8.3 is percent weight gain vs square root of exposure time with labels specifying property changes corresponding to different exposure times and percent weight changes.

It is seen in Fig. 8.4 that both percent reduction in strength and stiffness depend nonlinearly on exposure time. Furthermore, the logarithmic representation shown appears to be fairly good.

Six additional specimens were immersed in $36^{\circ} \mathrm{C}$ distilled water to assess the effect of temperature on environmental degradation. Exposure time was $1008 \mathrm{~h}$. Reduction in stiffness was $7 \%$ and reduction in strength, $6 \%$. Recall that $892 \mathrm{~h}$ exposure in $50^{\circ}$ distilled water produced a comparable $6 \%$ reduction in stiffness and a considerably larger $21 \%$ reduction in strength. Thus, it appears that exposure in $36^{\circ} \mathrm{C}$ distilled water has about the same effect on stiffness as $50^{\circ} \mathrm{C}$ water, but strength may be less affected.

Effects of exposure in room-temperature water were also investigated. Exposure times were $100 \mathrm{~h}$ (six specimens) and $1000 \mathrm{~h}$ (six specimens). For the $100-\mathrm{h}$ presoak , the average weight gain (with respect to the as-received condition) was $0.24 \%$. Tensile tests revealed a stiffness loss of $3.32 \%$ and strength loss of $2.87 \%$. For the 1000 -h presoak, the average weight gain was $0.77 \%$. The average loss in tensile stiffness was $5.91 \%$, and the average loss in tensile 


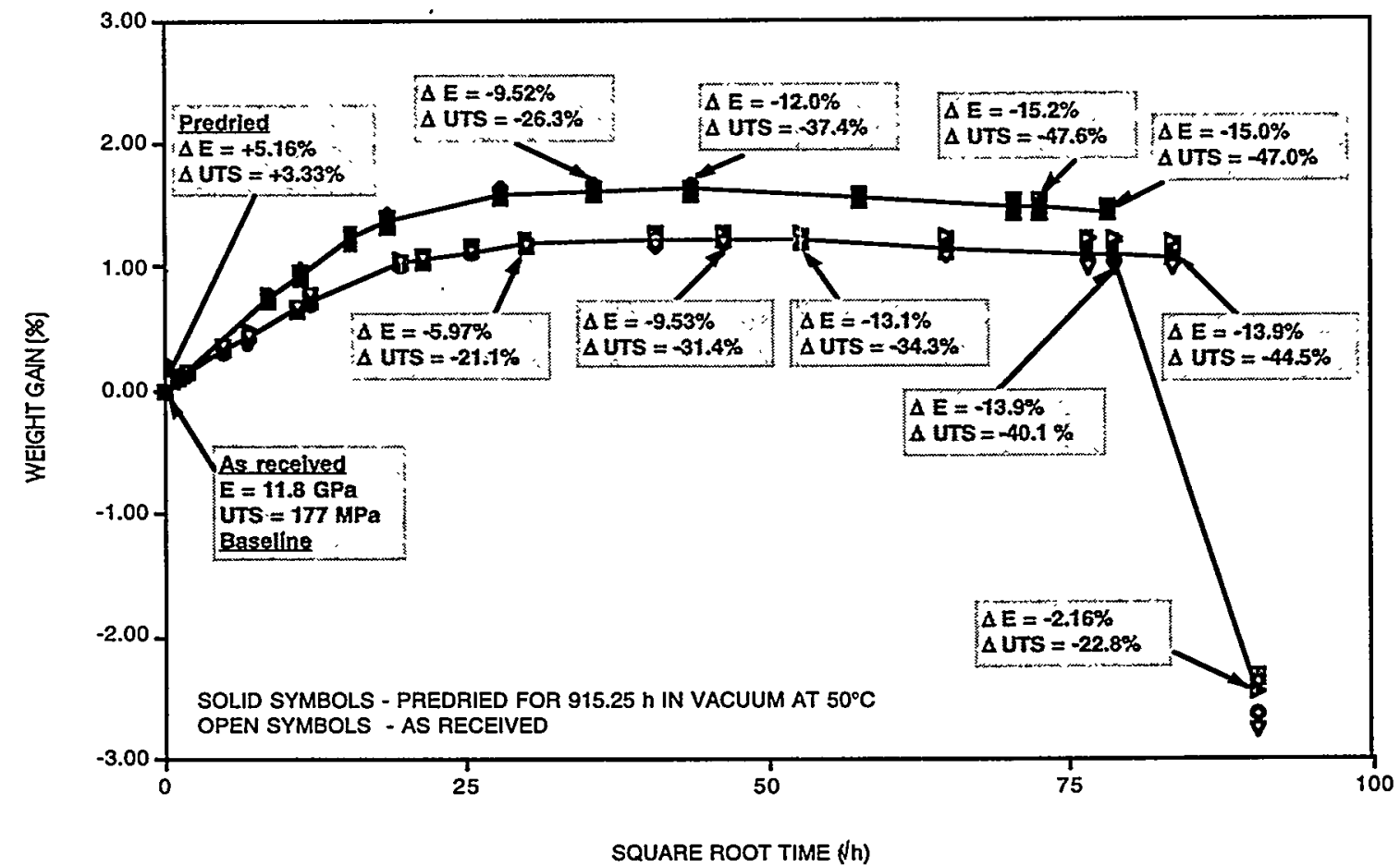

Fig. 8.3. Percent weight change due to exposure in $50^{\circ} \mathrm{C}$ distilled water showing strength and stiffness loses corresponding to times in Fig. 8.2.

ORNL 99-1498 EFG

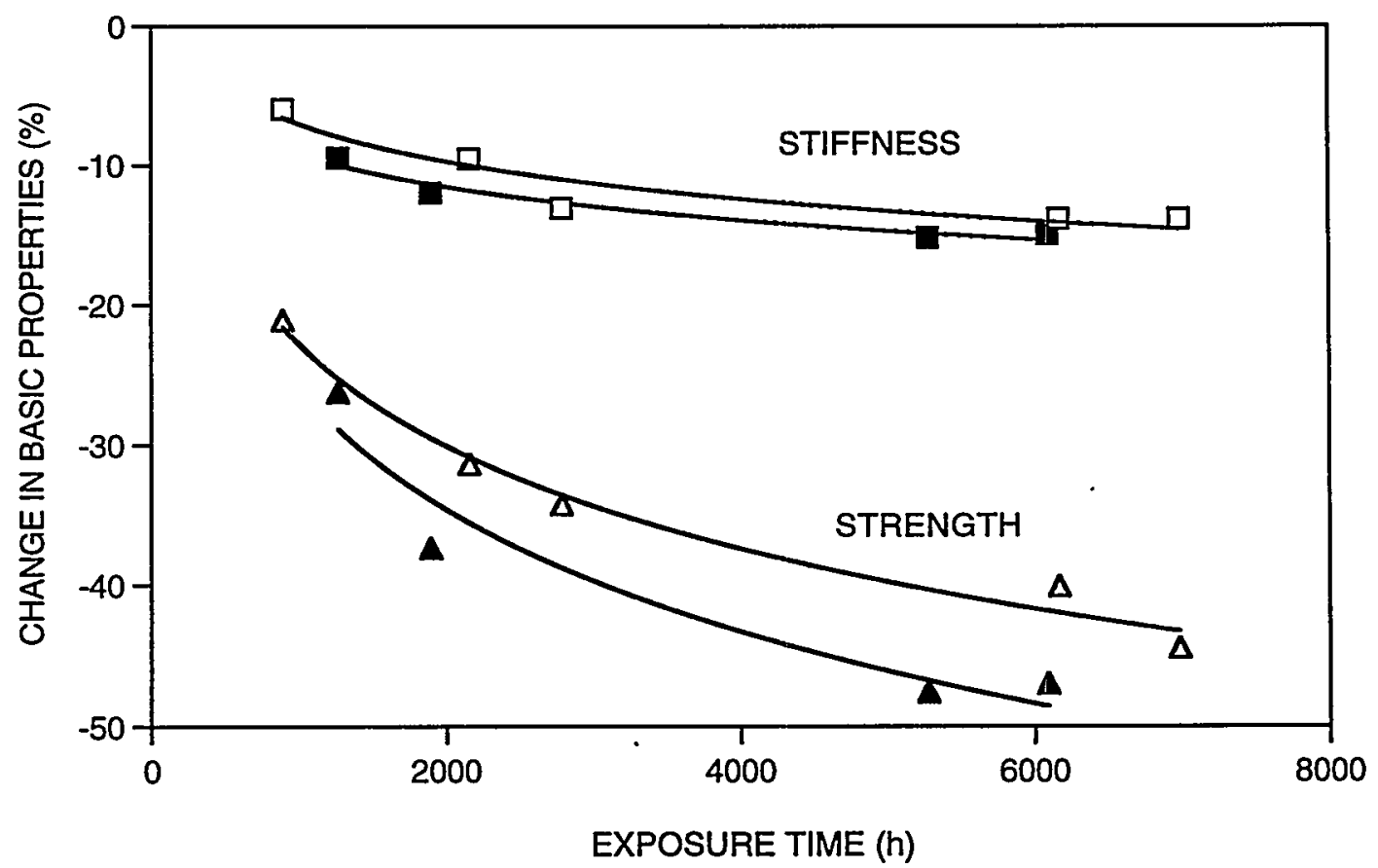

Fig. 8.4. Percent change in tensile properties due to exposure in $50^{\circ} \mathrm{C}$ distilled water for (1) specimens predried for $915 \mathrm{~h}$ in vacuum at $50^{\circ} \mathrm{C}$-solid symbols, and (2) specimens immersed in "as-received" condition-open symbols. 
strength was $8.8 \%$. Note that the effect of room-temperature exposure can be predicted from $50^{\circ} \mathrm{C}$ exposure data. Knowing the percent weight change due to room-temperature moisture exposure, an equivalent $50^{\circ} \mathrm{C}$ exposure time can be obtained from the graph in Fig. 8.2. Having an equivalent $50^{\circ} \mathrm{C}$ exposure time, percent property reductions can be assessed from the graph in Fig. 8.4. Following this procedure, a stiffness loss of $3 \%$ and a strength loss of $10 \%$ were predicted for a 1000 -h room-temperature presoak.

Prolonged exposure in $50^{\circ} \mathrm{C}$ water represents an important bounding condition, which was studied and evaluated to gain a better understanding of environmental material and property degradation. However, it should be recognized that the $6168-\mathrm{h}$ exposure in $50^{\circ} \mathrm{C}$ water hardly represents a typical service condition for an automotive composite. A 1000 -h exposure in roomtemperature water is judged to be a more representative bounding moisture exposure likely to be encountered under normal operating conditions. Thus, here and throughout this report, $1000-h$ exposure in room-temperature distilled water is chosen as the most representative bounding condition.

\subsection{TENSILE PROPERTIES}

\subsubsection{Room-Temperature Behavior}

In-air room-temperature values of stiffness, E, ultimate tensile strength (UTS), and failure strain, $\varepsilon_{\mathrm{f}}$, were established from 899 stiffness tests and 94 tensile tests. The untabbed dogboneshaped tensile specimens were used ${ }^{3}$ in all tests. Tensile and stiffness tests were performed according to the test method described in Ref. 3. The average stiffness, UTS, and strain at failure, were $11.8 \mathrm{GPa}(8.54), 177 \mathrm{MPa}(10.3)$, and $2.02 \%$ (10.5), respectively. (Here and throughout this chapter, numbers given in parentheses after the property are percent coefficients of variation, unless noted otherwise). The minimum B-basis ${ }^{5}$ UTS was calculated: UTS $_{\min }=149 \mathrm{MPa}$. Poisson's ratio measurements were carried out using four specimens from plaque B29. Each face of each specimen was instrumented with an axial and transverse 6.4-mm-long strain gage. The average room-temperature value was 0.32 .

Tensile properties obtained in 94 tensile tests were assessed with the purpose of establishing a possible correlation between UTS and stiffness. The plot of UTS vs stiffness in Fig. 8.5 demonstrates that dependence of UTS on stiffness can be reasonably well approximated with a linear correlation over the range of the data. Comparison with the reference material correlation is shown in Fig. 8.5 as well.

The dependence of stiffness on fiber content was investigated using six specimens with varying stiffness values in a fiber burnout procedure [American Society for Testing and Materials (ASTM) D 2584-687 ]. Results shown in Fig. 8.6 indicate that tensile stiffness and fiber content (wt \%) can be correlated with a linear law. Thus, strength and stiffness are linearly related to fiber content, as might be expected.

Results of the tensile tests were assessed to establish a proportional limit. The proportional limit was defined as the point $\left(\sigma_{\mathrm{PL}}, \varepsilon_{\mathrm{PL}}\right)$ in stress-strain space where the tensile stress-strain curve departs from linearity. The procedure described in Sect. 3.2 of Ref. 2 was employed to calculate proportional limit stress and strain values for each tensile test. The following averages

\footnotetext{
*Poisson's ratio tests performed by R. L. Battiste.
} 


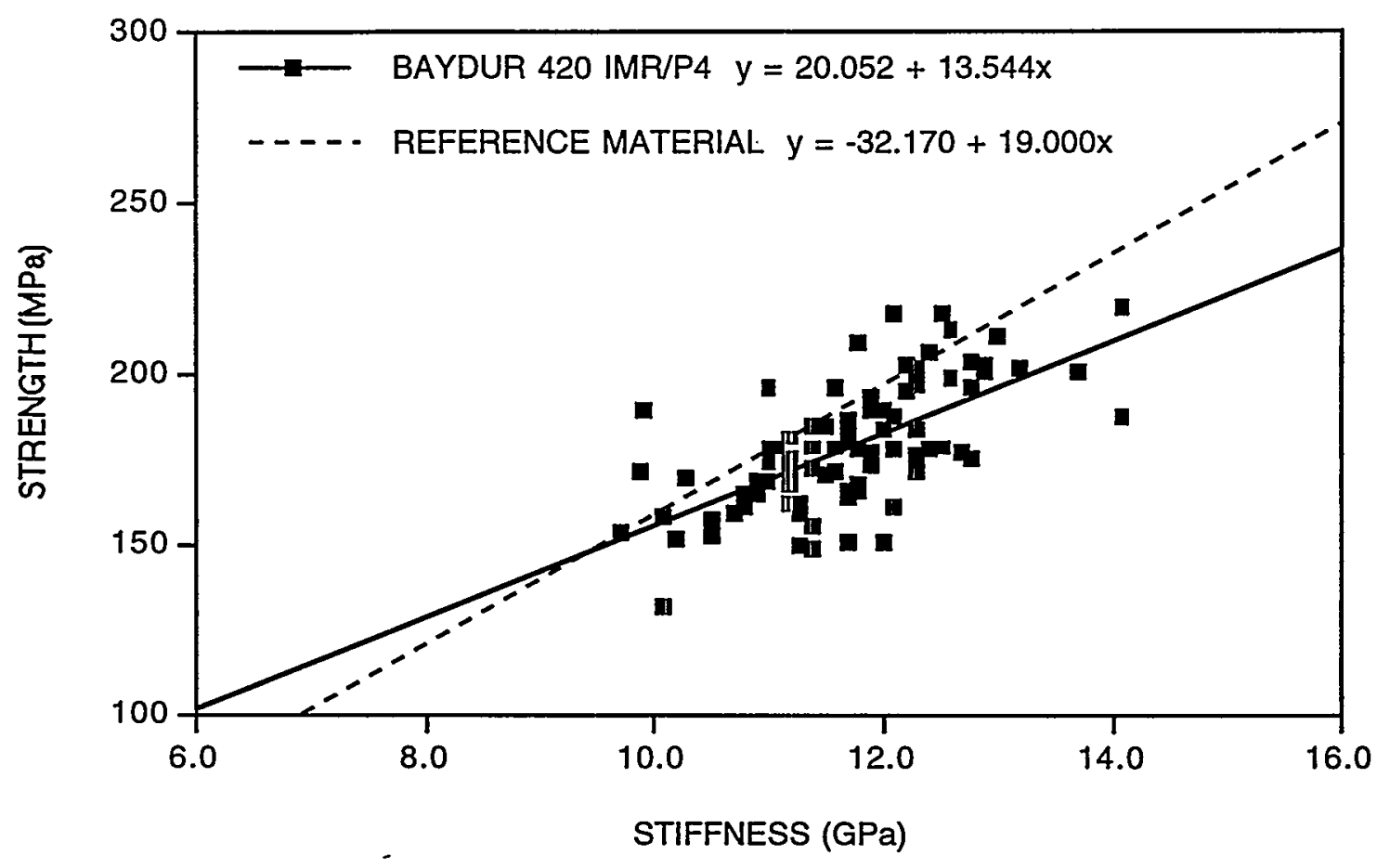

Fig. 8.5. Relation between tensile strength and stiffness.

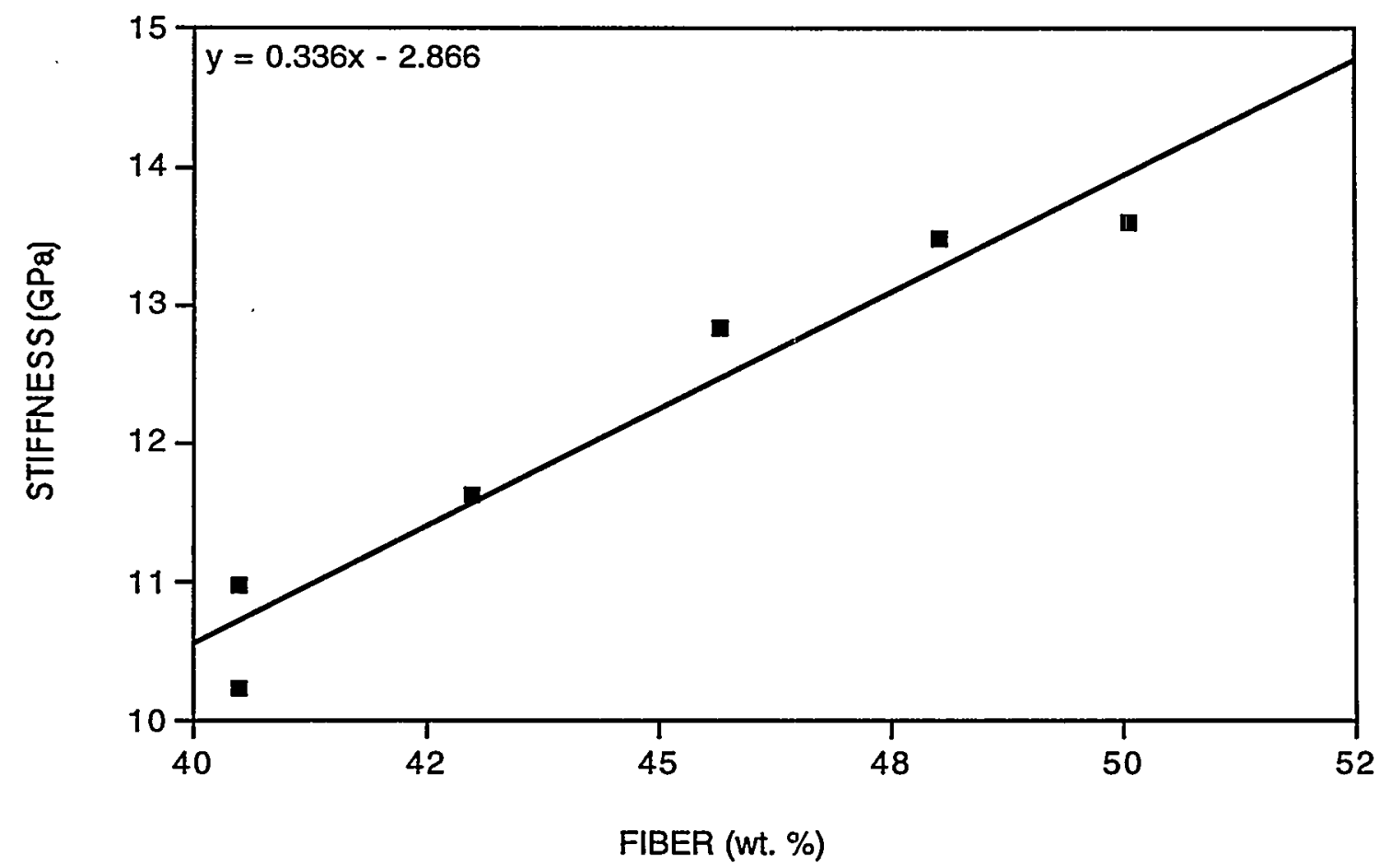

Fig. 8.6. Dependence of tensile stiffiness on fiber content. 
were established: $\sigma_{\mathrm{PL}}=35.0 \mathrm{MPa}(15.6)$, and $\varepsilon_{\mathrm{PL}}=0.31 \%$ (18.2). The proportional limit stress is $20 \%$ of the UTS. The proportional limit strain is $15 \%$ of the failure strain. The proportional limit stress and strain for the reference material were $24 \%$ and $18 \%$ of the UTS and failure strain, respectively. Thus the present material shows an earlier departure from linearity than the reference material.

The effect of rate on tensile behavior was investigated in 16 tests conducted at the following constant strain rates: $10^{-6}, 10^{-4}, 10^{-2}$, and $10 \mathrm{~s}^{-1}$. Four tests were performed at each strain rate. Specimens from plaque B10 with similar virgin stiffness values were selected for these tests. Results are summarized in Fig. 8.7. The plot of stiffness vs strain rate in Fig. 8.7(a) shows a $10 \%$ increase in stiffness as the strain rate increases from $10^{-6}$ to $10^{-2} \mathrm{~s}^{-1} .0$ (Note that reliable values of stiffness were not obtainable at $10 \mathrm{~s}^{-1}$ ). The effect of strain rate on UTS illustrated in Fig. 8.7(b) appears to be more pronounced. As the strain rate increases from $10^{-6}$ to $10^{-2} \mathrm{~s}^{-1}$, the average UTS increases by about $20 \%$, then decreases slightly as the strain rate increases to $10 \mathrm{~s}^{-1}$. The variation in failure strain with strain rate in Fig. 8.7(c) follows the same pattern. The failure strain increases by about $14 \%$ as the strain rate increases from $10^{-6}$ to $10^{-2}$ $\mathrm{s}^{-1}$ and decreases as the strain rate continues to increase to $10 \mathrm{~s}^{-1}$.

Note that the effect of strain rate for the present material is qualitatively similar to that reported for the reference material. However, where the present material shows a noticeable increase in stiffness (10\%) and failure strain (14\%), the corresponding changes are small for the reference material. Conversely, the reference material produced a higher increase (39\%) in UTS with strain rate than the present material (20\%).

\subsubsection{Temperature Effects}

The effect of temperature on tensile properties was assessed from 45 tensile tests conducted at $-40,23,50$, and $120^{\circ} \mathrm{C}$ on specimens from plaques $\mathrm{B} 4$ and $\mathrm{B} 7$. The values of the Poisson's ratio at different temperatures were established using four specimens from plaque B29. ${ }^{*}$ The average tensile properties and Poisson's ratio at different temperatures are presented in Table 8.2.

It is seen that values of stiffness and UTS obtained at elevated temperatures are noticeably lower than those obtained at room temperature. Conversely, tensile strength and stiffness increase with decreasing temperature, resulting in a "stronger" material at $-40^{\circ} \mathrm{C}$. Similar behavior was reported for the reference material.

Percent changes in stiffness and strength from room-temperature values are presented in Fig. 8.8.

Results in Fig. 8.8 indicate that simple straight-line approximations may be used to represent changes in strength and stiffness with temperature. Furthermore, particularly for design purposes, the two linear approximations may be combined into the following single linear correlation for both strength and stiffness:

$$
\Delta\left(\mathrm{E}, \sigma_{\mathrm{UTS}}\right) \times 100 \%=6.64-0.28 \mathrm{~T} .
$$

\footnotetext{
*Poisson's ratio tests performed by R. L. Battiste.
} 


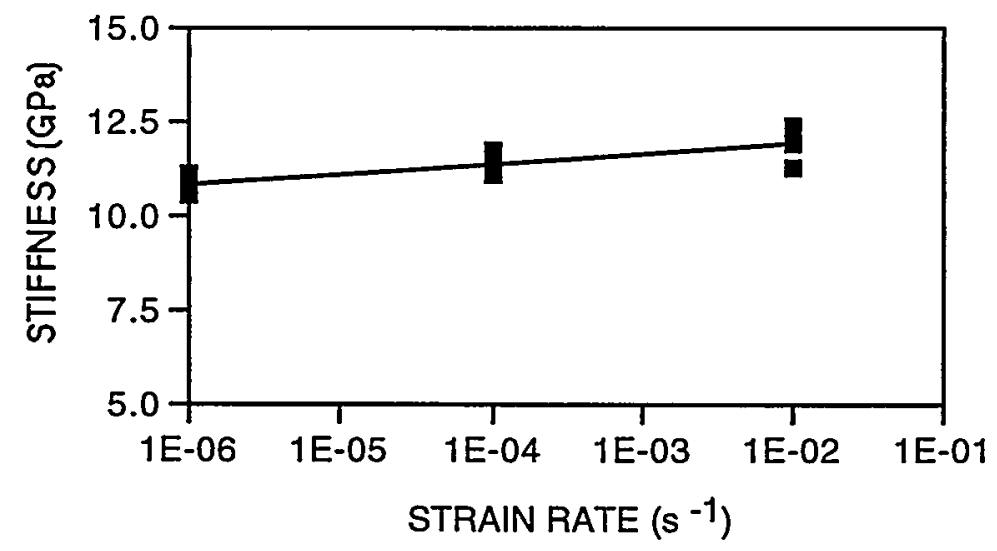

(a) Stiffness.

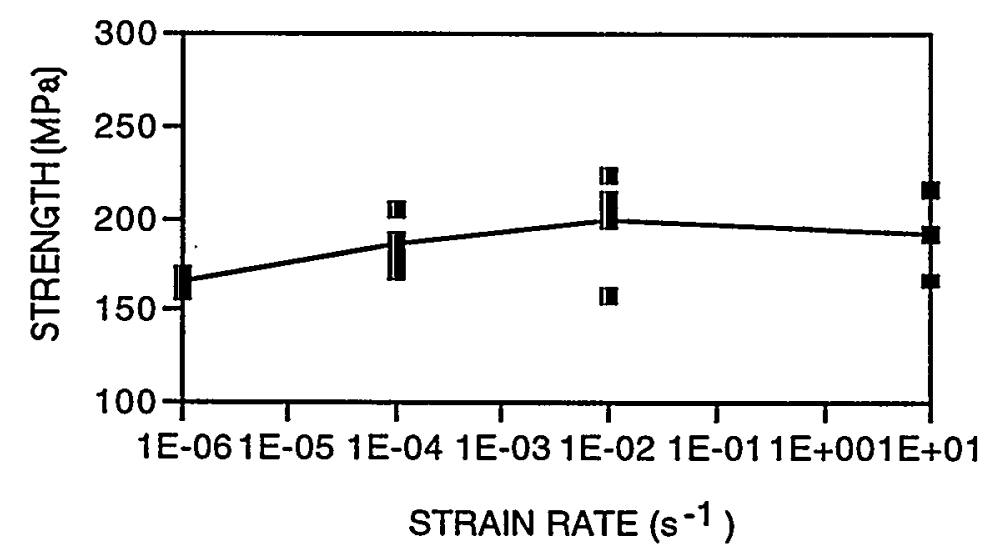

(b) Strength.

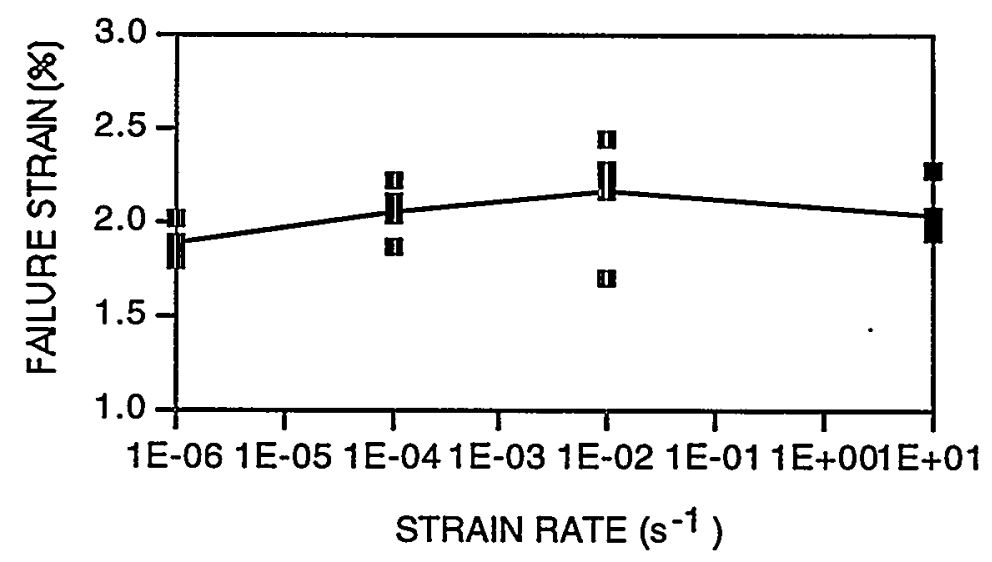

(c) Failure strain.

Fig. 8.7. Effect of strain rate on tensile properties. 
Table 8.2. Average tensile properties at different temperatures

\begin{tabular}{lllll}
\hline \multirow{2}{*}{ Property } & \multicolumn{4}{c}{ Temperature } \\
\cline { 2 - 5 } & \multicolumn{1}{c}{$-40^{\circ} \mathrm{C}$} & \multicolumn{1}{c}{$23^{\circ} \mathrm{C}$} & \multicolumn{1}{c}{$50^{\circ} \mathrm{C}$} & $120^{\circ} \mathrm{C}$ \\
\hline Stiffness, GPa & $14.2(6.92)$ & $11.8(8.54)$ & $10.4(8.38)$ & $7.86(12.4)$ \\
UTS, MPa & $211(12.1)$ & $177(10.3)$ & $168(10.4)$ & $135(16.5)$ \\
Strain at failure, \% & $2.18(13.0)$ & $2.02(10.5)$ & $2.03(13.0)$ & $2.09(8.49)$ \\
Poisson's ratio & 0.31 & 0.32 & 0.33 & 0.34 \\
\hline
\end{tabular}

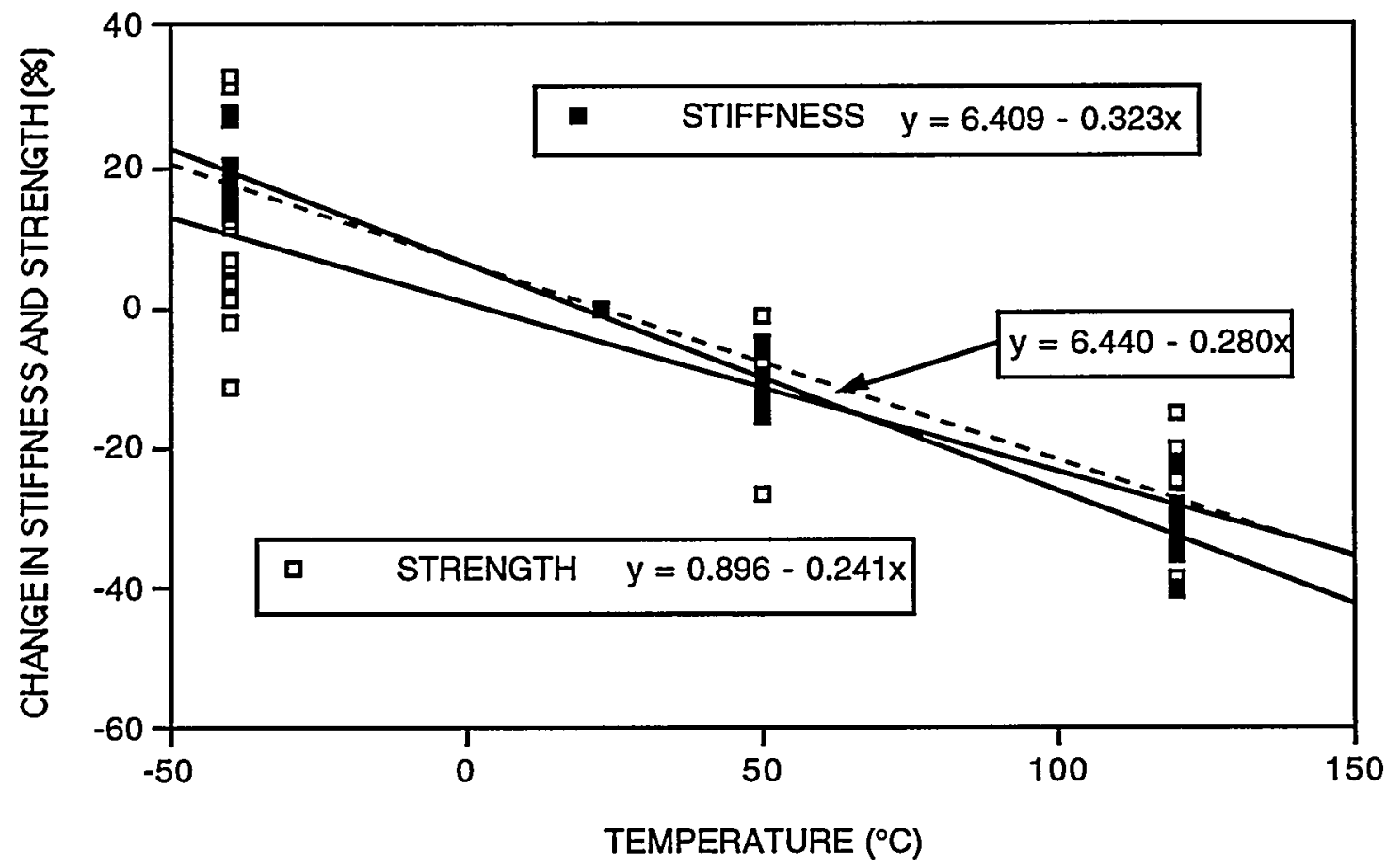

Fig. 8.8. Percent change in stiffness and UTS with temperature. The dashed line approximately represents both correlations.

The singular linear correlation is specifically formulated to give $0 \%$ change at room temperature. Based on this correlation, strength and stiffness at different temperatures and corresponding multiplication factors can be calculated.

Note that room-temperature property values in Table 8.3 are the baseline values given in Sect. 8.3.1. Multiplication factors for determining strength and stiffness at a given temperature from room-temperature values are presented in Fig. 8.9 together with the multiplication factors for the reference material. It is seen that the present material is slightly less temperature dependent.

The tensile properties obtained at various temperatures were further assessed with the purpose of establishing a possible correlation between UTS and stiffness. In addition, it was 
Table 8.3. Tensile properties at different temperatures and corresponding multiplication factors

\begin{tabular}{cccc}
\hline Temperature $\left({ }^{\circ} \mathrm{C}\right)$ & $\mathrm{E}(\mathrm{GPa})$ & UTS $(\mathrm{MPa})$ & Factor \\
\hline-40 & 13.9 & 209 & 1.18 \\
23 & 11.8 & 177 & 1.00 \\
50 & 10.9 & 163 & 0.92 \\
120 & 8.61 & 129 & 0.73 \\
\hline
\end{tabular}

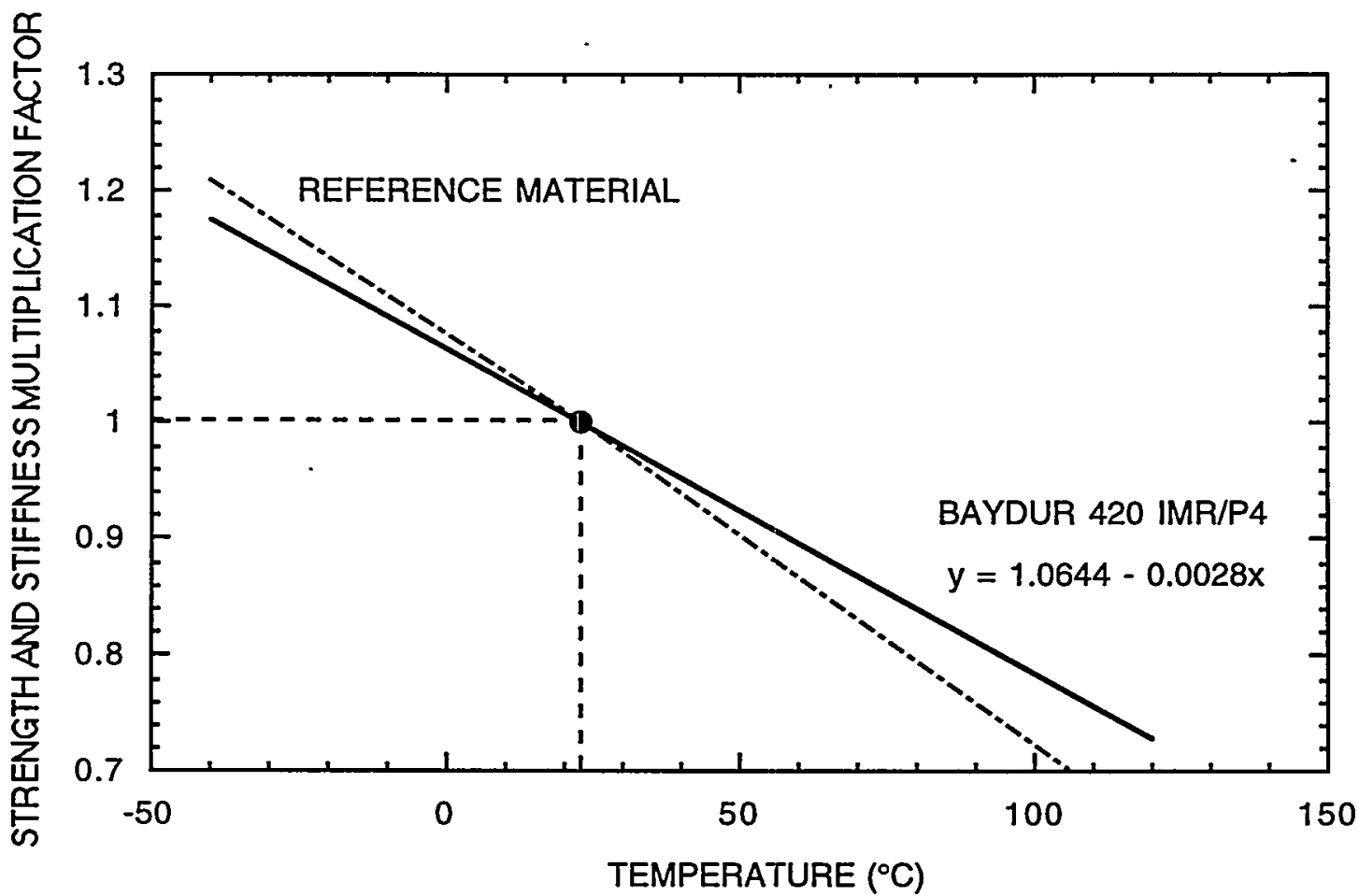

Fig. 8.9. Multiplication factor for determining strength and stiffness at given temperature from room-temperature values.

important to decide whether the same correlation would be valid at different temperatures. The plot of UTS vs stiffness in Fig. 8.10(a) demonstrates that the dependence of UTS on stiffness can be reasonably well approximated with a linear correlation. Furthermore, the graph in Fig. 8.10(a) indicates that the following single linear law can be used to correlate strength and stiffness at all temperatures between 40 and $120^{\circ} \mathrm{C}$ :

$$
\sigma_{\mathrm{UTS}}=35.27+12.61 \mathrm{E}
$$

Room-temperature tensile properties were reassessed in the similar manner [see Fig. $8.10(b)]$. Noteworthy that the strength/stiffness correlation based on room-temperature tests [solid line in Fig. $8.10(b)$ ] is virtually the same as that based on tests at various temperatures 


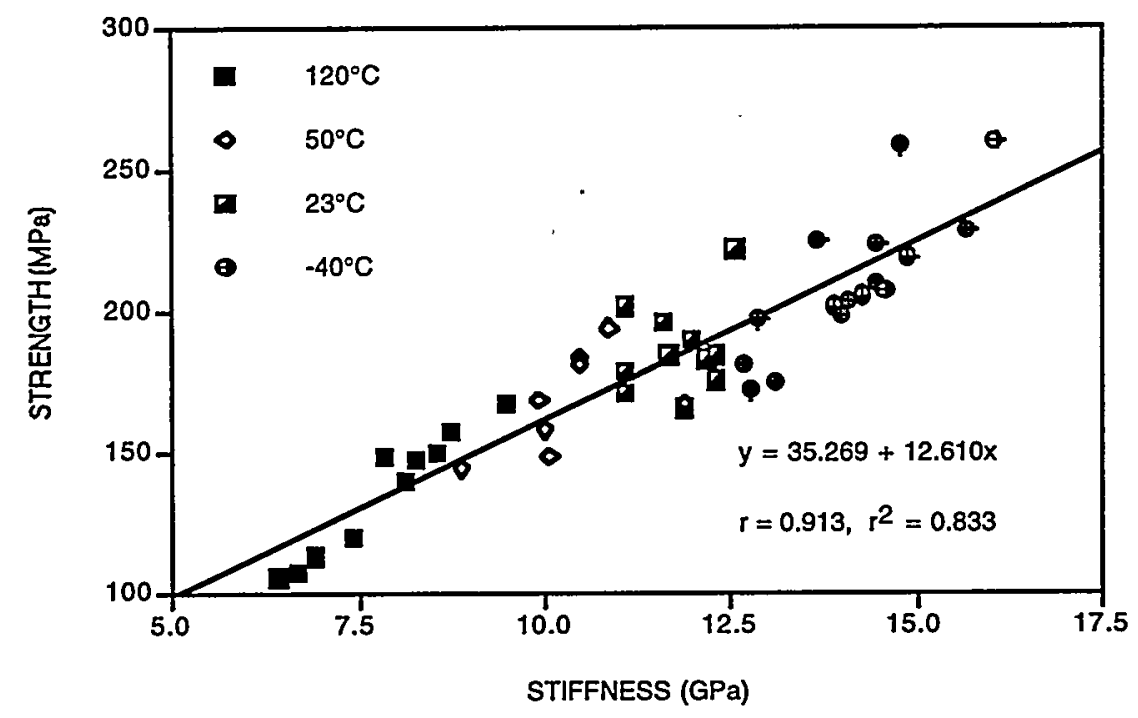

(a) Data from temperature effects study.

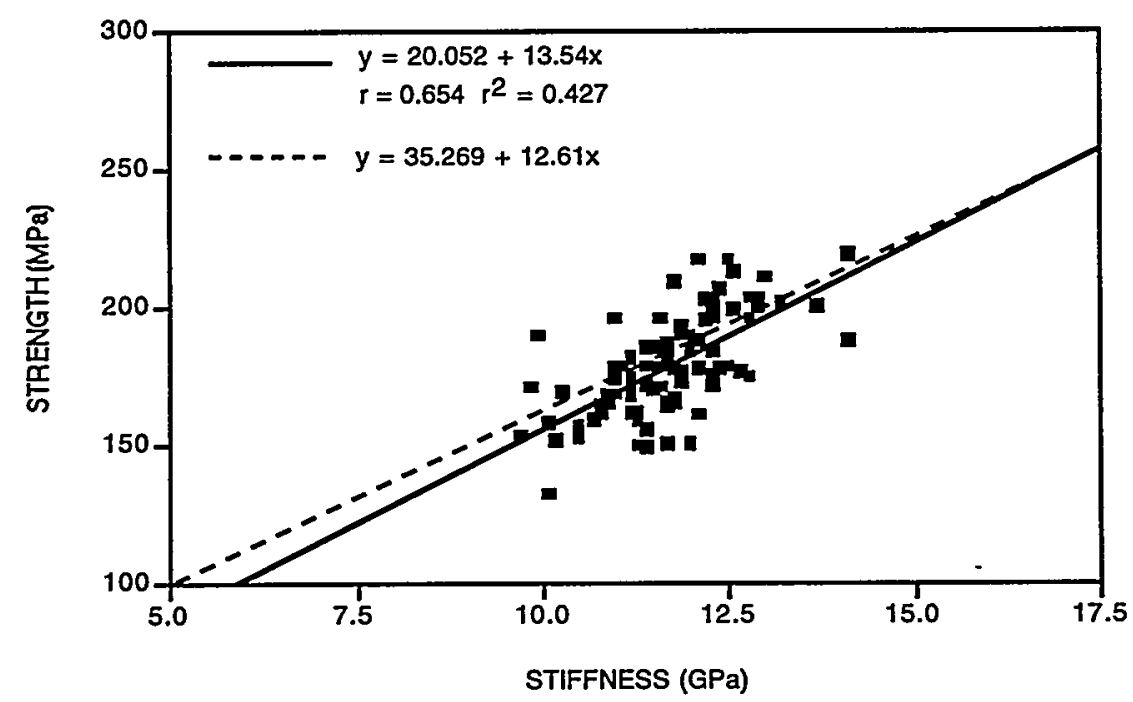

(b) Data from temperature effects study (solid line) compared to room-temperature data (dashed line) from Fig. 8.5.

Fig. 8.10. Correlation between UTS and stiffness.

[dashed line in Fig. 8.10(b)]. It is thus recommended that the single correlation given above be used to describe the dependence of UTS on stiffness at all temperatures between -40 and $120^{\circ} \mathrm{C}$.

\subsubsection{Environmental Effects}

For the present effort, the 1000-h exposure in room-temperature distilled water was chosen as the most severe, yet realistic, bounding condition (see Sect. 8.2). For this condition, the stiffness reduction factor was 0.94 , and the strength reduction factor was 0.91 .

The effects of exposure to windshield washer fluid (30\% distilled water and $70 \%$ methanol) were also investigated. Exposure times were 100, 1000, and $2160 \mathrm{~h}$. Results are 
summarized in Table 8.4. All reduction factors are based on at least six tests. Stiffness reductions were established with reference to the virgin stiffness for each specimen. Strength reductions were established relative to plaque average UTS values.

Note that for the reference material 1080-h exposure in windshield washer fluid caused a stiffness loss less than $5 \%$ and a strength loss less than $10 \%$. Thus, it would appear that the P4 material is more sensitive to windshield washer fluid exposure. It is also seen that reduction factors for stiffness and strength are similar (unlike in the case of moisture exposure, where the reduction in strength significantly outpaces the reduction in stiffness). Furthermore, the stiffness loss is similar and reduction in strength is significantly lower than those due to moisture exposure of the same duration.

The effects of exposure in windshield washer fluid are also shown in Fig. 8.11, where percent changes in basic tensile stiffness and strength are plotted vs exposure time.

Table 8.4. Effect of exposure in windshield washer fluid on tensile strength and stiffness

\begin{tabular}{ccc}
\hline Exposure time (h) & $\begin{array}{c}\text { Stiffness reduction } \\
\text { factor }\end{array}$ & $\begin{array}{c}\text { Strength reduction } \\
\text { factor }\end{array}$ \\
\hline 100 & 0.93 & 0.93 \\
1000 & 0.88 & 0.89 \\
2160 & 0.87 & 0.88 \\
\hline
\end{tabular}

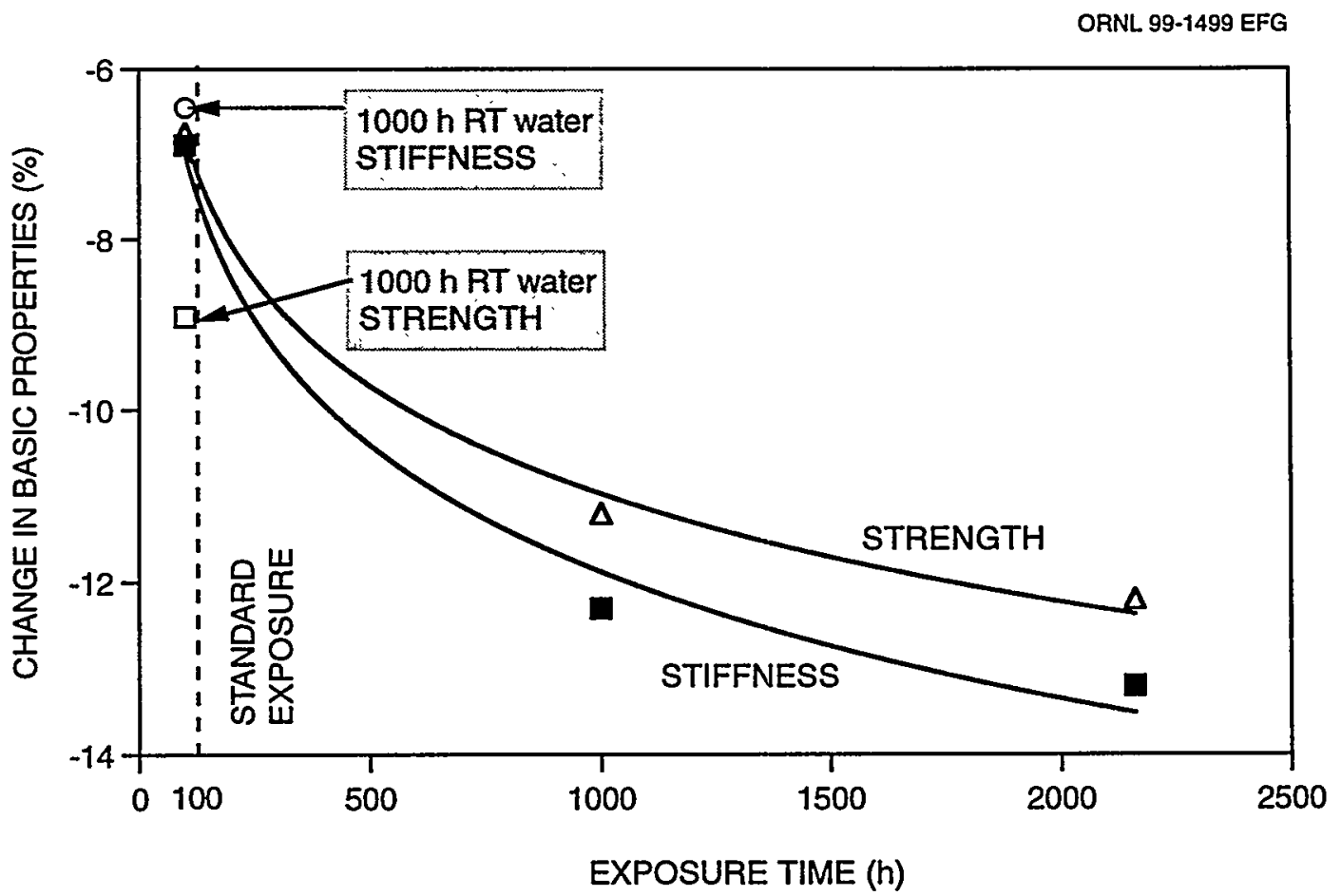

Fig. 8.11. Percent change in tensile properties due to exposure in windshield washer fluid. 
Just as in the case of moisture exposure, it is recognized that 2160-h exposure in windshield washer fluid does not represent a realistic service condition for an automotive composite. Thus, $100 \mathrm{~h}$ was chosen as the bounding condition (standard exposure in Fig. 8.11) for windshield washer fluid exposure. Note that stiffness and strength reduction factors for $100-\mathrm{h}$ exposure are both 0.93 . Recall that stiffness and strength reduction factors for 1000 -h room-temperature water exposure were 0.94 and 0.91 , respectively. Thus a single factor of 0.91 can be used to represent realistic environmental effects on tensile strength and stiffness.

\subsection{COMPRESSIVE PROPERTIES}

\subsubsection{Room-Temperature Behavior}

In-air room-temperature compressive properties were established from 17 tests on specimens cut from plaques B16 (9 specimens) and B17 (8 specimens). Flat specimens with tabs were used. ${ }^{3}$ The tab material was G-11 composite, an epoxy reinforced with woven fiberglass cloth. The adhesive used for bonding the tabs to the test specimens was Hysol's EA 93009NA A/B. An experimental version of the adhesive was successfully used for $120^{\circ} \mathrm{C}$ testing. Compression tests employed an IITRI fixture (Procedure B in ASTM D 3410 ${ }^{\circ}$ ). The test method was as described in Ref. 3.

The average compressive stiffness, ultimate compressive strength (UCS), and compressive strain at failure, were $11.6 \mathrm{GPa}(12.9),-190 \mathrm{MPa}(20.1)$, and $-2.08 \%$ (33.1), respectively. It can be seen that the stress-strain behavior is fairly symmetric; that is, compressive and tensile properties are comparable, with compressive strength being slightly higher than the UTS. A similar observation was made for the reference material.

Compressive strength is plotted vs compressive stiffness in Fig. 8.12. To facilitate comparison with tensile behavior, absolute values of UCS are used. As in the case of the

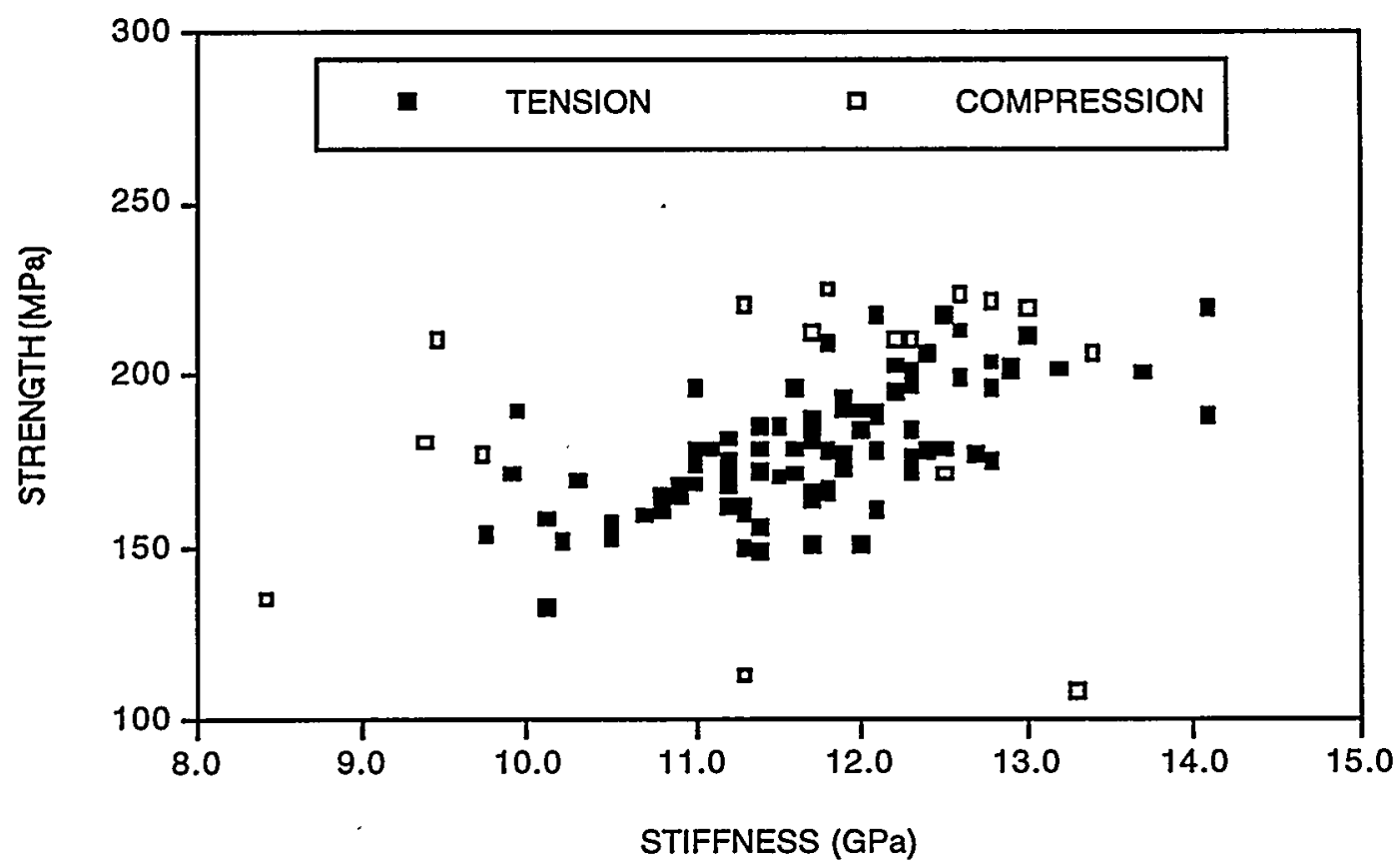

Fig. 8.12. Relation between strength and stiffness. 
reference material, the tensile and compressive sets of data are fairly close (with the exception of two outlying compression data points). It is therefore reasonable to assume that the dependence of strength on stiffness follows the same pattern for both tension and compression.

The effect of rate on compressive behavior was investigated in 11 tests conducted with constant load rates of 117,$100 ; 1,171$; and $11.7 \mathrm{lb} / \mathrm{min}$ (approximately equivalent to strain rates of $10^{-2}, 10^{-4}$, and $10^{-6} \mathrm{~s}^{-1}$, respectively). Results are summarized in Fig. 8.13. The plot of stiffness vs load rate in Fig. 8.13(a) shows a $21 \%$ increase in stiffness as the rate increases from 11.7 to $117100 \mathrm{lb} / \mathrm{min}$. The effect of rate on UCS is illustrated in Fig. 8.13(b). As the load rate increases from 11.7 to $117,100 \mathrm{lb} / \mathrm{min}$, the average UCS increases by about $41 \%$. The variation in failure strain with rate in Fig. 8.13(c) is not significant. Similar observations were made for the reference material.

\subsubsection{Temperature Effects}

The effects of temperature on compressive properties were investigated in 38 tests conducted at $-40,23,50$, and $120^{\circ} \mathrm{C}$. The average compressive properties at different temperatures are presented in Table 8.5. It is seen that both stiffness and strength decrease with increasing temperature. However, the change is much more dramatic for strength than for stiffness. Percent changes in stiffness and strength from room-temperature values are presented in Fig. 8.14.

It can be seen in Fig. 8.14 that changes in compressive strength and stiffness with temperature cannot be represented by a single expression. The following linear representations are proposed:

$$
\begin{gathered}
\Delta \mathrm{E} \times 100 \%=5.382-0.234 \mathrm{~T}\left({ }^{\circ} \mathrm{C}\right) ; \\
\Delta \mathrm{UCS} \times 100 \%=12.903-0.561 \mathrm{~T}\left({ }^{\circ} \mathrm{C}\right) .
\end{gathered}
$$

The above correlations are specifically formulated to give $0 \%$ change at room temperature. Based on these correlations, compressive stiffness and strength at different temperatures and corresponding multiplication factors can be calculated (see Table 8.6).

Multiplication factors for determining compressive strength and stiffness at a given temperature from room-temperature values are presented in Fig. 8.15 together with the factor for the corresponding tensile property.

Results in Fig. 8.15 demonstrate that compressive strength is significantly more temperature dependent than compressive stiffness. The stiffness multiplication factors in tension and compression are close. In fact, a single stiffness multiplication factor can be used to cover both tension and compression. However, the strength multiplication factor in compression differs considerably from that in tension. These results are not surprising, because compressive strength is a matrix dominated property, while tensile strength is governed by fiber behavior, and matrix behavior is considerably more temperature dependent than that of the fibers.

\subsubsection{Environmental Effects}

The effects of environment on compressive properties were assessed in 31 tests on specimens presoaked in $50^{\circ} \mathrm{C}$ distilled water. Twelve specimens were exposed for $912 \mathrm{~h}$, and 


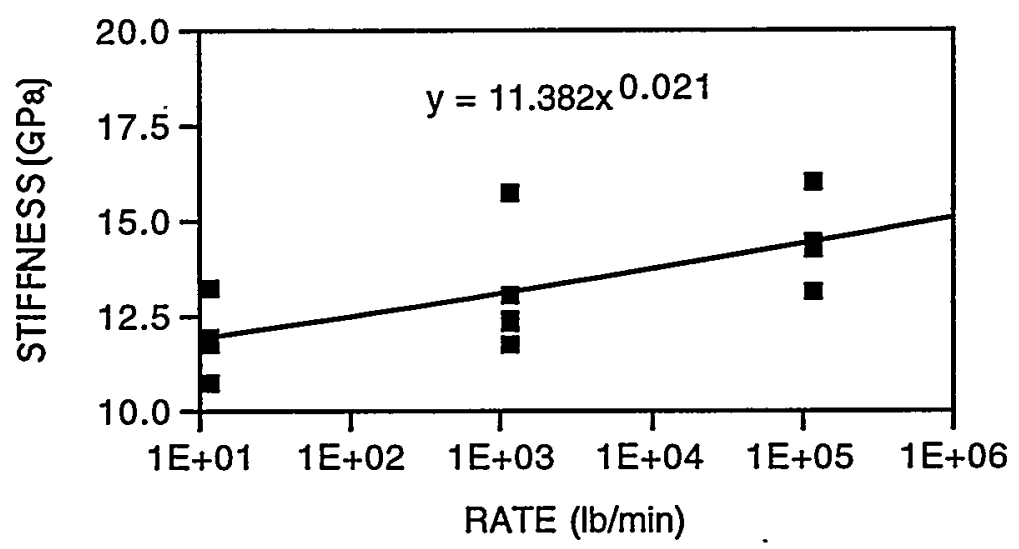

(a) Stiffness.

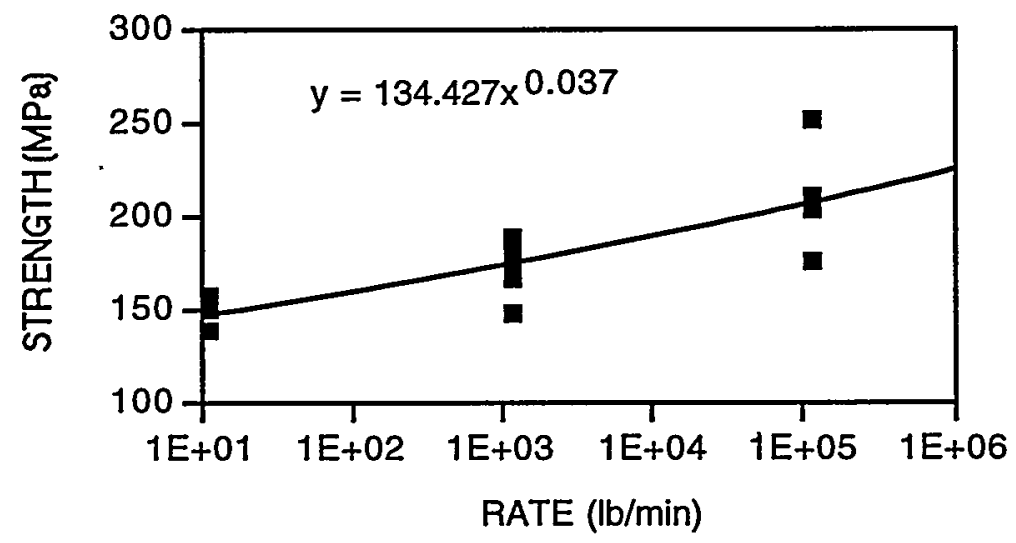

(b) Strength.

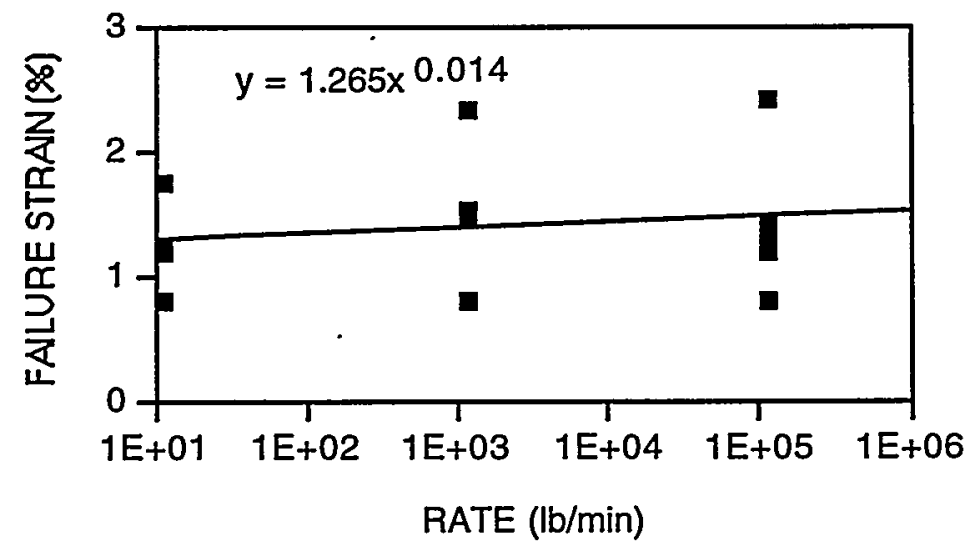

(c) Failure strain.

Fig. 8.13. Effect of rate on compressive properties. 
Table 8.5. Average compressive properties at different temperatures

\begin{tabular}{lcccc}
\hline \multicolumn{1}{c}{ Property } & $-40^{\circ} \mathrm{C}$ & $23^{\circ} \mathrm{C}$ & $50^{\circ} \mathrm{C}$ & \multicolumn{1}{c}{$120^{\circ} \mathrm{C}$} \\
\hline Stiffness, GPa & $13.1(6.44)$ & $11.6(12.9)$ & $10.5(8.20)$ & $8.76(9.68)$ \\
UCS, MPa & $-265(4.94)$ & $-190(20.1)$ & $-143(15.2)$ & $-82.9(5.76)$ \\
\hline
\end{tabular}

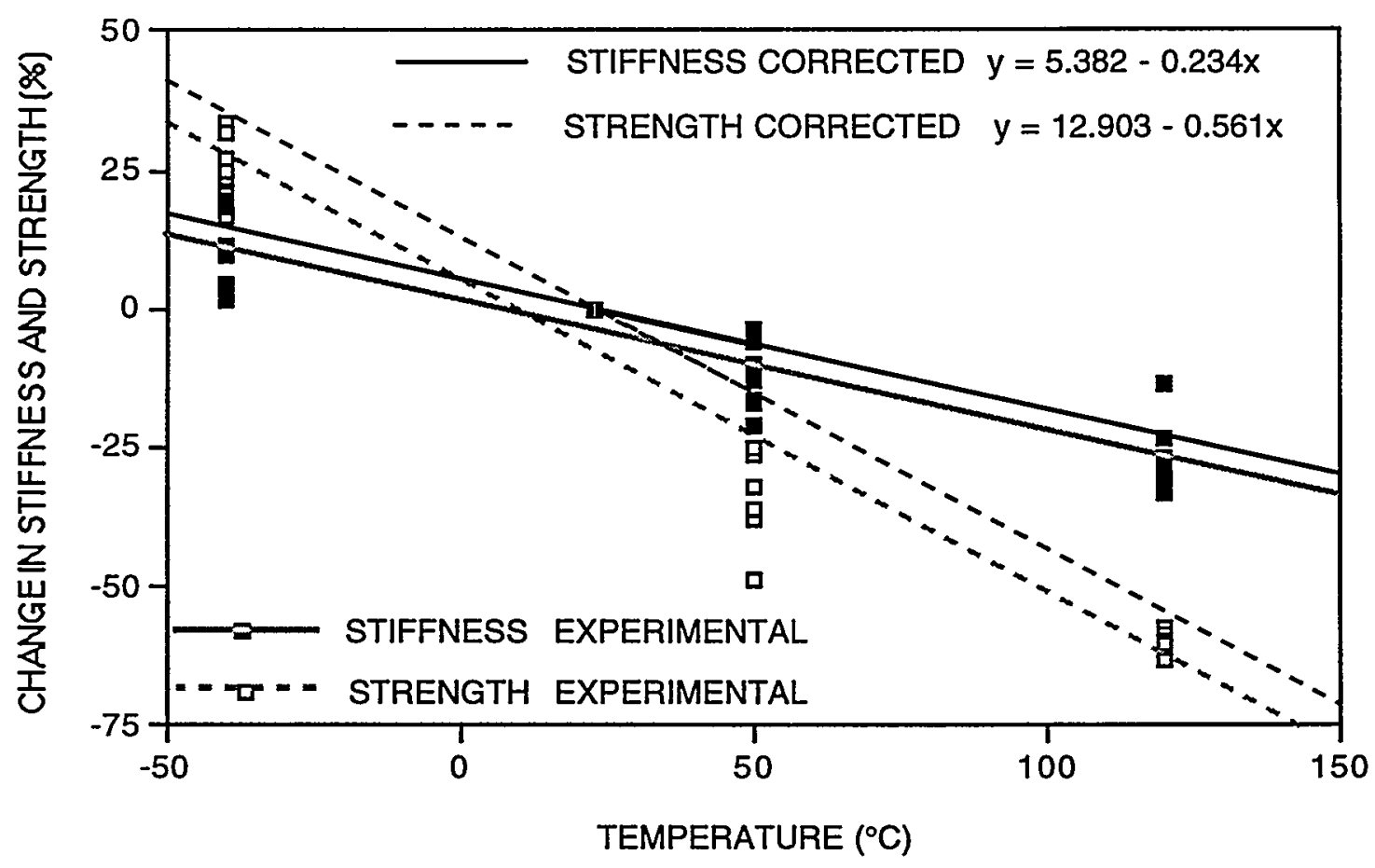

Fig. 8.14. Percent change in compressive stiffness and strength with temperature. The "corrected" curves have been shifted vertically to pass through zero at $23^{\circ} \mathrm{C}$.

Table 8.6. Compressive properties at different temperatures and corresponding multiplication factors

\begin{tabular}{ccccc}
\hline Temperature $\left({ }^{\circ} \mathrm{C}\right)$ & $\mathrm{E}_{\mathrm{C}}(\mathrm{GPa})$ & Stiffness factor & UCS $(\mathrm{MPa})$ & Strength factor \\
\hline-40 & 13.3 & 1.15 & -257 & 1.35 \\
23 & 11.6 & 1.00 & -190 & 1.00 \\
50 & 10.9 & 0.94 & -161 & 0.85 \\
120 & 8.93 & 0.77 & -86.6 & 0.46 \\
\hline
\end{tabular}




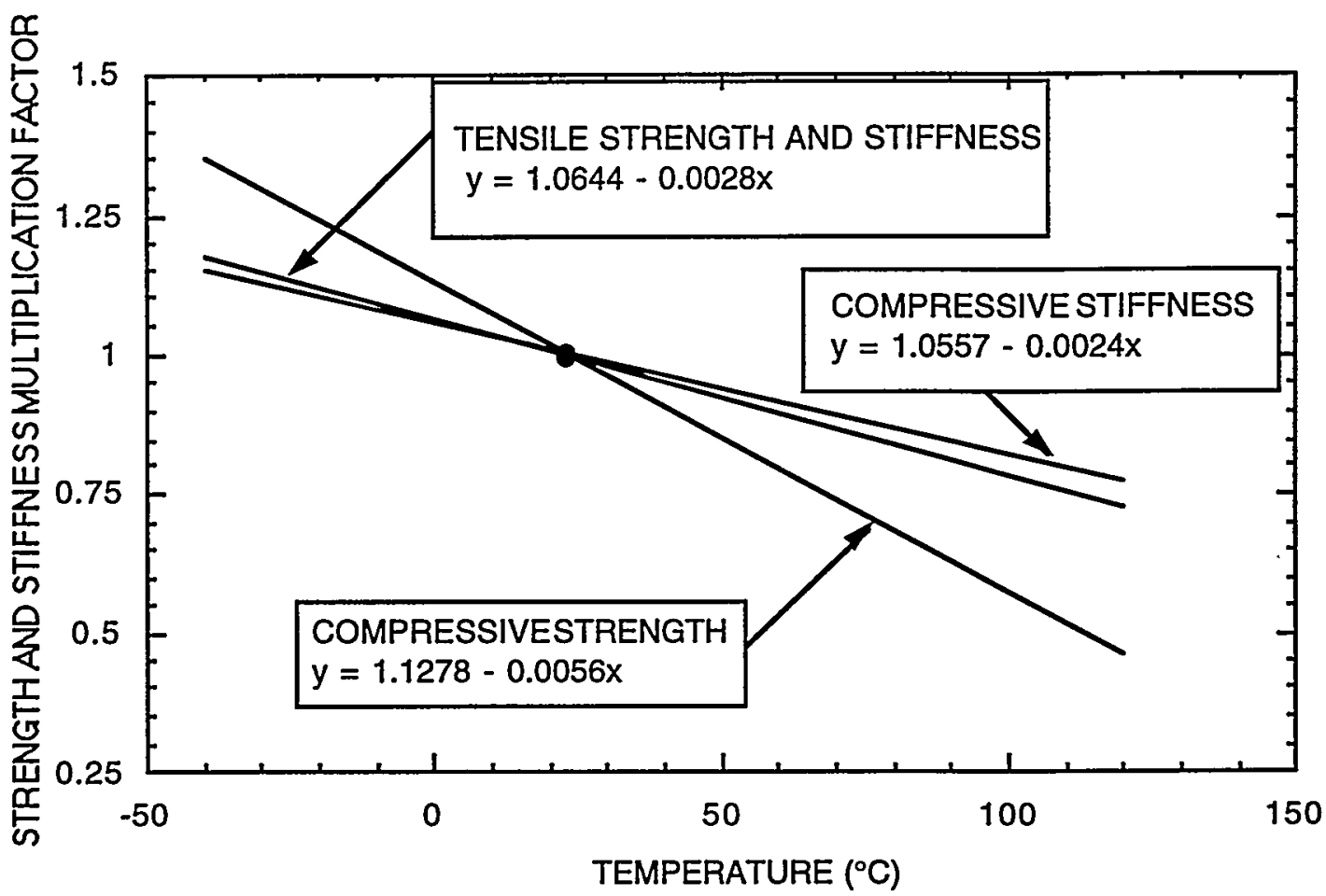

Fig. 8.15. Multiplication factor for determining stiffness and strength at given temperature from room-temperature values.

nineteen specimens, for $2160 \mathrm{~h}$. Results are summarized in Table 8.7. Note that the environmental reduction factors in compression were close to those obtained in tension for the same exposure conditions. In the case of the $892 \mathrm{~h}$ exposure in $50^{\circ} \mathrm{C}$ distilled water, the tension stiffness reduction factor was 0.94 , and the tension strength reduction factor was 0.79 . For the exposure time of $2160 \mathrm{~h}$, tension stiffness and strength reduction factors were 0.92 and 0.69 , respectively. Considering that (1) the environmental degradation of compressive properties is comparable to that of tensile properties and that (2) there was a larger database for examining the environmental degradation of tensile properties, the environmental reduction factors for tension can be applied to compression. It is further recommended that the tensile property reduction factor of 0.91 be used to bound compression for 1000 -h exposure in room-temperature distilled water.

Table 8.7. Room-temperature compressive properties following different exposure conditions and corresponding reduction factors

\begin{tabular}{ccccc}
\hline $\begin{array}{c}\text { Exposure } \\
\text { conditions }\end{array}$ & $\mathrm{E}_{\mathrm{C}}(\mathrm{GPa})$ & $\begin{array}{c}\text { Stiffness reduction } \\
\text { factor }\end{array}$ & UCS (MPa) & $\begin{array}{c}\text { Strength reduction } \\
\text { factor }\end{array}$ \\
\hline $\begin{array}{c}50^{\circ} \mathrm{C} \text { distilled } \\
\text { water, } 912 \mathrm{~h}\end{array}$ & $10.8(3.48)$ & 0.98 & $-141(8.16)$ & 0.84 \\
$\begin{array}{c}50^{\circ} \mathrm{C} \text { distilled } \\
\text { water, } 2160 \mathrm{~h}\end{array}$ & $10.4(11.0)$ & 0.90 & $-115(7.56)$ & 0.62 \\
\hline
\end{tabular}




\subsection{IN-PLANE SHEAR PROPERTIES}

\subsubsection{Room-Temperature Behavior}

The in-air room-temperature values of the elastic shear modulus, ultimate shear strength, and failure shear strain were determined using 11 Iosipescu specimens from 3 different plaques (B19-B21). The V-notched beam (losipescu) shear specimens and test method are described in Ref. 3. The tab material and adhesive used for bonding the tabs were the same as for the compression specimen described in Sect. 8.4.1.

The average in-plane shear modulus, shear strength, and shear strain at failure were 4.80 GPa (6.99), $166 \mathrm{MPa}$ (2.33), and 4.66\% (5.13), respectively. These values are higher than those obtained for the reference material, where the average in-plane shear modulus was $4.48 \mathrm{GPa}$, shear strength was $110 \mathrm{MPa}$, and shear strain at failure was $3.2 \%$. The roomtemperature elastic shear properties reported by ACC-shear modulus of $4.74 \mathrm{GPa}$ and shear strength of $153 \mathrm{MPa}$-are fairly close to those obtained here.

The Young's modulus, E, shear modulus, G, and Poisson's ratio, v, in an isotropic material are related by the expression

$$
E=2 G(1+v) .
$$

Using this expression with $G=4.80$ and $v=0.32$, a Young's modulus of $12.7 \mathrm{GPa}$ is calculated, which is higher than the average measured $\mathrm{E}$ of $11.8 \mathrm{GPa}$. However, it should be noted that the average values of the Young's modulus obtained from the reference tensile tests on plaques B19-B21 were $12.3,11.8$, and $12.2 \mathrm{GPa}$, respectively. Thus, an average Young's modulus for the three plaques B19-B21 is $12.1 \mathrm{GPa}$, which is close to the calculated value. This observation supports the in-plane isotropy assumption made in Part 1.

\subsubsection{Temperature Effects}

The effects of temperature on shear properties were investigated in 14 Iosipescu shear tests, 6 tests at $50^{\circ} \mathrm{C}$, and 8 tests at $120^{\circ} \mathrm{C}$. The average shear properties are presented in Table 8.8. Shear properties at $120^{\circ} \mathrm{C}$ reported by $\mathrm{ACC}$ - shear modulus of $3.31 \mathrm{GPa}$ and shear strength of $78.0 \mathrm{MPa}$ - compare well to those presented here. Both shear modulus and strength decrease with increasing temperature. However, the shear strength is significantly more temperature dependent. At $50^{\circ} \mathrm{C}$ the average decrease in shear modulus is $10.8 \%$, and the average decrease in strength, $22.2 \%$. Likewise, at $120^{\circ} \mathrm{C}$ the average decrease in modulus was $31.9 \%$, and the average decrease in strength, $54.4 \%$.

Table 8.8. Average shear properties at different temperatures

\begin{tabular}{llll}
\hline \multirow{2}{*}{ Property } & \multicolumn{3}{c}{ Temperature } \\
\cline { 2 - 4 } & $23^{\circ} \mathrm{C}$ & $50^{\circ} \mathrm{C}$ & $120^{\circ} \mathrm{C}$ \\
\hline Shear modulus, $\mathrm{GPa}$ & $4.80(6.99)$ & $4.28(2.33)$ & $3.27(5.13)$ \\
Shear strength, $\mathrm{MPa}$ & $166(4.19)$ & $129(4.01)$ & $75.6(9.99)$ \\
Shear strain at failure, \% & $4.66(10.9)$ & $3.60(8.82)$ & $2.35(12.7)$ \\
\hline
\end{tabular}


Percent changes in shear modulus and strength from room-temperature values are presented in Fig. 8.16.

Results in Fig. 8.16 indicate that simple straight-line approximations may be used to represent changes in shear strength and stiffness with temperature:

$$
\begin{gathered}
\Delta \mathrm{G} \times 100 \%=7.498-0.326 \mathrm{~T}\left({ }^{\circ} \mathrm{C}\right) ; \\
\Delta \tau^{\mathrm{f}} \times 100 \%=12.673-0.551 \mathrm{~T}\left({ }^{\circ} \mathrm{C}\right) .
\end{gathered}
$$

These correlations are specifically formulated to give $0 \%$ change at room temperature. Based on these correlations, shear modulus and strength at different temperatures and corresponding multiplication factors can be calculated. These are given in Table 8.9.

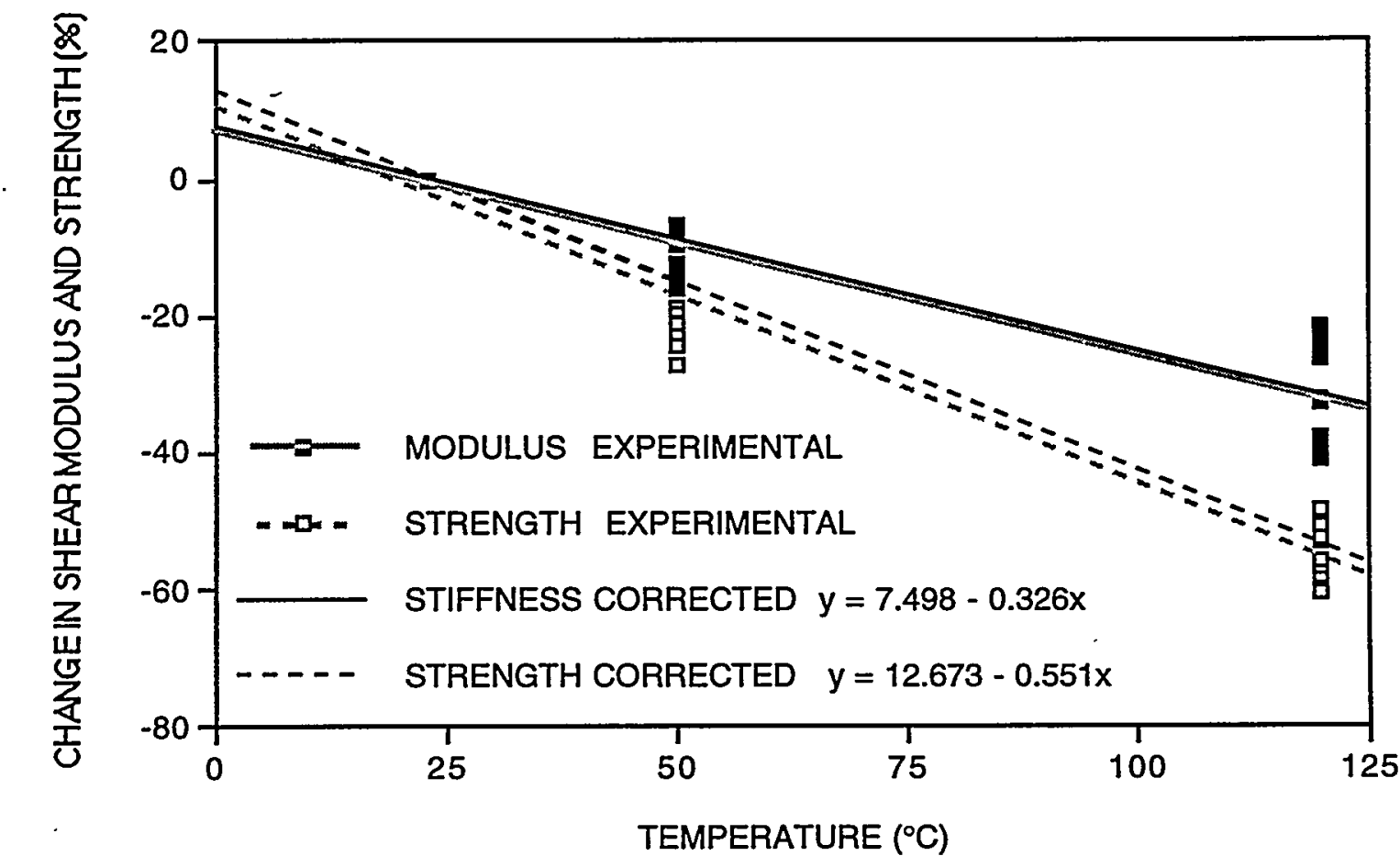

Fig. 8.16. Percent change in shear modulus and strength with temperature. The "corrected" curves have been shifted vertically to pass through zero at $23^{\circ} \mathrm{C}$.

Table 8.9. Shear properties at different temperatures and corresponding multiplication factors

\begin{tabular}{ccccc}
\hline $\begin{array}{c}\text { Temperature } \\
\left({ }^{\circ} \mathrm{C}\right)\end{array}$ & $\begin{array}{c}\text { Shear modulus } \\
(\mathrm{GPa})\end{array}$ & Modulus factor & $\begin{array}{c}\text { Shear strength } \\
(\mathrm{MPa})\end{array}$ & $\begin{array}{c}\text { Strength } \\
\text { factor }\end{array}$ \\
\hline 23 & 4.80 & 1.00 & 166 & 1.00 \\
50 & 4.37 & 0.91 & 141 & 0.85 \\
120 & 3.26 & 0.68 & 77.3 & 0.47 \\
\hline
\end{tabular}


Multiplication factors for determining shear modulus and strength at a given temperature from room-temperature values are shown in Fig. 8.17 together with the factors for corresponding tensile and compressive properties.

The effect of temperature on stiffness is similar in tension, compression, and shear, as it should be for an isotropic material. For consistency, the stiffness multiplication factor obtained in tension can be used to cover both compression and shear. Conversely, the shear strength multiplication factor is very close to that in compression and significantly below that in tension.

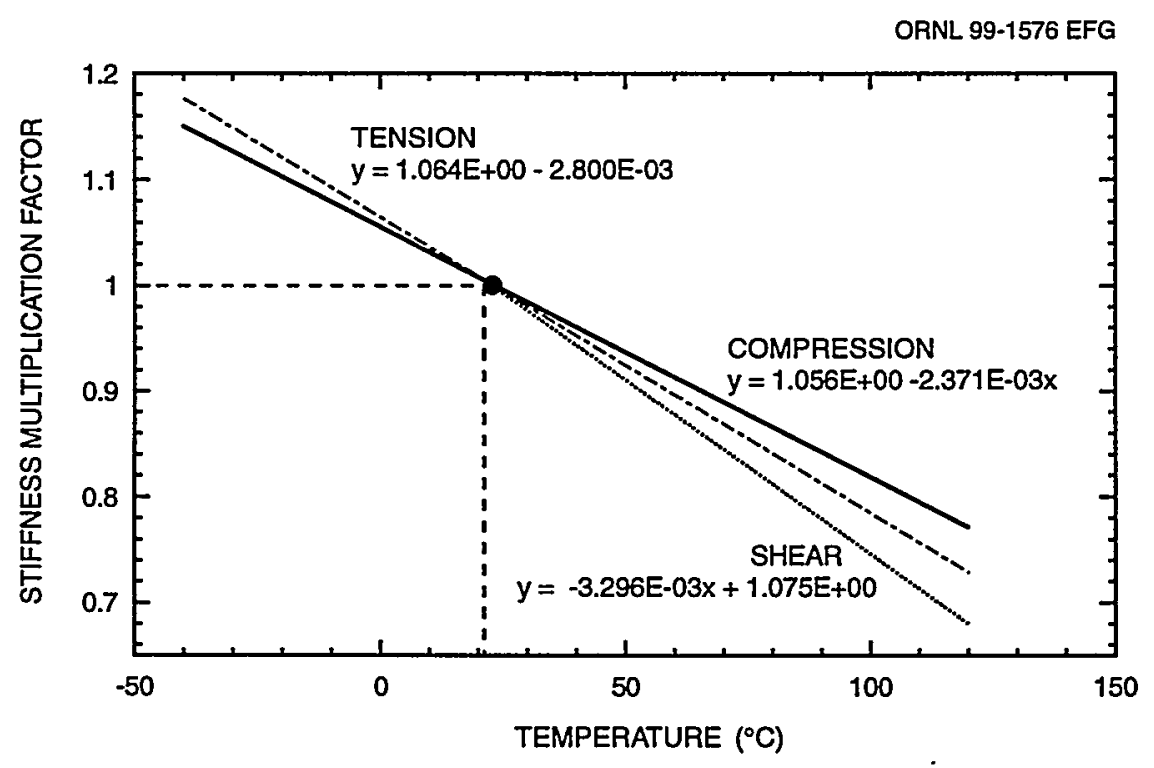

(a) Stiffness.

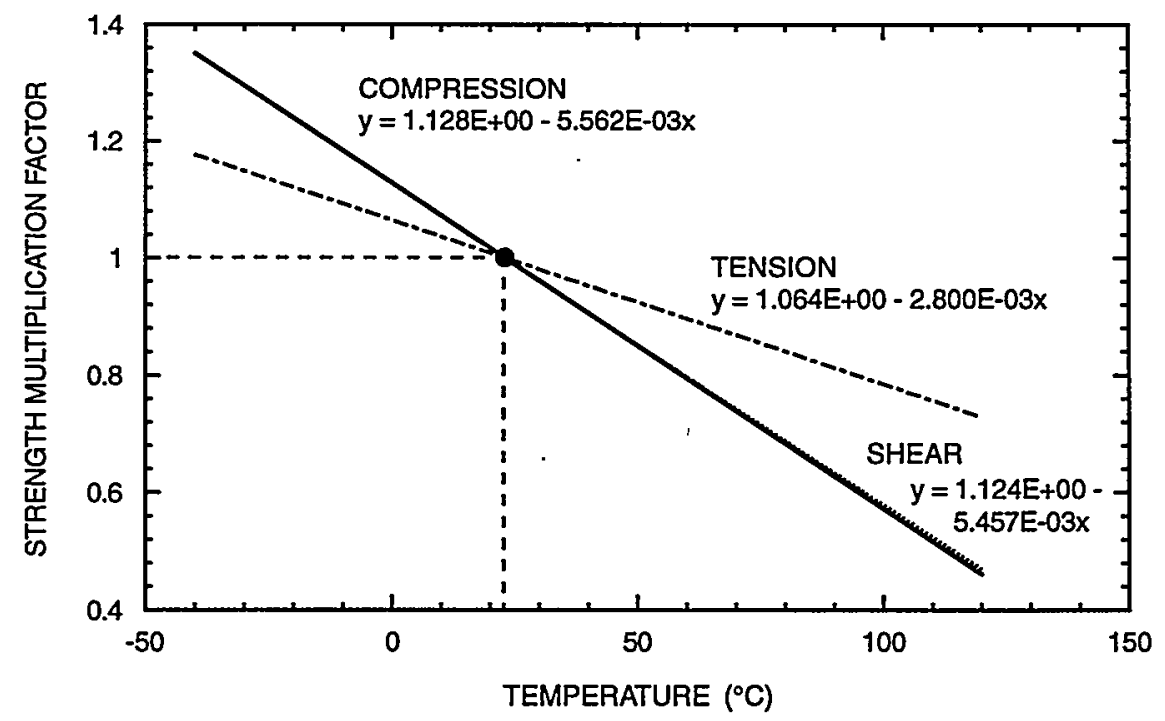

(b) Strength.

Fig. 8.17. Multiplication factors for determining stiffness and strength at a given temperature from room-temperature values. 
Note that the formula relating $\mathrm{E}$ and $\mathrm{G}$ still holds at 50 and $120^{\circ} \mathrm{C}$. Using $v=0.33$ and 0.34 , respectively, and $\mathrm{G}$ values in Table 8.9 , the following values of Young's modulus can be calculated: $11.6 \mathrm{GPa}$ at $50^{\circ} \mathrm{C}$ and $8.74 \mathrm{GPa}$ at $120^{\circ} \mathrm{C}$. These results compare fairly well with the tensile stiffness values of $10.9 \mathrm{GPa}$ at $50^{\circ} \mathrm{C}$ and $8.61 \mathrm{GPa}$ at $120^{\circ} \mathrm{C}$ given in Table 8.3. This suggests that the assumption of isotropy can be extended to elevated temperatures.

\subsubsection{Environmental Effects}

Two fluids, $50^{\circ} \mathrm{C}$ distilled water and windshield washer fluid, were used to assess environmental degradation of shear properties. Eight Iosipescu shear specimens were soaked in $50^{\circ} \mathrm{C}$ distilled water for $2160 \mathrm{~h}$ prior to testing. The average values of shear modulus and shear strength were $4.45 \mathrm{GPa}$ and $107 \mathrm{MPa}$, respectively. The corresponding environmental reduction factors are 0.93 for stiffness and 0.64 for strength. These factors are close to the reduction factors obtained in tension ( 0.92 for stiffness and 0.69 for strength) and in compression ( 0.90 for stiffness and 0.62 for strength).

Using the formula relating Young's modulus and shear modulus, $v=0.33$ and $G=$ 4.45 $\mathrm{GPa}, \mathrm{E}=11.8 \mathrm{GPa}$ is calculated. This value is somewhat higher than $\mathrm{E}=10.9 \mathrm{GPa}$ measured after $2160 \mathrm{~h}$ exposure in $50^{\circ} \mathrm{C}$ distilled water. This, however, may be because shear specimens were cut from "stronger" plaques with higher average plaque stiffness. The material can still be viewed as isotropic under environmental conditions.

Six specimens, two from plaque B18 and four from plaque B19, were exposed to windshield washer fluid for $100 \mathrm{~h}$ and then tested. Because specimens had to be tested promptly after removal from the fluid to minimize fluid loss due to evaporation, strain gages were not applied. Therefore, no strains were measured in these tests. The strength reduction factor was 0.97 . The strength reduction factor in tension for the same exposure conditions was 0.93 .

Considering that (1) the environmental degradation of shear properties is comparable to that of tensile properties, and (2) there is a larger data base for examining the environmental. degradation of tensile properties, the environmental reduction factors for tension will be applied to shear. It is further recommended that the tensile property reduction factor of 0.91 be used to bound shear for $1000 \mathrm{~h}$ exposure in room-temperature distilled water.

\subsection{SUMMARY}

The present material exhibits no consistent strong or weak direction. Thus, all test specimens were cut in, and all investigations carried out for a single $\left(0^{\circ}\right)$ direction. Basic elastic constants and strength properties are summarized in Table 8.10.

Table 8.10. Basic room-temperature elastic constants and strength properties for the chopped-fiber material

\begin{tabular}{lccc}
\hline & Tension & Compression & Shear \\
\hline Stiffness, GPa & 11.8 & 11.6 & 4.80 \\
Strength, MPa & 177 & -190 & 166 \\
Strain at failure, \% & 2.02 & -2.08 & 4.60 \\
Poisson's ratio & 0.32 & & \\
\hline
\end{tabular}


Stiffness values for the chopped-fiber material are close to those obtained for the reference material in the $90^{\circ}$ direction and considerably higher than those produced for the $0^{\circ}$ direction. Strength properties for the chopped-fiber material are between the corresponding $0^{\circ}$ and $90^{\circ}$ properties of the reference material.

For the chopped-fiber material, strength and stiffness decrease with increasing temperature. A single multiplication factor can be used for determining tensile, compressive, and shear stiffness at a given temperature from room-temperature values (the tensile factors are recommended). However, the temperature effects on strength are different in tension, compression, and shear. The temperature multiplication factors are summarized in Table 8.11.

Based on extended exposure studies of chopped-fiber tensile specimens, 1000-h exposure in room-temperature distilled water was chosen as the most severe bounding condition. Effects of the 100-h exposure in windshield washer fluid were found to be bounded by the effects of the 1000-h exposure in room-temperature distilled water. An overall environmental knock-down factor for design of 0.91 is recommended. The corresponding factor for the reference material was 0.83 .

Table 8.11. Basic properties at different temperatures and corresponding multiplication factors

\begin{tabular}{|c|c|c|c|c|c|c|}
\hline \multirow{2}{*}{$\begin{array}{c}\text { Temperature } \\
\left({ }^{\circ} \mathrm{C}\right) .\end{array}$} & \multicolumn{2}{|c|}{ Tension } & \multicolumn{2}{|c|}{ Compression } & \multicolumn{2}{|c|}{ Shear } \\
\hline & $\begin{array}{l}\text { Stiffness } \\
\text { factor }\end{array}$ & $\begin{array}{l}\text { Strength } \\
\text { factor }\end{array}$ & $\begin{array}{l}\text { Stiffness } \\
\text { factor }\end{array}$ & $\begin{array}{c}\text { Strength } \\
\text { factor }\end{array}$ & $\begin{array}{l}\text { Stiffness } \\
\text { factor }\end{array}$ & $\begin{array}{c}\text { Strength } \\
\text { factor }\end{array}$ \\
\hline-40 & 1.18 & 1.18 & 1.15 & 1.35 & - & 一 \\
\hline 23 & 1.00 & 1.00 & 1.00 & 1.00 & 1.00 & 1.00 \\
\hline 50 & 0.92 & 0.92 & 0.94 & 0.85 & 0.91 & 0.85 \\
\hline 120 & 0.73 & 0.73 & 0.77 & 0.46 & 0.68 & 0.47 \\
\hline
\end{tabular}




\title{
9. FLEXURE AND SHORT-BEAM SHEAR PROPERTIES
}

\author{
M. B. Ruggles
}

\subsection{OUT-OF-PLANE FLEXURE PROPERTIES}

\subsubsection{Room-Temperature Behavior}

The in-air room-temperature values of the out-of-plane flexural stiffness, modulus of rupture (MOR) (which is equal to elastically calculated maximum bending stress at failure), and failure strain in flexure were determined in three-point bend tests. The beam specimen used was simply a $25.4 \mathrm{~mm} \times 75 \mathrm{~mm} \times 3.2 \mathrm{~mm}$ rectangle. The support span was $50 \mathrm{~mm}$. The test procedure, which employed an MTS 642.10 bend fixture, was as described in Ref. 3.

Six beam specimens from three different plaques (B18-B20) were used. The average flexural stiffness, MOR, and failure strain were $11.8 \mathrm{GPa}(13.6), 332 \mathrm{MPa}(8.13)$, and 2.59\% (11.2), respectively. Because the beam width was considerably greater than the beam thickness, the stiffness values were calculated from

$$
E=\left(1-v^{2}\right) \sigma / \varepsilon
$$

which comes from Hooke's law with the transverse strain equal to zero. The apparent modulus of elasticity in flexure is equal to that in tension, while failure strains in flexure are somewhat higher than their uniaxial counterparts. It is noteworthy that the MOR values are almost a factor of two greater than the UTS. Thus, the load-carrying capacity is almost twice that which would be indicated by limiting the elastically calculated maximum stress to the UTS. It may be argued that the higher MOR is due to the nonlinear stress-strain curve (see Chap. 10, Fig. 10.2). However, beam theory calculations indicate that the maximum stress in the inelastic case is $95 \%$ of the maximum stress in the elastic case. Thus, had the increase in MOR been strictly due to the nonlinear stressstrain curve, the following would hold:

$$
\text { MOR }=(1 / 0.95) \text { UTS , }
$$

making MOR only very slightly greater than UTS. Similar observations were made for the reference (CSM) material, where the bending was allowed to attain a value of 1.5 times that in the simple tension case.

\subsubsection{Temperature Effects}

The effects of temperature were investigated in 12 flexure tests, 6 at $50^{\circ} \mathrm{C}$ and 6 at $120^{\circ} \mathrm{C}$. The average flexure properties are presented in Table 9.1. Note that strains were not measured at $120^{\circ} \mathrm{C}$; thus no stiffness or failure strain values are available for that temperature.

Both flexural stiffness and MOR decrease with temperature. At $50^{\circ} \mathrm{C}$, the stiffness multiplication factor is 0.90 , and the strength multiplication factor is 0.95 . The corresponding tension stiffness and strength multiplication factors are both equal to 0.92. Compression stiffness and strength multiplication factors at $50^{\circ} \mathrm{C}$ are 0.94 and 0.85 , respectively. Thus at $50^{\circ} \mathrm{C}$ as well as at room temperature, a higher allowable could be provided in Part 1 for primary out-of-plane bending than for primary membrane loading. A factor of 1.5 was used. 
Table 9.1. Average flexure properties at different temperatures

\begin{tabular}{lccc}
\hline \multirow{2}{*}{ Property } & \multicolumn{3}{c}{ Temperature $\left({ }^{\circ} \mathrm{C}\right)$} \\
\cline { 2 - 4 } & 23 & 50 & 120 \\
\hline Flexural stiffness, GPa & $11.8(13.6)$ & $10.6(5.64)$ & - \\
MOR, MPa & $332(8.13)$ & $314(1.98)$ & $190(6.39)$ \\
Strain at failure, \% & $2.59(11.2)$ & $2.69(4.67)$ & - \\
\hline
\end{tabular}

At $120^{\circ} \mathrm{C}$, the MOR drops considerably, producing a multiplication factor of 0.57 . The corresponding tension stiffness and strength multiplication factor is 0.73 . Thus, the reduction in MOR is significantly greater than the reduction in UTS. At $120^{\circ} \mathrm{C}$ the load-carrying capacity in bending is only 1.4 times that indicated by the UTS. In Part 1, bending stresses were limited to 1.2 times the membrane stress limit.

\subsubsection{Environmental Effects}

Two fluids, two temperatures, and different exposure times were used to assess effects of environment. Fourteen beam specimens were presoaked in $50^{\circ} \mathrm{C}$ distilled water for $2160 \mathrm{~h}$. The MOR reduction factor was 0.65 . The corresponding UTS reduction factor was 0.69 . Six beams were also presoaked in $23^{\circ} \mathrm{C}$ distilled water for $1000 \mathrm{~h}$, producing an MOR reduction factor of 0.91. The UTS reduction factor for the same condition was 0.91 as well. Eight beam specimens were presoaked in windshield washer fluid for $100 \mathrm{~h}$. The MOR reduction factor was 0.99 . The corresponding UTS reduction factor was 0.93 . These results suggest that the environmental reduction factor obtained in uniaxial tension, i.e., 0.91 , may be used to represent the effects of environment on flexure.

\subsection{SHORT-BEAM SHEAR*}

\subsubsection{Room-Temperature Behavior}

The propensity for interlaminar shear failure was investigated in short-beam three-point bend tests. The specimen used was a $6 \mathrm{~mm} \times 3.2 \mathrm{~mm} \times 13 \mathrm{~mm}$ rectangle. The support span was $12.5 \mathrm{~mm}$. Tests were conducted according to ASTM D $2344^{9}$ testing procedure. Six beam specimens from plaque B30 were used. The average shear strength and MOR were $32 \mathrm{MPa}(7.40)$ and $289 \mathrm{MPa}$, respectively. The average maximum shear stress is $11 \%$ of the MOR. Recall that the larger specimens produced an MOR of $332 \mathrm{MPa}$. A specimen size effect is apparent. Note that microscopic examination showed no evidence of interlaminar shear; failure was due to bending.

\subsubsection{Moisture Effects}

Six short-beam specimens from plaque B30 were presoaked in $100^{\circ} \mathrm{C}$ distilled water for $16 \mathrm{~h}$ to assess the effects of environment. Elahi and Weitsman ${ }^{4}$ predicted that the 16 -h exposure in $100^{\circ} \mathrm{C}$ distilled water would be equivalent to a $1000-\mathrm{h}$ exposure in $23^{\circ} \mathrm{C}$ distilled water. Hence this exposure history was chosen. The average shear strength and MOR for the presoaked specimens were $18 \mathrm{MPa}$ (4.60) and $164 \mathrm{MPa}$, respectively. The MOR environmental reduction factor was 0.57 . Note that the larger specimens presoaked in room-temperature distilled water for

\footnotetext{
*Tests performed by D. C. Howard.
} 
$1000 \mathrm{~h}$ produced an MOR of $304 \mathrm{MPa}$ (reduction factor of 0.91 ). A specimen size effect is again apparent. Environmental degradation in smaller specimens is considerably more rapid and severe. However, moisture exposure has not enhanced the interlaminar shear failure. Microscopic examination showed no evidence of interlaminar shear, indicating that failure was due to bending.

\subsection{DISCUSSION}

At 23 and $50^{\circ} \mathrm{C}$ the load-carrying capacity in bending is found to be almost twice that which would be indicated by limiting the elastically calculated maximum stress to the UTS. Hence at 23 and $50^{\circ} \mathrm{C}$ a higher allowable was provided in Part 1 for primary bending than for primary membrane loading, and a factor of 1.5 was used. The same observation was made for the reference material at room temperature. In fact, Ref. 1 specifies that for out-of-plane bending away from geometric discontinuities, the membrane plus bending stress intensity, $P+Q$, is limited to

$$
\mathrm{P}+\mathrm{Q} \geq 1.5 \mathrm{~S}_{\mathrm{t}}
$$

However, in the case of the reference material, flexure tests on which this higher limit is based were limited to room temperature. Results obtained for the chopped-fiber material demonstrate - that at $120^{\circ} \mathrm{C}$ the load-carrying capacity in bending is only 1.4 times that indicated by the UTS. Therefore, the primary bending at $120^{\circ} \mathrm{C}$ was reduced in Part 1 to 1.2 times the membrane allowable.

Additional short-beam tests were conducted on the reference composite to investigate the propensity for interlaminar shear failure. Specimens were cut from plaque P40 in the $90^{\circ}$ direction. ${ }^{*}$ Six short-beam specimens were tested. The average shear strength and MOR were 41.6 $\mathrm{MPa}(1.40)$ and $323 \mathrm{MPa}$, respectively. Note that microscopic examination again showed no evidence of interlaminar shear. Failure was due to bending. Six short-beam specimens from plaque $\mathrm{P} 40$ were presoaked in $100^{\circ} \mathrm{C}$ distilled water for $16 \mathrm{~h}$ to assess the effects of environment. The average shear strength and MOR for the presoaked specimens were $28.2 \mathrm{MPa}(4.60)$ and $221 \mathrm{MPa}$, respectively. The MOR environmental reduction factor was 0.68 (compared to 0.57 for the chopped-fiber material). Moisture exposure does not appear to have enhanced the interlaminar shear failure. Microscopic examination showed no evidence of interlaminar shear, indicating that failure was due to bending.

Results of the short-beam tests for the chopped-fiber and reference materials are compared in Fig. 9.1. Both materials exhibit qualitatively similar behavior. The reference material consistently produced higher average values of MOR. This is in keeping with the higher roomtemperature UTS of the reference material in the $90^{\circ}$ direction (197 MPa) compared to the roomtemperature UTS of the chopped-fiber material (177 MPa).

\footnotetext{
* The stronger $90^{\circ}$ direction was used in an effort to increase the maximum shear stress to the point that an interlaminar shear failure would occur prior to a bending failure.
} 


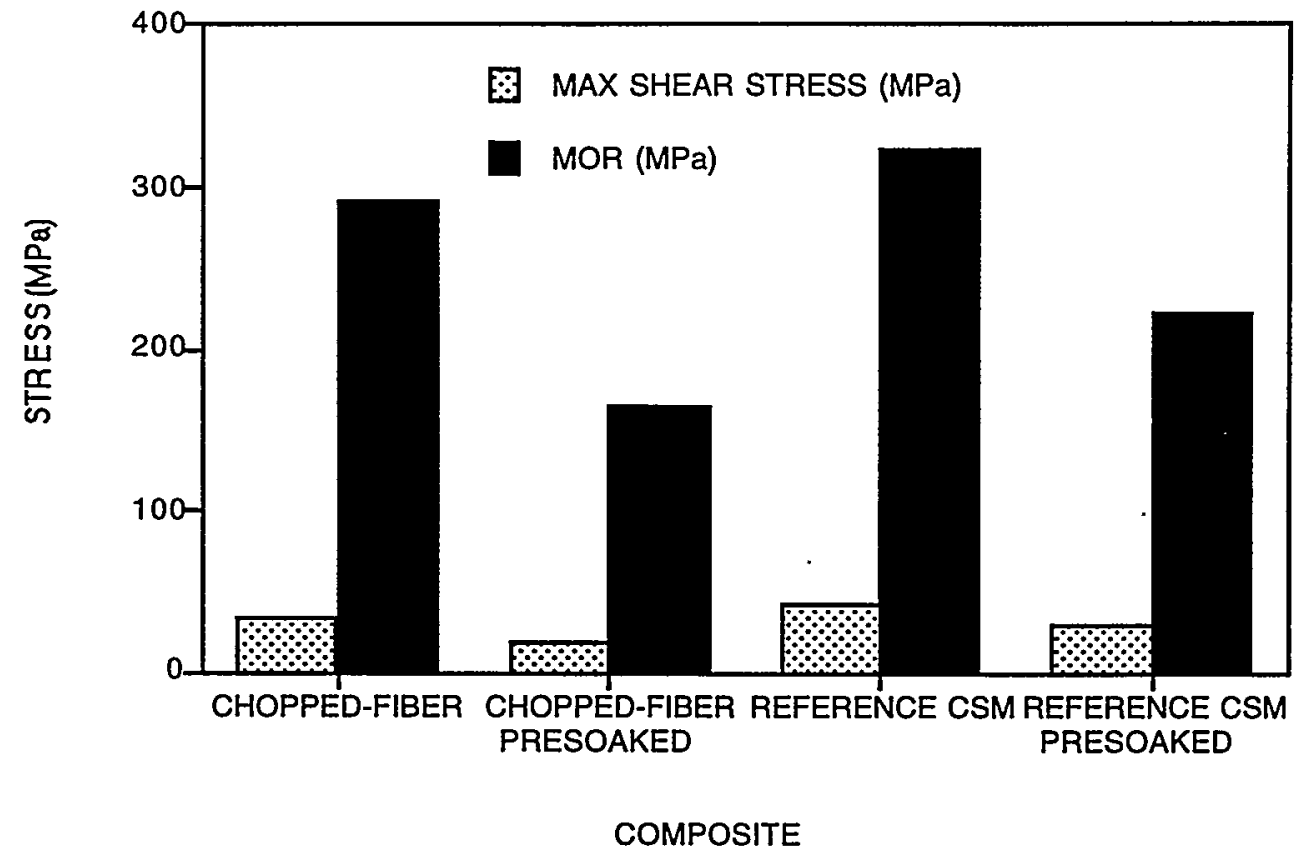

Fig. 9.1. Short-beam shear properties. Comparison of the chopped-fiber material and the reference composite results. 


\section{BIAXIAL FLEXURE TESTS AND STRENGTH CRITERION}

\section{J. M. Corum and R. L. Battiste}

\subsection{INTRODUCTION}

Biaxial flexure tests on circular disks were performed as a way of obtaining failure data under biaxial tension stress states. The resulting data were used for two purposes:

- assessing candidate biaxial strength criteria and

- determining environmental (temperature and fluids) allowable stress reduction factors for biaxial tension stress states.

The tests, plus use of the test data for the above two purposes, are described in this chapter.

As illustrated in Fig. 10.1, the biaxial flexure tests were on simply supported, ring-loaded circular disks. The specimen outside diameter was $94 \mathrm{~mm}$, and the thickness was nominally $3.2 \mathrm{~mm}$. The load-ring diameter was $38.1 \mathrm{~mm}$, while the support-ring diameter was $88.9 \mathrm{~mm}$.

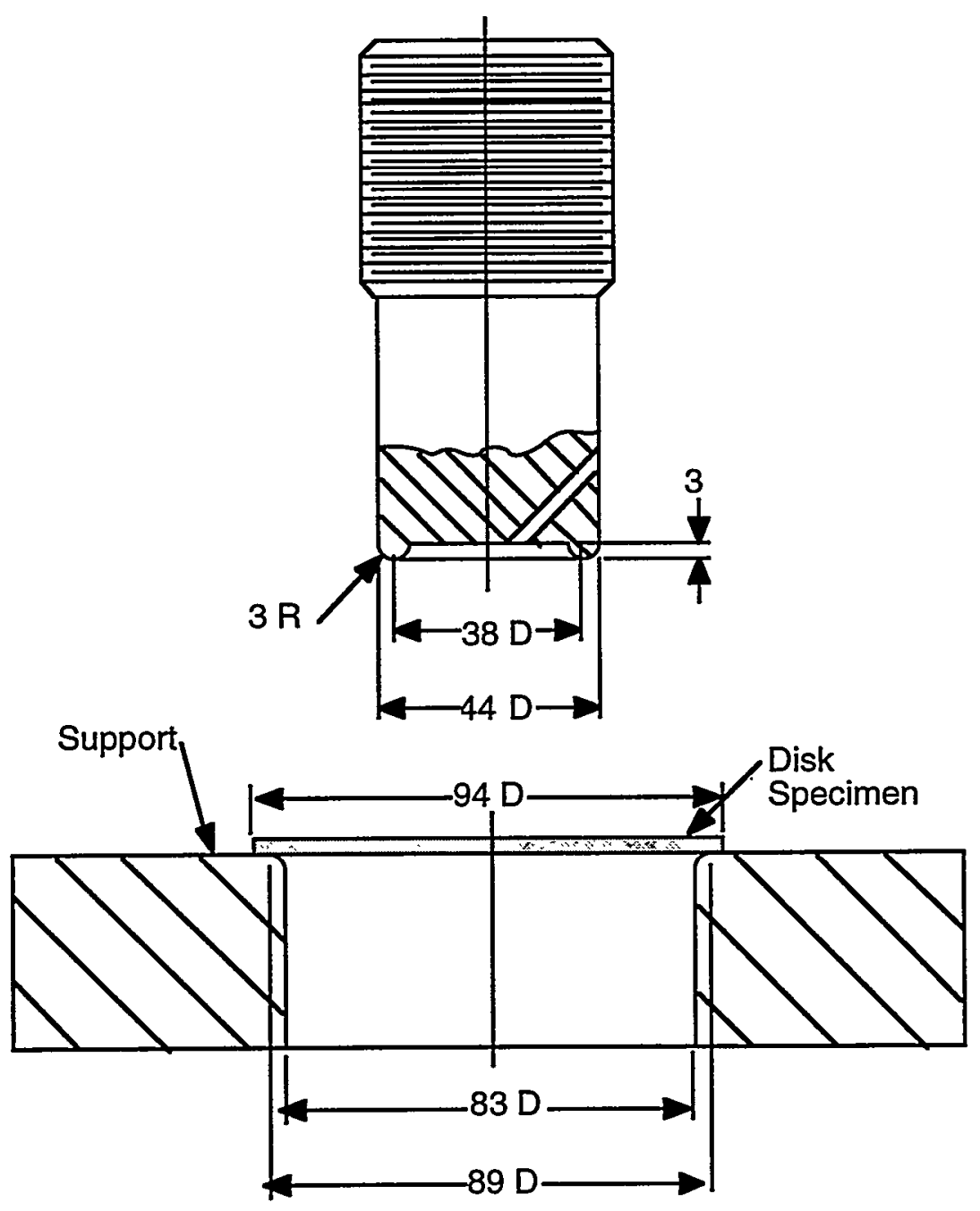

Fig. 10.1. Fixture for biaxial flexure tests. Dimensions are in millimeters. 
Small-deflection, elastic plate bending theory predicts that the maximum stresses on the bottom surface of the specimen are inside the load ring and are everywhere equibiaxial tension. However, long before failure, the deflections become large, and the nonlinear stress-strain response of the composite comes into play. At the large deflections, the maximum stresses shift to a location opposite the load ring. A nonlinear, inelastic, large-deflection, finite-element analysis is required to predict the stresses at failure.

Fifty-six tests were performed, as listed in Table 10.1. All of the tests were performed in air. In addition to room-temperature tests of as-received specimens, tests were performed at temperatures of 50 and $120^{\circ} \mathrm{C}$. Another group of specimens was presoaked for $100 \mathrm{~h}$ in windshield washer fluid (70\% methanol/30\% distilled water) prior to room-temperature testing. Two distilled-water presoak conditions were examined: $1000 \mathrm{~h}$ at room temperature and 6 months at $50^{\circ} \mathrm{C}$ (an extreme bounding condition). The reduction factors shown in the right-hand column of Table 10.1 are the ratio of the average failure load for each set of tests to the average for the asreceived room-temperature tests.

Table 10.1. Biaxial flexure tests

\begin{tabular}{lcrrc}
\hline \multicolumn{1}{c}{$\begin{array}{c}\text { Specimen and test } \\
\text { condition }\end{array}$} & $\begin{array}{c}\text { Number } \\
\text { of } \\
\text { specimens }\end{array}$ & $\begin{array}{c}\text { Maximum } \\
\text { load } \\
(\mathrm{N})\end{array}$ & $\begin{array}{r}\text { COV } \\
(\%)\end{array}$ & $\begin{array}{c}\text { Reduction } \\
\text { factor }\end{array}$ \\
\hline As received, room temperature & 8 & 11,403 & 5.4 & 1.00 \\
As received, $50^{\circ} \mathrm{C}$ & 8 & 8,497 & 4.2 & 0.75 \\
As received, $120^{\circ} \mathrm{C}$ & 8 & 4,785 & 8.3 & 0.42 \\
$100 \mathrm{~h}$ in $70 \%$ methanol/30\% water & 8 & 11,907 & 5.0 & 1.04 \\
$1000 \mathrm{~h}$ in room-temperature distilled & 8 & 9,568 & 11.8 & 0.84 \\
$\quad$ water & 16 & 6,336 & 6.1 & 0.56 \\
6 months in $50^{\circ} \mathrm{C}$ distilled water & & & & \\
\hline
\end{tabular}

\subsection{BIAXIAL STRENGTH CRITERION}

Candidate biaxial strength criteria were evaluated using the room-temperature biaxial test results, along with room-temperature tensile, compressive, and shear results reported in Chap. 8 . As mentioned in Sect. 10.1, use of the biaxial results for this purpose required that the maximum stresses in the disks at failure be predicted by a nonlinear finite-element analysis, which, in turn, required a representation of the nonlinear tensile stress-strain curve of the composite.

The chosen stress-strain representation is shown in Fig. 10.2. It is a power-law fit through three points: zero, the average proportional limit (P. L.) on the average elastic line, and the average failure point. Poisson's ratio was taken to be 0.3 , and the average thickness of the disks was $2.9 \mathrm{~mm}$. The nonlinear analysis was carried out using axisymmetric solid elements in the ABAQUS finite-element program.*

Comparisons of the resulting deformation predictions with measured deflections and strains are shown in Figs. 10.3 and 10.4, respectively. Figure 10.3 shows the applied load vs the

\footnotetext{
${ }^{*}$ C. R. Lutrell did the analysis work, ORNL.
} 


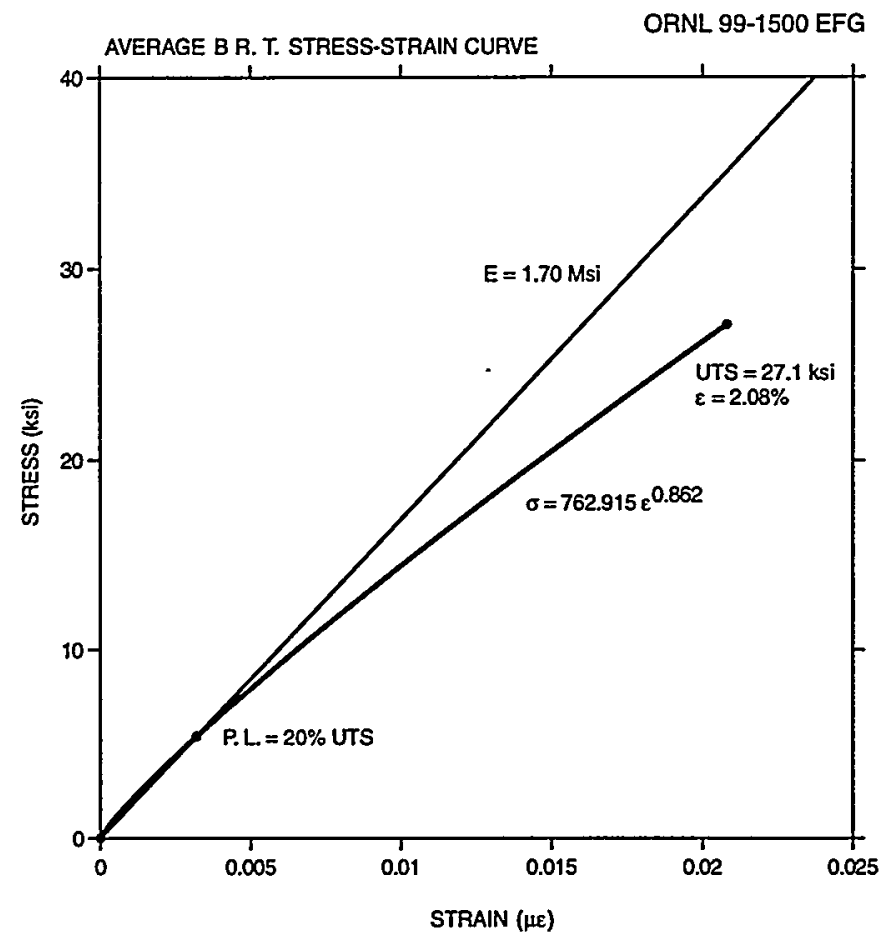

Fig. 10.2. Power-law representation of "average" nonlinear stress-strain curve for P4 chopped glass fiber/Baydur $420 \mathrm{IMR}$ composite ( $1 \mathrm{ksi}=6.895 \mathrm{MPa}$ ).

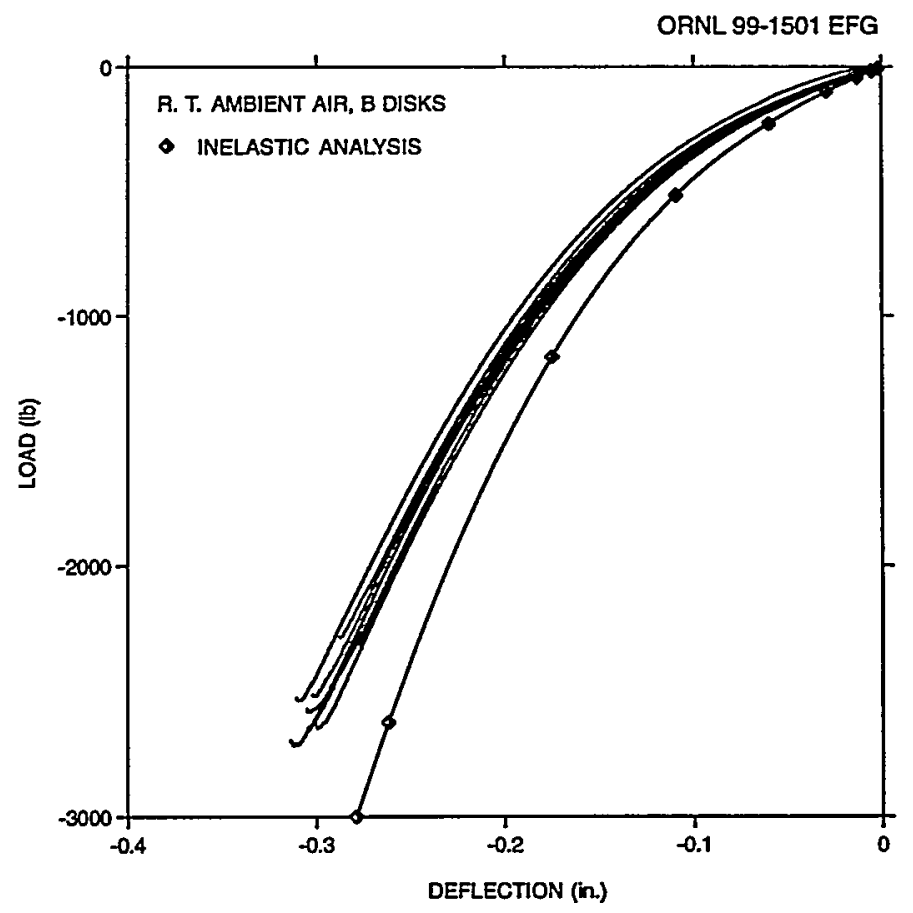

Fig. 10.3. Comparison of measured and predicted biaxial flexure specimen deflections $(1 \mathrm{lb}=4.448 \mathrm{~N}, 1$ in. $=25.4 \mathrm{~mm})$. 


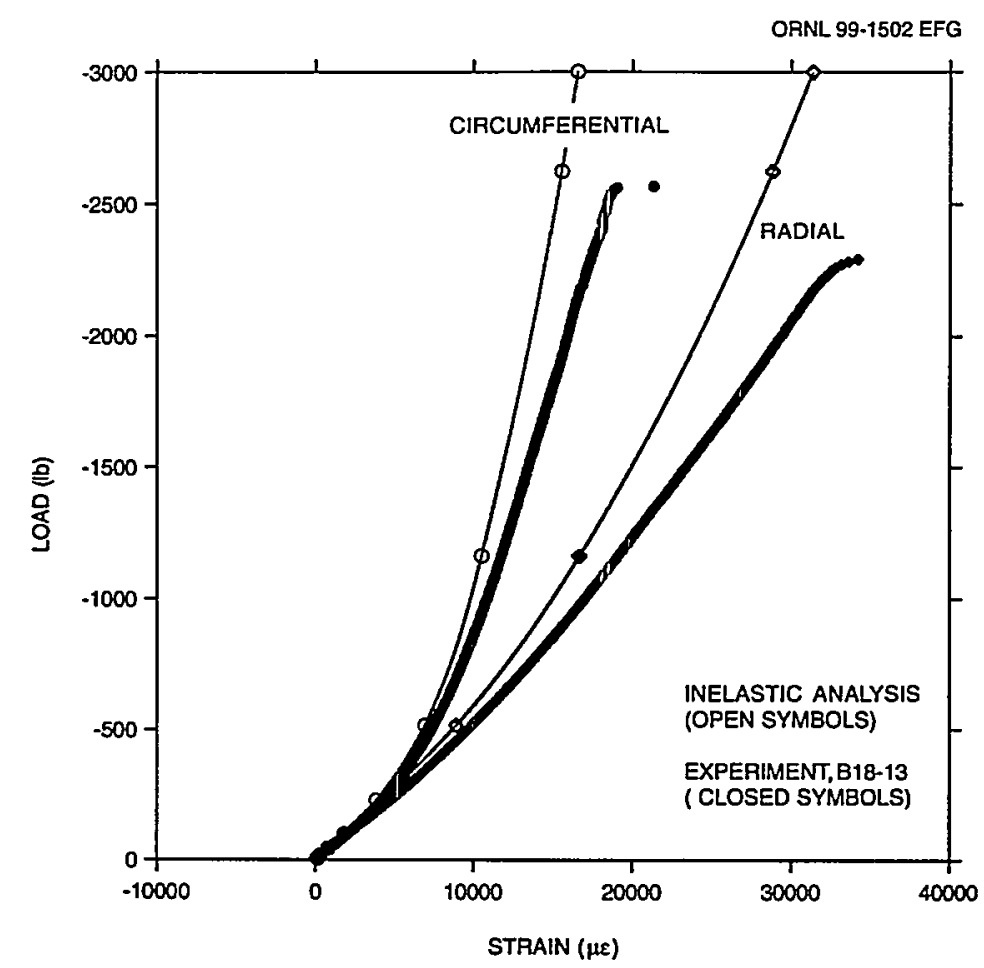

Fig. 10.4. Comparison of measured and predicted strains at location of maximum stresses opposite ring load $(1 \mathrm{lb}=4.448 \mathrm{~N})$.

deflection at the load ring (test machine stroke). The eight individual test traces are compared with the nonlinear analysis prediction. The deflections are somewhat underpredicted by the analysis. The same is true of surface strains, as shown in Fig. 10.4. Circumferential and radial strain gages were located on the specimen surface opposite the load ring for several of the specimens. The results plotted in Fig. 10.4 are from one near-average specimen.

Figure 10.5 shows the predicted maximum principal stresses vs applied load. This plot was used to determine the maximum principal failure stresses corresponding to each failure load. Initial cracking in all cases occurred along a circle opposite the ring load.

As reported in Chap. 9, the out-of-plane flexural strength of flat beams is higher than the UTS. It is consequently expected that the biaxial flexure strength would likewise be higher than the corresponding strength for uniform biaxial tension. The ratio of beam MOR values to UTS* was thus used to adjust the biaxial data downiward to correspond more directly to biaxial tension. For beams taken from the same plaques as the biaxial disk specimens, the average MOR/UTS ratio at room temperature was 1.75. The radial and circumferential bend stresses from Fig. 10.5 were divided by this ratio to estimate biaxial tensile stresses for use in assessing candidate biaxial failure criteria.

The candidate theories considered are shown in Fig. 10.6, where they are compared with the average measured failure points. The failure points-uniaxial tension, compression, shear, and biaxial tension-are divided by the UTS to produce a dimensionless plot. Since the material

\footnotetext{
* The average UTS for the plaques from which the beams came was used.
} 


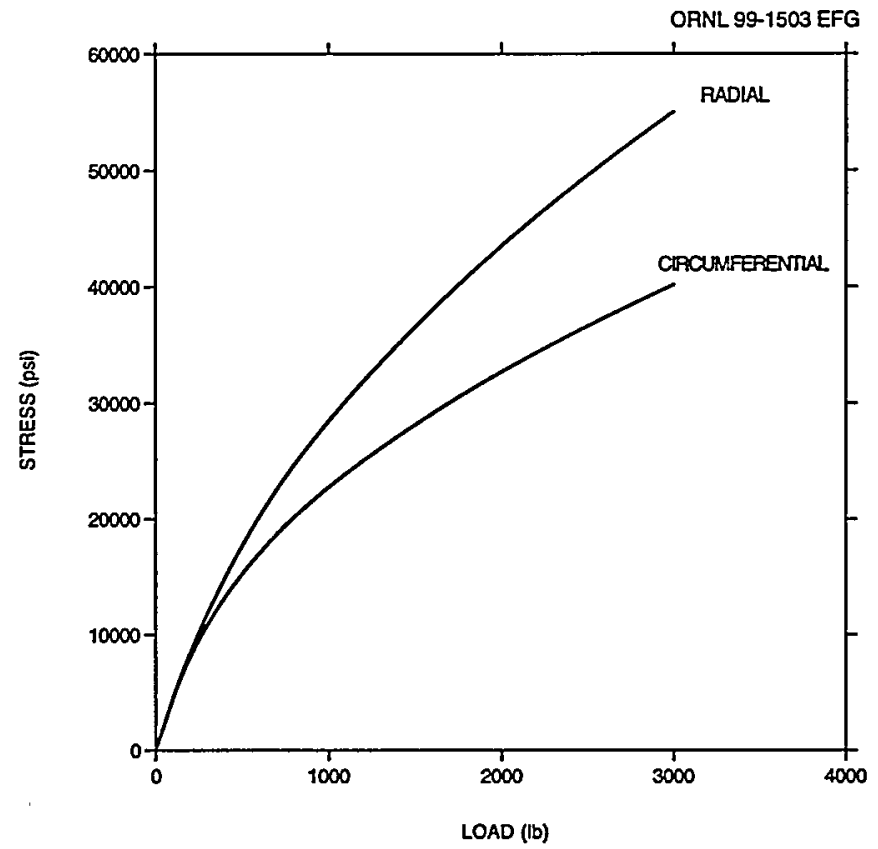

Fig. 10.5. Predicted maximum principal stresses in biaxial flexure tests $(1$ psi $=$ $\left.6.895 \times 10^{-3} \mathrm{MPa}, 1 \mathrm{lb}=4.448 \mathrm{~N}\right)$.

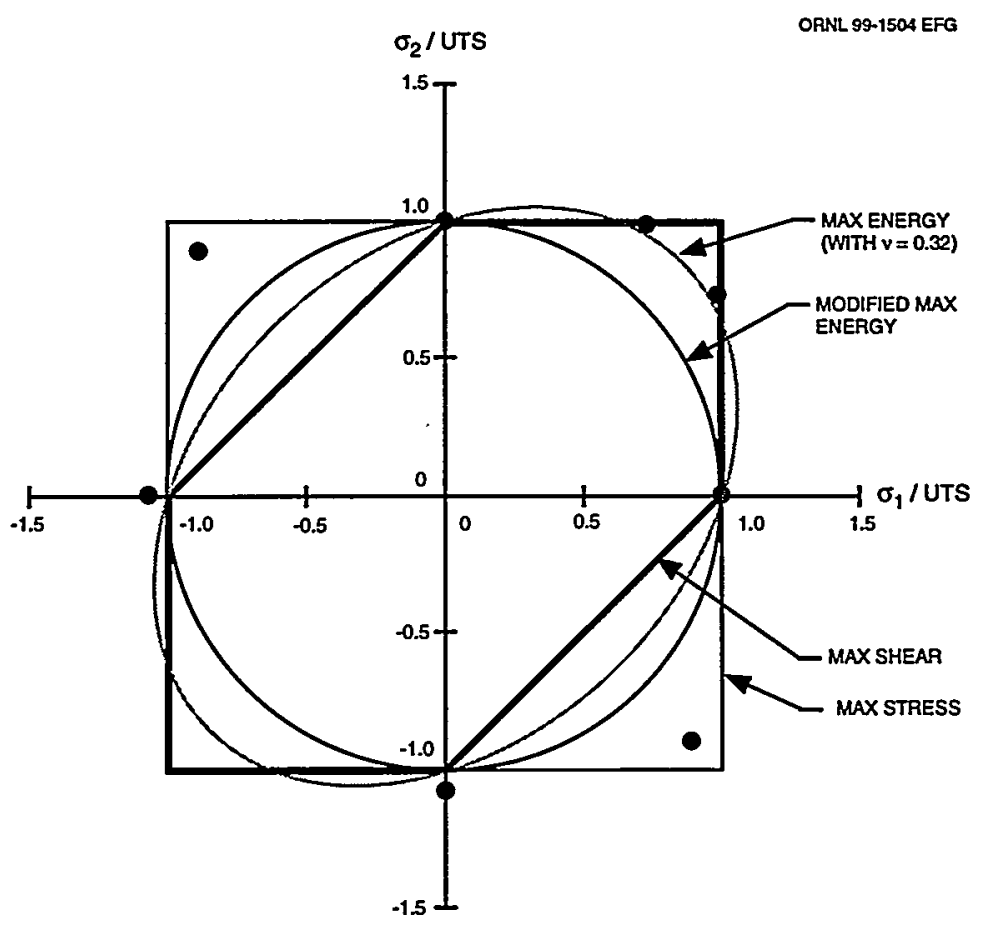

Fig. 10.6. Candidate failure criteria compared with room-temperature failure data. The maximum stress criteria (square) best represents the data. 
is assumed to be isotropic, each failure point is shown twice to reflect symmetry (e.g., pure shear can be shown in both the second and fourth quadrants). The maximum shear theory, adopted for the reference CSM composite, is the dark hexagon; the maximum stress theory is the square; the maximum energy theory (shown for a Poisson's ratio of 0.32 ) is the ellipse; and the modified maximum energy theory is the circle.* The maximum stress theory appears to best represent the data. It is just slightly unconservative for pure shear, but the design margin built into the allowable stress should adequately absorb this small difference. For the reference CSM composite, the shear points were much closer to the maximum shear theory. Hence, it was adopted there.

The maximum stress theory, which was adopted in Part 1 , is even simpler to use than the maximum shear theory. They differ only in quadrants 2 and 4 .

\subsection{TEMPERATURE EFFECTS}

The failure points in Fig. 10.6 are for room temperature only. Ideally, a strength reduction on UTS for elevated temperatures would handle other stress states as well, but, as already reported in Chap. 8, that is not the case.

Table 10.2 is a tabulation of the elevated-temperature strength reduction factors for the various stress states, including biaxial flexure. The tension, compression, and shear factors are from Chap. 8, while the uniaxial flexure factors are from Chap. 9, and the biaxial flexure factors are from Table 10.1 .

The values in parentheses are the ratio of each factor to the corresponding tensile factor. These values in parentheses were used to construct the 50 and $120^{\circ} \mathrm{C}$ biaxial failure plots in Figs. 10.7 and 10.8, respectively. The room-temperature values shown in Fig. 10.6 were adjusted by the ratios shown in parentheses. The biaxial tension values required some further adjustment, since the uniaxial flexure MOR/UTS ratios at 50 and $120^{\circ} \mathrm{C}$ were different from the roomtemperature ratio of 1.75 . The $50^{\circ} \mathrm{C}$ value was 1.80 , and the $120^{\circ} \mathrm{C}$ value was 1.37 .

At $50^{\circ} \mathrm{C}$, the governing temperature reduction factor is that corresponding to biaxial tension- 0.75 from Table 10.2 . At $120^{\circ} \mathrm{C}$, it can be seen from Fig. 10.8 that the compression reduction factor should govern -0.46 from Table 10.2 .

Table 10.2. Strength reduction factors ${ }^{a}$ at $50^{\circ} \mathrm{C}$ and $120^{\circ} \mathrm{C}$ relative to room temperature

\begin{tabular}{lll}
\hline \multicolumn{1}{c}{ Stress state } & \multicolumn{1}{c}{$50^{\circ} \mathrm{C}$} & $120^{\circ} \mathrm{C}$ \\
\hline Tension & $0.92(1.0)$ & $0.73(1.0)$ \\
Compression & $0.85(0.92)$ & $0.46(0.63)$ \\
Shear & $0.85(0.92)$ & $0.47(0.64)$ \\
Biaxial flexure & $0.75(0.82)$ & $0.42(0.58)$ \\
Uniaxial flexure & $0.95(1.03)$ & $0.57(0.78)$ \\
\hline
\end{tabular}

$a_{\text {Numbers in parentheses are the ratios of the factors to the corre- }}$ sponding tension factor, e.g., $0.85 / 0.92=0.92$ for compression at $50^{\circ} \mathrm{C}$.

*These theories are described more fully in Ref. 2. 


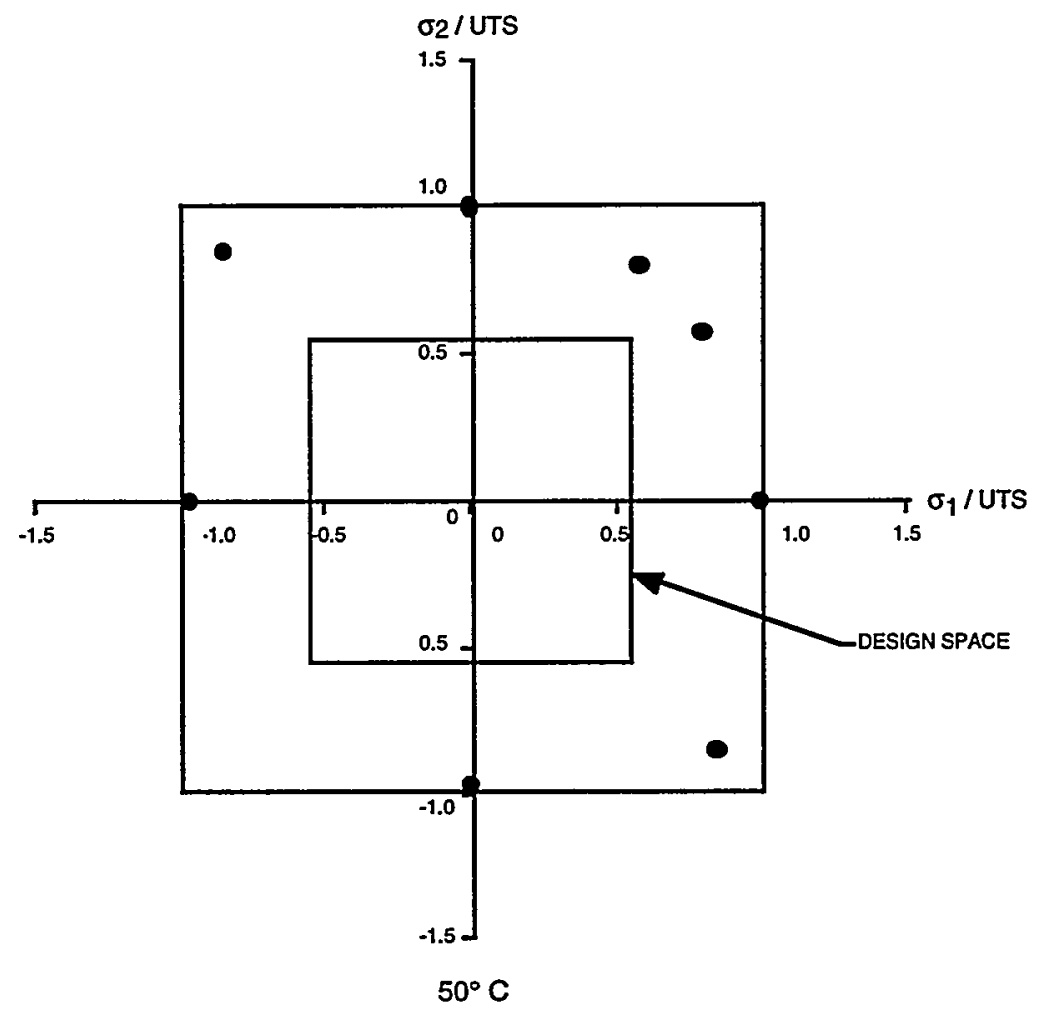

Fig. 10.7. Failure data points at $50^{\circ} \mathrm{C}$ compared to maximum stress theory and to the allowable design space, based on $2 / 3$ UTS $_{\min }$.

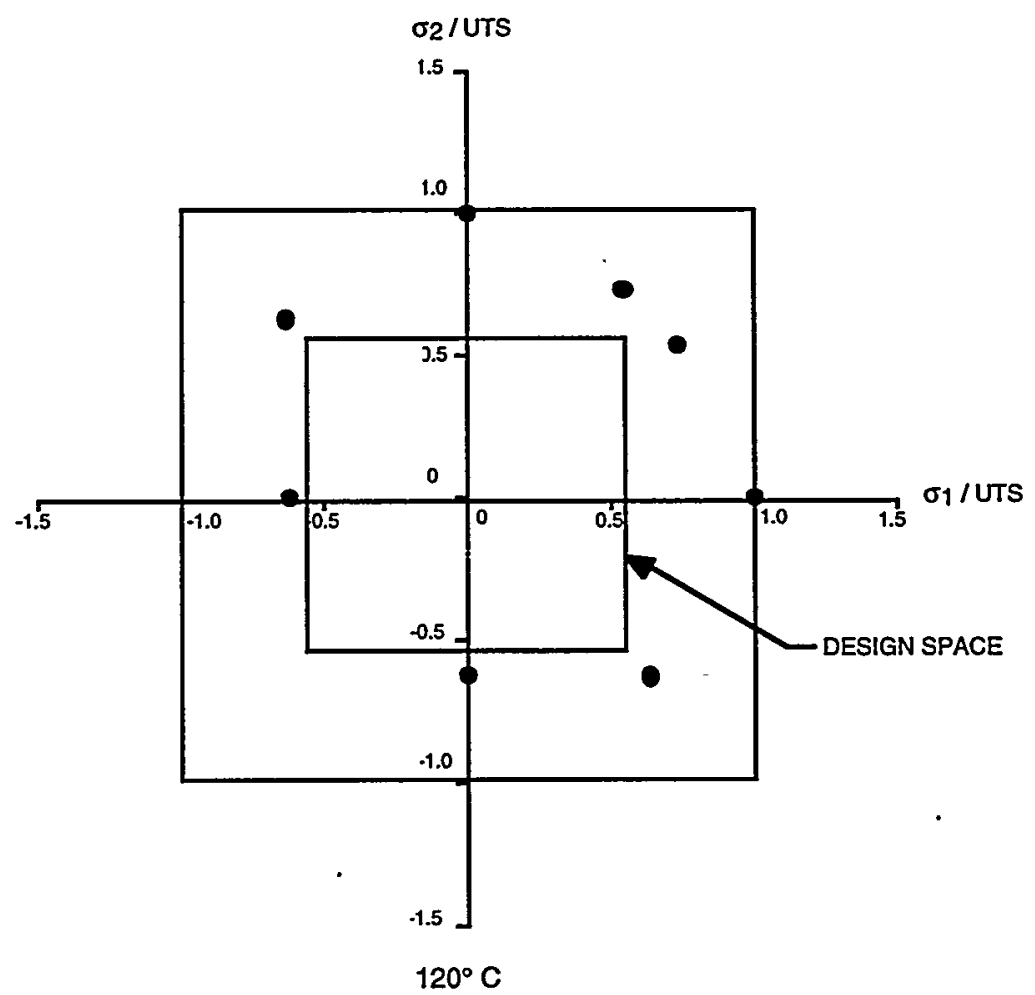

Fig. 10.8. Failure data points at $120^{\circ} \mathrm{C}$ compared to maximum stress theory and to the allowable design space. 
As listed in Table 10.1, biaxial flexure tests were performed on three groups of specimens subject to presoaks in fluids:

- $100 \mathrm{~h}$ in $70 \%$ methanol/30\% distilled water,

- $1000 \mathrm{~h}$ in room-temperature distilled water,

- 6 months in $50^{\circ} \mathrm{C}$ distilled water.

The corresponding strength reduction factors were $1.04,0.84$, and 0.56 .

The methanol/water results agreed with uniaxial flexure MOR results-there was no effect. The UTS was reduced by a factor of 0.93 for the same presoak.

In the case of the 1000-h water soak at room temperature, which is the reference condition, the UTS and uniaxial flexure strengths were both reduced by a factor of 0.91 . The biaxial flexure results were reduced by 0.84 .

While the long-term water soak at $50^{\circ} \mathrm{C}$ is an extreme condition that would not be experienced by an automotive structure, it is interesting to note that all stress states-tension, compression, shear, uniaxial flexure, and biaxial flexure-were affected about the same. The biaxial reduction factor of 0.56 was slightly lower than the others, which ranged from 0.62 to 0.69 . This is logical since the exposure was 6 months rather the 3 months used for the others.

For design purposes, the 0.84 factor from the $1000 \mathrm{~h}$ in distilled water case is recommended as a bounding factor to cover practical fluid exposures.

\subsection{DISCUSSION}

Considering the failure strengths at room temperature for all of the stress states examined-tension, compression, shear, and biaxial tension-it was concluded that the data are adequately represented by the simple maximum stress failure criterion. This finding for the P4 chopped-glass-fiber/Baydur 420 IMR composite differs from that for the reference continuousstrand-mat composite. There, the shear failures were much closer to the maximum shear stress criterion. ${ }^{2}$ Consequently, the shear stress criterion was used in Ref. 1.

By evaluating failure data for the chopped-glass-fiber composite at temperatures of 50 and $120^{\circ} \mathrm{C}$, it was concluded that stress states other than uniaxial tension require reduction factors of 0.75 and 0.46 , respectively. Uniaxial tension requires reduction factors of 0.92 and 0.73 , respectively. For the reference continuous-strand-mat composite, elevated temperature data for stress states other than uniaxial tension were unavailable. Thus, reduction factors from the latter were used for all stress states. Those reduction factor values were 0.90 at $50^{\circ} \mathrm{C}$ and 0.66 at $120^{\circ} \mathrm{C}^{1}$

Examination of available data for the chopped-glass-fiber composite on the effects of prior fluid exposure on strength led to the recommendation that a single bounding strength reduction factor of 0.84 , which came from biaxial flexure tests, be adopted to bound all practical fluid exposure effects. The corresponding factor used for the reference continuous-strand-mat composite was 0.83.1 


\title{
11. EFFECTS OF STRESS CONCENTRATIONS
}

\author{
J. M. Corum, R. L. Battiste, M. B. Ruggles, and W. Ren
}

\subsection{INTRODUCTION}

Evaluation of the effects of holes is an important part of design and damage tolerance assessment procedures for composite structures. Automotive structures typically have a multitude of holes, and their effect on structural strength and stiffness must be assessed. Furthermore, the damage tolerance assessment procedure of Part 1 includes demonstrating the adequacy of a structure with a 6.4-mm-diam hole assumed to occur in the worst possible location-and it is suggested that impact damage can be represented by a circular hole of equivalent area for evaluating the effect on the structure. These evaluations require a knowledge of the effective stress concentration factor for holes. This chapter describes an experimental study of the effect of circular holes on tensile, fatigue, and creep-rupture strengths, and a criterion is presented for quantifying the effect of hole size. The results were incorporated into Chap. 6 of Part 1.

\subsection{BACKGROUND-STRESS CONCENTRATION FACTORS FOR CIRCULAR HOLES}

Consider a circular hole in a uniaxially loaded, infinitely wide plate. Theoretically, the stress concentration factor (SCF) for a hole of any size in an infinitely wide plate is 3.0. In composites, however, the effective SCF depends on hole size, varying from 1.0 for small holes to 3.0 for large holes. The reason for this difference can be explained by Fig. 11.1, which depicts, schematically, the stress distributions at the edge of a large and small circular hole. Here $\sigma$ is the predicted local stress, and $\bar{\sigma}$ is the uniformly applied stress away from the hole. Whitney and Nuismer ${ }^{6}$ proposed that failure occurs only when the stress over some distance $d_{o}$ exceeds the UTS. They suggested that $d_{0}$ is a material property and that it represents the distance over which the composite must be critically stressed in order to find a flaw sufficient to initiate failure.

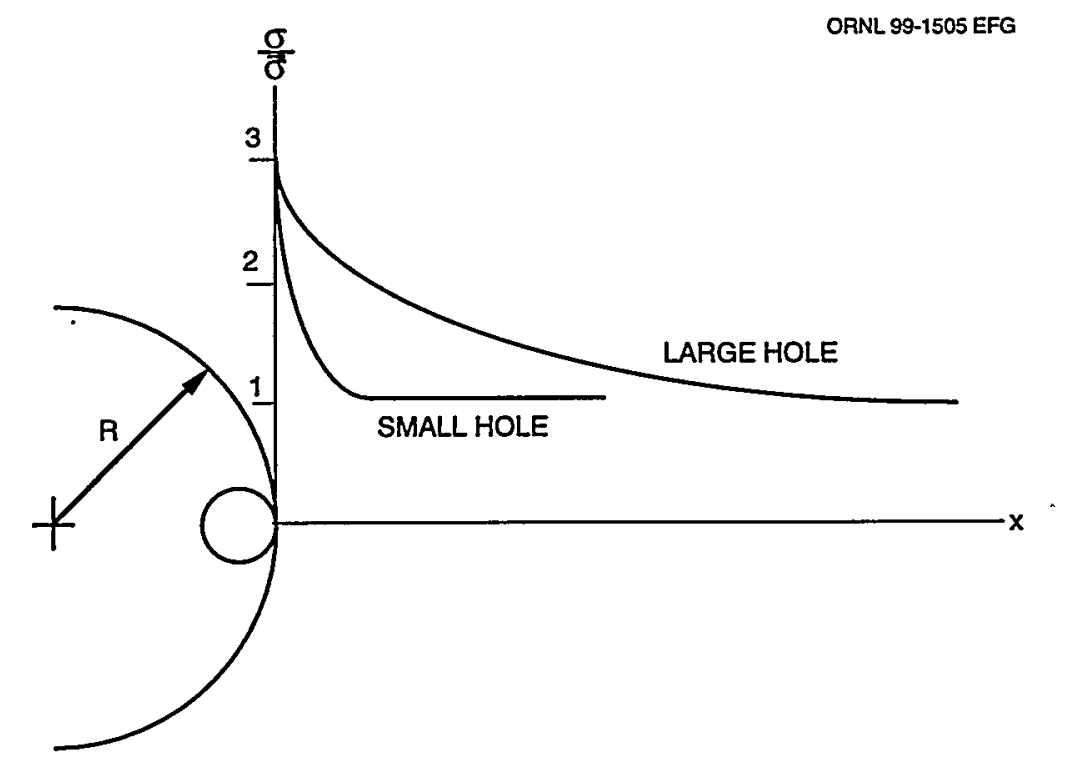

Fig. 11.1. Schematic representation of predicted stress distributions at large and small holes in a uniaxially loaded, infinitely wide plate. 
Whitney and Nuismer suggested two possible criteria to relate the stress concentration effect to hole size and the dimension $\mathrm{d}_{0}$. We have adopted the simpler of the two:

$$
\frac{\bar{\sigma}_{\infty}}{\mathrm{UTS}}=\frac{2}{\left(2+\xi^{2}+3 \xi^{4}\right)}
$$

where

$$
\xi=\frac{R}{R+d_{0}}
$$

and $\bar{\sigma}_{\infty}$ is the remote uniform uniaxial stress in an infinitely wide plate. For the quasi-isotropic glass/epoxy laminate examined by Whitney and Nuismer, $d_{0}$ was found to be $1.0 \mathrm{~mm}$. The larger the value of $d_{0}$, the more tolerant the composite to stress concentrations and damage.

For finite-width plates, as depicted in Fig. 11.2, two SCFs are commonly used, one based on gross stress, $\bar{\sigma}$, and one based on the average net stress, $\sigma_{\mathrm{n}}$. The corresponding definitions are

$$
\mathrm{SCF}_{\mathrm{g}}=\sigma_{\max } / \bar{\sigma}
$$

and

$$
\mathrm{SCF}_{\mathrm{n}}=\sigma_{\max } / \sigma_{\mathrm{n}}=\mathrm{SCF}_{\mathrm{g}}\left(1-\frac{\mathrm{a}}{\mathrm{w}}\right)
$$

since

$$
\sigma_{n}=\bar{\sigma}\left(\frac{w}{w-a}\right)
$$

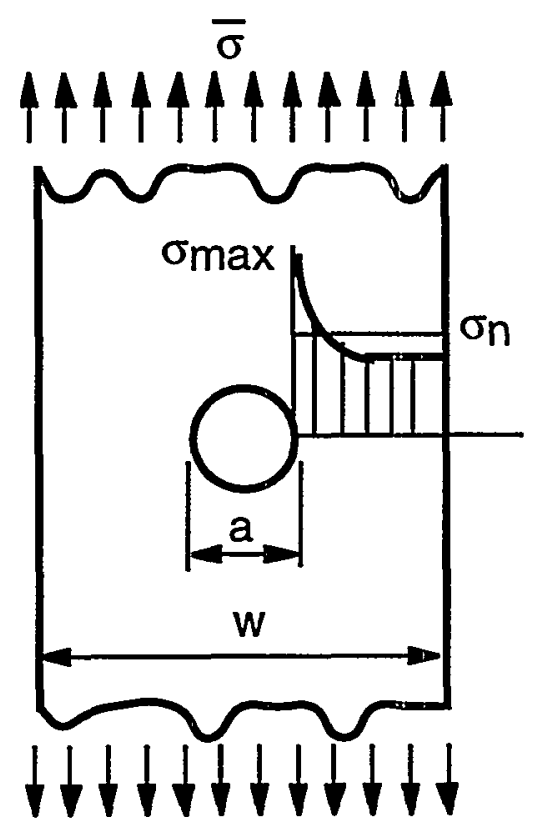

Fig. 11.2. Schematic of stress distribution and hole in a finite-width plate. 
Peterson ${ }^{10}$ presents an empirical formula for $\mathrm{SCF}_{\mathrm{n}}$ that covers the entire $\mathrm{a} / \mathrm{w}$ range.

$$
\operatorname{SCF}_{\mathrm{n}}=2+(1-\mathrm{a} / \mathrm{w})^{3}
$$

Thus, for a finite-width plate,

$$
\sigma_{\max }=\left[2+(1-a / w)^{3}\right] \bar{\sigma} /(1-a / w)
$$

For an infinitely wide plate,

$$
\sigma_{\max }=3 \bar{\sigma}_{\infty}
$$

Equating Eqs. (11.6) and (11.7) gives the following relationship between the applied stress $\bar{\sigma}$ in a finite-width plate and the corresponding stress, $\bar{\sigma}_{\infty}$, in an equivalent infinitely wide plate.

$$
\bar{\sigma}_{\infty}=\frac{1}{3}\left[2+(1-a / w)^{3}\right] \bar{\sigma} /(1-a / w)
$$

Whitney and Nuismer used this relation to adjust the stresses from their finite-width plate tests to the equivalent stresses in infinitely wide plates. These equivalent infinitely wide plate data were then used to determine $d_{o}$ in Eq. (11.1). This same procedure is used in the following section.

\subsection{TENSIE TEST RESULTS}

Twenty-two tensile tests were performed on specimens with holes, as shown in Table 11.1. The hole diameters examined ranged from 3.2 to $25.4 \mathrm{~mm}$, while the specimen widths ranged from 25.4 to $75.4 \mathrm{~mm}$. The average gross failure stress for each case is given in the $\bar{\sigma}$ column. The equivalent infinitely wide plate stress was calculated using Eq. (11.8)

The calculated stress concentration factors for each case are tabulated in Table 11.2. The apparent SCF values were calculated assuming that the maximum stress in each case was equal to the UTS for the plaque from which the specimen came.* The apparent SCF was thus the UTS divided by the gross or net stress. The first two SCF columns in Table 11.2 correspond to the

Table 11.1. Average results for tensile tests of hole specimens

\begin{tabular}{ccccc}
\hline $\begin{array}{c}\text { Hole diameter, } \\
\mathrm{a}(\mathrm{mm})\end{array}$ & $\begin{array}{c}\text { Specimen width, } \\
\mathrm{w}(\mathrm{mm})\end{array}$ & $\begin{array}{c}\text { Number of } \\
\text { specimens }\end{array}$ & $\begin{array}{c}\bar{\sigma} \\
(\mathrm{MPa})\end{array}$ & $\begin{array}{c}\bar{\sigma}_{\infty} \\
(\mathrm{MPa})\end{array}$ \\
\hline 3.2 & 25.4 & 6 & 152.8 & 155.4 \\
6.4 & 25.4 & 6 & 120.6 & 129.7 \\
6.4 & 42.4 & 2 & 127.7 & 130.9 \\
12.7 & 42.4 & 5 & 100.5 & 111.9 \\
25.4 & 75.4 & 3 & 92.3 & 106.3 \\
\hline
\end{tabular}

*The plaque UTS was unavailable for the plaque from which the 25.4-mm-diam hole specimens came; the average UTS for all plaques was used in that case. 
Table 11.2. Apparent SCF values

\begin{tabular}{ccccc}
\hline $\begin{array}{c}\text { Hole diameter } \\
\mathrm{a}(\mathrm{mm})\end{array}$ & $\begin{array}{c}\text { Specimen width, } \\
\mathrm{w}(\mathrm{mm})\end{array}$ & $\mathrm{SCF}_{\mathrm{g}}$ & $\mathrm{SCF}_{\mathrm{n}}$ & $\mathrm{SCF}_{\infty}$ \\
\hline 3.2 & 25.4 & 1.14 & 0.98 & 1.12 \\
6.4 & 25.4 & 1.44 & 1.08 & 1.34 \\
6.4 & 42.4 & 1.36 & 1.15 & 1.33 \\
12.7 & 42.4 & 1.77 & 1.24 & 1.59 \\
25.4 & 75.4 & 2.02 & 1.34 & 1.75 \\
\hline
\end{tabular}

actual finitely wide plates. The last column corresponds to equivalent infinitely wide plates, in which case $\mathrm{SCF}_{\mathrm{g}}=\mathrm{SCF}_{\mathrm{n}}$.

Figure 11.3 shows the ratio of the notched strength, $\bar{\sigma}_{\infty}$, for the infinite plate to the UTS (the inverse of $\mathrm{SCF}_{\infty}$ ) as a function of hole size. The solid curve is a fit of Eq. (11.1) to the experimental results for a $d_{o}$ value of $2.5 \mathrm{~mm}$. The dashed line shows the equation with a $d_{o}$ value of $1.0 \mathrm{~mm}$, which was the value found by Whitney and Nuismer for a quasi-isotropic glass/epoxy laminate. For sufficiently large hole sizes, both curves eventually reach a notched-strength-toUTS ratio of 0.33 , corresponding to an SCF of 3.0.

Except for the case of the 25.4-mm-diam hole, for which plaque UTS values were unavailable, Eq. (11.1) fits the chopped-fiber composite experimental points well. Clearly, with

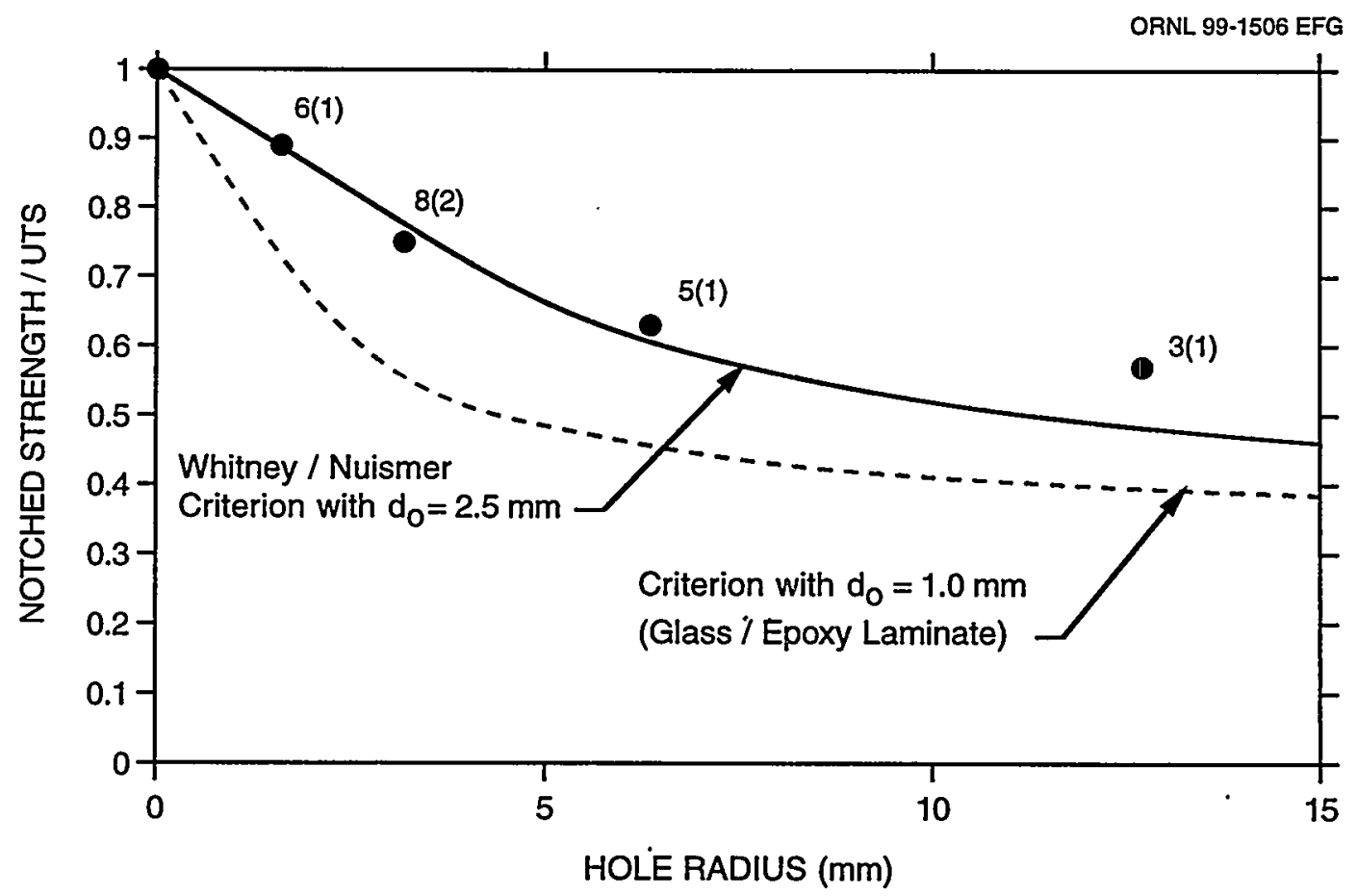

Fig. 11.3. Experimentally determined and predicted ratio of notched strength, $\sigma_{\infty}$ to UTS vs hole size. The first number above each data point is the number of specimens tested. The second number, in parenthesis, is the number of specimen widths tested. 
the larger $d_{0}$ value, the chopped-glass-fiber composite is less sensitive to holes, and presumably other notches, than the laminate studied by Whitney and Nuismer.

\subsection{FATIGUE TEST RESULTS}

Nine fatigue tests were performed on specimens with 6.4-mm-diam holes, and four were performed on specimens with 3.2-mm-diam holes. All specimens were $25.4 \mathrm{~mm}$ wide and came from a single plaque, B8. The tests all had a minimum to maximum stress ratio, $R$, of 0.1 . The results are shown in Fig. 11.4, where the adjusted maximum stress is shown as a percentage of the plaque average UTS. Recall that the adjusted stress is the applied stress multiplied by the ratio $\mathrm{E}_{\text {average }} / \mathrm{E}_{\text {specimen. }}$. The resulting fatigue curves are compared with the average curve for unnotched specimens.

Net stress concentration factors, $\mathrm{SCF}_{\mathrm{n}}$, calculated from the fatigue curves in Fig. 11.4, are tabulated in Table 11.3. Note that at low cycles these $\mathrm{SCF}_{\mathrm{n}}$ values are in reasonable agreement

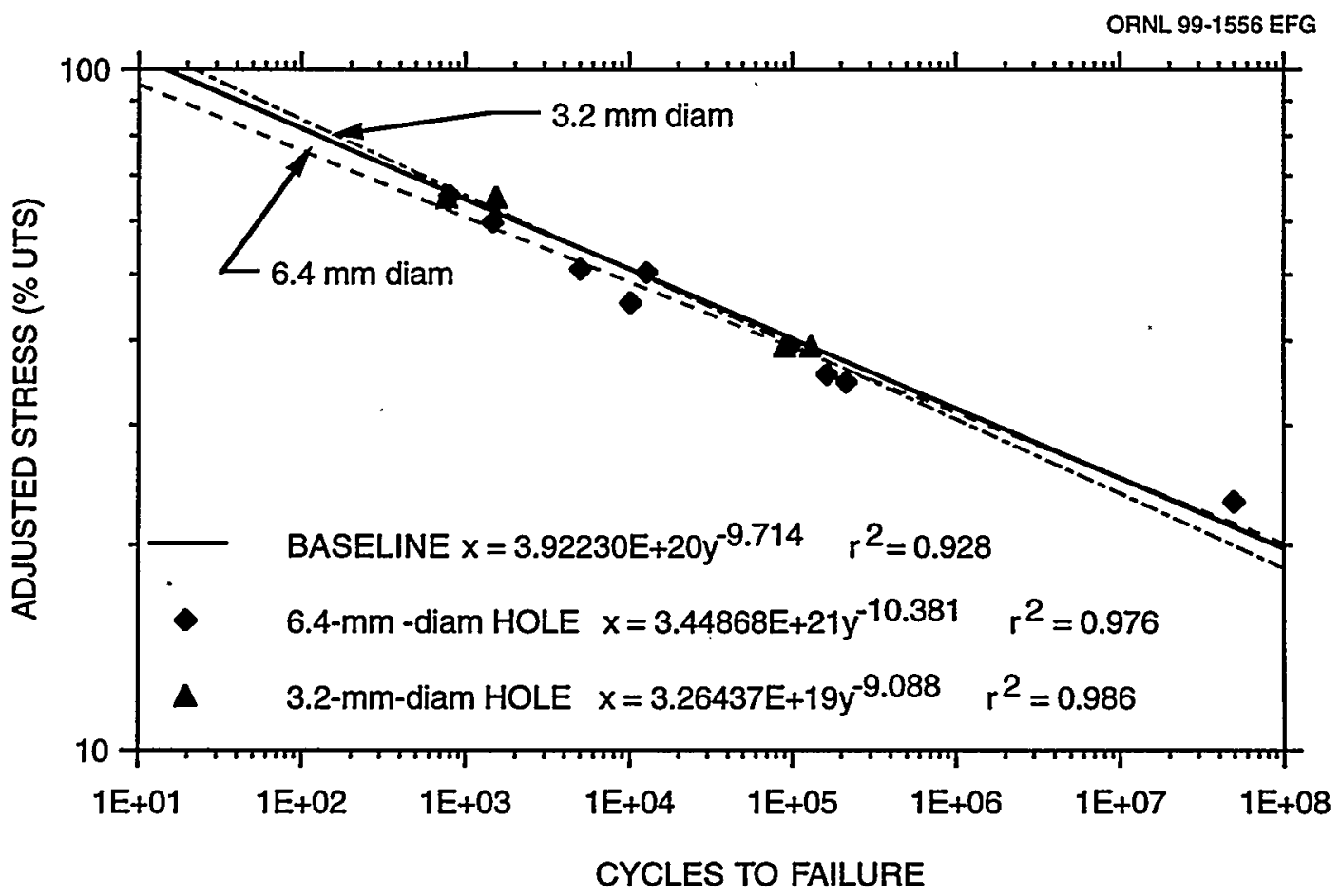

Fig. 11.4. Fatigue curves for specimens with circular holes compared with baseline curve for unnotched specimen.

Table 11.3. Apparent $\mathrm{SCF}_{\mathbf{n}}$ values for hole specimens tested in fatigue

\begin{tabular}{ccc}
\hline \multirow{2}{*}{$\begin{array}{c}\text { Cycles to } \\
\text { failure }\end{array}$} & \multicolumn{2}{c}{$\mathrm{SCF}_{\mathbf{n}}$} \\
\cline { 2 - 3 } & 3.2 -mm diam & 6.4-mm diam \\
\hline $10^{4}$ & 1.01 & 1.05 \\
$10^{6}$ & 1.05 & 1.03 \\
$10^{8}$ & 1.10 & 1.01 \\
\hline
\end{tabular}


with the tension values for 25.4-mm-wide specimens in Table 11.2. The values are 1.10 or less even at $10^{8}$ cycles.

The relative insensitivity to holes is illustrated by the photograph of a failed 3.2-mmdiam hole specimen in Fig. 11.5. Cracking can be seen at the hole, but also at other locations as well. Failure ultimately occurred away from the hole. This occurred in two of the four $3.2-\mathrm{mm}$ diam hole specimens.

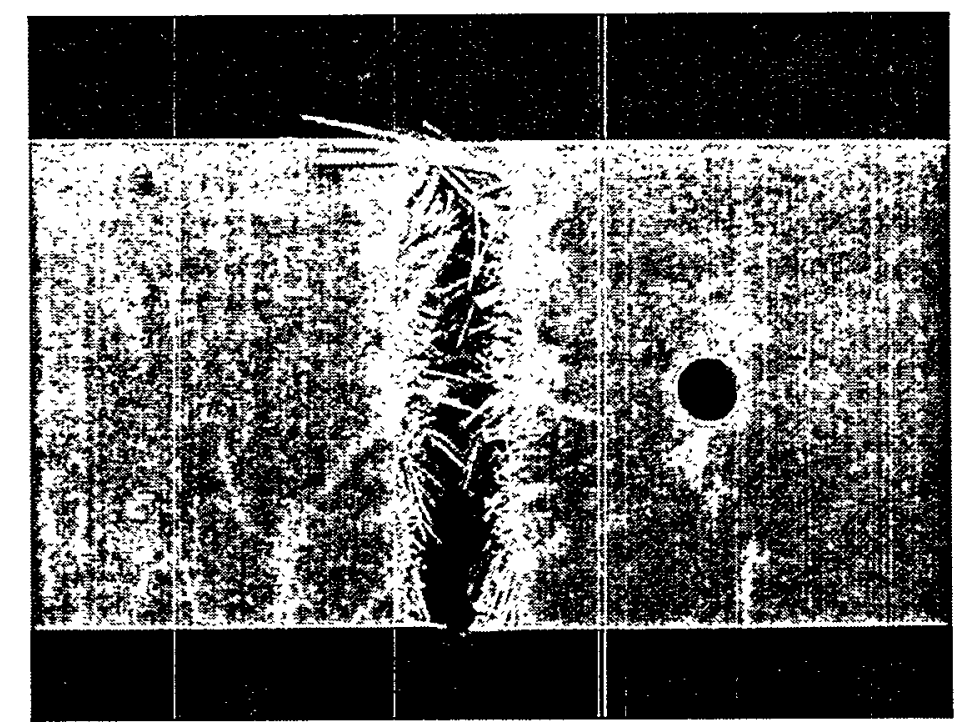

Fig. 11.5. Photograph of failed specimen with $3.2-\mathrm{mm}$-diam hole, illustrating relative insensitivity to stress concentration.

\subsection{CREEP-RUPTURE TEST RESULTS}

Five creep-rupture tests in air with a nominal $50 \%$ relative humidity $(\mathrm{RH})$ were initiated on 25.4-mm-wide specimens with a 6.4-mm-diam hole. The results to date are shown in Fig. 11.6. Two of the specimens have failed; three are runouts. From these results, it appears that the $\mathrm{SCF}_{\mathrm{n}}$ at $5000 \mathrm{~h}$ is less than 1.19 and probably closer to 1.1 .

\subsection{DISCUSSION}

Consider first tensile, fatigue, and creep-rupture tests on 25.4-mm-wide specimens with 6.4-mm-diam holes. Similar tests were performed on the reference CSM composite, so a direct comparison can be made. Table 11.4 summarizes the results. The results are very similar for both composites. The predicted $\mathrm{SCF}_{\mathrm{n}}$ from Eq. (11.5) is 2.42. Thus the effective values for these random fiber automotive composites are significantly less than predicted.

More generally, the effective SCF for a hole in an infinite plate depends on hole size, varying from 1.0 for a very small hole to 3.0 for a large one. The Whitney/Nuismer criterion given in Eq. (11.1), with $\mathrm{d}_{0}=2.5 \mathrm{~mm}$, was found to describe this dependence for the choppedfiber composite. Using this criterion, designers can calculate the effective SCF for any hole size. 


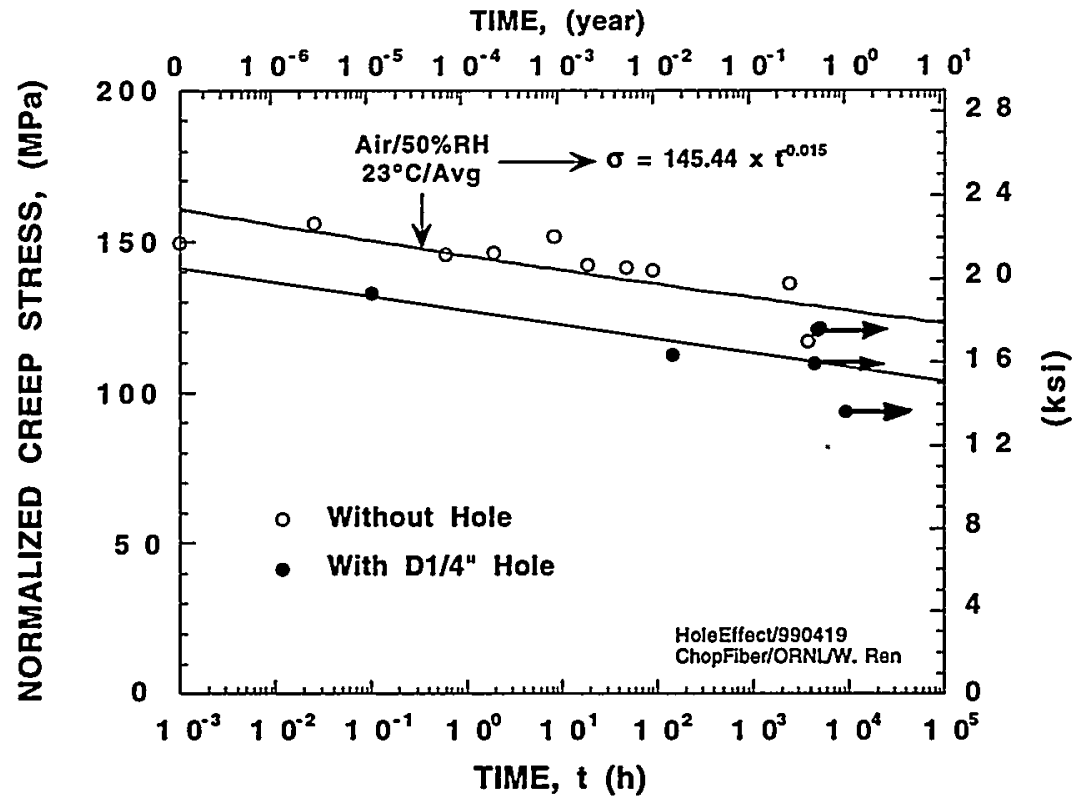

Fig. 11.6. Creep-rupture points for specimens with 6.44-mm-diam circular hole compared with baseline curve for unnotched specimens.

Table 11.4. Apparent net SCF in tests of 25.4-mm-wide specimens with 6.4-mm-diam holes

\begin{tabular}{lccc}
\hline \multirow{2}{*}{ Composite } & \multicolumn{3}{c}{$\mathrm{SCF}_{\mathrm{n}}$} \\
\cline { 2 - 4 } & $\begin{array}{r}\text { Tensile } \\
\text { strength }\end{array}$ & $\begin{array}{c}10^{6} \text { cycle } \\
\text { fatigue strength }\end{array}$ & $\begin{array}{c}10^{5} \mathrm{~h} \text { creep-rupture } \\
\text { strength }\end{array}$ \\
\hline P4 chopped fiber & 1.08 & 1.03 & $<1.19$ \\
Reference CSM & 1.10 & 1.11 & 1.16 \\
\hline
\end{tabular}




\title{
12. FATIGUE BEHAVIOR
}

\author{
J. M. Corum, R. L. Battiste, and M. B. Ruggles
}

\subsection{INTRODUCTION}

Chapter 5 of Ref. 1 provided design rules for cyclic loading of the reference CSM composite. Two design curves were provided: one for a minimum to maximum stress ratio, $R$, of 0 (tensile cycling) and one for an $\mathrm{R}$ ratio of -1 (completely reversed cycling). The latter curve was for use with a modified Goodman relation to account for mean stress effects. The former curve could be used directly for the common case of tensile loadings.

The design curves were derived from average fatigue curves by applying a margin of 20 on cycles to failure. It was shown in Ref. 2 that the factor of 20 ensured that stiffness loss during cycling would not exceed $10 \%$ for the reference material.

The design curves in Ref. 1 were applicable to all temperatures. It was shown that by expressing the maximum stress in fatigue tests at various temperatures as a percentage of the at. temperature UTS, a single curve was obtained (see Chap. 10 of Ref. 2).

The purpose of this chapter is to examine the fatigue behavior of the Baydur $420 \mathrm{IMR} / \mathrm{P} 4$ chopped-fiber composite in the same manner as was done for the reference composite, and to determine what modifications, if any, are required to the rules of Ref. 1 . The following sections discuss baseline behavior, environmental effects, cumulative damage, mean stress effects, and design curve development.

\subsection{BASELINE CURVES AND BEHAVIOR $(R=0.1)$}

All of the tensile fatigue tests utilized untabbed, dogbone specimens that were nominally $203 \mathrm{~mm}$ long by $25.4 \mathrm{~mm}$ wide ( $20.3 \mathrm{~mm}$ wide in the gage section). The specimens and the fixturing for the various types of tests (hot, cold, and immersed in fluids) are described in Ref. 3.

For the tensile fatigue tests, the following relation, recommended by $\mathrm{ACC}$ and given in Ref. 3, was used to determine test frequency:

$$
\mathrm{f}=\left(\mathrm{kS}_{\mathrm{ult}}\right) /\left(\mathrm{S}_{\max }-\mathrm{S}_{\min }\right) \text {, }
$$

where $\mathrm{k}$ is a constant ( $3 \mathrm{~Hz}$ was used), $\mathrm{S}_{\mathrm{ult}}$ is the UTS of the composite (177 MPa was used), $S_{\max }$ is the maximum stress in the cycle, and $S_{\min }$ is the minimum cyclic stress $\left(S_{\min }=0.1 S_{\max }\right)$. With the values in parenthesis, the frequency relation reduces to

$$
\mathrm{f}=590 / \mathrm{S}_{\max },
$$

which resulted in frequencies ranging from about $4 \mathrm{~Hz}$ in the low-cycle range to more than $10 \mathrm{~Hz}$ at the high-cycle end.

Seventy-four baseline room-temperature/ambient-air tensile fatigue tests were performed on as-received specimens from five plaques. The results are shown in the S-N plot of Fig. 12.1. The power law curve is fit to the failure points. The dashed lines indicate the data scatter, which increases with decreasing maximum stress. 


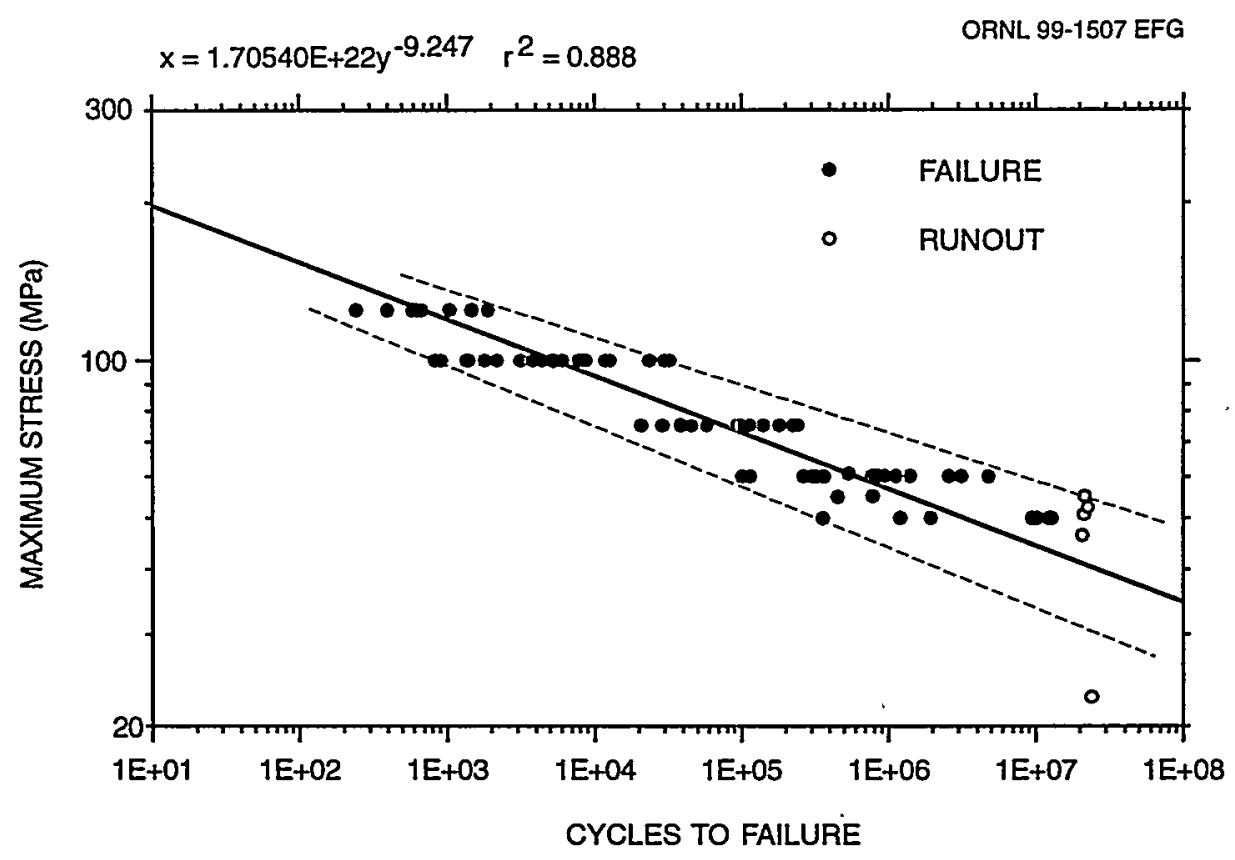

Fig. 12.1. Maximum stress vs cycles to failure for room-temperature tests in air.

Use of an adjusted stress ( $\mathrm{E}_{\mathrm{avg}} / \mathrm{E}_{\text {specimen }} \times$ actual stress) reduces the data scatter, as can be seen in Fig. 12.2. The coefficient of determination, $\mathrm{r}^{2}$, in Fig. 12.2 is 0.928 vs 0.888 in Fig. 12.1.

Presumably, the stress adjustment using the initial stiffness accounts for the variation in fiber content, and hence strength. Comparison with the reference CSM fatigue curve in Fig. 12.2 shows the chopped-fiber composite to be significantly stronger in fatigue.

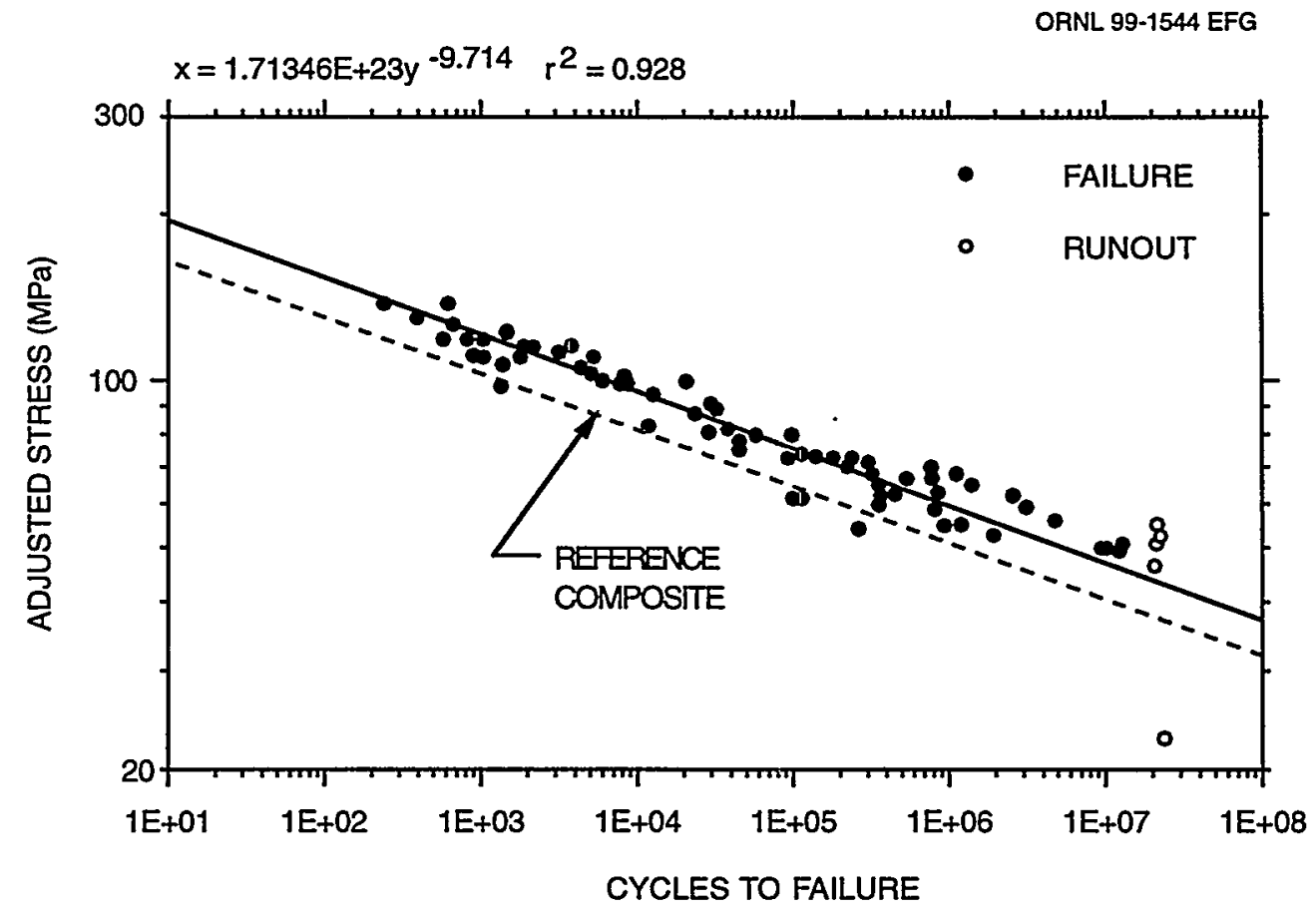

Fig. 12.2. Adjusted stress vs cycles to failure for room-temperature tests in air. 
The same plot is shown in Fig. 12.3, except that the stress is expressed as a percent of the average room-temperature UTS value for all plaques (177 MPa for the chopped-fiber material). On this basis, the reference composite is somewhat stronger in fatigue. There is very little difference between the curve representing all the chopped-fiber composite data in Fig. 12.3 and the corresponding curves for the individual plaques from which the specimens were taken.

To determine temperature effects on fatigue, specimens from a single plaque, B4, were tested at $-40,23,50$, and $120^{\circ} \mathrm{C}$. The resulting S-N curves are shown in Fig. 12.4. At low cycles, fatigue strength decreases with increasing temperature, just as does the tensile strength. However, the material becomes less sensitive to cycling as the temperature is increased, so that at high cycles temperature has little effect, except at $-40^{\circ} \mathrm{C}$, where the strength is less than even at $120^{\circ} \mathrm{C}$. Figure 12.5 shows the same curves, but with stress normalized to the at-temperature UTS values. This normalization does not adequately bring the curves together as it did for the reference composites. Hence, it was not used in Part 1.

To handle the effects of temperature in Part 1, the factors in Table 12.1 were derived from the curve equations in Fig. 12.4. These factors relate the fatigue strength at various cycles to the room-temperature strength at those cycles.

Fatigue damage is reflected in the reduction of stiffness with cycles and, in the case of tension-tension cycling, in the increase of maximum strain in each cycle with cycling. These reflections of fatigue damage were investigated at room temperature using specimens from a single plaque, $\mathrm{B} 32$.

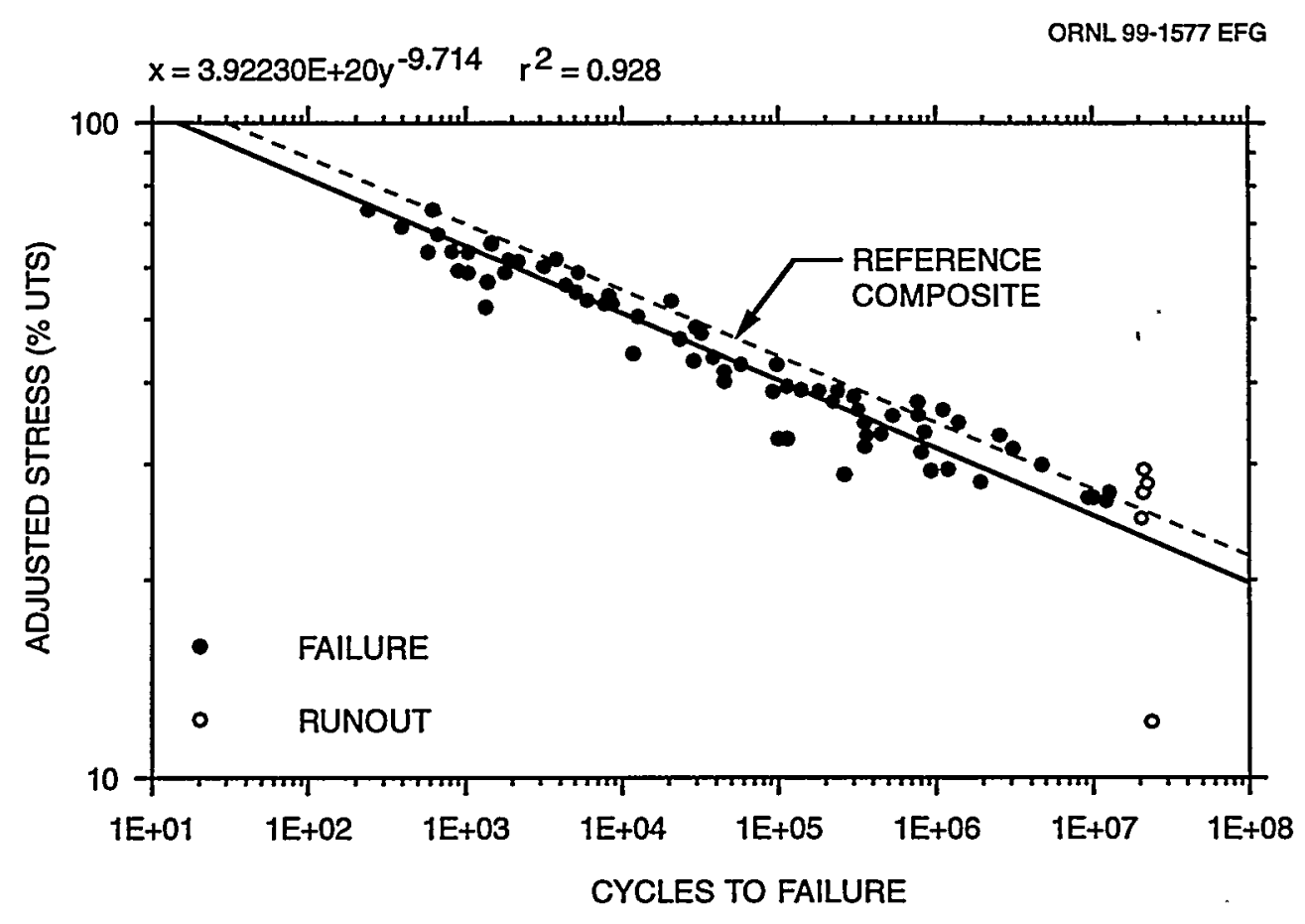

Fig. 12.3. Adjusted stress as \% UTS vs cycles to failure for room-temperature tests in air. 


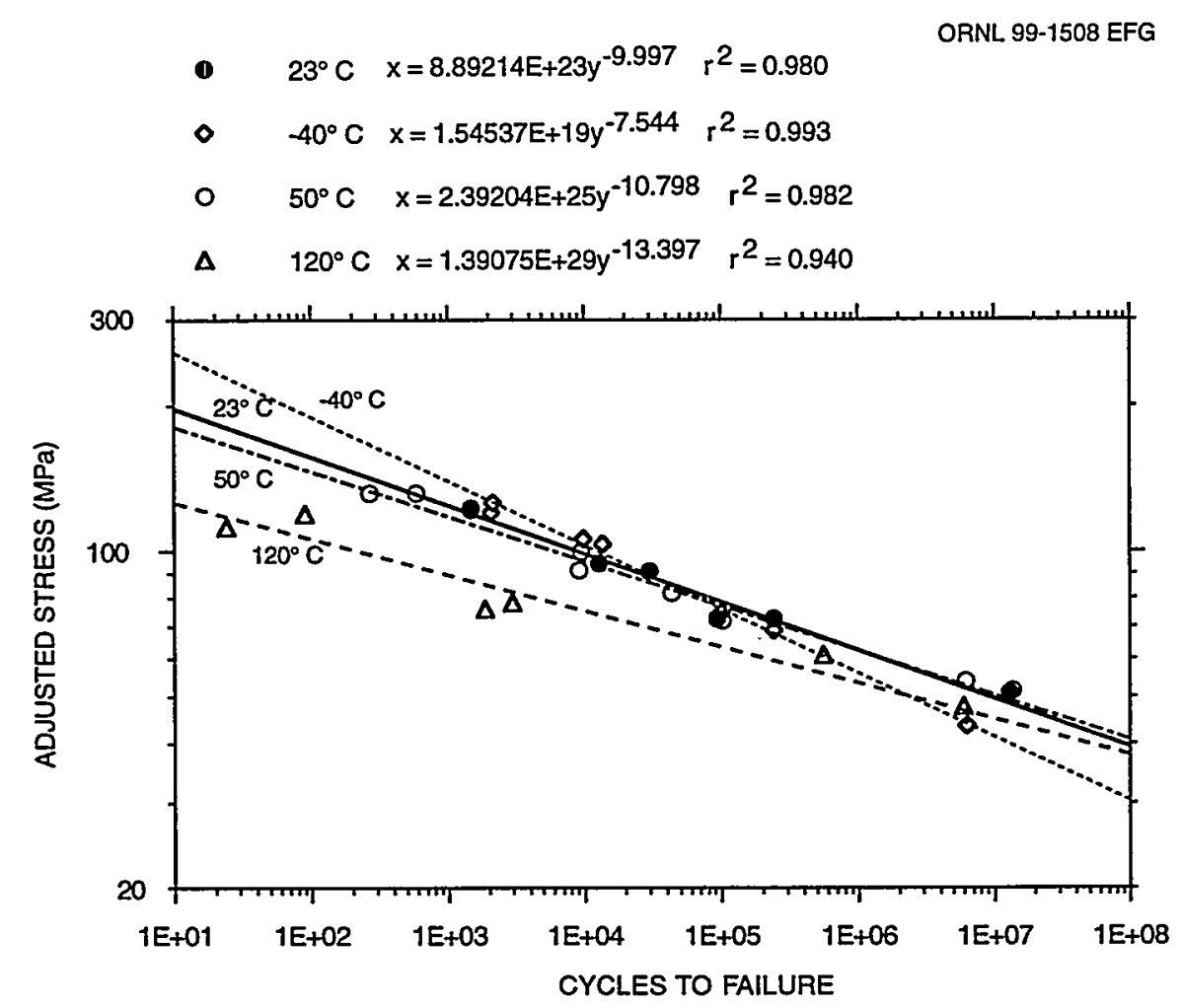

Fig. 12.4. Effect of temperature on fatigue curves. Equations used to obtain factors in Table 12.1.

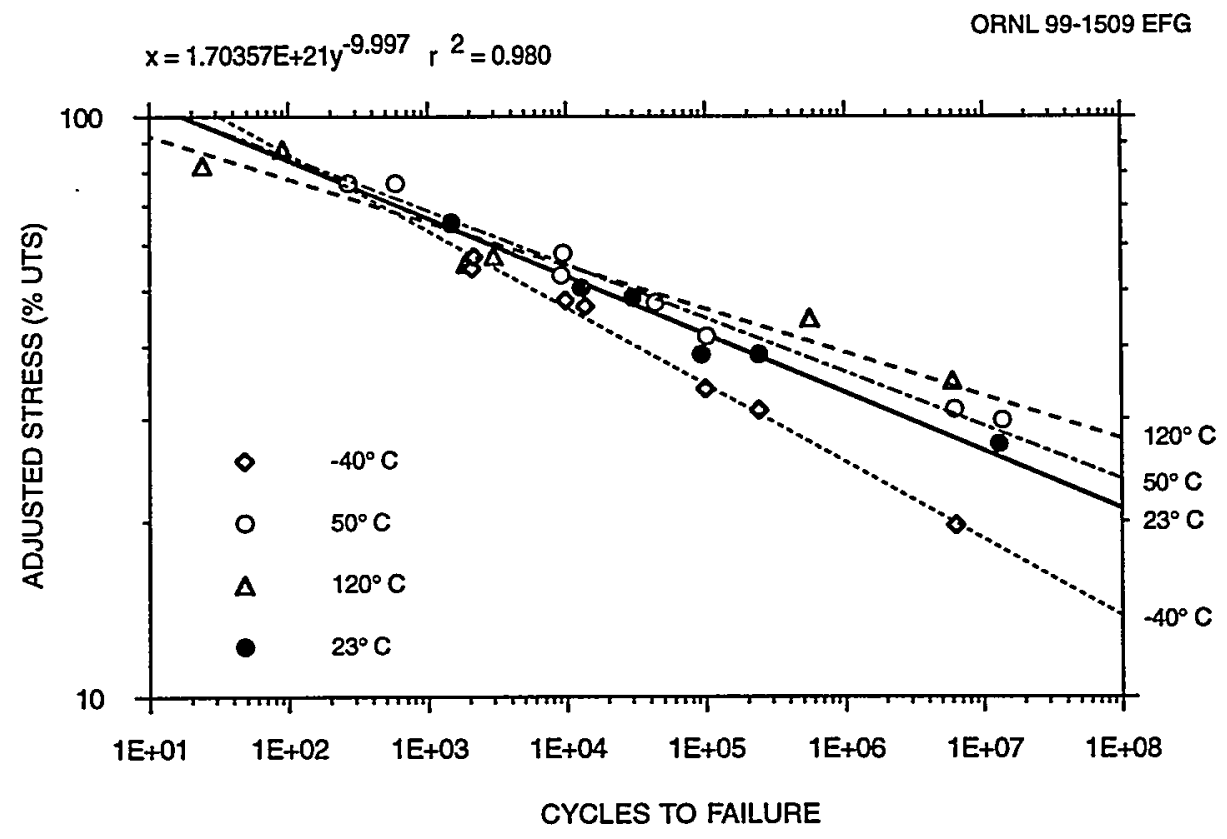

Fig. 12.5. Fatigue curves normalized to at-temperature UTS values. 
Table 12.1. Fatigue strength factors to account for temperature

\begin{tabular}{ccccc}
\hline \multirow{2}{*}{$\begin{array}{c}\text { Temperature } \\
\left({ }^{\circ} \mathrm{C}\right)\end{array}$} & $10^{2}$ & $10^{4}$ & $10^{6}$ & $10^{8}$ \\
\cline { 2 - 5 } & 1.21 & 1.04 & 0.90 & 0.77 \\
-40 & 1.00 & 1.00 & 1.00 & 1.00 \\
23 & 0.93 & 0.96 & 1.00 & 1.03 \\
50 & 0.68 & 0.76 & 0.86 & 0.96 \\
120 & & & & \\
\hline
\end{tabular}

Static stiffnesses, as opposed to dynamic stiffnesses measured during the fatigue cycles, were chosen as the most accurate and consistent measure of residual damage. The actual fatigue cycles had a haversine wave form. After prespecified numbers of cycles, the fatigue cycling was stopped, and a single triangular loading with an amplitude of $21 \mathrm{MPa}$ was applied, during which loading and unloading stiffnesses were measured. ${ }^{*}$ The resulting stiffnesses are shown as a function of cycle number in Fig. 12.6. The data scatter reflects the normal specimen-to-specimen variations in stiffness; there is no apparent trend with maximum cyclic stress. The increase in stiffness at the end of life for three of the specimens is due to fatigue cracking immediately under one of the extensometer points, which caused a loss of strain transfer to the extensometer.

The same stiffness reduction data are replotted in Fig. 12.7 as stiffness reduction vs life fraction $\mathrm{n}_{/} \mathrm{N}_{\mathrm{f}}$, where $\mathrm{N}_{\mathrm{f}}$ is the number of cycles to failure. Except for the two tests to a maximum stress of $68 \%$ of the UTS for which damage on initial loading tends to mask the fatigue effects, the curves look reasonably consistent. Note that reductions are as high as $12 \%$ at $n / N_{f}=0.05$, which corresponds to the design margin of 20 used for the reference composite and which assured in that case that stiffness reductions were no greater than $10 \%$. Figure 12.8 illustrates that a factor of 20 margin on cycles does not assure that the stiffness reduction at high cycles will not exceed $10 \%$.

Figure 12.9 shows the peak strain reached in each cycle for the same tests as a function of cycle number. The strain increases slowly as damage sites form. Fiber debonding and cracking are probably responsible for the turn-up of the curves later in life. The threshold between the two rates of damage growth is approximately represented by the curve labeled "rapid damage growth threshold" in Fig. 12.9. Ideally, the design margin would preclude rapid damage growth, but this was not feasible with the reference CSM composite. ${ }^{2}$

\subsection{ENVIRONMENTAL EFFECTS}

The effects of two fluids-distilled water and windshield washer fluid (70\% methanol/30\% distilled water)-were examined in fatigue. Specimens were presoaked in a fluid and then tested in that same fluid. ${ }^{\dagger}$ Methods of doing this are described in Ref. 3.

Consider water first. Two presoak conditions were used: (1) $100 \mathrm{~h}$ at room temperature, and (2) 3 months at $50^{\circ} \mathrm{C}$. The latter was intended, as explained in Chap. 8, as a bounding condition of near saturation. The results of tests in room-temperature water of specimens having

\footnotetext{
* The $21 \mathrm{MPa}$ was measured from the minimum stress in the fatigue cycle and was sufficiently small to preclude contributing additional damage.

†Note that some of the high cycle tests lasted about $100 \mathrm{~h}$, which added significantly to the total exposure.
} 


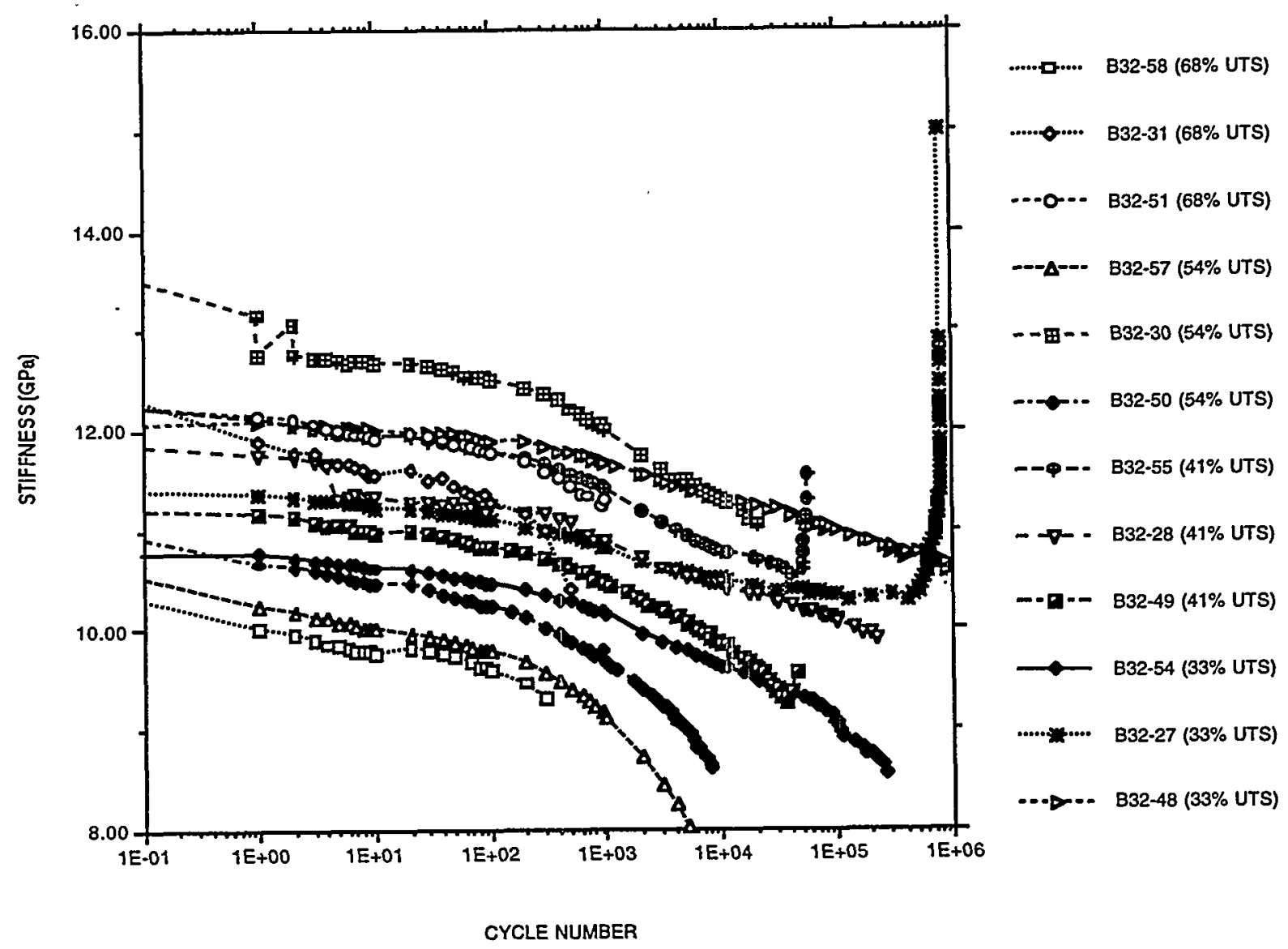

Fig. 12.6. Variation of residual stiffness vs cycle number for twelve tests on plaque B32 specimens. The maximum stresses ranged from $33 \%$ to $68 \%$ of the plaque UTS. 


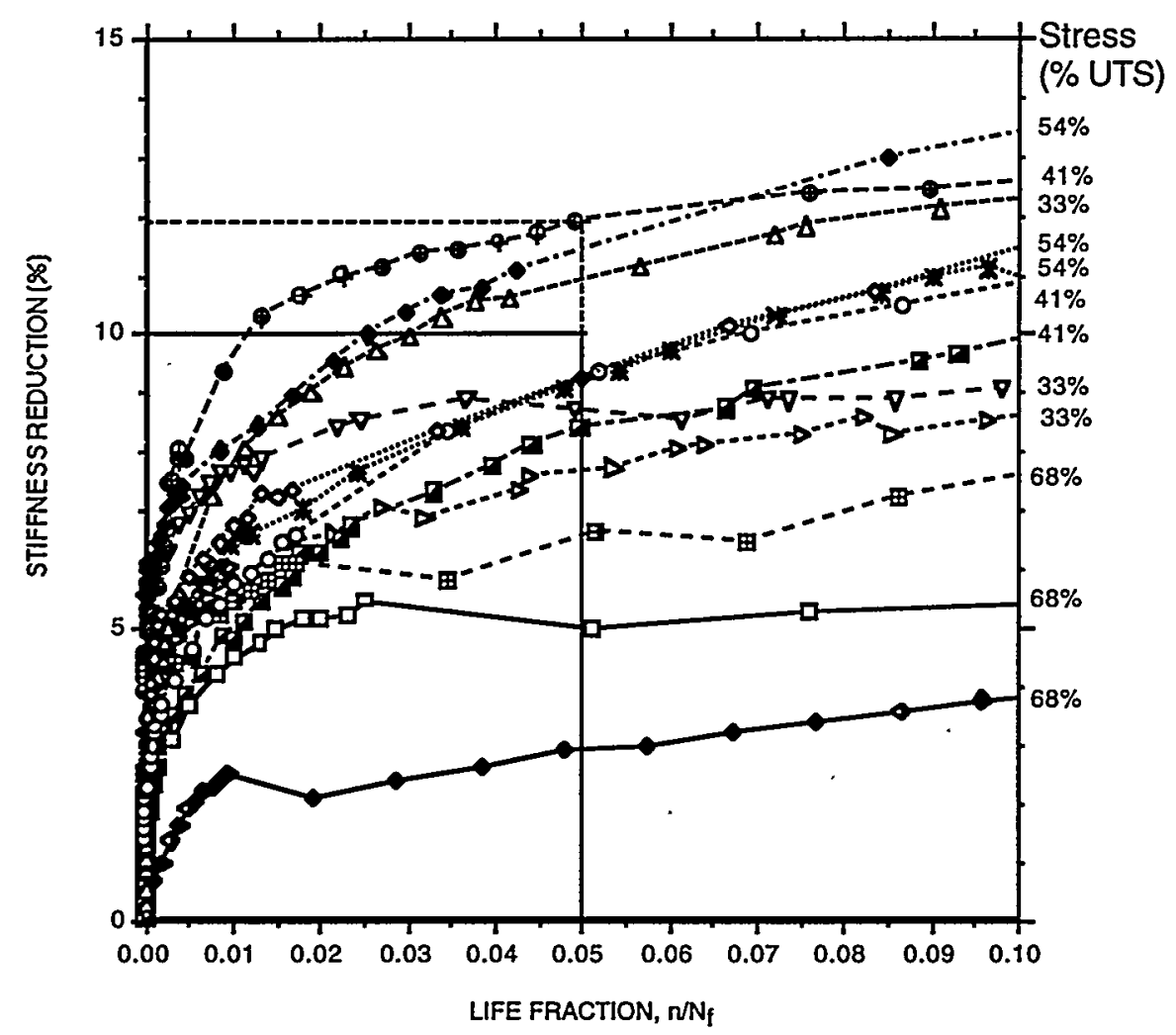

Fig. 12.7. Stiffness reduction as a function of life fraction, $n_{/} \mathbf{N}_{f}$

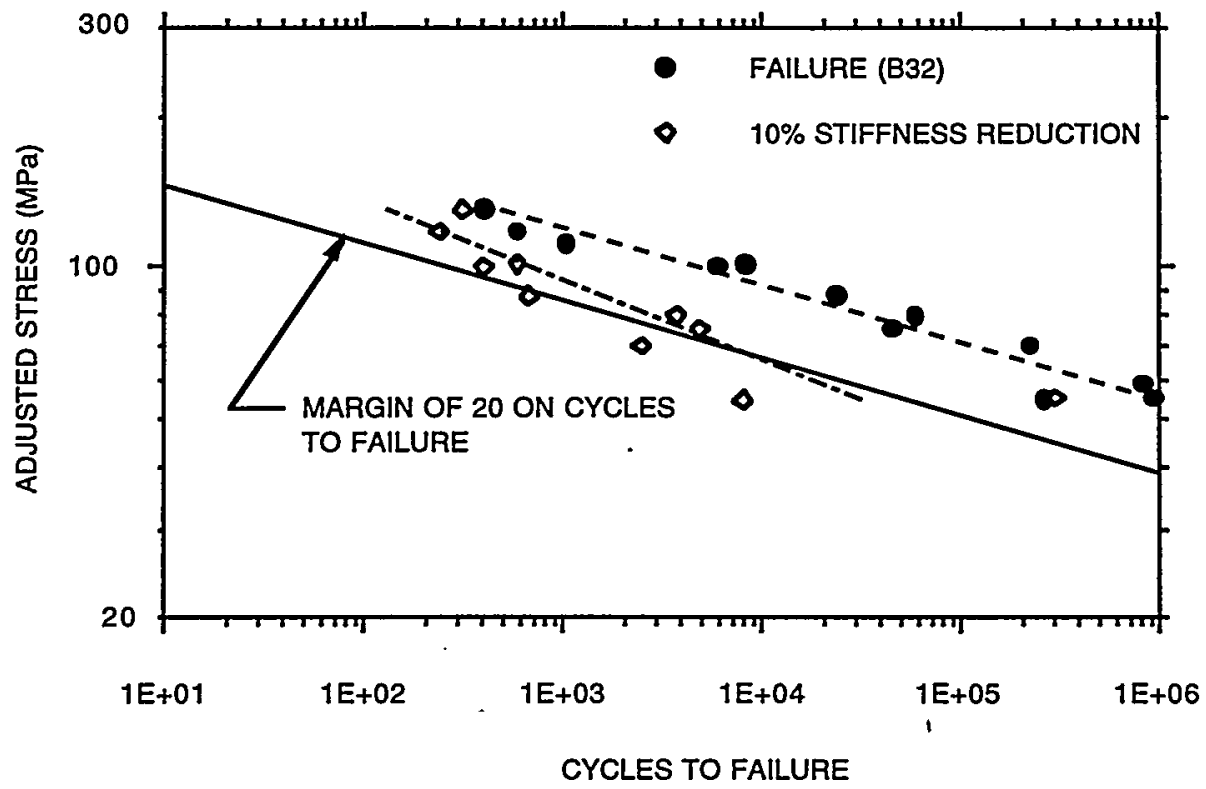

Fig. 12.8. Cycles to $10 \%$ stiffness reduction compared to curve based on margin of 20 on cycles to failure. 


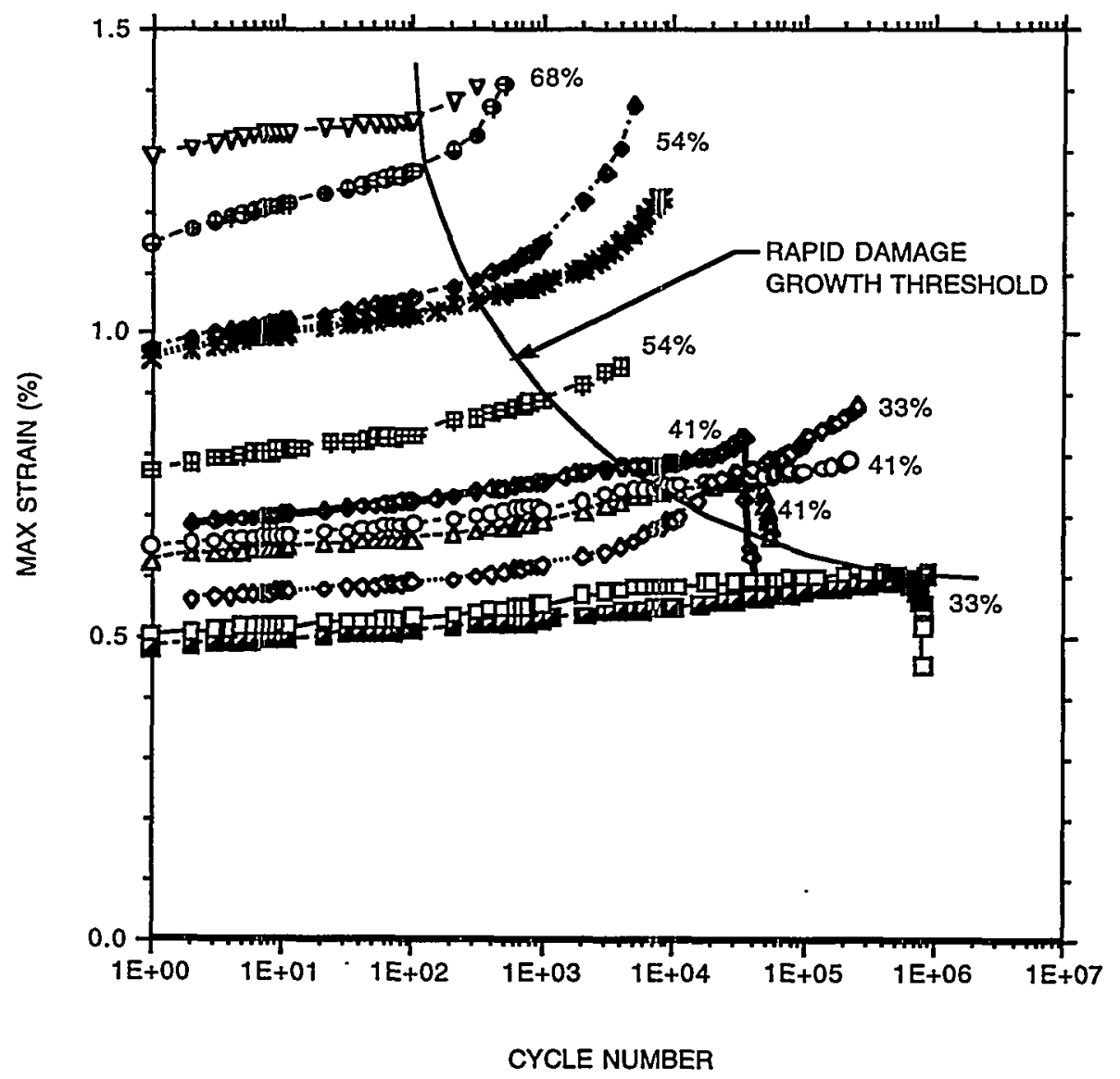

Fig. 12.9. Peak cyclic strain vs cycle number for B32 tests. The drop off at the ends of three of the curves is due to cracking under an extensometer point.

had the two different presoaks are shown in Fig. 12.10 where they are compared with the baseline curve from Fig. 12.3. The saturated specimens were from plaque B5, while the 100-h soak specimens were from plaque B32. Expressing the results as a percent of the corresponding plaque UTS helps to make the results more comparable. The equations in Fig. 12.10 were used to calculate environmental reduction factors for each case; i.e., the reduction factor at a given cyclic life is the ratio of the failure stress calculated for an exposure condition to the corresponding baseline failure stress.

Figure 12.11 compares results for plaque B5 specimens presoaked for 3 months in distilled water at $50^{\circ} \mathrm{C}$ but tested at either 23 or $50^{\circ} \mathrm{C}$. The $\mathrm{B} 5$ results are normalized to the roomtemperature UTS of plaque B5. The $50^{\circ} \mathrm{C}$ test results are just slightly below the $23^{\circ} \mathrm{C}$ results, reflecting the higher test temperature.

Turning now to windshield washer fluid, consider Fig. 12.12, which compares the results of tests in room-temperature windshield washer fluid of plaque B32 specimens presoaked $100 \mathrm{~h}$ in room-temperature washer fluid with baseline in-air test data. The washer fluid has only a very small effect at the lower cycles. 
- $23^{\circ} \mathrm{C}$ BASELINE $x=3.92230 E+20 y^{-9.714} r^{2}=0.928$

- $23^{\circ} \mathrm{C}$ SATURATEd (AT $50^{\circ} \mathrm{C}$ ) $\mathrm{x}=3.10834 \mathrm{E}+23 y^{-12.349} \mathrm{r}^{2}=0.917$

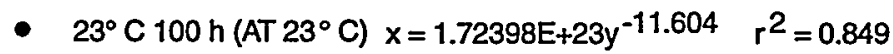

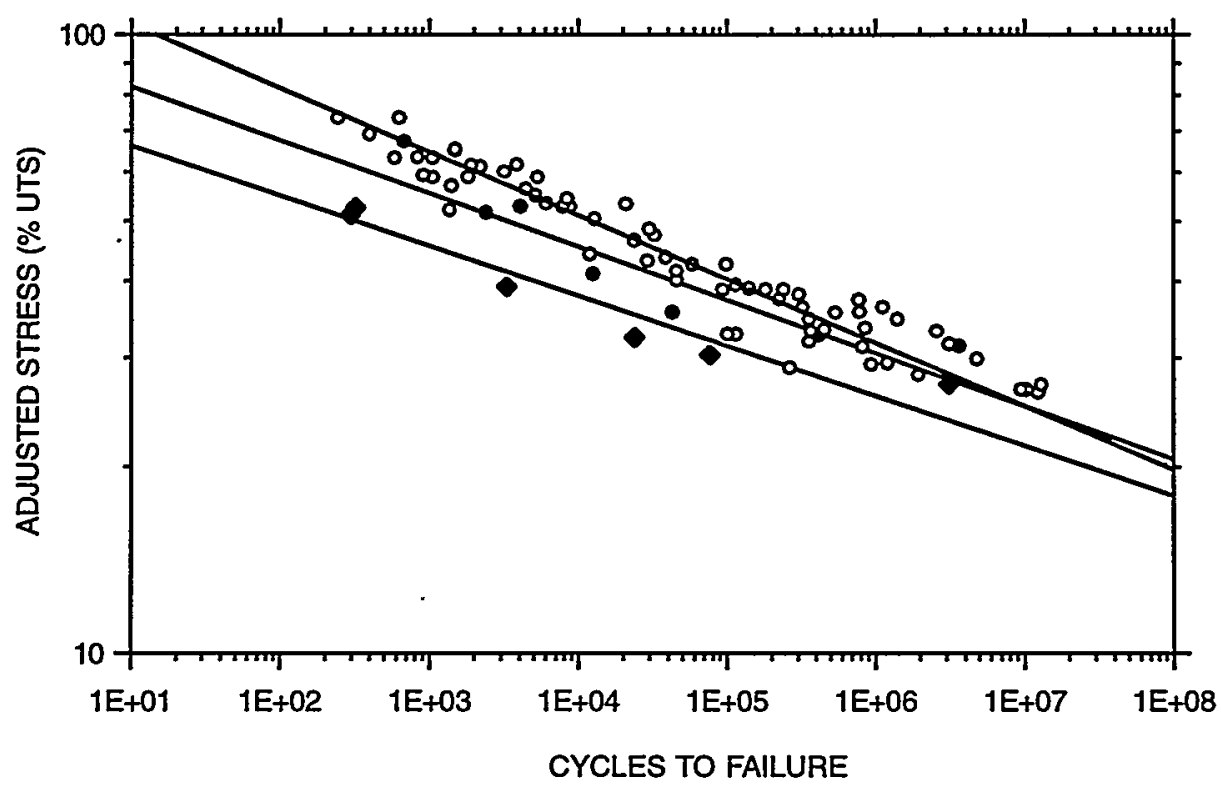

Fig. 12.10. Effects of prior soaks in distilled water on room-temperature fatigue strength. 

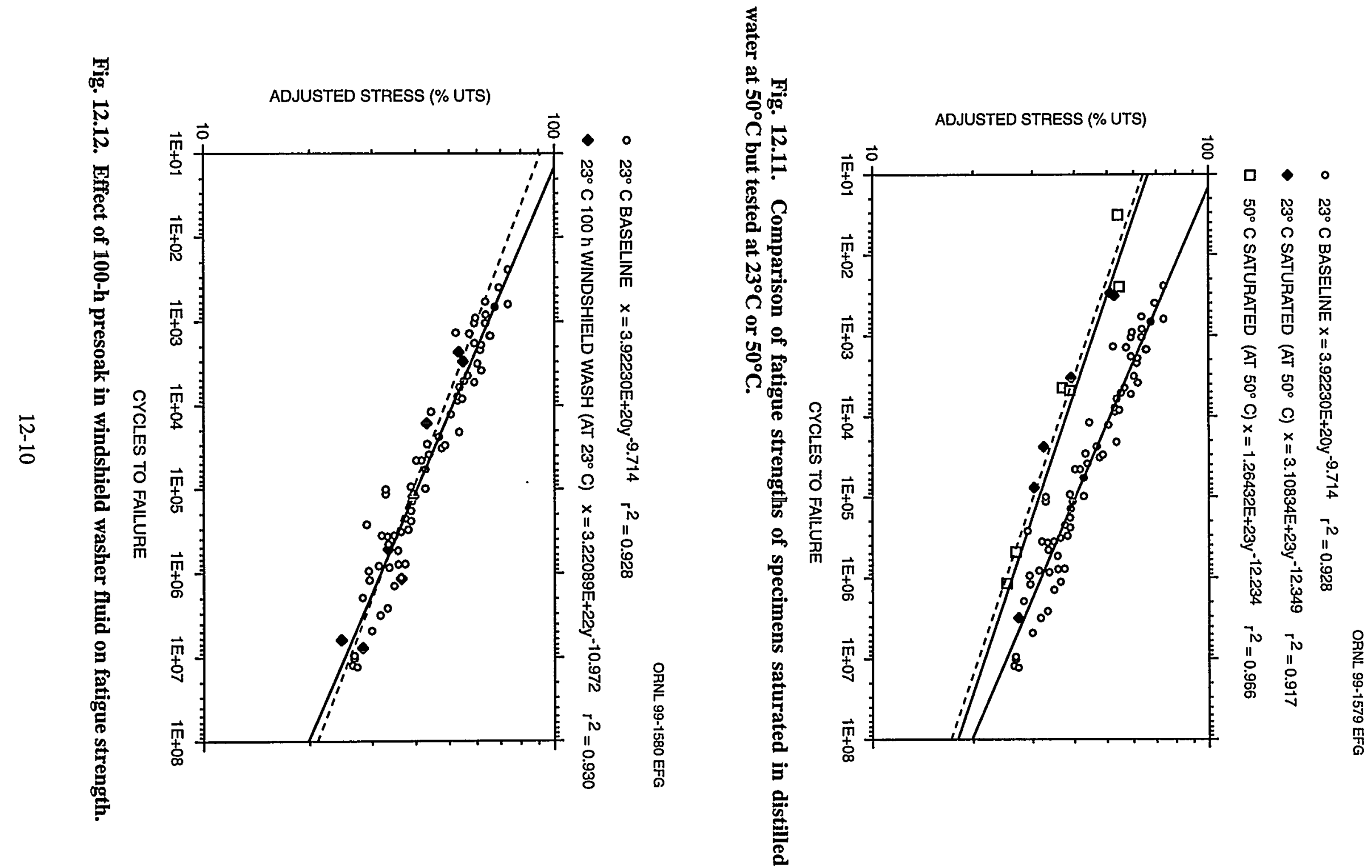
Table 12.2 tabulates calculated fatigue reduction factors that account for environmental effects in terms of the room-temperature baseline curve of Fig. 12.3. Just as in the case of the elevated-temperature reduction factors in Table 12.1, these factors tend to go up with number of cycles, indicating that the resistance to cycling is lower in air at room temperature than for the other conditions.

Because data were not available for the reference 1000 -h soak in distilled water at room temperature, those reduction factors were estimated, based on the following two observations. First, it was shown in Chap. 8 that at least the UTS reduction for a $1000-\mathrm{h}$ soak at $23^{\circ} \mathrm{C}$ can be predicted based on the strength reduction corresponding to the same weight gain for a soak at $50^{\circ} \mathrm{C}$. Second, weight gain data presented in Ref. 4 indicate that it takes about five times longer to gain the same weight at room temperature as at $50^{\circ} \mathrm{C}$. Thus, a 3-month $(2190-\mathrm{h})$ soak at $50^{\circ} \mathrm{C}$ is equivalent to approximately $11,000 \mathrm{~h}$ at $23^{\circ} \mathrm{C}$. On this basis the plot in Fig. 12.13 was constructed, from which the fatigue reduction factors for $1000 \mathrm{~h}$ at $23^{\circ} \mathrm{C}$ were determined by interpolation.

Table 12.2. Fatigue strength factors to account for fluid environments

\begin{tabular}{lcccc}
\hline \multirow{2}{*}{ Environment } & \multicolumn{4}{c}{ Cycles } \\
\cline { 2 - 5 } & $10^{2}$ & $10^{4}$ & $10^{6}$ & $10^{8}$ \\
\hline Water, saturated at $50^{\circ} \mathrm{C}$ for 3 months & 0.67 & 0.74 & 0.82 & 0.91 \\
Water, $100 \mathrm{~h}$ at $230^{\circ} \mathrm{C}$ & 0.82 & 0.89 & 0.96 & 1.04 \\
Water, $1000 \mathrm{~h}$ at $23^{\circ} \mathrm{C}$ (estimated) & 0.75 & 0.82 & 0.89 & 0.97 \\
Windshield wash, $100 \mathrm{~h}$ at $23^{\circ} \mathrm{C}$ & 0.90 & 0.95 & 1.01 & 1.06 \\
\hline
\end{tabular}

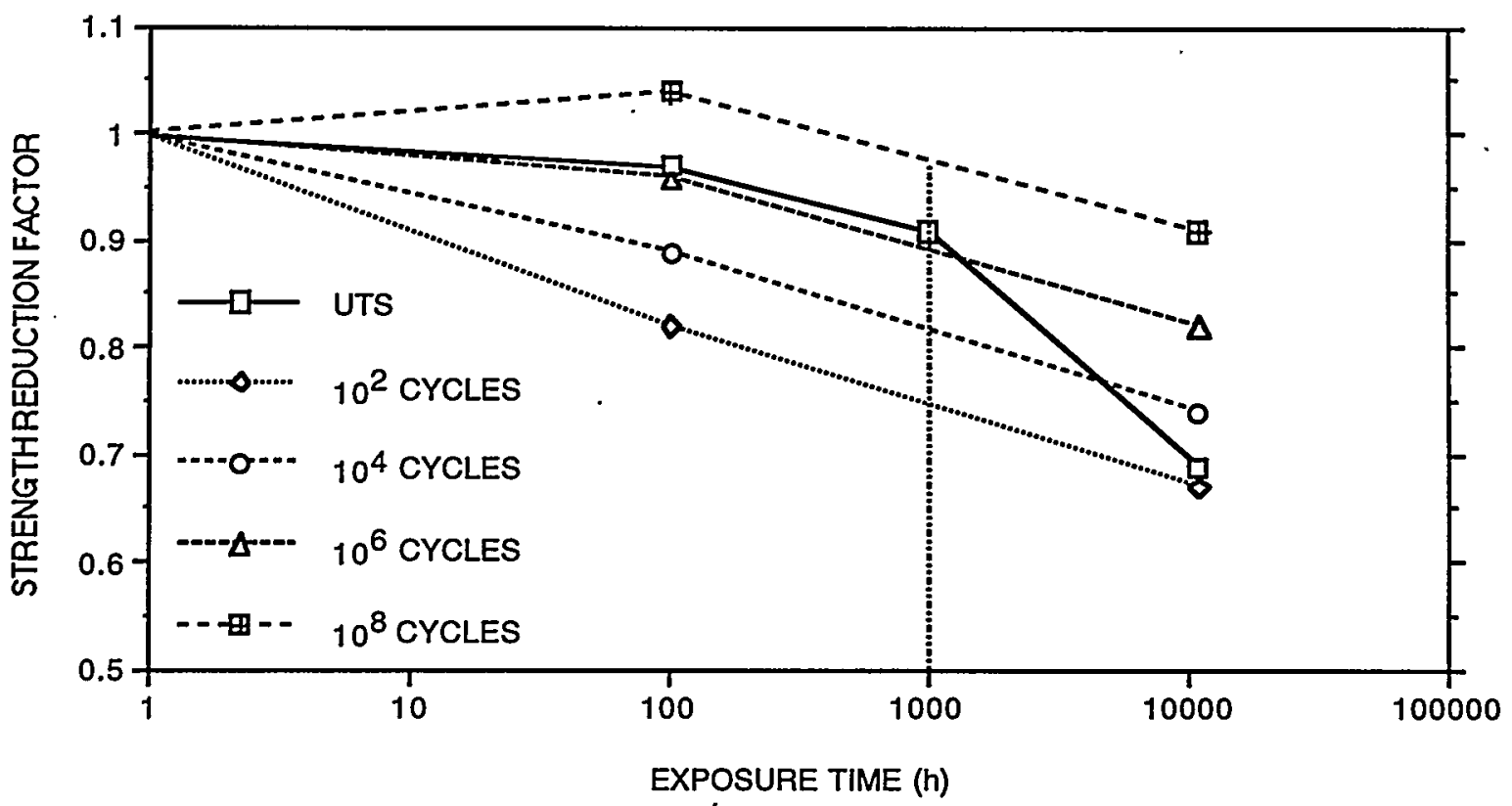

Fig. 12.13. Strength reduction factors for presoaks in distilled water at $23^{\circ} \mathrm{C}$. The points plotted at $11,000 \mathrm{~h}$ are from $2190 \mathrm{~h}$ presoaks at $50^{\circ} \mathrm{C}$, as explained above. 
Figure 12.14 graphically compares $10^{6}$ cycle fatigue strength reduction factors from Tables 12.1 and 12.2 with similar factors from Ref. 2 for the reference CSM composite. Although the conditions are not exactly the same in the two cases, it can be concluded that the choppedfiber composite is more resistant to temperature and environmental effects than is the reference composite.

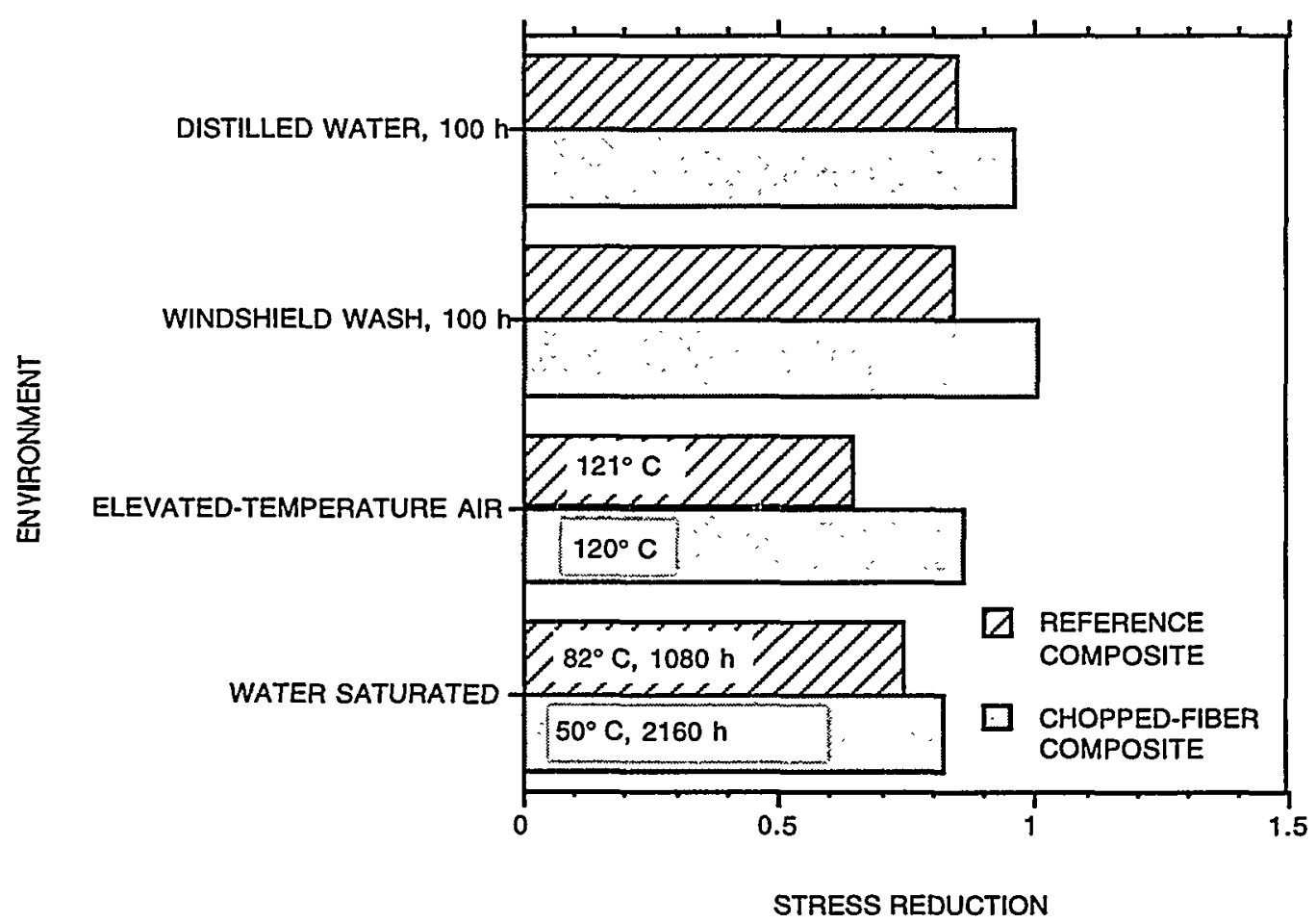

Fig. 12.14. Comparison of $10^{6}$ fatigue strength reduction factors for chopped-fiber composite with those of reference CSM composite.

\subsection{BLOCK LOADING EFFECTS (CUMULATIVE DAMAGE)}

Miner's rule $\left(\sum \mathrm{n} / \mathrm{N}_{\mathrm{f}}=1\right)$ for fatigue damage accumulation at varying stress levels was used in Ref. 1 for the reference CSM composite, and it was adopted in Part 1 of this report as well. This section describes the justification for that choice.

Three nominal block loading sequences (cycling at one stress level for a fraction of the expected life and then changing to a second stress level for the remainder of life) were examined using specimens from a single plaque (B5). The sequences were as follows.

- $55 / 100 \mathrm{MPa}(6$ duplicate tests)

- $60 / 100 \mathrm{MPa}$ (5 duplicate tests)

- $100 / 60 \mathrm{MPa}$ (5 duplicate tests)

The baseline fatigue curve for plaque B5, based on 25 failure points, is shown in Fig. 12.15. The dashed lines, which bound the data points, indicate that the scatter is relatively large. This makes an evaluation of Miner's rule with just a few tests somewhat tenuous. 


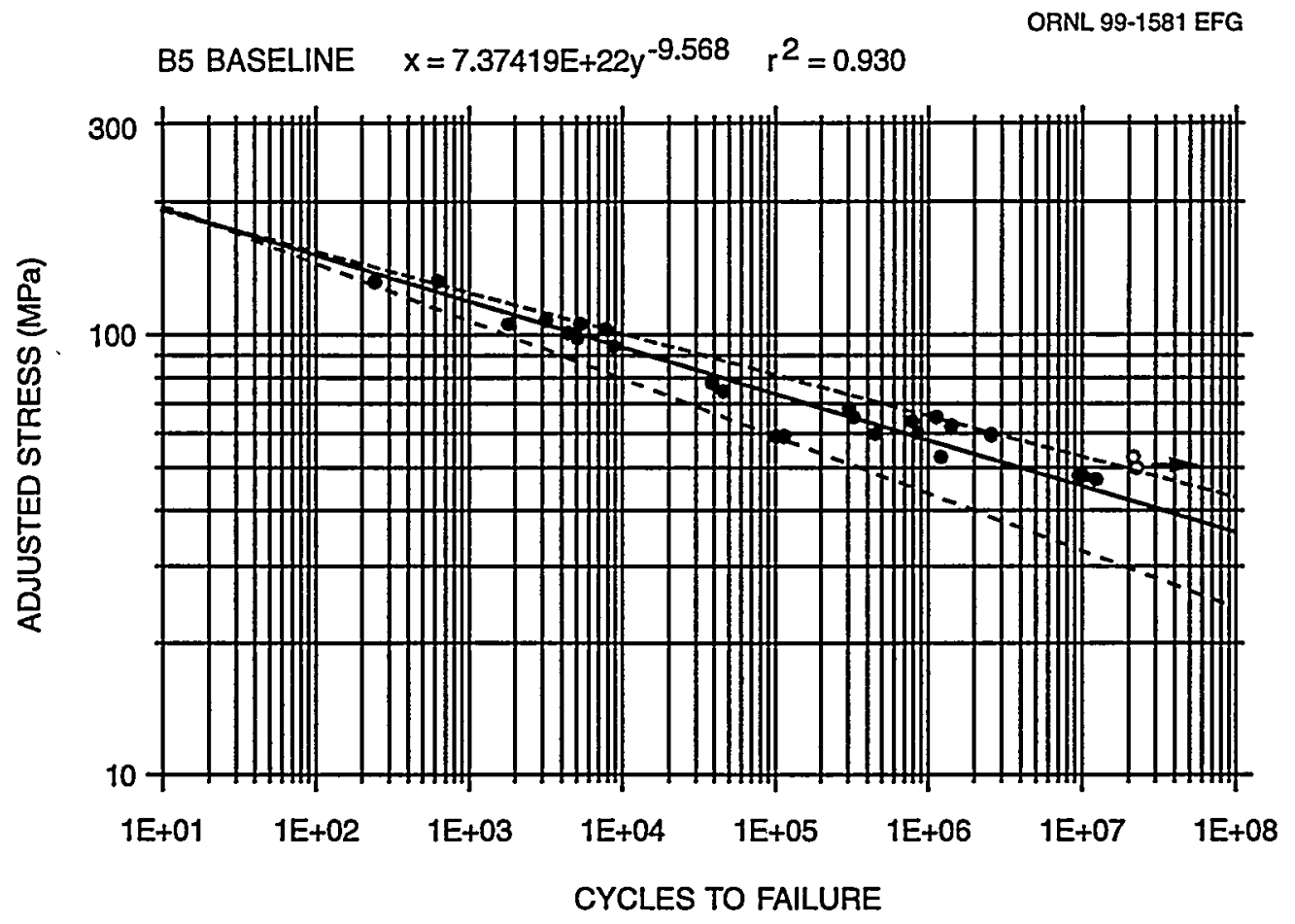

Fig. 12.15. Baseline fatigue curve for plaque B5.

The stress levels given above are the applied stresses. Based on these stress levels and Fig. 12.15, the original intent was to cycle at the first stress level for half of the expected life $\left(\mathrm{n}_{1} / \mathrm{N}_{1}=0.5\right)$. Later the above stress levels were converted to adjusted stresses. This significantly changed $\mathrm{N}_{\mathrm{f}}$ for each specimen and consequently the life fraction for the first loading. This, combined with the inherent data scatter, resulted in some specimens failing during the first loading step, in which case $\mathrm{N}_{2}$ was zero. obtained:

It seemed most logical to use all of these data. The following results were subsequently

\begin{tabular}{|c|c|c|}
\hline Nominal loading & Average $\sum n / N_{f}$ & Range of values \\
\hline $55 / 100$ & 1.57 & 1.36 \\
\hline $60 / 100$ & 1.13 & 1.49 \\
\hline $100 / 60$ & 1.73 & 1.82 \\
\hline
\end{tabular}

Although the statistics are poorer than desired, Miner's rule does appear to be conservative and, in light of the fatigue design margin used, adequate for design. 


\subsection{MEAN STRESS EFFECTS}

To adequately characterize mean stress effects in composites, just for uniaxial loadings, requires an extensive series of tests involving multiple levels of tensile and compressive mean stresses. Such data developed by Owen and Smith ${ }^{11}$ for chopped-strand-mat/polyester-resin laminates indicate that while increasing tensile mean stresses significantly degrade fatigue strength, compressive mean stresses are beneficial at low cyclic stresses and have little effect or are slightly beneficial at high cyclic stresses. Owen and Smith found two failure modes at play: tensile and compressive. The former occurred only when the stress cycle was wholly tensile. If the stress cycle went even slightly into compression, the compressive mode occurred.

For the chopped-fiber/urethane composite, only three types of fatigue cycles were investigated:

- the tension-tension ( $\mathrm{R}=0.1)$ tests discussed in previous sections,

- compression-compression $(\mathrm{R}=10)$ tests, and

- fully reversed, tension-compression $(R=-1)$ tests.

The specially designed specimen used for the latter two test series is described in Ref. 5 .

The results of the compression-compression and fully reversed tests are compared in Fig. 12.16 with the baseline tension-tension data presented earlier in Fig. 12.2. The ordinate is the maximum stress in the tension-tension and fully reversed tests; it is the absolute value of the minimum stress in the compression-compression tests. Plotted on this basis, the compressioncompression and fully reversed fatigue strengths are nearly identical. This may relate to the fact that the specimens of both clearly failed in a compressive mode, as opposed to the tensile mode in which the tensile-tensile specimens failed.

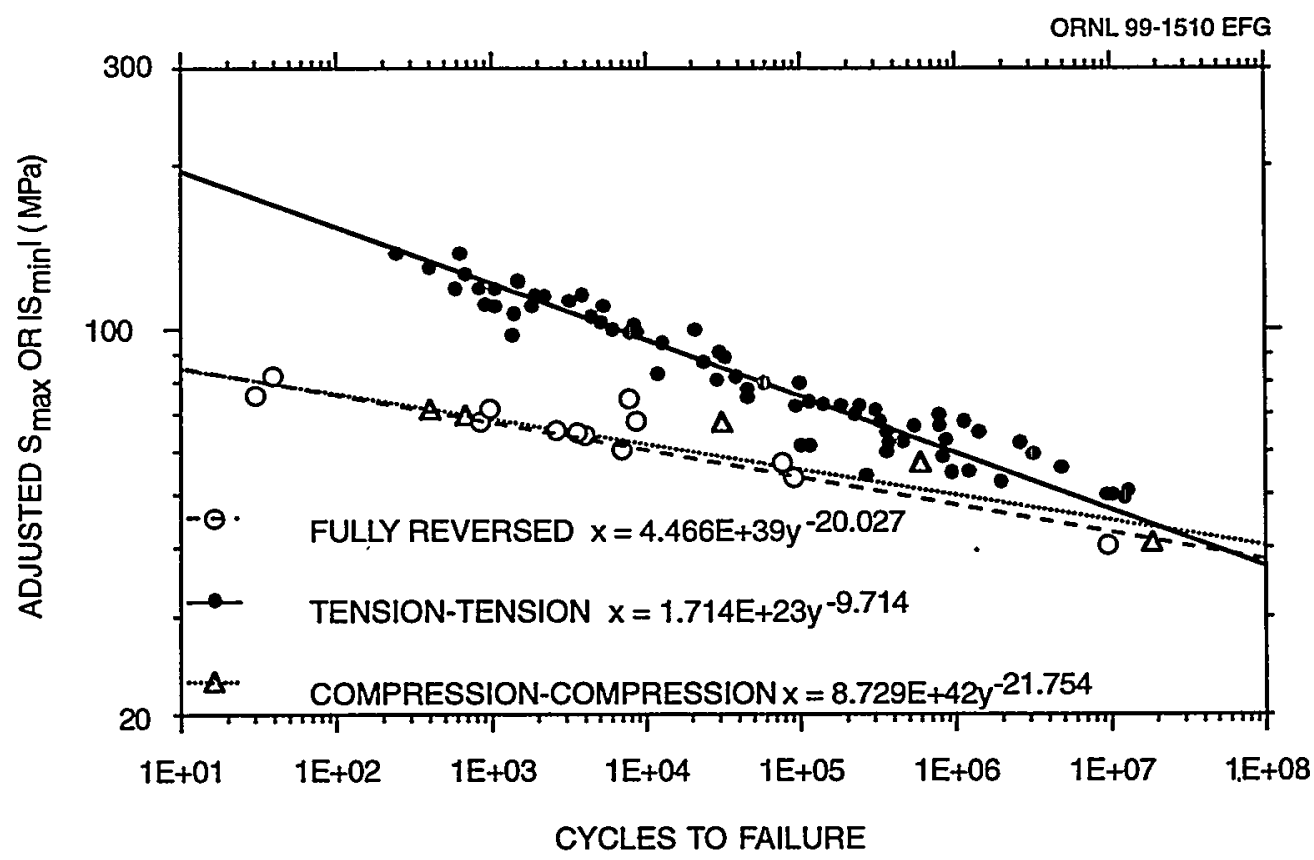

Fig. 12.16. Compression-compression and fully reversed fatigue results compared to tension-tension baseline data. The ordinate for the compression-compression results is the absolute value of the minimum stress. 
Figure 12.17 is a photograph of a typical failed specimen from each group of tests. The maximum applied stresses (or absolute value of the minimum in the compression-compression case) ranged from 36 to $39 \%$ of the UTS for these three specimens. The difference in failure modes is pronounced. Tensile specimens (top) generally exhibited relatively clean, straight-across breaks, with little evidence of "delaminations" on the edges." On the other hand, the compression-compression specimens (middle) and the fully reversed specimens (bottom) exhibited extensive splitting and shearing between fiber layers, as evidenced by the edges of the specimens.

Figure 12.18 plots results from the same tests as in Fig. 12.16, but with the ordinate changed to cyclic stress amplitude $\left[\left(\sigma_{\max }-\sigma_{\min }\right) / 2\right]$. The fully reversed curve is unaffected by this change since the maximum stress and stress amplitude are equal in that case. Clearly, stress amplitude does not correlate the data.

In Refs. 1 and 2 for the reference CSM composite, a modified Goodman relation was used to account for mean stress effects on fatigue life. Three possibilities, originally investigated by Owen and Smith, 12 were examined:

1. Goodman relation:

$$
\sigma_{\mathrm{a}}=\sigma_{\mathrm{o}}\left(1-\frac{\sigma_{\mathrm{m}}}{\sigma_{\mathrm{ult}}}\right) \text {, }
$$

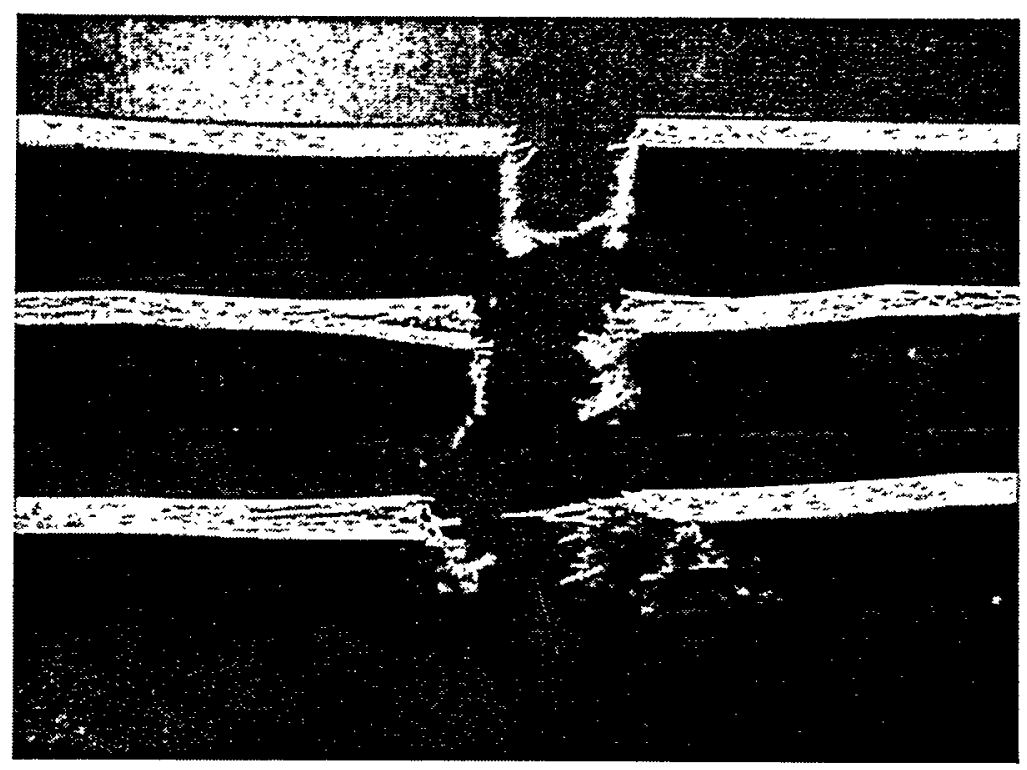

Fig. 12.17. Typical failed fatigue specimens, all tested at a comparable maximum cyclic stress level (absolute value of minimum stress in compression-compression case). Top specimen: tension-tension. Middle specimen: compression-compression. Bottom specimen: fully reversed.

\footnotetext{
${ }^{*}$ The chopped-fiber mats were fabricated in one piece. There were no layers or laminae as such.
} 


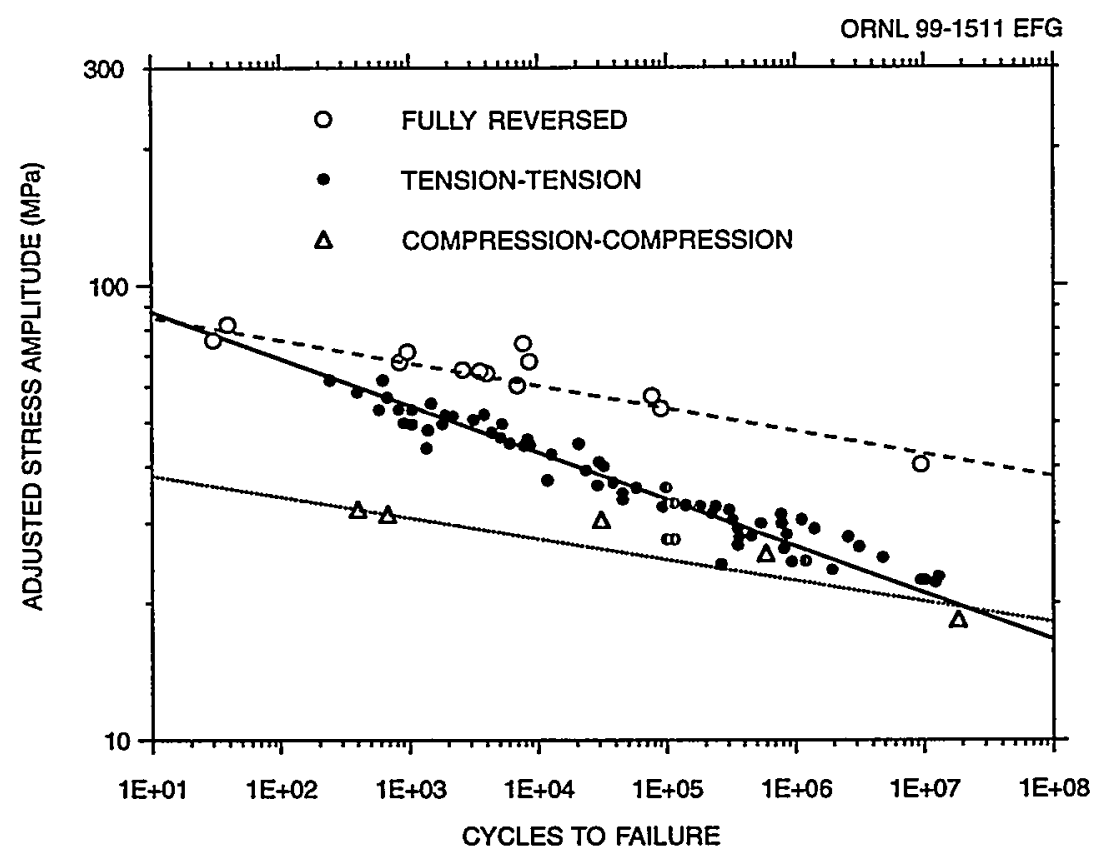

Fig. 12.18. Compression-compression and fully reversed fatigue results compared to tension-tension baseline data, plotted on basis of cyclic stress amplitude.

2. Goodman with creep-rupture strength:

$$
\sigma_{\mathrm{a}}=\sigma_{\mathrm{o}}\left(1-\frac{\sigma_{\mathrm{m}}}{\sigma_{\mathrm{r}}}\right), \text { and }
$$

3. modified Goodman with creep-rupture strength:

$$
\sigma_{\mathrm{a}}=\sigma_{\mathrm{r}}\left(\frac{1-\frac{\sigma_{\mathrm{m}}}{\sigma_{\mathrm{r}}}}{1+\frac{\sigma_{\mathrm{m}}}{\sigma_{\mathrm{r}}}}\right) .
$$

All of these expressions relate the stress amplitude, $\sigma_{\mathrm{a}}$, in a test with a mean stress, $\sigma_{\mathrm{m}}$, in terms of the stress amplitude, $\sigma_{0}$, in a completely reversed, zero mean stress $(R=-1)$ test having the same cyclic life. The second relation is attributed to Boller; Owen and Smith proposed the third relation to add conservatism. These latter two use the creep-rupture strength, $\sigma_{\mathrm{r}}$, corresponding to the test time rather than the short-time ultimate.

With the $R=-1$ curve giving $\sigma_{0}, \sigma_{a}$ for the $R=0$ (assumed the same as $R=0.1$ ) case can be predicted using the Goodman relations. The dashed lines in Fig. 12.19 depict the resulting predictions. The top dashed curve is from the usual Goodman relation, using the UTS. The middle curve is from the Goodman relation with $\sigma_{\mathrm{r}}$ corresponding not to the test time, but to $5000 \mathrm{~h}$, the assumed operating life of an automobile and, hence, the maximum time a structure would be subjected to fatigue cycles. The bottommost curve is from the modified Goodman relation, with $\sigma_{\mathrm{r}}$ again corresponding to $5000 \mathrm{~h}$. 


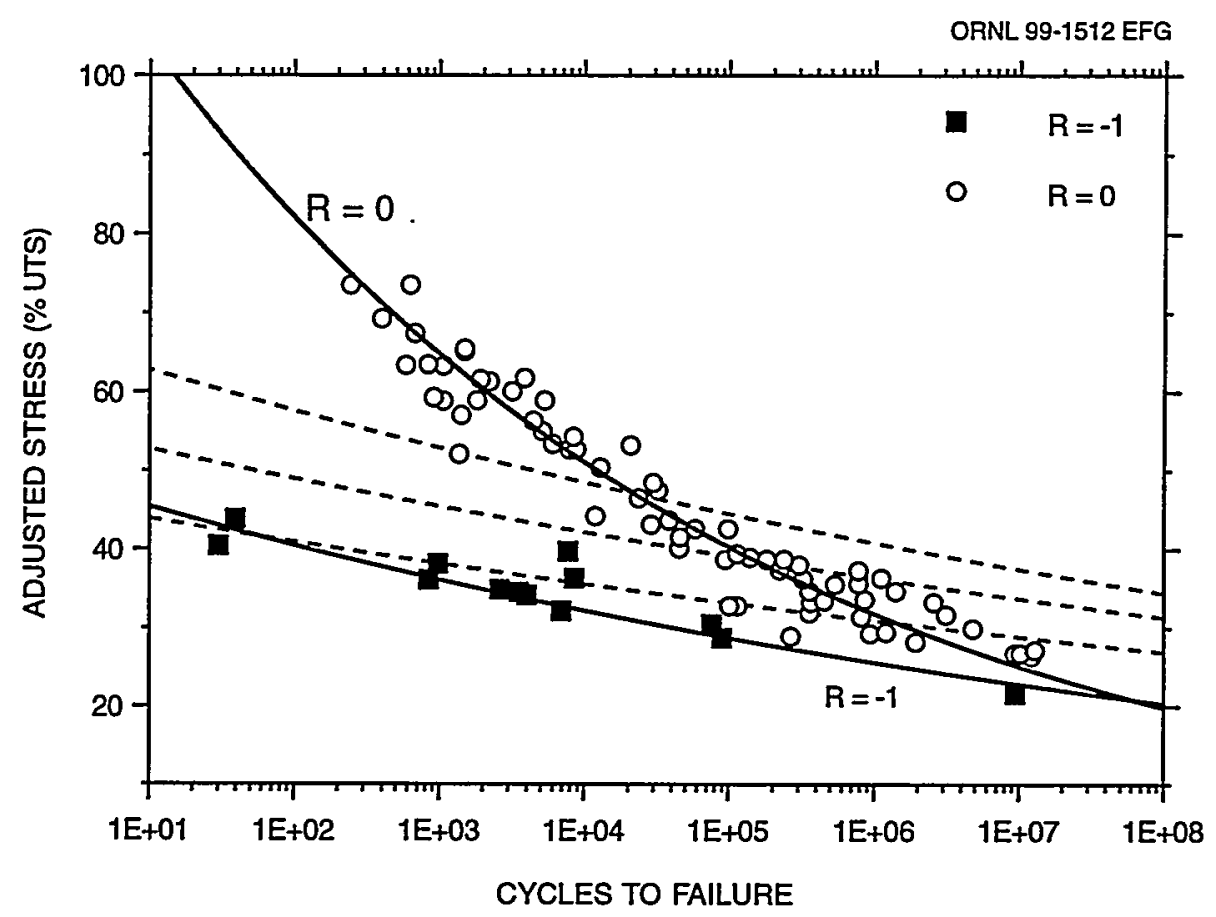

Fig. 12.19. Comparison of Goodman relation predictions with tensile cycling data ( $R=0.1$ assumed to hold for $R=0$ as well). The dashed lines are predictions for $R=0$ based on the $\mathrm{R}=-1$ curve using the following Goodman relations. Top curve: Goodman with UTS, middle curve: Goodman with $\sigma_{\mathrm{r}}$ corresponding to $5000 \mathrm{~h}$, lower curve: Modified Goodman with $\sigma_{\mathrm{r}}$ corresponding to $5000 \mathrm{~h}$.

None of the Goodman relations conservatively predicts the tension-tension data or even qualitatively predicts the nature of the curve. ${ }^{*}$ Thus, another approach is needed.

Conle and Ingall ${ }^{13}$ adapted a parametric stress and fatigue life relationship, developed for metals, to composites. The stress parameter, which simply combines the maximum cyclic stress and the stress amplitude, is

$$
\sqrt{\mathrm{S}_{\max } \cdot \mathrm{S}_{\mathrm{a}}}
$$

Conle and Ingall looked at data from the literature as well as their own data on an automotive composite, XMC polyester/glass. $\dagger$ They found that to use the stress parameter, failure results must be grouped according to failure mode-tension or compression. A separate parameter is needed for each.

Figure 12.20 shows the three sets of data that were plotted in Figs. 12.16 and 12.18 replotted against the parameter $\sqrt{\mathrm{S}_{\max } \cdot \mathrm{S}_{\mathrm{a}}}$ or, in the case of compression-compression cycling, $\sqrt{\left|S_{\max }\right| \cdot S_{a}}$. While the parameter does tend to bring the fully reversed and tension-tension data into better agreement, in an average sense, it pulls the fully reversed and compression-

\footnotetext{
*Owen and Smith ${ }^{11}$ also found that their tension-tension results were "not entirely consistent" with the constant mean stress data.

†Combined chopped fiber and continuous fibers in an "X" pattern.
} 


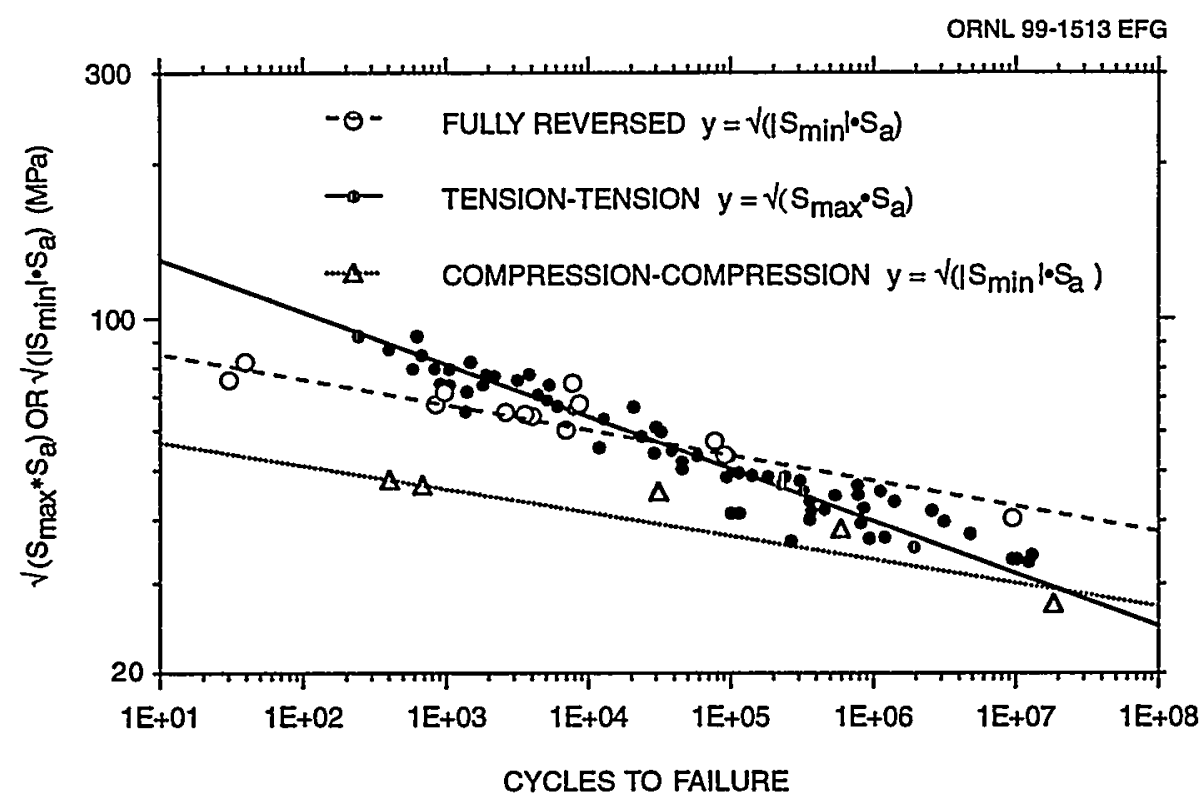

Fig. 12.20. Correlation of fatigue data on basis of stress parameter $\sqrt{S_{\max } \cdot S_{a}} \cdot$ Note that for compression-compression cycling, $\left|S_{\min }\right|$ is used in place of $S_{\max }$.

compression data apart (see Fig. 12.16). Thus, at least two separate treatments are needed here too, depending on whether the failure mode is tension or compression.

In the absence of more data, we will assume that a tensile mean stress of any magnitude leads to a tensile failure mode. A zero or negative mean stress, on the other hand, is assumed to result in failure in a compressive mode. For a positive mean stress, the parameter $\sqrt{\mathrm{S}_{\max } \cdot \mathrm{S}_{\mathrm{a}}}$ should be used. For zero or negative levels of mean stress, it is assumed that $\left|S_{\min }\right|$ governs as in Fig. 12.16.

This separation is used to develop design curves in the next section.

\subsection{DESIGN CURVES}

For cycling with a positive mean stress, it is recommended that the design fatigue curve be based on placing a margin of 20 on cycles to failure and an additional reduction factor of 0.84 (=UTS $\mathrm{Uin}_{\min } / \mathrm{UTS}_{\mathrm{avg}}$ ) on stress. The resulting final design curve is shown in Fig. 12.21. The additional reduction factor on stress is felt to be necessary because of data scatter, especially at the lower stresses. It also will help limit stiffness reductions to values closer to the desired $10 \%$ (see Fig. 12.8). The design margin is meant to cover several uncertainties in addition to data scatter. This additional factor was not used in the case of the reference CSM composite.

For zero and negative mean stresses, an analogously derived design-fatigue curve is shown in Fig. 12.22. The factor of 20 curve is derived from the average fully-reversed curve since it is slightly below the compression-compression curve (see Fig. 12.16). The final recommended design curve again has the additional reduction factor of 0.84 on stress. 


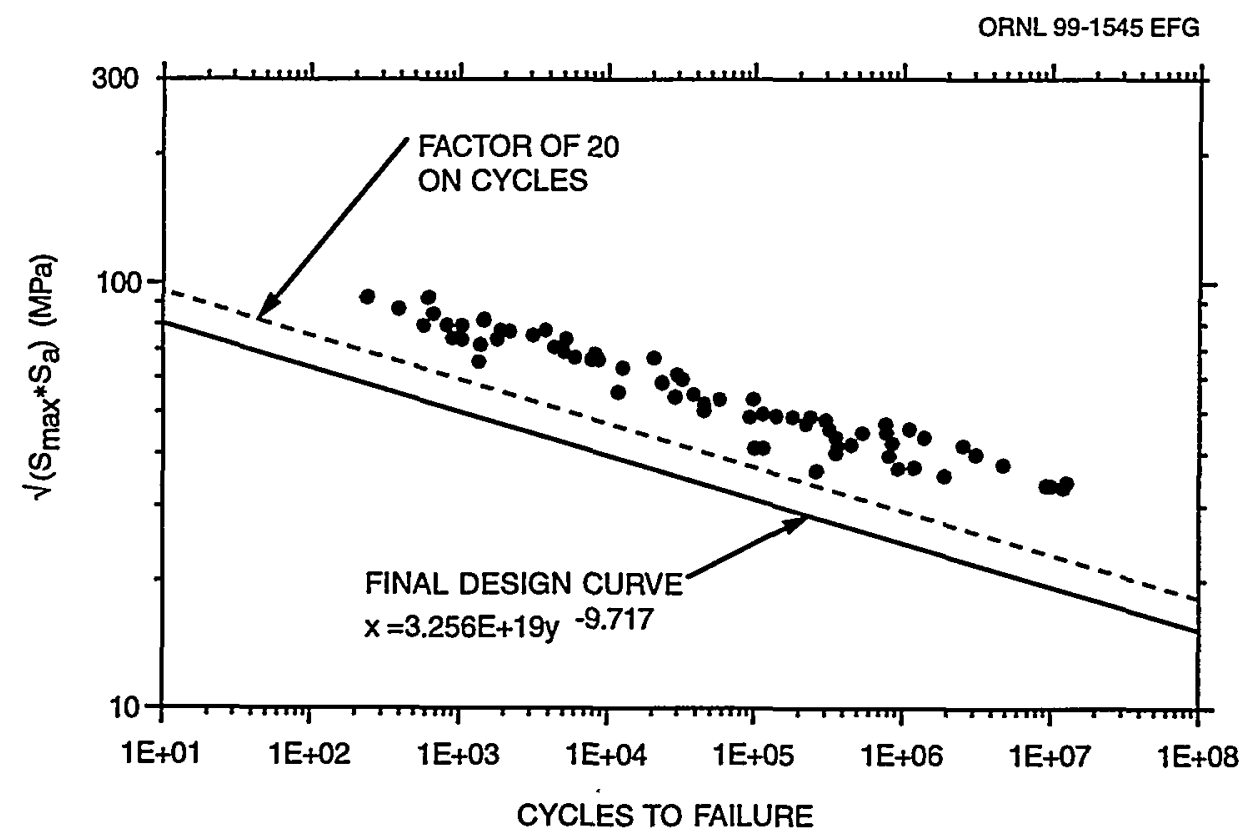

Fig. 12.21. Design fatigue curve for positive mean stresses compared with tensiontension fatigue data.

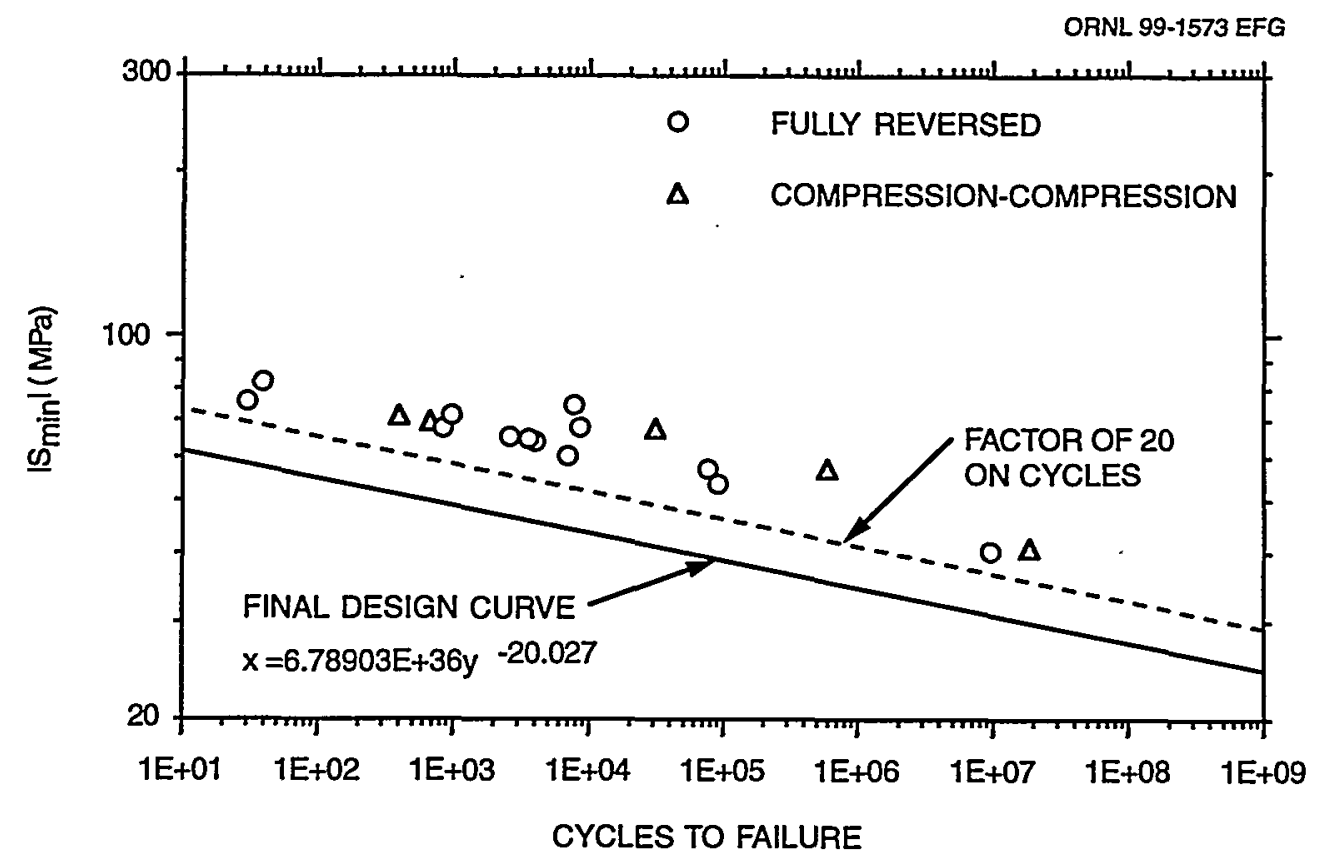

Fig. 12.22. Design fatigue curve for zero or negative mean stresses compared with fully reversed fatigue and compression-compression fatigue data. 


\subsection{SUMMARY AND DISCUSSION}

The room-temperature fatigue strength of the chopped-fiber composite is significantly higher than that of the reference CSM, although the fatigue curves are essentially parallel. Unlike for the reference composite, the chopped-fiber composite's resistance to fatigue cycling goes up with temperature so that at high cycles the $120^{\circ} \mathrm{C}$ fatigue strength is almost equal to that at room temperature. This means that a single fatigue curve with stress expressed as percent of the attemperature UTS cannot be used to represent fatigue at various temperatures, as was done for the reference composite. Factors on the room-temperature fatigue curve are recommended for this purpose.

Two fluid environments-water and windshield washer fluid (70\% methanol/30\% water)-were examined. The resistance to both is greater for the chopped-fiber composite than for the reference CSM composite. As was the case for elevated temperatures, environmental fatigue strength reduction factors go up with increasing cycles to failure. At $10^{8}$ cycles, the worst environment-water saturation-leads to a reduction factor of only 0.91 .

As was the case for the reference composite, Miner's rule $\left(\sum n / N_{f}=1\right)$ for failure under different loadings appears adequate. Block loading test sequences all led to average life-fraction summations greater than 1.0 .

The treatment of mean stress effects for the chopped-fiber composite was more involved than it was for the reference composite. For the latter, a modified form of Goodman's relation was judged to be adequate. That was not the case for the chopped-fiber composite, where two different stress parameters were found to be necessary. When the failure mode is tensile, the parameter $\sqrt{S_{\max } \cdot S_{a}}$, where $S_{a}$ is the alternating stress, is recommended. For a compression failure mode, $\left|S_{\min }\right|$ is recommended. It was assumed that positive mean stresses always lead to the tensile failure mode, while zero and negative mean stresses lead to the compressive failure mode. Since other failure modes, e.g., shear, might require additional parameters, design application is tenuous without further relevant data.

Finally, design curves for these two cases were developed. In each case, a margin of 20 was first applied on cycles to failure, followed by an additional reduction factor of 0.84 (=UTS $\mathrm{Uin}_{\min } / \mathrm{UTS}_{\mathrm{avg}}$ ), which was judged necessary to handle data scatter. The additional factor, which was not thought necessary for the reference composite, also helps limit stiffness reductions during cycling to values closer to the desired $10 \%$. 


\title{
13. CREEP DEFORMATION
}

\author{
W. Ren and C. R. Brinkman
}

\subsection{INTRODUCTION}

This chapter is dedicated to development of creep deformation models for the choppedfiber/Baydur $420 \mathrm{IMR} / \mathrm{P} 4$ composite. All the models are based on experimental data generated in representative automotive service environments, which were selected based on the previous investigation of the reference material. 2,14 The representative environments included air with a nominal $50 \%$ relative humidity (air/50\%RH), distilled water immersion, and windshield washer fluid immersion. The test temperatures ranged from -40 to $120^{\circ} \mathrm{C}$, but not in all environments. Because the mechanical response of the material is sensitive to loading rate, all tests were loaded at a constant nominal strain rate of $0.04 / \mathrm{min}$. $\left(6.7 \times 10^{-4} / \mathrm{s}\right)$. A total of 131 tests were conducted. The experimental results were analyzed, and only those within the stress-strain linear range were employed to develop creep deformation models. In the application of these models, two conditions should always be kept in mind:

1. The models represent the average creep deformation behavior of the material.

2. The models represent the creep deformation as if creep-rupture would not occur.

The first condition is based on the fact that significant scatter was observed in the experimental data, mostly resulting from local variation of fiber content. The models were developed in an attempt to represent the average creep deformation behavior of the material, and this average was restricted to the number of tests conducted for a given test condition for this investigation. An effort was also made to minimize the data scatter by multiplying the strain by a normalization factor as follows:

$$
\text { normalized strain }=\text { strain } \times \mathrm{E}_{\text {specimen }} / \mathrm{E}_{\text {average }} \text {, }
$$

where

$$
\begin{aligned}
\mathrm{E}_{\text {specimen }} & =\text { Young's modulus of the specimen at } 23^{\circ} \mathrm{C}, \\
\mathrm{E}_{\text {average }} & =\text { average Young's modulus of the material at } 23^{\circ} \mathrm{C} .
\end{aligned}
$$

The average Young's modulus value used was $11.7 \mathrm{GPa}{ }^{*}$

The second condition is also related to the data scatter. Since creep-rupture under the same test condition occurred at various times, the creep deformation models were based on the assumption that rupture had not occurred. Therefore, the deformation models should be applied with the consideration of creep-rupture life, which is described in Chap. 14.

Since automotive design requires a 15 -year service life with 3000 - to 5000 -h operating times, and the tests in the present investigation were conducted for less than 1 year, design margins must be relied on to cover the resulting uncertainty.

\footnotetext{
*This differs slightly from the final average of $11.8 \mathrm{GPa}$ given in Chap. 8.
} 


\subsection{BASELINE CREEP DEFORMATION}

\subsubsection{Creep Deformation Data in Air with 50\% RH at Room Temperature Under Tension}

Air with a nominal $50 \% \mathrm{RH}$ level ${ }^{*}$ at room temperature $\left(23^{\circ} \mathrm{C}\right)$ under tension was used as the baseline test condition, with which results from the other test environments were compared. Totally, 33 specimens from plaques B2, B3, and B9 were tested in this condition, and of these 33 tests, 21 were within the stress-strain linear range and were employed for creep deformation modeling.

Part of the baseline creep deformation data is presented in Fig. 13.1. Although data scatter exists, the results indicate that the creep strain increases approximately proportionally to the stress for tests at $125 \mathrm{MPa}$ and below.

\subsubsection{Linearity, Data Reduction, and Model Development}

For linear deformation to occur, the following two conditions should be satisfied:

1. Strain is proportional to stress.

2. Strain is completely recovered after the stress is removed.

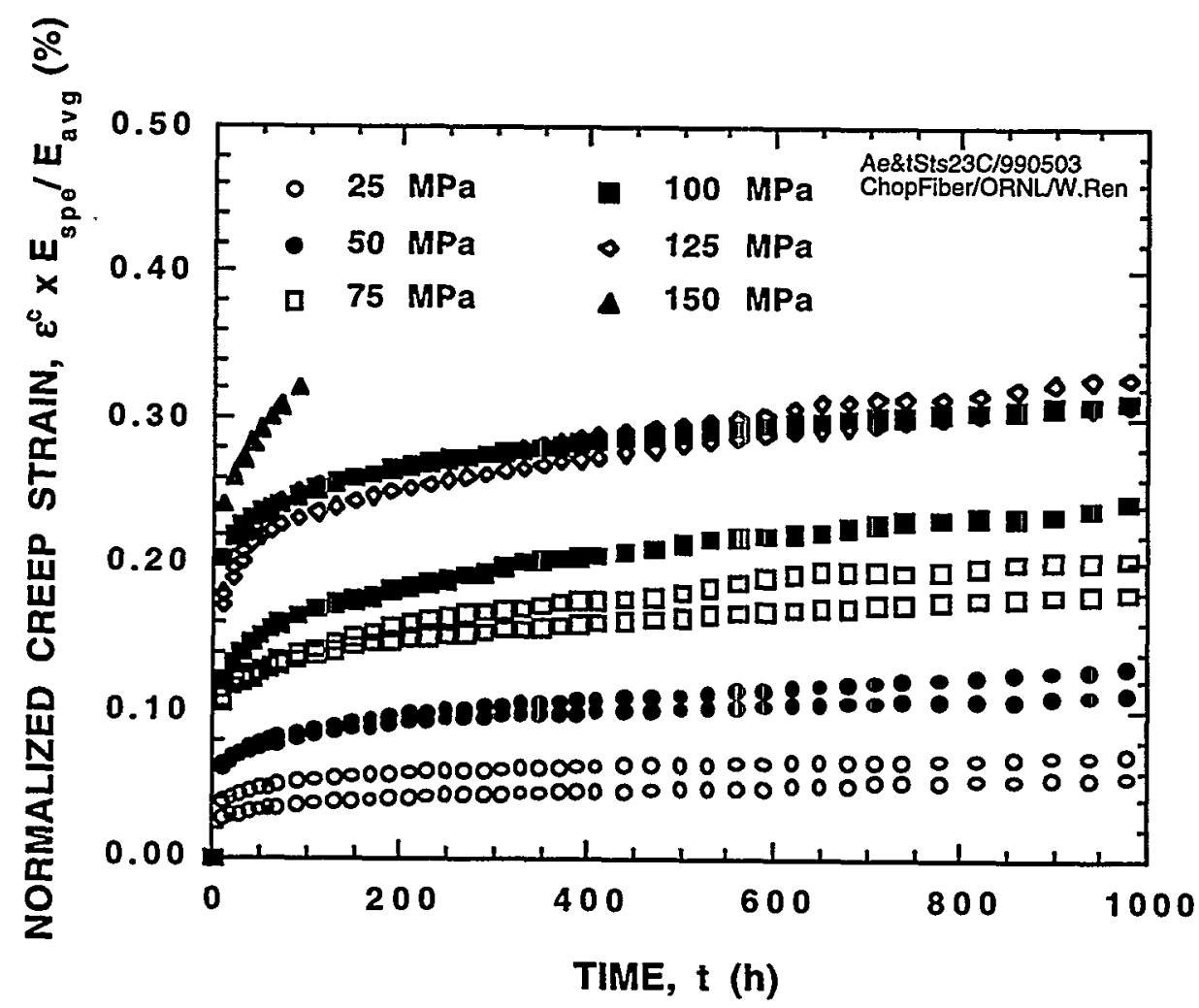

Fig. 13.1. Part of the experimental time-dependent creep deformation data for the baseline condition. It is seen that creep strain increases approximately proportionally to the stress for tests at $125 \mathrm{MPa}$ and below.

\footnotetext{
${ }^{*}$ Lab humidity was not precisely controlled but averaged about $50 \%$.
} 
To develop models for a practical design guideline, linearity was specifically defined for this investigation to satisfy only the first condition. This moves the linearity limit higher than that defined by both conditions.

To conduct data reduction and model development, a general equation for timedependent creep strain as a function of stress, time, and temperature was adopted as follows:

$$
\varepsilon^{c}(\sigma, t, T)=K f(\sigma) G(t) F(T)
$$

where $f(\sigma), G(t)$, and $F(T)$ are stress, time, and temperature functions, respectively. The quantity $\mathrm{K}$ is the environmental factor, which can be a constant or a function of stress and temperature. Equation (13.2) must satisfy

$$
f(0)=0, \quad G(0)=0, \quad F\left(T_{0}\right)=1,
$$

where $T_{o}$ is a reference temperature. The creep deformation models were developed by obtaining proper functions and values for Eq. (13.2) based on experimental results from various testing conditions.

From the linear relationship between stress and strain observed in Fig. 13.1, the stress function $f(\sigma)$ can be expressed as a simple linear function. The time function $G(t)$ is known from experience to normally be a simple power law for creep. It was possible to express $F(T)$ in a form that resembles the WLF equation. ${ }^{*}$ Consequently, the terms in Eq. (13.2) are given as follows:

$$
\begin{gathered}
f(\sigma)=C \sigma \\
G(t)=t^{\beta} \\
F(T)=\exp \left[\frac{C_{1}\left(T-T_{o}\right)}{C_{2}+T-T_{o}}\right],
\end{gathered}
$$

where $C, \beta, C_{1}$, and $C_{2}$ are constants that are to be specified, as well as $T_{0}$ and $K$, based on experimental data.

To determine $C, \beta, C_{1}, C_{2}, T_{0}$, and $K$ for the baseline condition, the baseline temperature, $\mathrm{T}_{\mathrm{o}}=535^{\circ} \mathrm{R}\left(23^{\circ} \mathrm{C}\right)$, was specified as the reference temperature, and the environmental factor was given a value $\mathrm{K}=1$ for air $/ 50 \% \mathrm{RH}$. Then Eq. (13.2) can be written ás follows:

$$
\varepsilon^{c}=\mathrm{C} \sigma \cdot \mathrm{t}^{\beta}
$$

Dividing both sides by the stress yields:

$$
\varepsilon^{\mathrm{c}} / \sigma=\mathrm{Ct}^{\beta}
$$

If the linear relationship observed in Fig. 13.1 is true, the data at and below $125 \mathrm{MPa}$ should satisfy Eq. (13.8) and be plotted as a single power law curve that represents the creep strain caused by a unit stress, i.e., creep compliance, as a function of time. relationship.

${ }^{*}$ Note that the form of Eq. (13.2) does not comply with the standard format of a time-temperature shift factor 
Figure 13.2 gives the experimental data in the form of creep compliance $\varepsilon^{\mathrm{c}} / \sigma$ vs time t. All the data in Fig. 13.2 fall within an error band of $\Delta \varepsilon^{c} / \sigma=0.0017 \%$. There is no clear trend with stress in these data. The upper-band limit is the data for $62.5 \mathrm{MPa}$ instead of the highest stress of $120 \mathrm{MPa}$, while the lower limit is for $37.5 \mathrm{MPa}$ instead of the lowest stress of $25 \mathrm{MPa}$. This indicates that the error band is largely a result of data scatter The average creep deformation behavior within the linear range was thus represented by averaging all the compliance curves. A least-squares fit of the average curve for Eq. (13.8) yielded $C=9.59 \times 10^{-4}$ and $\beta=0.141$ to give Eq. (13.9).

$$
\varepsilon^{\mathcal{C}} / \sigma=9.59 \times 10^{-4} \mathrm{t}^{0.141}
$$

The creep deformation model for various stresses within the linear range can then be obtained by multiplying both sides of Eq. (13.9) by stress $\sigma$ :

$$
\begin{gathered}
\varepsilon^{c}=9.59 \times 10^{-4} \sigma t^{0.141} . \\
\sigma \leq 125 \mathrm{MPa} .
\end{gathered}
$$

Equation (13.10) is plotted in Fig. 13.3 with the average experimental data. Good agreement between the model and the data is obvious.

Only the experimental data up to $1000 \mathrm{~h}$ of testing were employed in developing Eq. (13.10) and are presented in Fig. 13.3. The tests actually continued for about seven more

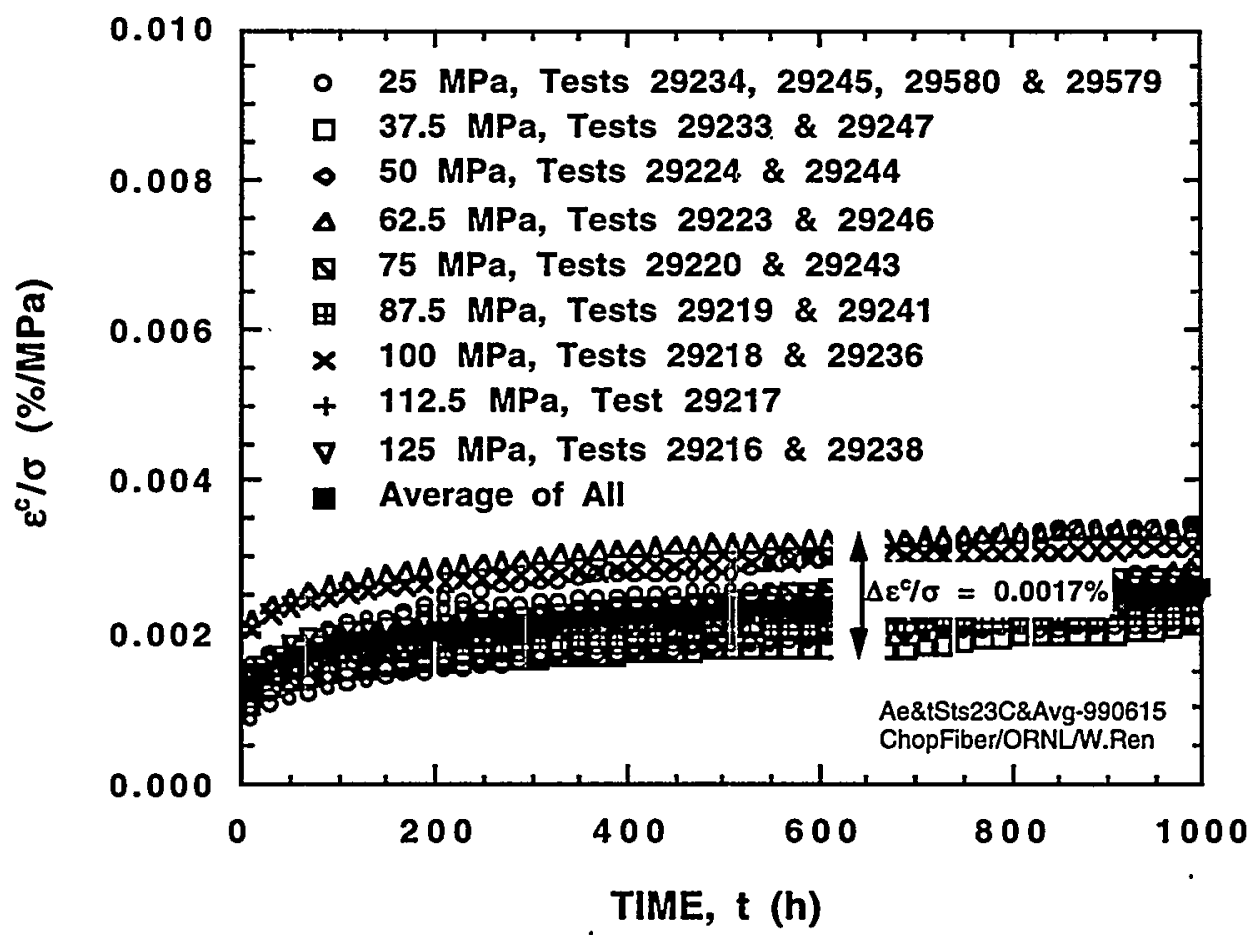

Fig. 13.2. Experimental data for the baseline condition in the form of timedependent creep compliance $\varepsilon / \sigma$ vs time $t$. 


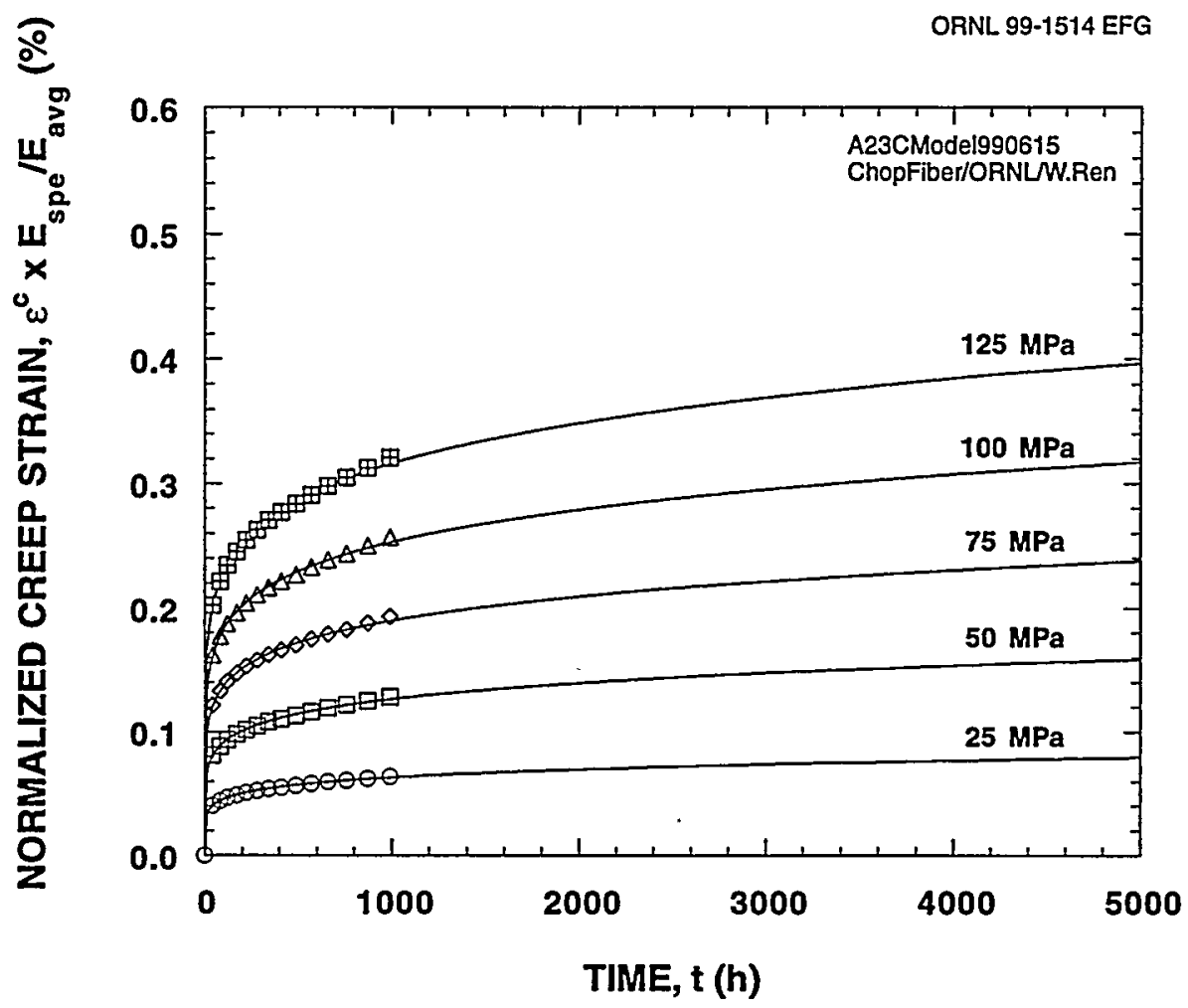

Fig. 13.3. Creep deformation model and average experimental data for the baseline condition.

months. Abnormal creep deformation variations were observed after more than $1000 \mathrm{~h}$ of testing; these are believed to be caused by seasonal humidity and temperature variations because the deformation variations coincided with the local weather profile. Therefore, these should be represented in the environmental effects section later in this chapter.

Since Eq. (13.9) and its curve represent the elementary baseline creep deformation behavior of the material, it was used as the basis for comparison with the curves for other test environments.

\subsection{TEMPERATURE EFFECTS IN AIR}

\subsubsection{Creep Compliance at Various Temperatures}

Temperature effects on creep deformation in air were investigated for $-40,50$, and $120^{\circ} \mathrm{C}$ to compare with the baseline. For tests at $-40^{\circ} \mathrm{C}$, samples were cooled in a chamber with liquid nitrogen vapor. For tests at 50 and $120^{\circ} \mathrm{C}$, the specimens were heated by heating tape wrapped around and then covered with insulation cloth.

Curves for average creep compliance as a function of time at various temperatures developed from the experimental data are presented in Fig. 13.4. The general trend of creep deformation increasing with temperature is obvious. However, note that the curve for $50^{\circ} \mathrm{C}$, although slightly higher than that for $23^{\circ} \mathrm{C}$, is actually comparable to that for $23^{\circ} \mathrm{C}$ within the $23^{\circ} \mathrm{C}$ error band. It is believed that the less-than-expected increase in creep deformation at $50^{\circ} \mathrm{C}$ 


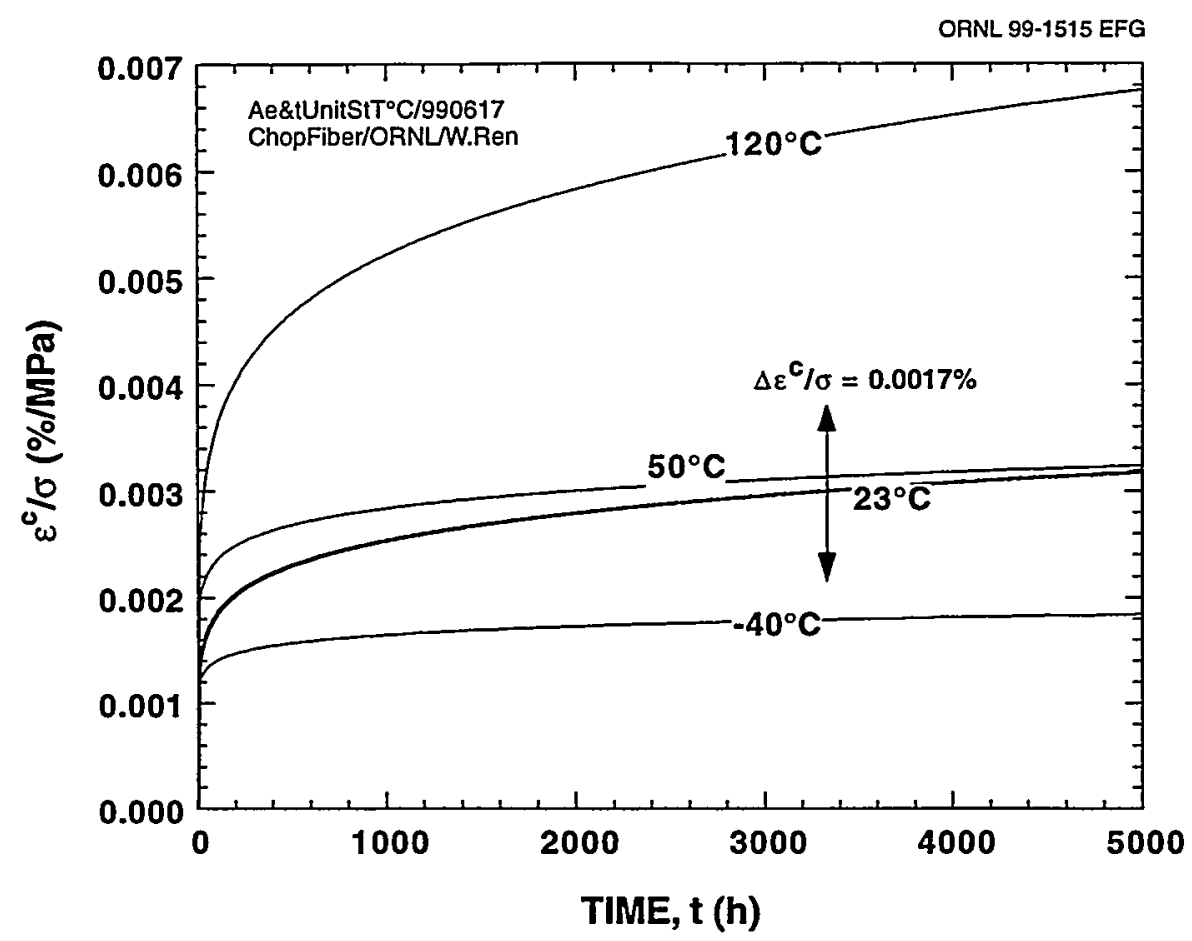
temperatures.

Fig. 13.4. Average measured creep compliance as a function of time for various

was caused by its dry specimen condition. All the specimens for elevated temperature tests were heated overnight before loading for the temperature to become stabilized. It is quite understandable that the specimens inevitably were dried during this process. The previous investigation of the reference material indicated that dry conditions tend to reduce creep deformation. ${ }^{2}$

To obtain the values of $\mathrm{C}_{1}$ and $\mathrm{C}_{2}$ in Eq. (13.6) for temperature effects, another two temperatures, -40 and $120^{\circ} \mathrm{C}$, far apart from the baseline temperature of $23^{\circ} \mathrm{C}$, were employed to emphasize the temperature-dominated mechanisms in the creep deformation. The required automobile operating time $(5000 \mathrm{~h})$ was also used in developing the model. By applying creep strain values at $5000 \mathrm{~h}$ at $-40,23$, and $120^{\circ} \mathrm{C}$ to Eqs. (13.2) and (13.6), the values of $\mathrm{C}_{1}$ and $\mathrm{C}_{2}$ were determined to be

$$
\mathrm{C}_{1}=12 \text { and } \mathrm{C}_{2}=2698 \text {. }
$$

With these values of $C_{1}$ and $C_{2}$, the temperature function $F(T)$ in Eq. (13.6) is plotted in Fig. 13.5, and temperature factors for various temperatures can thus be directly read from the plot. The solid circles in Fig. 13.5 represent the temperatures at which tests were conducted.

The creep compliance at various temperatures directly derived from the test data and calculated from Eq. (13.2) with the parameters obtained above are presented in Fig. 13.6 using solid and dashed lines, respectively. Note that the calculated curve for $50^{\circ} \mathrm{C}$ is higher than that directly derived from the test data. This indicates that the creep deformation at $50^{\circ} \mathrm{C}$ should be greater than the test curve if the same humidity for $23^{\circ} \mathrm{C}$ was maintained in the specimens at $50^{\circ} \mathrm{C}$. 
ORNL 99-1516 EFG

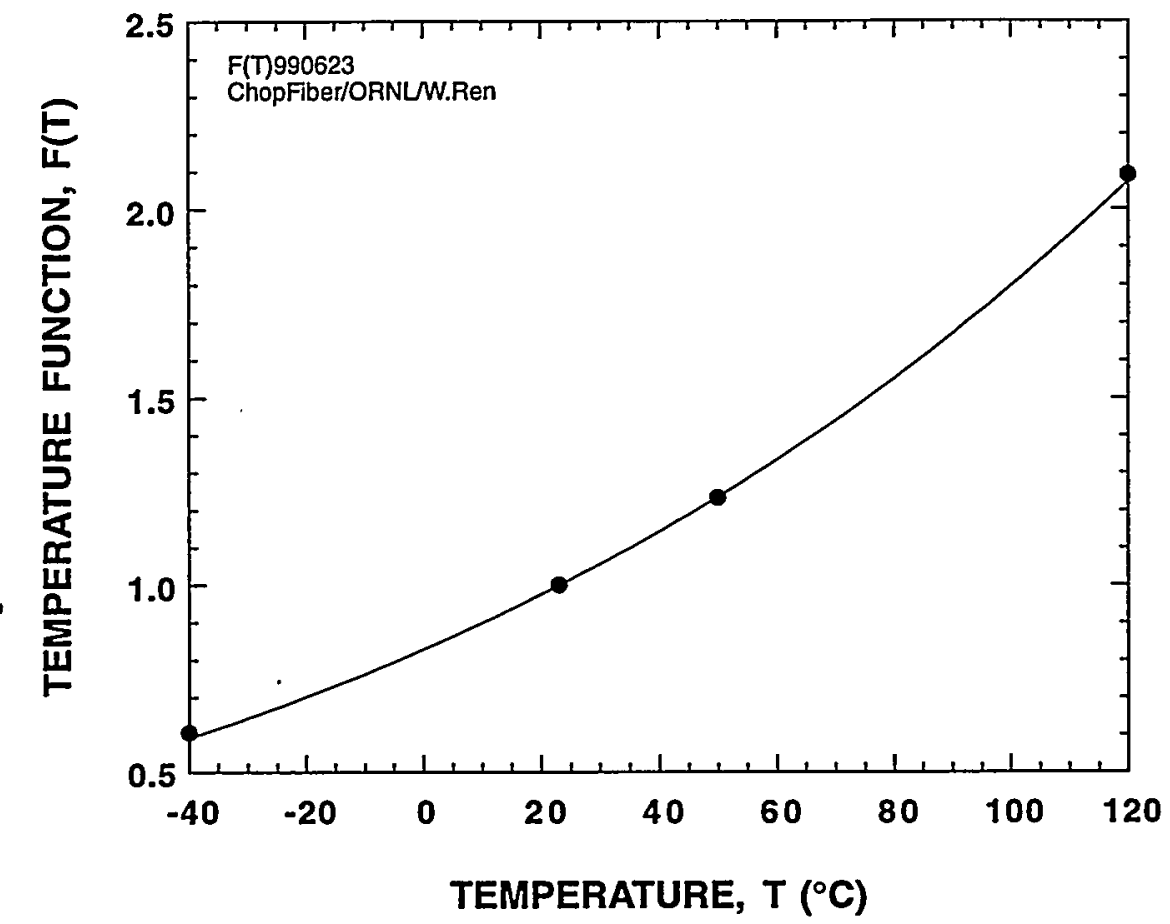

Fig. 13.5. Temperature function $F(T)$ for creep deformation.

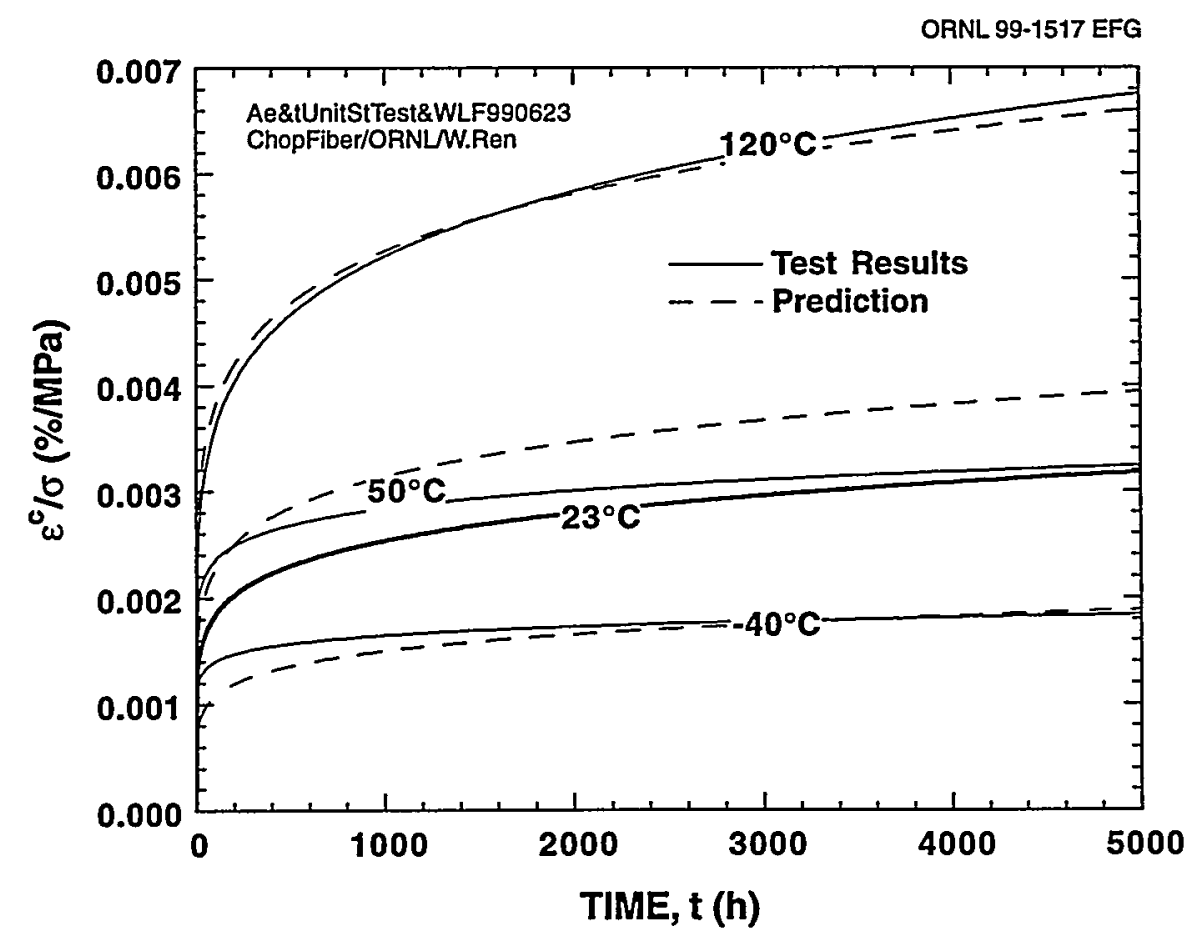

Fig. 13.6. Creep compliance at various temperatures directly derived from the test data (solid lines) and calculated from Eq. (13.2) (dashed lines). 


\subsubsection{Creep Deformation Models for Various Temperatures}

With the parameters obtained above, Eq. (13.2) can be presented as follows:

$$
\varepsilon^{c}=9.59 \times 10^{-4} \sigma \mathrm{t}^{0.141} \cdot \exp \left[\frac{12 \cdot\left(\mathrm{T}-\mathrm{T}_{\mathrm{o}}\right)}{2698+\mathrm{T}-\mathrm{T}_{\mathrm{o}}}\right]
$$

where $\sigma \leq 125 \mathrm{MPa}$, the unit for creep strain $\varepsilon^{c}$ is $\%$, stress $\sigma \mathrm{MPa}$, and temperature T Rankine $\left({ }^{\circ} \mathrm{R}={ }^{\circ} \mathrm{C} \times 9 / 5+492\right)$. Creep curves for various stresses at $-40,50$, and $120^{\circ} \mathrm{C}$ predicted using Eq. (13.12) are given in Figs. 13.7-13.9 along with test data. The curves for $23^{\circ} \mathrm{C}$ are the same as presented in Fig. 13.3. For $50^{\circ} \mathrm{C}$, since the test data were actually from dry specimens as discussed above, they are obviously lower than the predicted curves as shown in Fig. 13.8. It can also be noted in Fig. 13.9 for $120^{\circ} \mathrm{C}$ that the test data at $75 \mathrm{MPa}$ tend to become higher than the predicted curve when approaching $5000 \mathrm{~h}$. That is the onset of tertiary creep, which will be discussed in the next section.

\subsubsection{Tertiary Creep at $120^{\circ} \mathrm{C}$}

Although little was observed at low temperatures, tertiary creep deformation became very noticeable at $120^{\circ} \mathrm{C}$, especially at low stresses. Test results indicated that at high stresses, tertiary creep was not obvious because rupture immediately followed. However, at stresses of $75 \mathrm{MPa}$ and lower, tertiary creep occurred without immediate rupture, and the creep deformation doubled. Figure 13.10 presents experimental creep strain curves at $120^{\circ} \mathrm{C}$ for low stresses. It can be

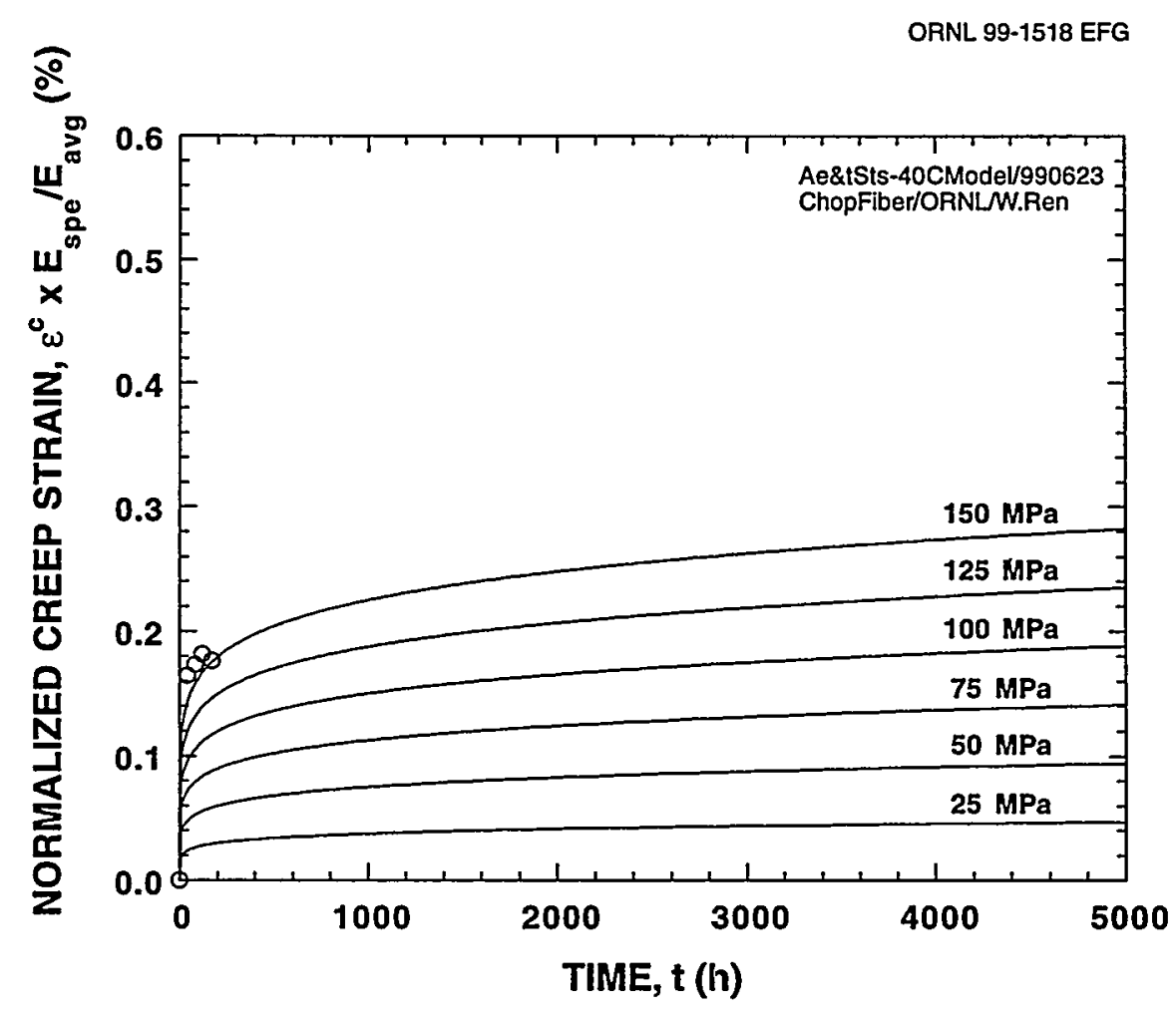

Fig. 13.7. Creep deformation curves predicted from the model and average experimental data for $-40^{\circ} \mathrm{C}$ under various stresses in air. The data are for $150 \mathrm{MPa}$. 


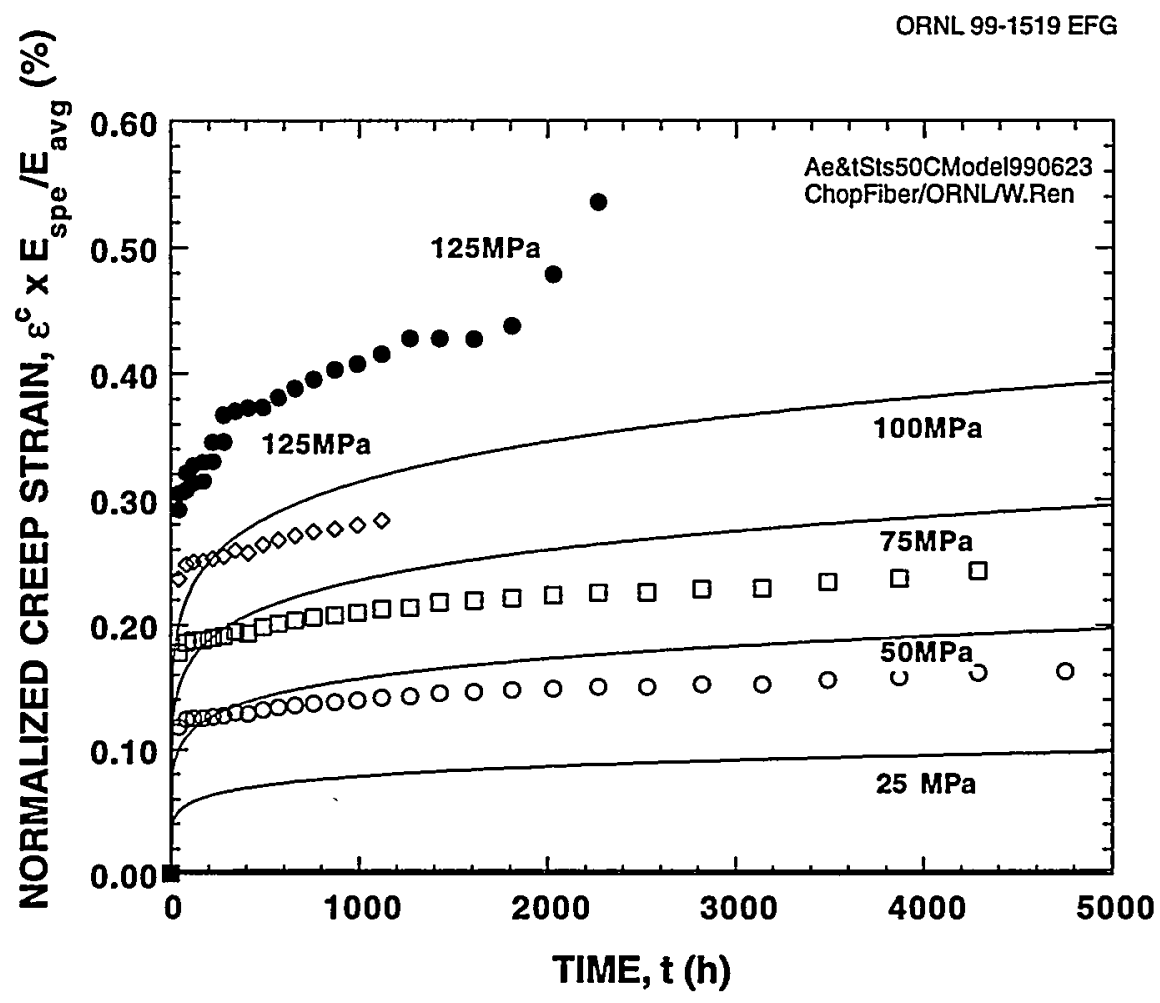

Fig. 13.8. Creep deformation curves predicted from the model and average experimental data for $50^{\circ} \mathrm{C}$ under various stresses in air.

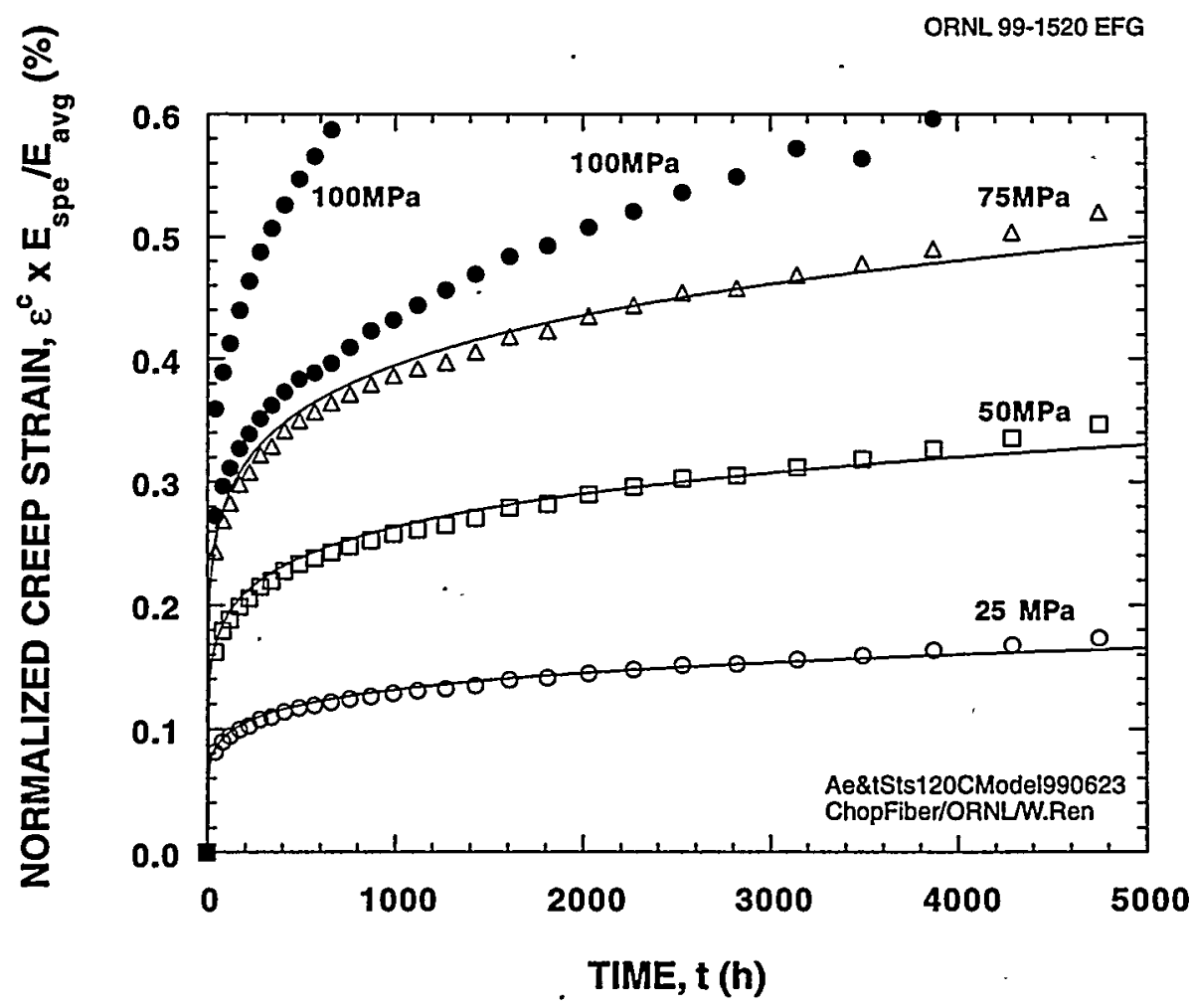

Fig. 13.9. Creep deformation curves predicted from the model and average experimental data for $120^{\circ} \mathrm{C}$ under various stresses in air. 


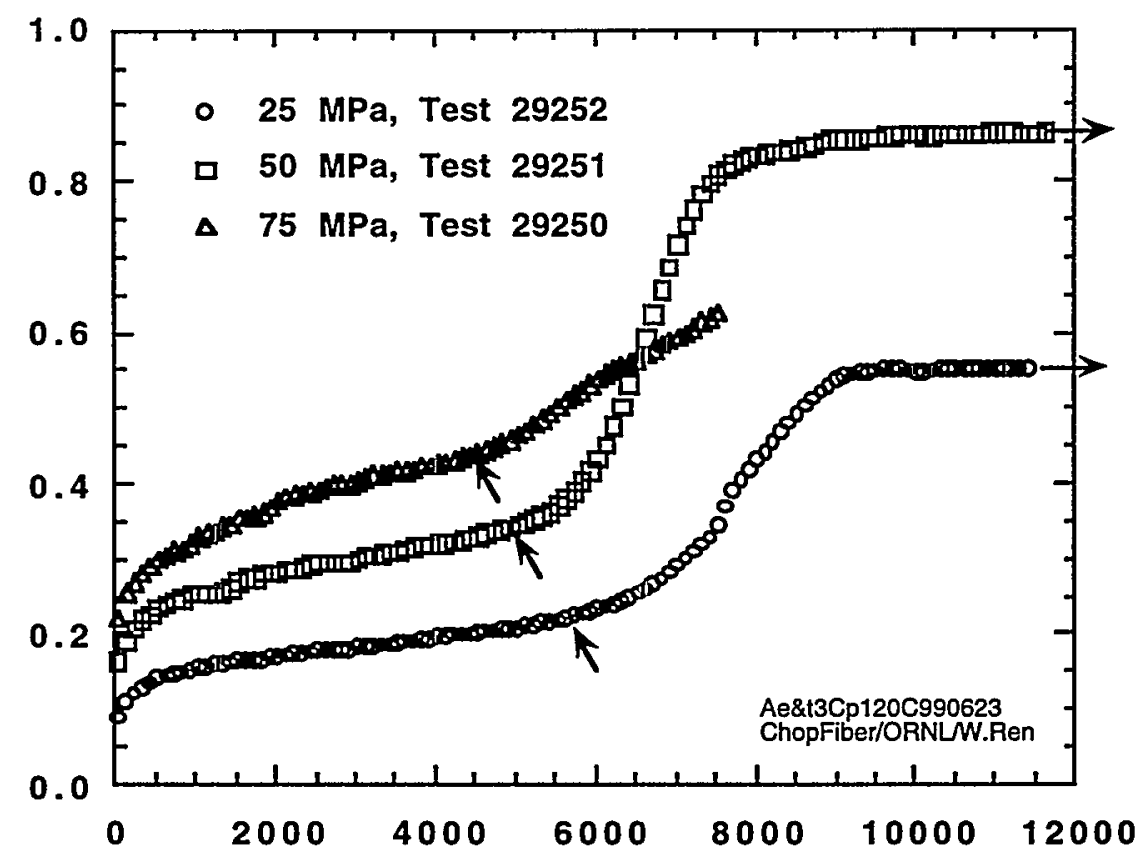

TIME, $\mathbf{t}(\mathbf{h})$

Fig. 13.10. Tertiary creep becomes obvious at $120^{\circ} \mathrm{C}$ under low stresses.

observed that the lower the stress, the later the tertiary creep initiates, and the longer it continues without rupture. Tertiary creep deformation may slow down as shown in the curves for 25 and $50 \mathrm{MPa}$. It is possible that the tertiary creep is caused by degradation mechanisms such as microcrack growth, fiber pull out, etc. The high rate tertiary creep and its slowing down probably reflect the presence of damage growth and damage arrest mechanisms within the composite.

For automotive structural component applications, the material is unlikely to be subjected to continuous load at $120^{\circ} \mathrm{C}$. Therefore, tertiary creep deformation may not become a serious design problem for $120^{\circ} \mathrm{C}$. However, since it can occur at very low stresses, it should still be treated with caution in design.

Another reason for the concern about tertiary creep is that it may occur after very long times at lower temperatures. In an analysis using the Time-Temperature Superposition Principle (TTSP), the time at which tertiary creep may occur at $25 \mathrm{MPa}$ and room temperature ranged from nine to several hundred years. The 9-year prediction falls within the 15 -year service life and is therefore of concern. The reason for this significant range uncertainty is that the shifting operation is performed on the log scale. A small amount of experimental data scatter can cause an error band of several decades in the predicted time. Unfortunately, data scatter is normally significant in random-fiber composites due to the inevitable local variation of fiber content. 


\subsection{ENVIRONMENTAL EFFECTS}

\subsubsection{Creep Compliance in Various Environments}

Environmental effects on creep deformation investigated included distilled water immersion at 23 and $50^{\circ} \mathrm{C}$ and windshield washer fluid immersion at $23^{\circ} \mathrm{C}$. All the specimens were presoaked before being loaded to ensure initial fluid absorption. Two kinds of presoak were performed. The short-term presoak was conducted by immersing the specimens in the fluids at $23^{\circ} \mathrm{C}$ for $100 \mathrm{~h}$, while the long-term presoak, only applied to distilled water, was at $50^{\circ} \mathrm{C}$ for 3 months.

The creep compliance curves for the above environments are compared with that for the baseline condition in Fig. 13.11. As expected, creep compliance increases in the order of $23^{\circ} \mathrm{C} / \mathrm{Air} / 50 \% \mathrm{RH}$, distilled water immersion at $23^{\circ} \mathrm{C}$ with short-term presoak, distilled water immersion at $50^{\circ} \mathrm{C}$ with long-term $50^{\circ} \mathrm{C}$ presoak, and windshield washer fluid immersion at $23^{\circ} \mathrm{C}$ with short-term presoak. The unexpected observation is that the curve for distilled water at $23^{\circ} \mathrm{C}$ with long-term $50^{\circ} \mathrm{C}$ presoak falls below that of the baseline after about $230 \mathrm{~h}$, making it slightly lower but still comparable to that of the baseline within the baseline error band. There are two possibilities that may have caused such observations. One is that the matrix was'chemically or micromechanically changed during the long-term presoak at $50^{\circ} \mathrm{C}$ and the polymer chains could no longer uncoil as normally occurs to provide creep deformation. The second one is that because the matrix was saturated with water, the glue that fixed the strain gage onto the specimen gradually deteriorated due to the water squeezed out from the specimen under load; therefore, the

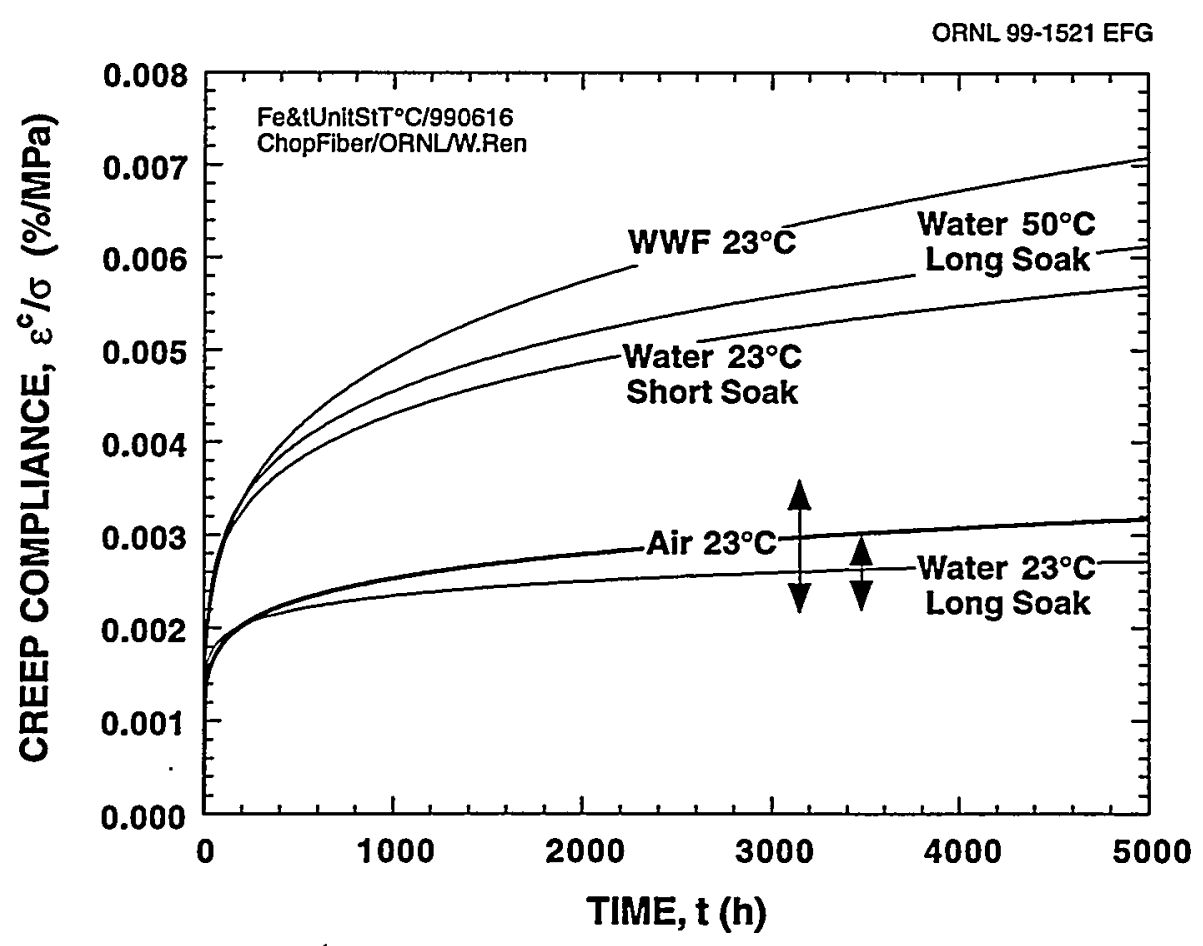

Fig. 13.11. Creep compliance curves for various environments. The windshield washer fluid and short-term water presoaks were each $100 \mathrm{~h}$ at room temperature. The long-term water soak was 3 months at $50^{\circ} \mathrm{C}$. 
strain gage could no longer elongate completely with the specimen, and this would obviously result in less measured strain. The second possibility is less likely because short-term presoak specimens may also become saturated after long-term testing. The first possibility is supported by the results from tensile tests. The average tensile strain is $2.02 \%$ in the baseline condition but only $1.52 \%$ after the long-term presoak at $50^{\circ} \mathrm{C}$. For practical engineering design purposes, the longterm presoak is an extremely unreal condition. Even if the long-term presoak limited creep deformation, it would not provide any engineering advantage in the material's application because the creep-rupture strength is severely degraded by the long-term presoak, as will be discussed in the next chapter.

\subsubsection{Creep Deformation Models for Various Environments}

Predictions based on the creep deformation model under various stresses for distilled water immersion at $23^{\circ} \mathrm{C}$ after the long-term $50^{\circ} \mathrm{C}$ presoak developed from the test-derived creep compliance curve are compared with the average test data in Fig. 13.12. Linearity between stress and strain was maintained up to approximately $50 \mathrm{MPa}$. The equation for the creep curves is also presented in the figure. Creep curves at any stresses below the linearity limit of $50 \mathrm{MPa}$ can be calculated from the equation.

The model for distilled water immersion at $23^{\circ} \mathrm{C}$ after the short-term presoak developed from test-derived creep compliance curve is compared with the average test data in Fig. 13.13. That for distilled water immersion at $50^{\circ} \mathrm{C}$ after long-term presoak is given in Fig. 13.14. Figure 13.15 gives the model for windshield washer fluid at $23^{\circ} \mathrm{C}$ after a short-term presoak.

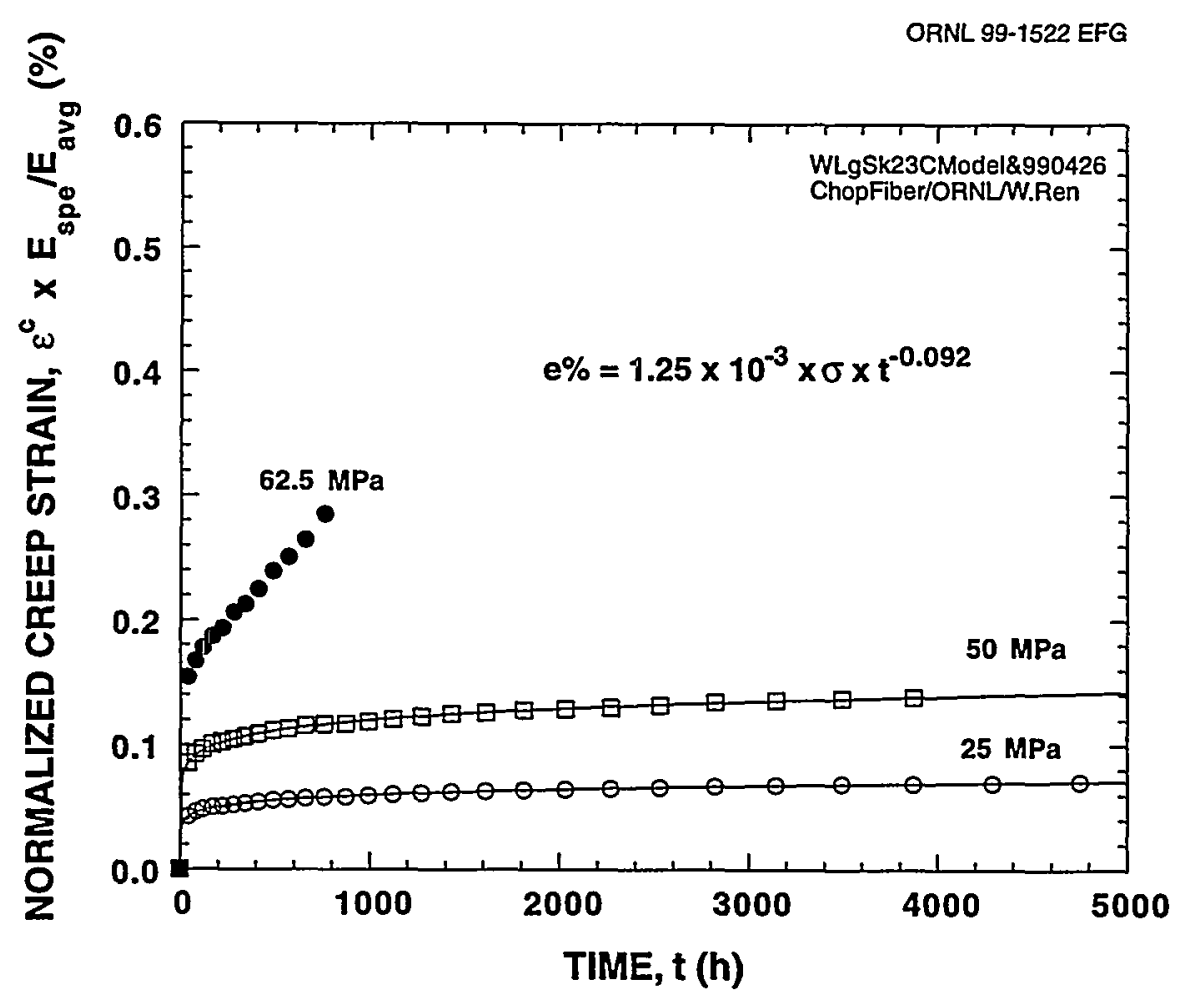

Fig. 13.12. Creep deformation model and the average test data for distilled water immersion at $23^{\circ} \mathrm{C}$ after long-term presoak at $50^{\circ} \mathrm{C}$. The average test data were generated by the same procedure as was illustrated in Fig. 13.2. The 62.5 MPa data are from one specific test. 


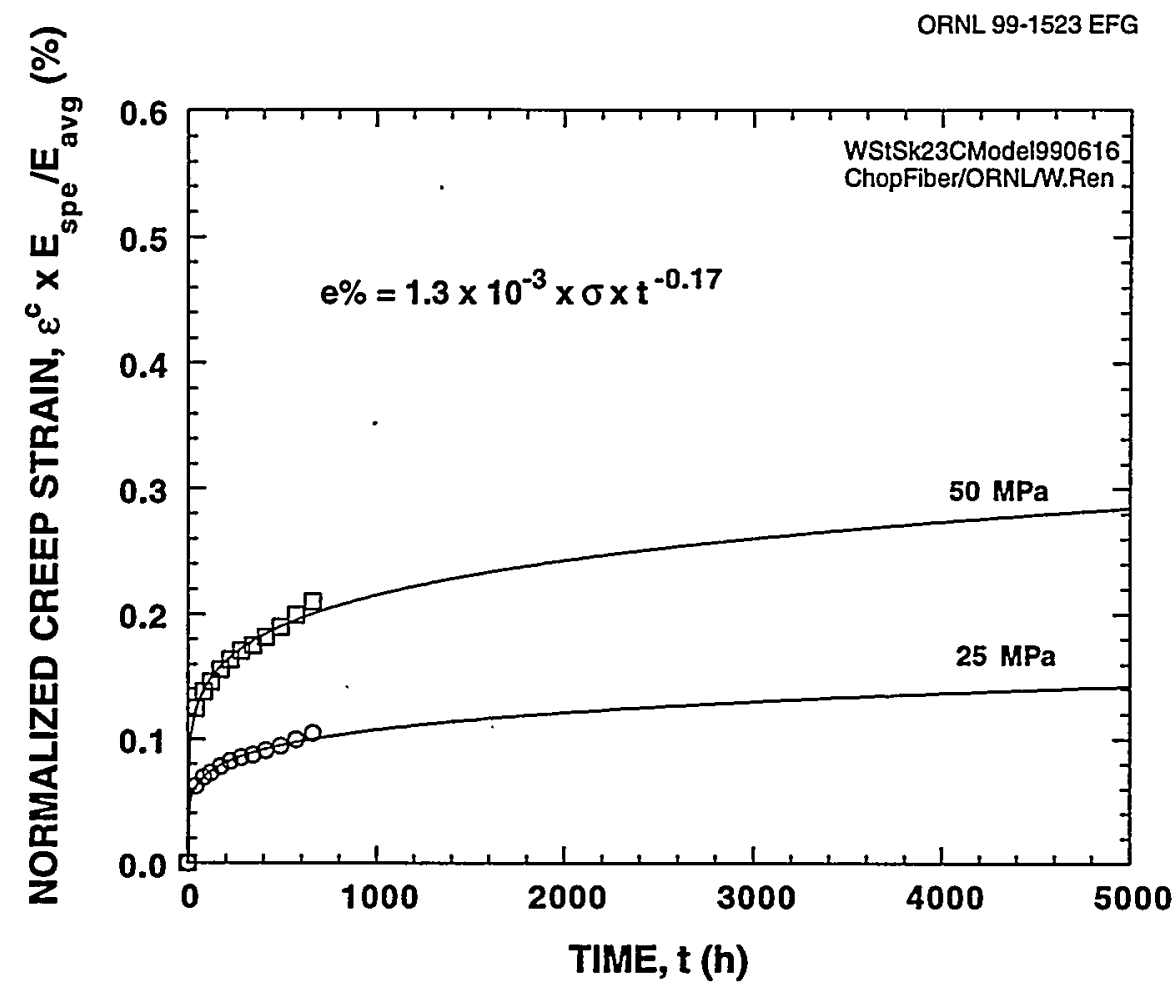

Fig. 13.13. Creep deformation model and the average test data for distilled water immersion at $23^{\circ} \mathrm{C}$ after short-term presoak at $23^{\circ} \mathrm{C}$.

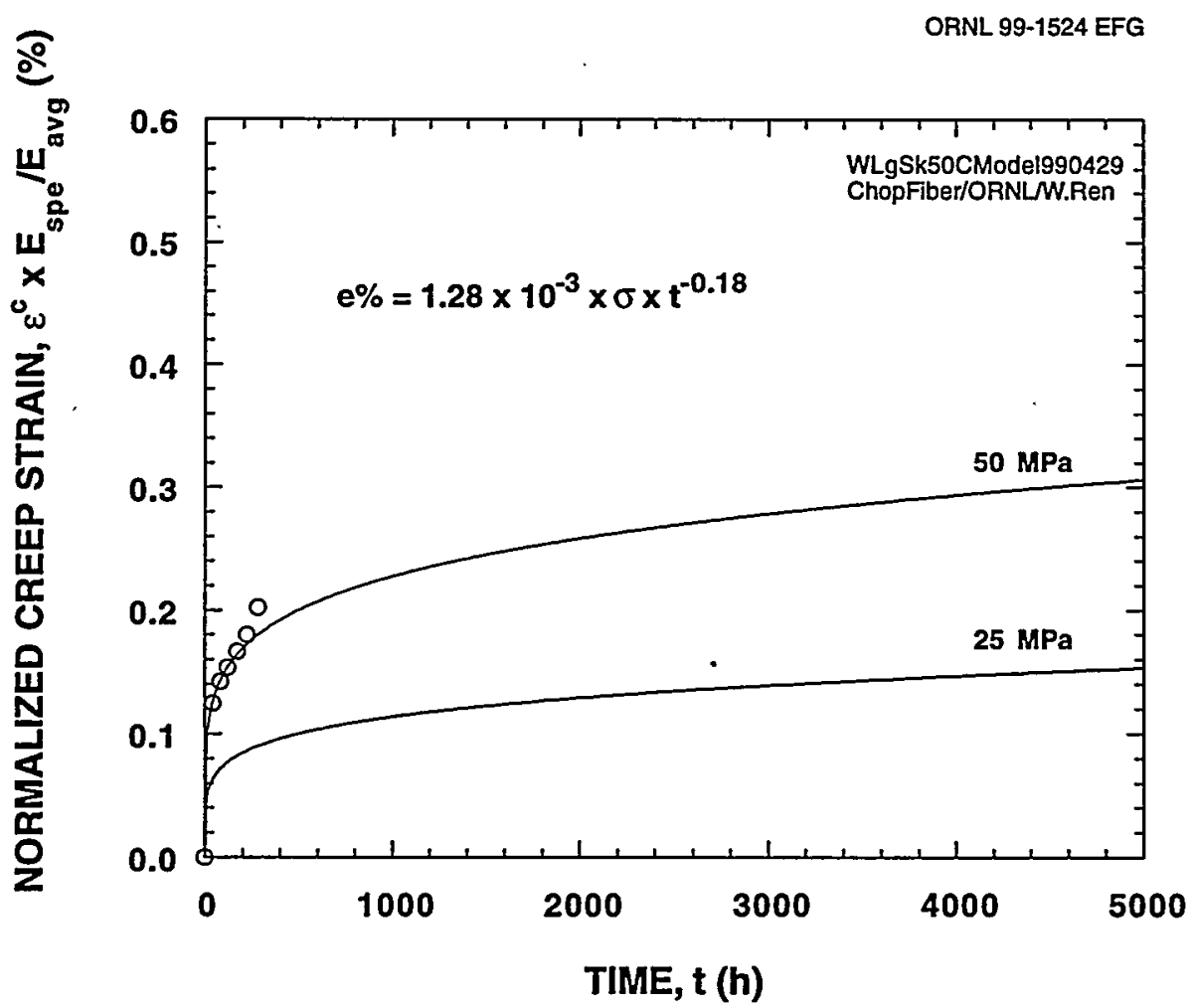

Fig. 13.14. Creep deformation model and the average test data for distilled water immersion at $50^{\circ} \mathrm{C}$ after long-term presoak at $50^{\circ} \mathrm{C}$. 


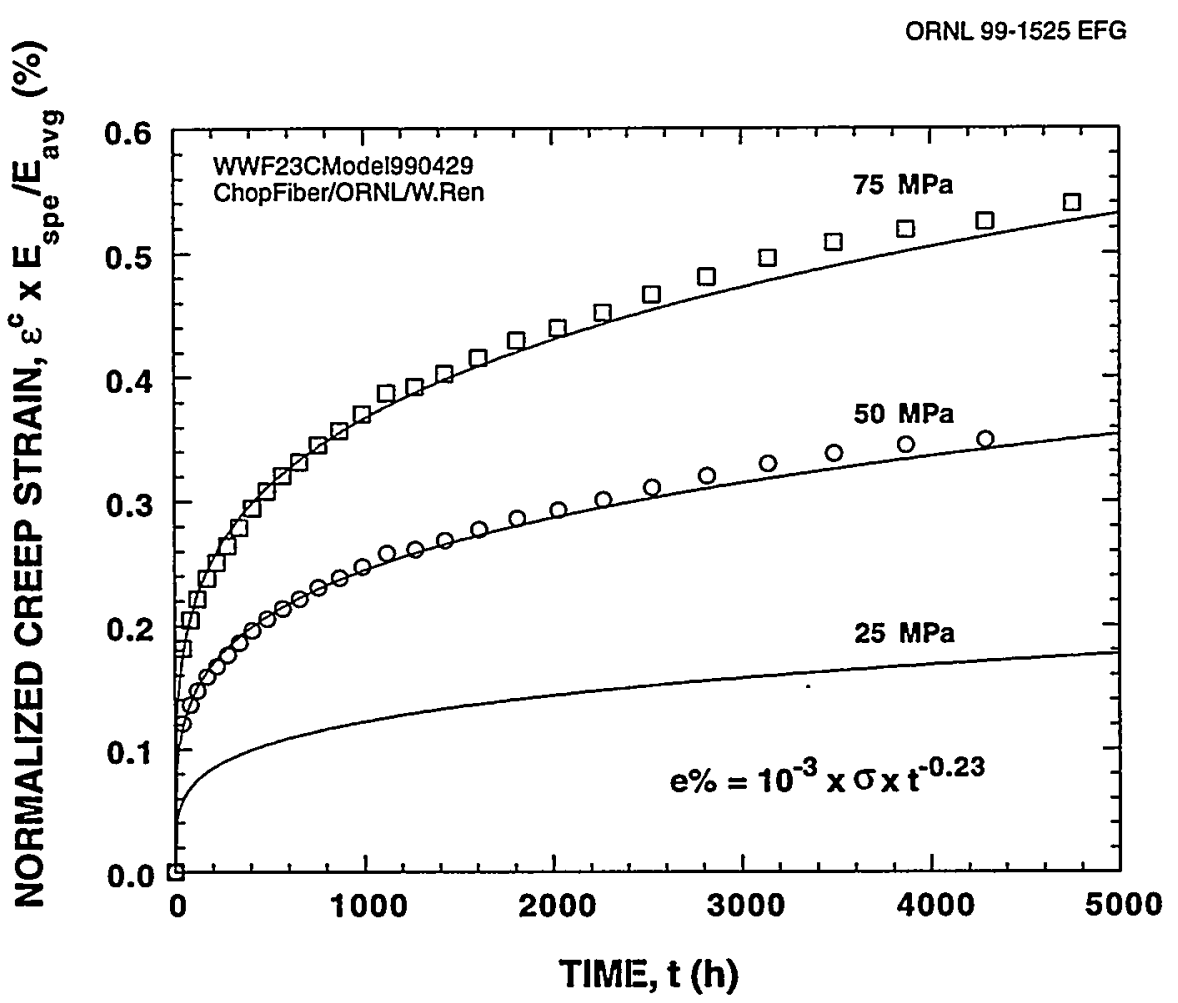

Fig. 13.15. Creep deformation model and the average test data for windshield washer fluid at $23^{\circ} \mathrm{C}$ after short-term presoak.

For practical engineering design purposes, simple environmental factors for creep deformation are desirable. These factors can be developed based on the baseline condition curve. Because creep deformation varies with time, the factors developed should at least be able to guarantee the predicting accuracy at the time of most importance. This time was selected as $5000 \mathrm{~h}$ since it is the required operating life of an automobile in which the vehicle may be exposed to certain service environments. The factors are derived by dividing the creep compliance value at $5000 \mathrm{~h}$ for a specific environment by that for the baseline condition. Creep compliance curves developed from test data are compared in Fig. 13.16 to those derived by multiplying the baseline curve with the environmental factors. The solid lines represent the test data derived curves while the dashed lines represent the curves obtained using the environmental factors. Obviously, presoak, the dashed curves are slightly higher than the solid ones at short-term but merge into the solid curves when approaching $5000 \mathrm{~h}$. The environmental factors developed for various environments are presented in Table 13.1. The parameter $K_{c}$ is a result of $K$ multiplied by $F(T)$, which represents environmental effects, including various temperatures in air.

\subsection{COMPRESSIVE CREEP DEFORMATION}

\subsubsection{Compressive Creep Compliance and Model in Air/50\% RH at $23^{\circ} \mathrm{C}$}

The creep compliance curve under compression in air with $50 \% \mathrm{RH}$ at $23^{\circ} \mathrm{C}$ is compared to that under tension in Fig. 13.17. The compressive curve represents the average behavior of only two tests conducted, and it falls within the $0.0017 \%$ error band of the tension curve. Therefore, it is assumed that the creep deformation behavior of the material is comparable under tension and compression, and the model for tension in air $/ 50 \% \mathrm{RH}$ at $23^{\circ} \mathrm{C}$ can be employed for compression for design purposes. 


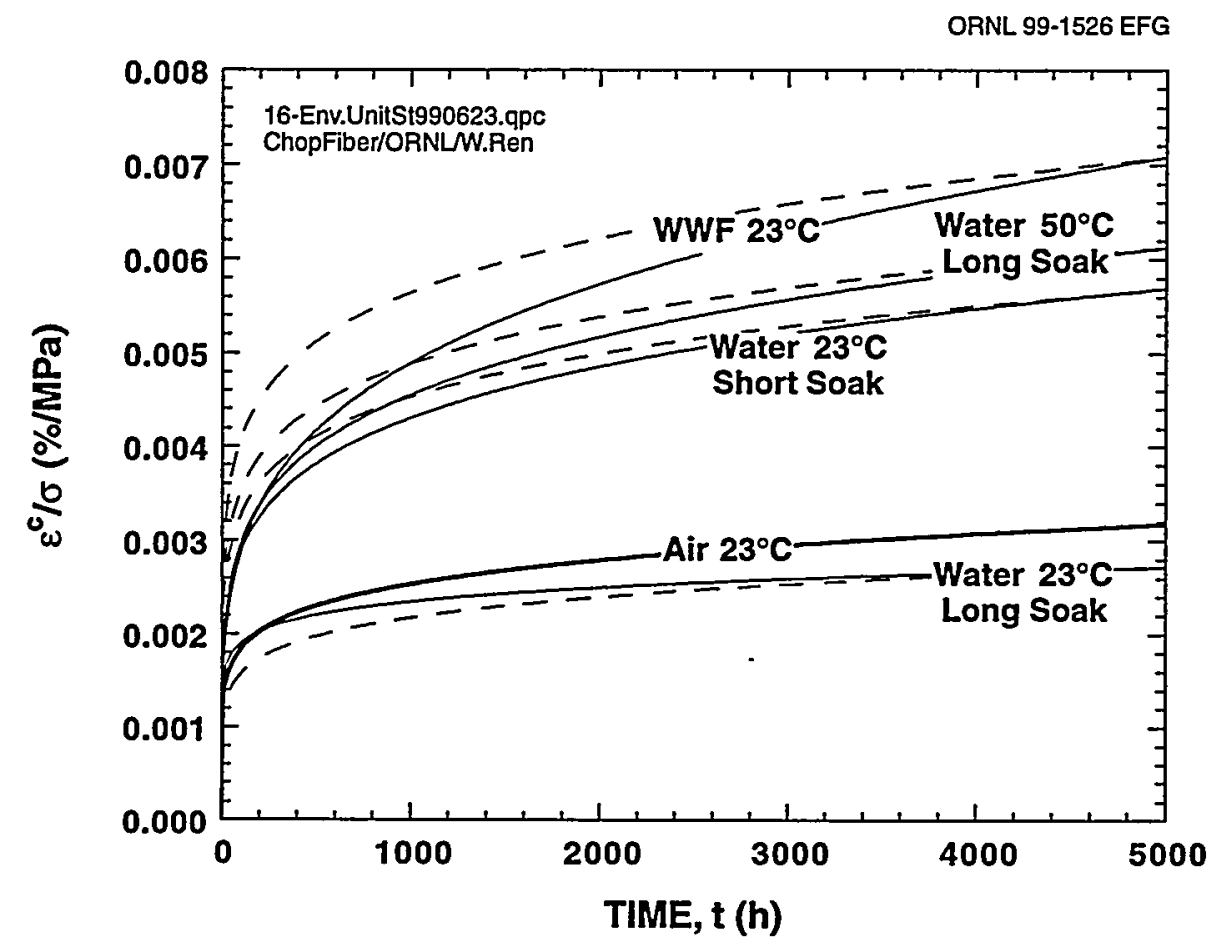

Fig. 13.16. Creep compliance curves developed (1) from test data (solid lines) and (2) by multiplying the baseline curve by the environmental factors (dashed lines).

Table 13.1. Environmental creep strain multiplication factors for various conditions

\begin{tabular}{lc}
\hline \multicolumn{1}{c}{ Environment ${ }^{a}$} & $\mathrm{~K}_{\mathrm{C}}$ \\
\hline$-40^{\circ} \mathrm{C}$ air/T & 0.59 \\
$23^{\circ} \mathrm{C}$ air/T\&C & 1.00 \\
$50^{\circ} \mathrm{C}$ air/T & 1.24 \\
$120^{\circ} \mathrm{C}$ air/T & 2.07 \\
$23^{\circ} \mathrm{C}$ water short soak $/ \mathrm{T}$ & 1.79 \\
$23^{\circ} \mathrm{C}$ water long soak $/ \mathrm{T} \& \mathrm{C}$ & 0.86 \\
$50^{\circ} \mathrm{C}$ water long soak $/ \mathrm{T}$ & 1.93 \\
Windshield washer fluid/T & 2.23 \\
\hline
\end{tabular}

$a_{\mathrm{T}}=$ tension, $\mathrm{C}=$ compression. 
ORNL 99-1527 EFG

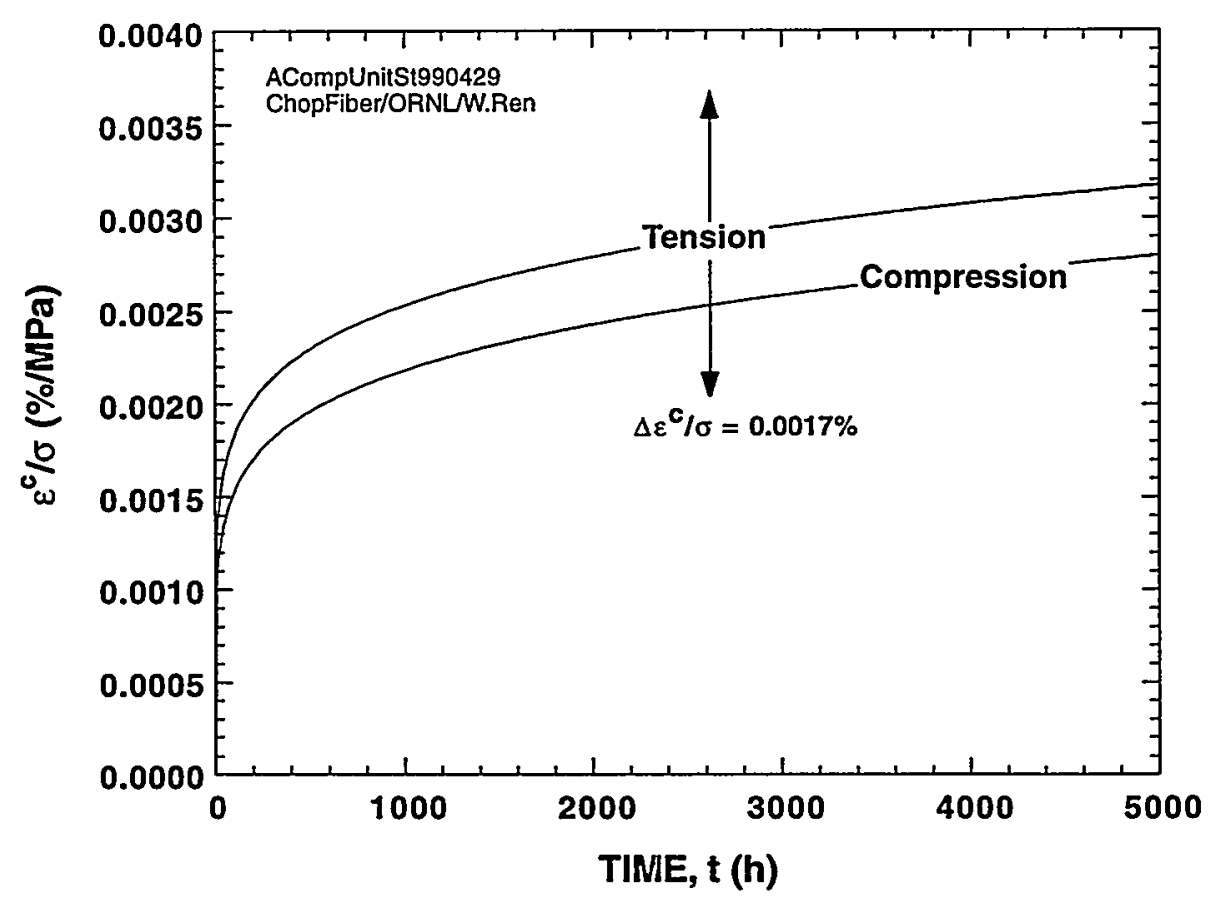

Fig. 13.17. Creep compliance curves under compression and tension in air with $50 \%$ RH at $23^{\circ} \mathrm{C}$.

\subsubsection{Compressive Creep Compliance and Model in Water at $23^{\circ} \mathrm{C}$}

The creep compliance data under compression at $23^{\circ} \mathrm{C}$ in water with the long-term presoak are compared to those under tension in Fig. 13.18. Obviously, the compressive data are comparable to those under tension. Therefore, the model for tension in water at $23^{\circ} \mathrm{C}$ can be employed for compression for design purposes. These observations are included in Table 13.1.

\subsection{SUMMARY AND DISCUSSION}

For tensile loading, it has been shown that time-dependent creep strains, in the linear stress-strain response range, can be approximated by a power law for room-temperature air at $50 \% \mathrm{RH}$ plus a series of creep-strain multiplication factors to account for other temperatures and for fluid environments. The room-temperature, ambient air creep strain is given by

$$
\varepsilon^{\mathrm{c}}(\%)=9.59 \times 10^{-4} \sigma \mathrm{t}^{0.141} \text {. }
$$

The temperature multipliers are given below.

\begin{tabular}{|c|c|}
\hline Temperature $\left({ }^{\circ} \mathrm{C}\right)$ & $\begin{array}{c}\text { Creep strain } \\
\text { multiplier }\end{array}$ \\
\hline-40 & 0.59 \\
\hline 23 & 1.00 \\
\hline 50 & 1.24 \\
\hline 120 & 2.07 \\
\hline
\end{tabular}




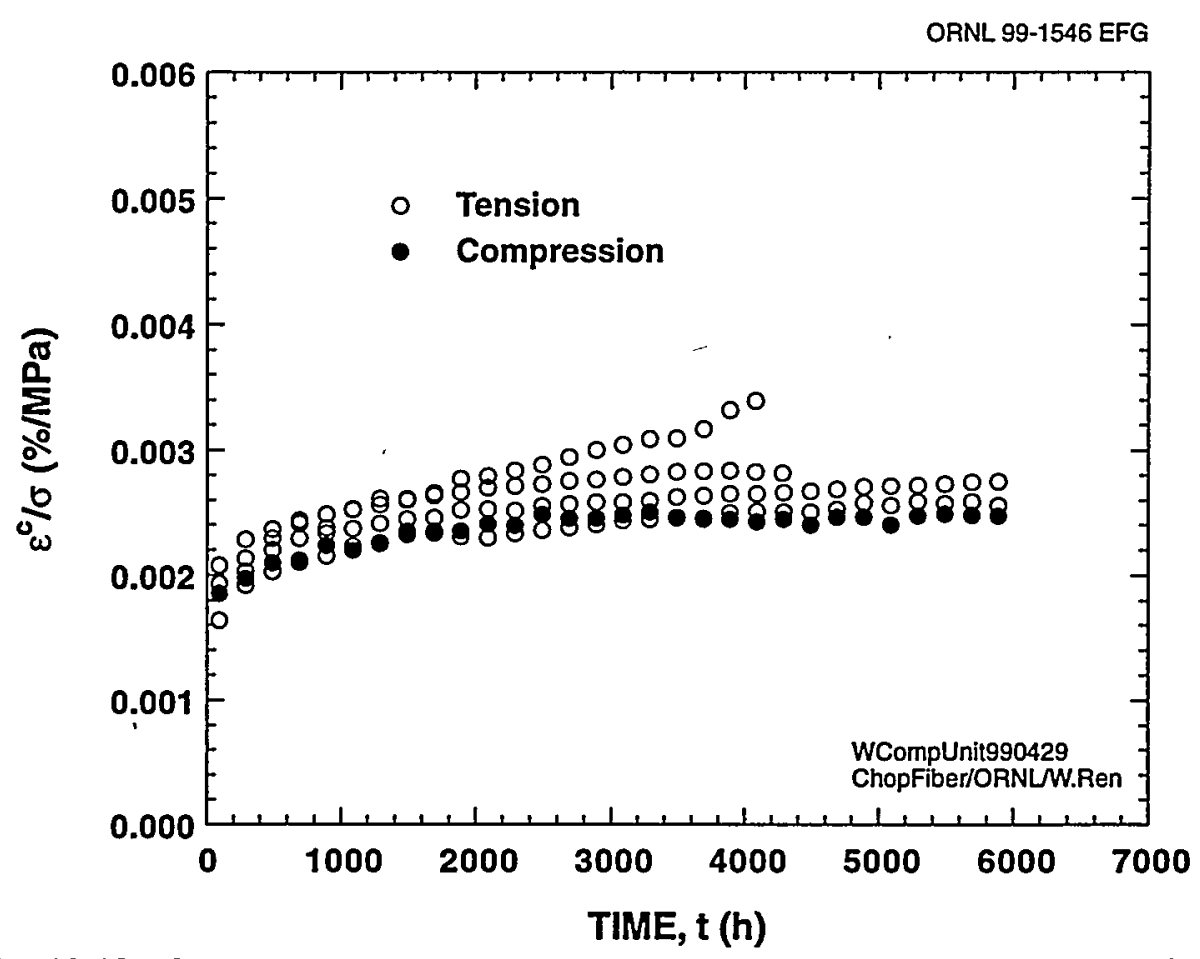

Fig. 13.18. Creep compliance data under compression and tension at $23^{\circ} \mathrm{C}$ in water with long-term presoak at $50^{\circ} \mathrm{C}$.

As discussed in Chap. 8, two standard fluid environments are recommended for design-1000-h presoak in room-temperature distilled water and $100 \mathrm{~h}$ presoak in roomtemperature windshield washer fluid. The first was not one of the test conditions used for the creep tests. However creep data for test times up to several hundred hours in water at $23^{\circ} \mathrm{C}$ are available for a $100-\mathrm{h}$ presoak. Combined, this distilled water exposure should adequately bound realistic water exposure situations. The fluid multipliers on creep strain are, consequently, distilled water 1.79 and windshield washer fluid 2.23 .

Only two compressive creep conditions were examined-room-temperature/50\% $\mathrm{RH}$ air and room-temperature water after a 3-month presoak in $50^{\circ} \mathrm{C}$ water. In both these cases, the compression results could be represented by the tensile model. On this basis, the tensile creep equation, together with the associated fluid factors given above, are judged to be adequate for compressive stress design use as well. This may not be the case for the temperature factors. It is suspected that as the temperature increases, compressive creep will become larger than tensile creep.

The basic room-temperature in-air creep of the chopped-fiber composite at $5000 \mathrm{~h}$ is slightly less than that reported in Ref. 2 for the reference CSM composite. Conversely, the creep temperature dependence of the chopped-fiber composite is slightly greater than that of the reference composite, and the effects of distilled water and windshield washer fluid are somewhat greater. 
13-18 


\title{
14. CREEP RUPTURE
}

\author{
W. Rèn and C. R. Brinkman
}

\subsection{INTRODUCTION}

This chapter is dedicated to development of the creep-rupture design allowable stress curves and equations for the P4 chopped-fiber/Baydur 420 IMR composite for representative automotive service environments. In addition to the tests discussed in Chap. 13 conducted to provide creep deformation information, more high stress tests performed to generate creep-rupture data are included in this chapter. Also included are tests under static tension with superimposed cyclic tensile loading to study rough roadway condition effects. Among the total of 131 creep tests, 73 reached the rupture point to provide creep-rupture information. The representative automotive service environments selected for investigation included air with $50 \%$ relative humidity (air/50\%RH), distilled water immersion, windshield washer fluid immersion, and battery acid splatter. The test temperatures ranged from -40 to $120^{\circ} \mathrm{C}$, but not in all environments. Based on the test results, the average and minimum creep-rupture stress curves were defined, and the recommended maximum time-dependent design allowable stress curves were derived, essentially by multiplying the minimum curves by 0.8 . The results are summarized and compared with those of the reference material in the last section of this chapter.

As in Chap. 13, normalization was conducted to minimize data scatter. However, the normalization factor in this chapter is the reciprocal of that for creep deformation in Chap. 13:

$$
\text { normalized stress }=\text { stress } \times \mathrm{E}_{\text {average }} / \mathrm{E}_{\text {specimen }} \text {, }
$$

where

$$
\begin{aligned}
\mathrm{E}_{\text {specimen }} & =\text { Young's modulus of the specimen at } 23^{\circ} \mathrm{C}, \\
\mathrm{E}_{\text {average }} & =\text { average Young's modulus of the material at } 23^{\circ} \mathrm{C} .
\end{aligned}
$$

An average Young's modulus value of $11.7 \mathrm{GPa}$ was used.

\subsection{TENSILE BEHAVIOR}

\subsubsection{Failure in Air with 50\% RH at Room Temperature}

Air with a nominal $50 \% \mathrm{RH}$ at room temperature $\left(23^{\circ} \mathrm{C}\right)$ is used as the baseline test condition, with which results from the other test environments are compared. Twenty-nine specimens from plaques B2, B3, and B9 were tested in the baseline condition. Of these 29 tests, 12 reached rupture, providing data for creep-rupture curves and equations.

Creep-rupture data for the baseline condition are presented in Fig. 14.1. The curve designated "Air/50\%RH $23^{\circ} \mathrm{C} / \mathrm{Avg}$ " was derived from the failure data points by a least- squares fit to represent the average creep-rupture behavior of the material in the baseline condition. The curve labeled "Air $/ 50 \% \mathrm{RH} 23^{\circ} \mathrm{C} / \mathrm{Min}$ " was obtained essentially by a parallel graphical shift of the average curve downward to a lower bound for all the data points. It is intended to represent the lowest testing stresses at which creep-rupture would not occur for a given time. The average and minimum curves for air $/ 50 \% \mathrm{RH}$ at $23^{\circ} \mathrm{C}$ will be used as the basis for comparison with test results under the other testing conditions. Another curve in Fig. 14.1 defined as 
TIME, (year)

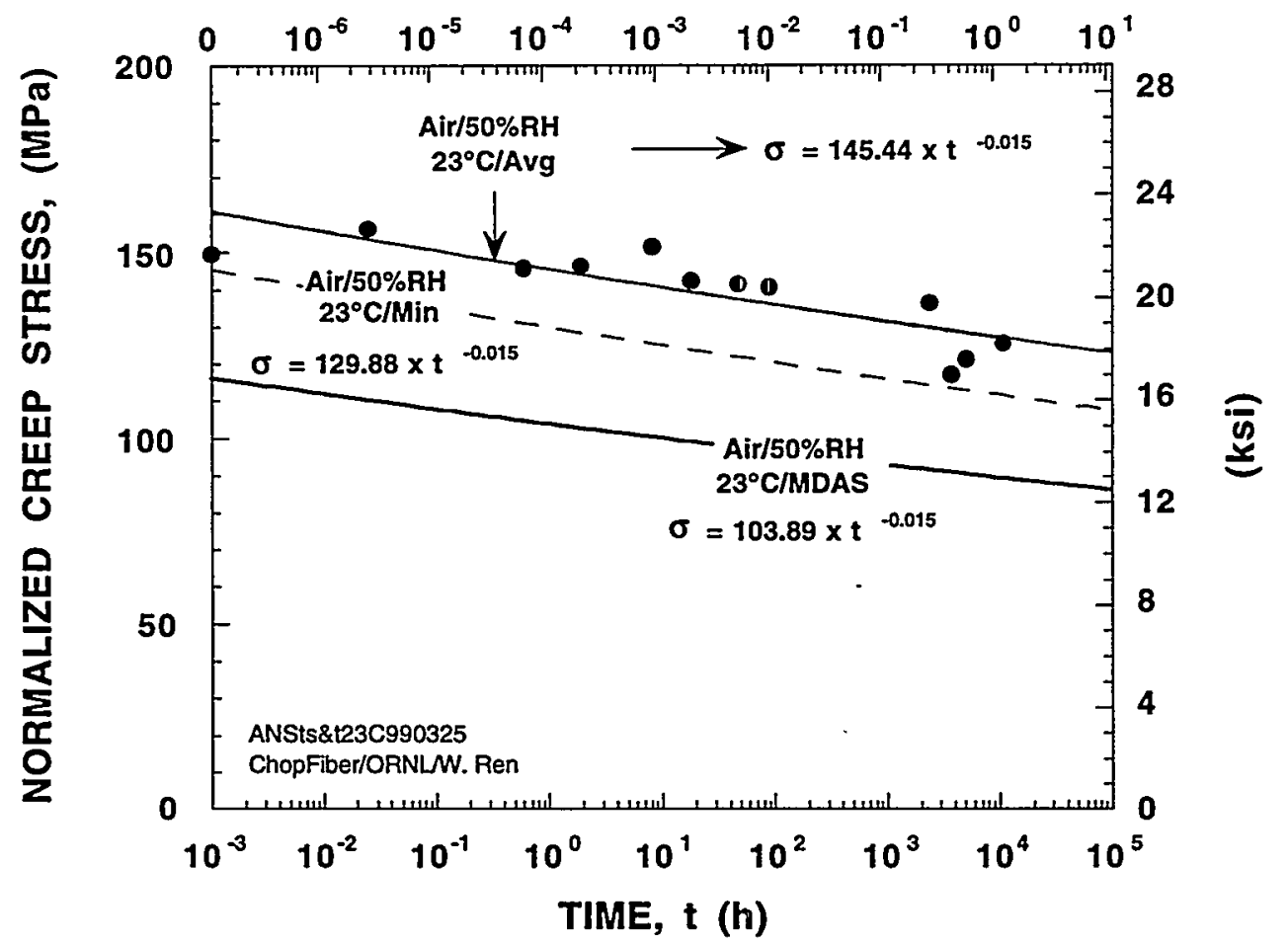

Fig. 14.1. Creep-rupture data for the baseline condition.

"Air/50\%RH $23^{\circ} \mathrm{C} / \mathrm{MDAS}$," in which MDAS stands for "maximum design allowable stress," is the minimum curve multiplied by a factor of 0.8 on stress. Equations for the average and minimum creep-rupture stress and maximum design allowable stress curves are also presented in Fig. 14.1. They all have the form:

$$
\sigma=\mathrm{Bt}^{\mathrm{m}}, \text { for } \mathrm{t} \geq 10 \mathrm{~h}
$$

Throughout this chapter, test data from various test conditions will be converted into curves and Eq. (14.2) with specific values of $B$ and $m$. These curves and equations can be used for the derivation of alternate design guidelines if desired.

It should be stressed that application of all the curves and Eq. (14.2) developed in this chapter is limited to creep-rupture times not less than $10 \mathrm{~h}$. This constraint is intended to eliminate the undue effects of short times before environments, considered later in this chapter, have their full effects. The detailed procedures for developing curves and equations in Fig. 14.1 are the same as discussed in the previous investigation for the reference material. ${ }^{2}$

\subsubsection{Temperature Effects in Air}

Temperature effects on creep-rupture behavior in air were investigated at $-40,50$, and $120^{\circ} \mathrm{C}$, just as was done in Chap. 13 .

Figure 14.2 compares the data at $-40,50$, and $120^{\circ} \mathrm{C}$ with those at $23^{\circ} \mathrm{C}$. Because of the difficulties in maintaining long-term creep tests at $-40^{\circ} \mathrm{C}$, the tests there were accidentally 


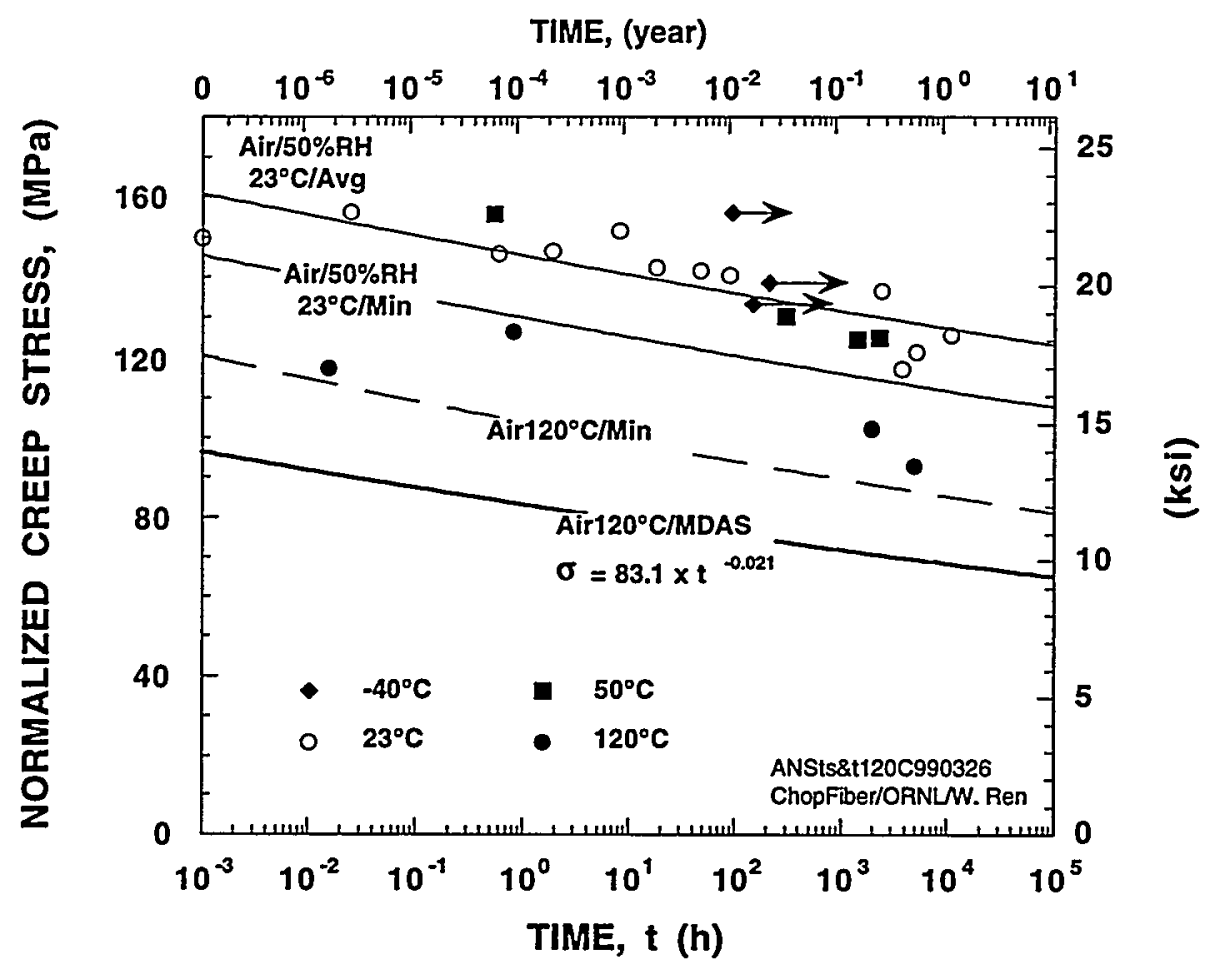

Fig. 14.2. Creep-rupture data in air at various temperatures, with minimum creeprupture stress and maximum design allowable stress curves and equation for $120^{\circ} \mathrm{C}$.

terminated before rupture occurred. Nevertheless, Fig. 14.2 clearly indicates that the material has at least equal, and most likely higher, creep-rupture stress at $-40^{\circ} \mathrm{C}$ compared to $23^{\circ} \mathrm{C}$. Therefore the minimum creep-rupture stress and the maximum design allowable stress curves and equation for $23^{\circ} \mathrm{C}$ are recommended for $-40^{\circ} \mathrm{C}$.

At $50^{\circ} \mathrm{C}$, limited data indicate that the average creep-rupture stress is equal to, or may become just slightly lower than, that at $23^{\circ} \mathrm{C}$ after a long time. Again, it is convenient and practical to use the minimum creep-rupture stress and the maximum design allowable stress curves and equation at $23^{\circ} \mathrm{C}$ for $50^{\circ} \mathrm{C}$.

It is obvious from Fig. 14.2 that the creep-rupture stress is significantly decreased at $120^{\circ} \mathrm{C}$. Calculation indicates that the minimum creep-rupture stress at $120^{\circ} \mathrm{C}$ is approximately $26 \mathrm{MPa}$ lower than that at $23^{\circ} \mathrm{C}$. The minimum creep-rupture stress and maximum design allowable stress curves for $120^{\circ} \mathrm{C}$ are given as "Air $/ 20^{\circ} \mathrm{C} / \mathrm{Min}$ " and "Air $/ 20^{\circ} \mathrm{C} / \mathrm{MDAS}$," respectively, in Fig. 14.2 along with the maximum design allowable stress equation for $120^{\circ} \mathrm{C}$.

As presented in Chap. 13, the composite under investigation demonstrated significant tertiary creep at $120^{\circ} \mathrm{C}$. For deformation-restricted structural applications, tertiary creep should be excluded. To address this issue, a comparison between creep-rupture time and tertiary creep initiation time is given in Fig. 14.3, which shows that at high stresses the initiation of tertiary creep is closely followed by rupture, and therefore, it should not constitute a design problem, while at stresses of 75 to $25 \mathrm{MPa}$, tertiary creep occurred after about $4600 \mathrm{~h}$ of continuous load at $120^{\circ} \mathrm{C}$ without subsequent immediate rupture. Since the design operating life for an automobile is accumulatively 3000 to $5000 \mathrm{~h}$, the tertiary creep initiation that may occur after more than $4000 \mathrm{~h}$ 


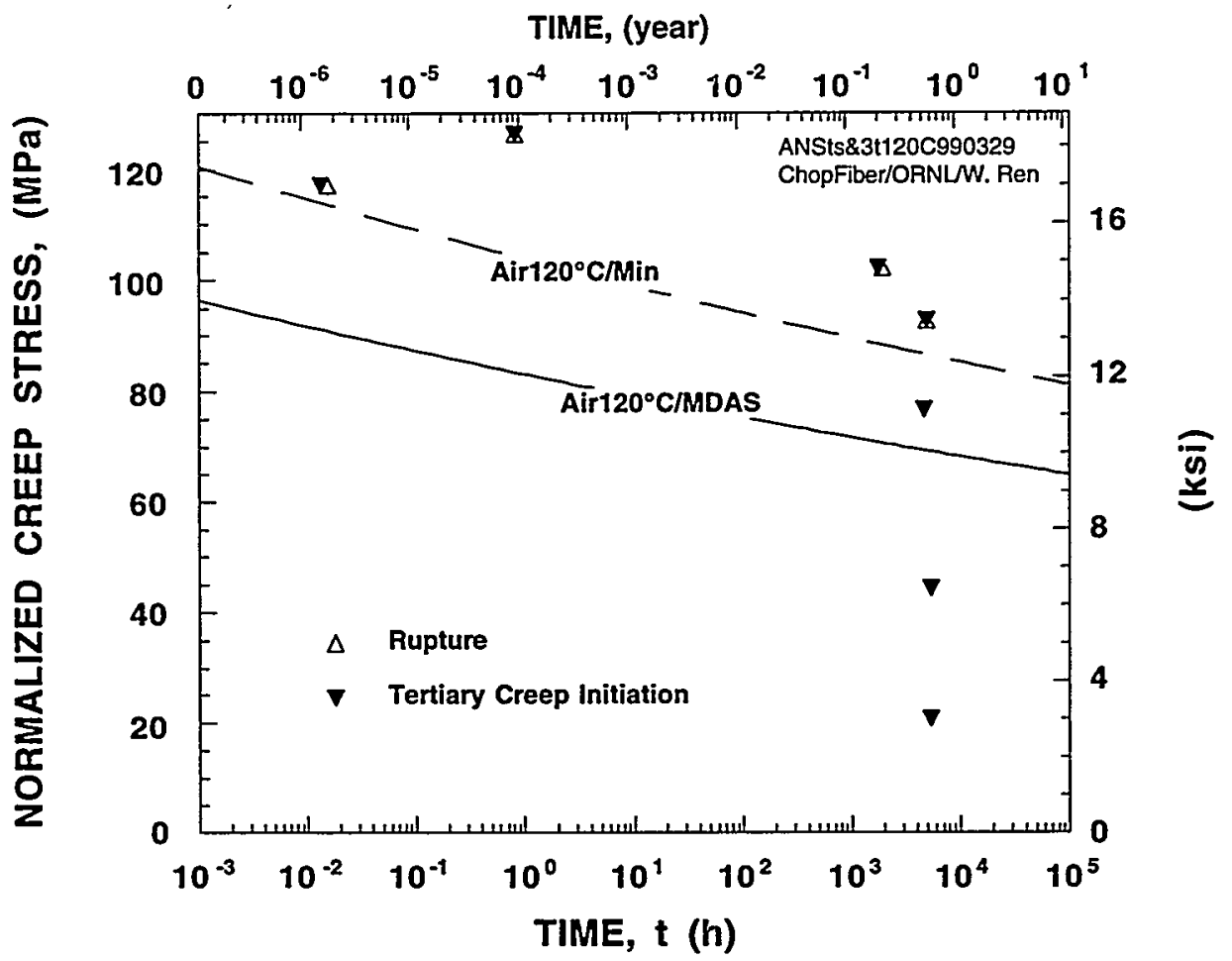

$120^{\circ} \mathrm{C}$.

Fig. 14.3. The initiation of tertiary creep compared to creep-ruptured points at

of continuous heat and load should not be considered as a serious problem from a creep-rupture point of view.

To summarize the above results and discussion, the recommended maximum design allowable stresses at various temperatures are calculated and listed in Table 14.1 for specific norupture time limits using Eq. (14.2) with the appropriate B and $\mathrm{m}$ values.

Table 14.1. Maximum design allowable stresses in air for specific no-rupture time limits

\begin{tabular}{|c|c|c|c|c|c|c|c|c|c|c|}
\hline \multirow{3}{*}{$\begin{array}{l}\text { Temperature } \\
\left({ }^{\circ} \mathrm{C}\right)\end{array}$} & \multicolumn{10}{|c|}{$\begin{array}{l}\text { Maximum design allowable stress } \\
(\mathrm{MPa})\end{array}$} \\
\hline & \multicolumn{4}{|c|}{ Hours } & \multicolumn{4}{|c|}{ Years } & \multicolumn{2}{|c|}{ Parameter } \\
\hline & 10 & 1000 & 3000 & 5000 & 1 & 5 & 10 & 15 & B & $\mathrm{m}$ \\
\hline-40 & 100.36 & 93.66 & 92.13 & 91.43 & 90.66 & 88.50 & 87.59 & 87.06 & 103.89 & -0.015 \\
\hline 23 & 100.36 & 93.66 & 92.13 & 91.43 & 90.66 & 88.50 & 87.59 & 87.06 & 103.89 & -0.015 \\
\hline 50 & 100.36 & 93.66 & 92.13 & 91.43 & 90.66 & 88.50 & 87.59 & 87.06 & 103.89 & -0.015 \\
\hline 120 & 79.18 & 71.88 & 70.24 & 69.49 & & & & & 83.1 & -0.021 \\
\hline
\end{tabular}




\subsubsection{Environmental Effects}

Investigation of environmental effects included distilled water immersion, windshield washer fluid immersion, battery acid splatter, and low-frequency load cycling. The distilled water immersion included tests at 23 and $50^{\circ} \mathrm{C}$ to show the combined effect of water and temperature.

The distilled water immersion condition was investigated to address humidity effects on creep rupture. During service, an automotive structural component can be exposed to various humidity conditions including air with relative humidity ranging from less than $10 \%$ to nearly $100 \%$ and water. The previous study showed that a distilled water immersion environment represents the worst of all humidity conditions affecting creep behavior of the reference material, which, like the present chopped fiber composite, ${ }^{10}$ had a urethane-based matrix. ${ }^{14}$

Prior to being tested in distilled water, the specimens were presoaked in distilled water for either a long term or short term. The long-term group, as described in Chaps. 8 and 13, was presoaked at $50^{\circ} \mathrm{C}$ for $2160 \mathrm{~h}$ ( 3 months), while the short-term group was presoaked at $23^{\circ} \mathrm{C}$ for $100 \mathrm{~h}$. The results are presented in Fig. 14.4, which shows the creep-rupture data points and the corresponding average curves for the two presoak conditions compared to those for air $/ 50 \% \mathrm{RH}$. Note that in both cases, the specimens were tested in distilled water at $23^{\circ} \mathrm{C}$. Obviously, water presoaking decreases creep-rupture strength; the longer the presoak and higher the presoak temperature, the lower the creep-rupture stress becomes. It can be noted that the short- and long-term curves are approximately parallel to each other. From tensile test results in water with a 1000 -h presoak at $23^{\circ} \mathrm{C}$, it is known that the UTS is 0.91 that of the baseline UTS. Based on this

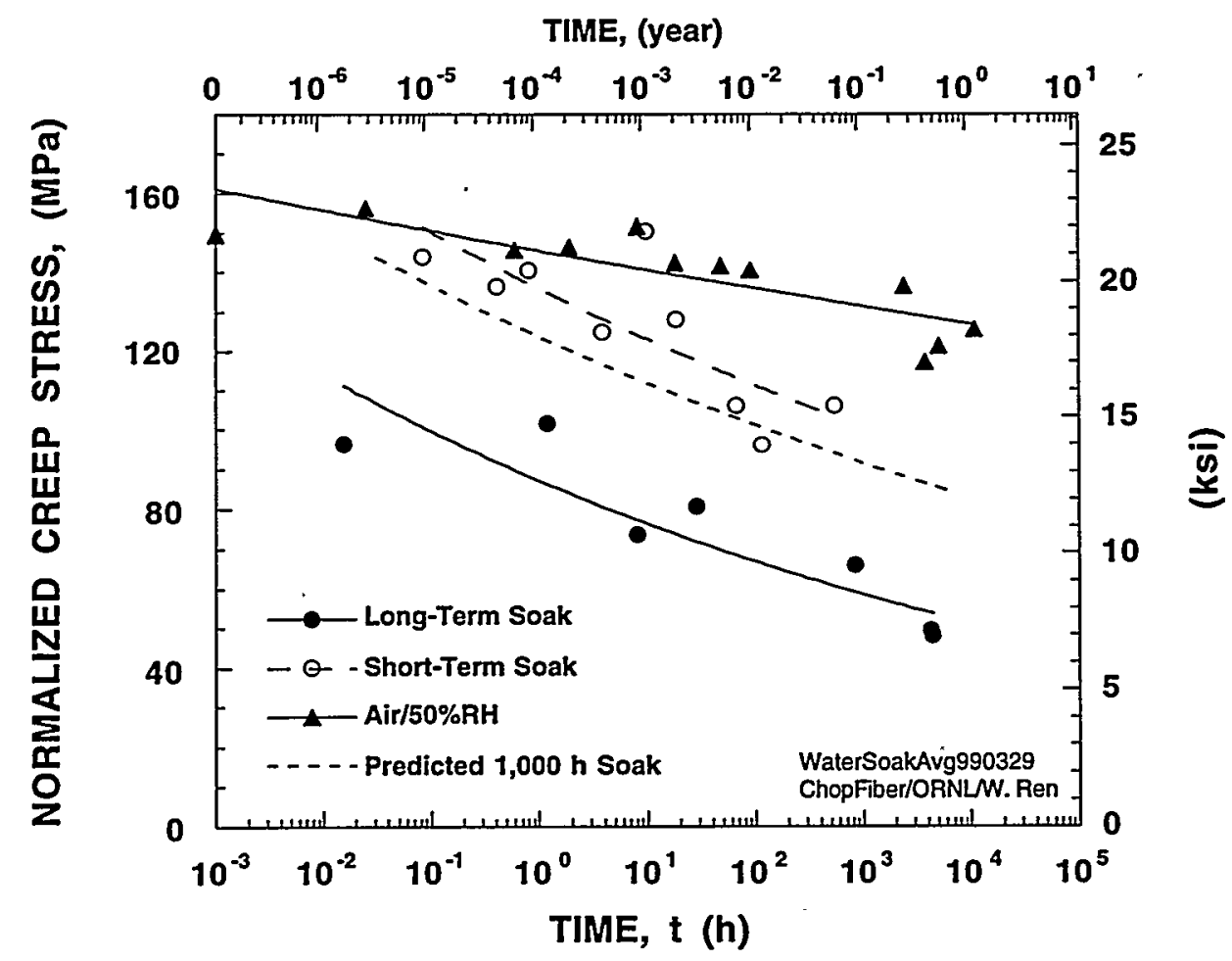

Fig. 14.4. Creep-rupture data and average creep-rupture curves in distilled water at $23^{\circ} \mathrm{C}$ with long-term $(2160 \mathrm{~h}) 50^{\circ} \mathrm{C}$ presoak, short-term $(100-\mathrm{h}) 23^{\circ} \mathrm{C}$ presoak, and in air/50\%RH. 
information, the short-term curve is moved downward to 0.91 of its value to be a prediction for the average creep-rupture stress curve in water with a $1000-\mathrm{h}$ presoak at $23^{\circ} \mathrm{C}$. The minimum creep-rupture and maximum design stress allowable curves for the short- and long-term presoak are developed and presented in Fig. 14.5.

The combined effects of test temperature and water on specimens with the long-term $50^{\circ} \mathrm{C}$ presoak are shown in Fig. 14.6. Average creep-rupture behavior analysis based on the open symbols for specimens tested at $23^{\circ} \mathrm{C}$ and the filled symbols for specimens tested at $50^{\circ} \mathrm{C}$ indicates that increasing the test water temperature to $50^{\circ} \mathrm{C}$ slightly decreases creep-rupture stress after long testing times. However, all the data points for $50^{\circ} \mathrm{C}$ can still be bounded by the minimum creep-rupture stress curve for $23^{\circ} \mathrm{C}$. Because continuous load in water at $50^{\circ} \mathrm{C}$ after a longterm presoak at $50^{\circ} \mathrm{C}$ is a very unlikely service condition for automotive structural components, the minimum creep-rupture stress and the maximum design allowable stress curves and equation for water with long-term presoak tested at $23^{\circ} \mathrm{C}$ are recommended for $50^{\circ} \mathrm{C}$.

For windshield washer fluid exposure effects, a simulated washer fluid was employed to avoid subtle variations in commercial products. The simulated fluid was made of 70 vol. \% pure methanol plus $30 \mathrm{vol}$. \% distilled water. Specimens were presoaked in the fluid for $100 \mathrm{~h}$ at $23^{\circ} \mathrm{C}$ before being loaded. The test results are presented in Fig. 14.7, which shows that the data points are comparable to those for water with the short-term presoak. The two points with arrows represent faster than water does after long-term loaded immersion, long-term loaded immersion in windshield washer fluid is a very unlikely situation for automotive structural components. Therefore, the minimum creep-rupture stress and the maximum design allowable stress curves for

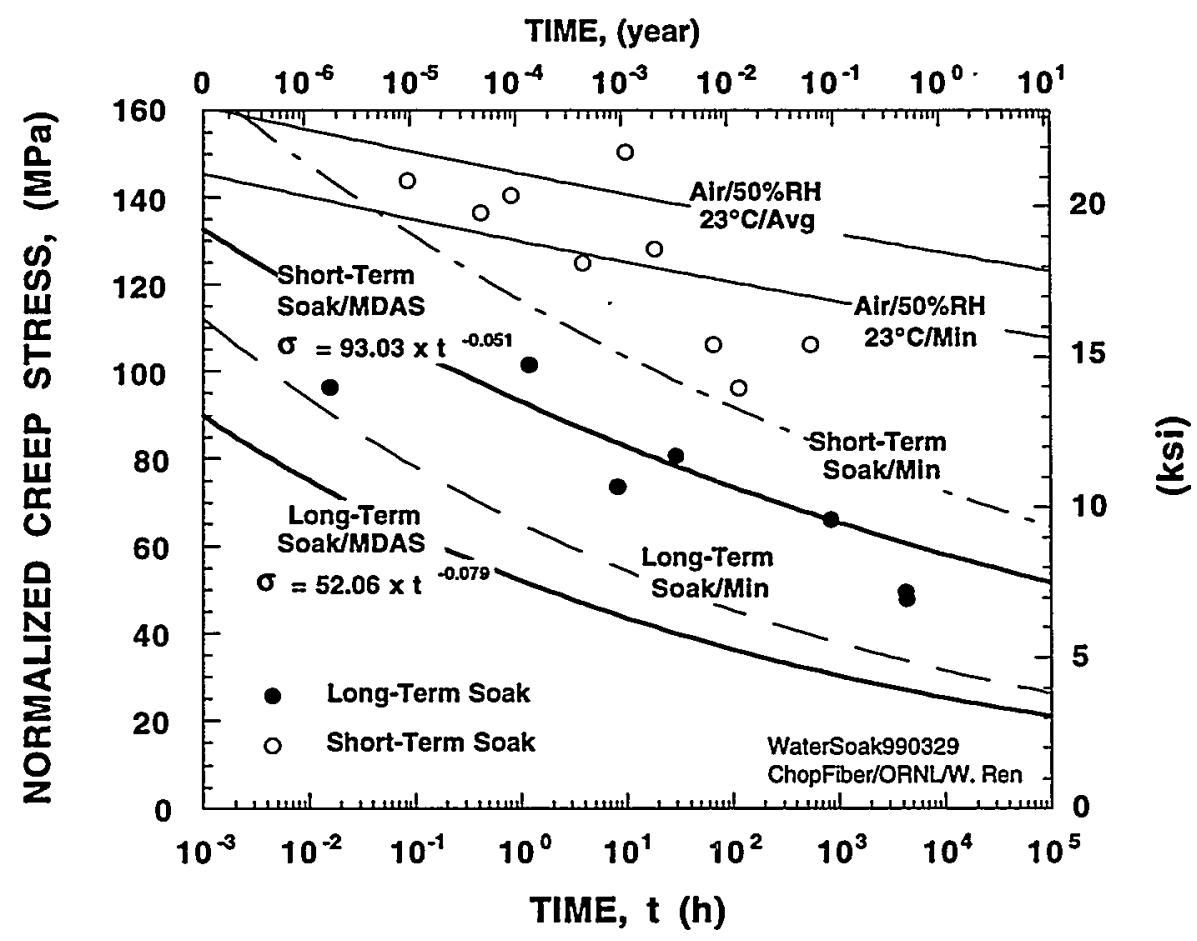

Fig. 14.5. Minimum creep-rupture stress and maximum design allowable stress curves and equations for distilled water immersion with long-term $50^{\circ} \mathrm{C}$ presoak and shortterm (100-h) $23^{\circ} \mathrm{C}$ presoak. 
TIME, (year)

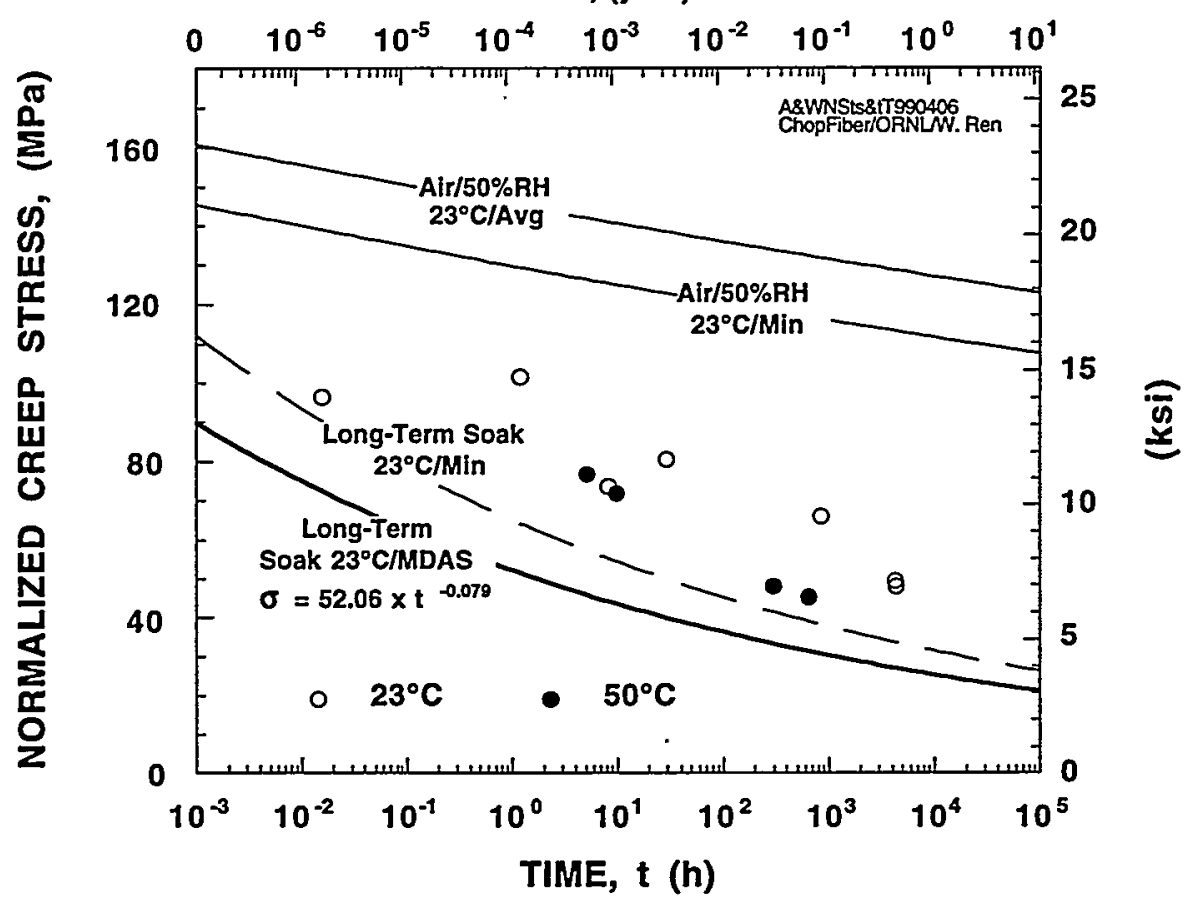

Fig. 14.6. Effect of test temperature on creep rupture of specimens previously soaked at $50^{\circ} \mathrm{C}$ for 3 months.

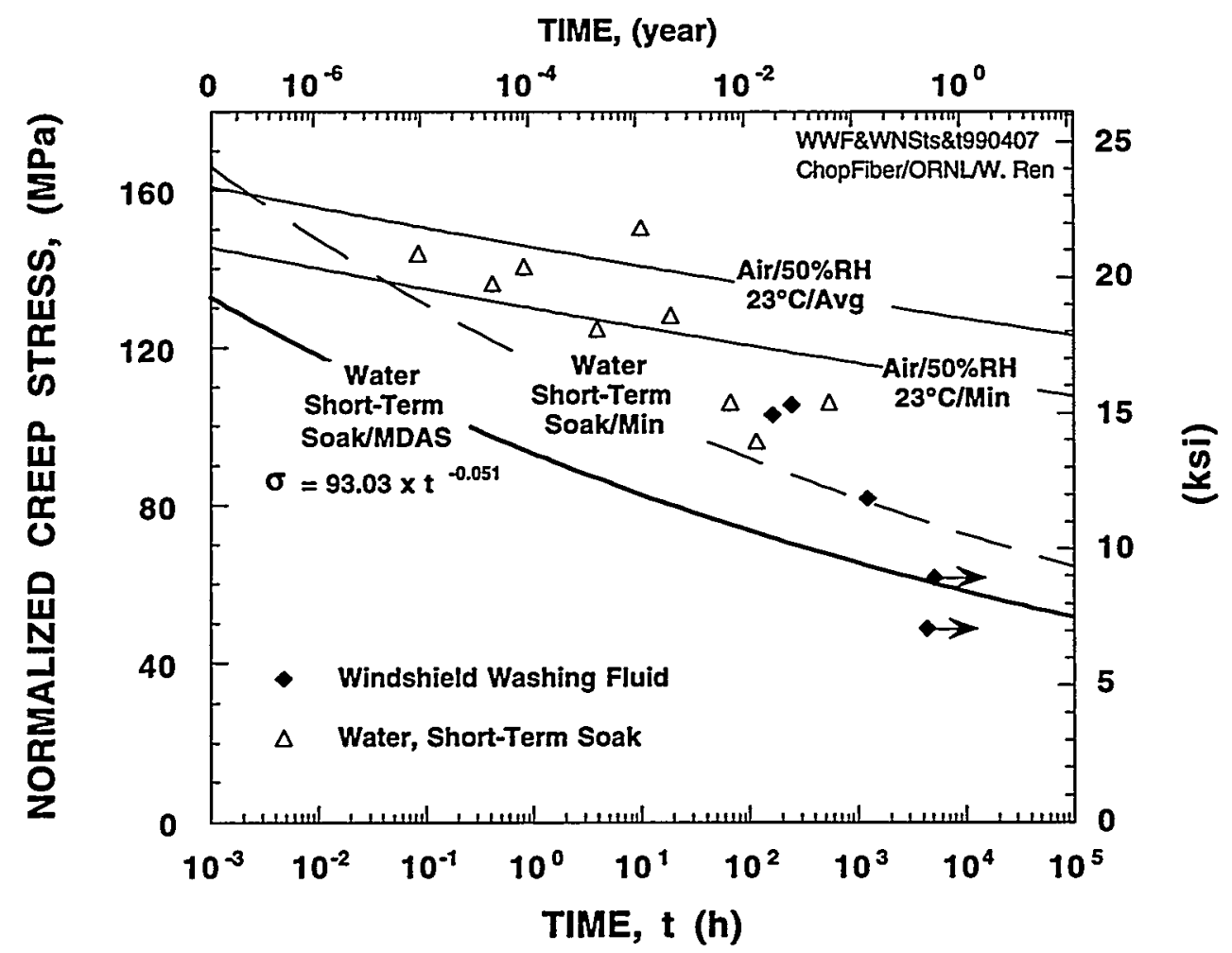

Fig. 14.7. Effect of windshield washer fluids on creep rupture compared to distilled water effect. 
water with short-term presoak are suggested for windshield washer fluid exposure for practical design purposes.

The battery acid splatter condition was simulated using a solution of $35 \mathrm{wt} \%$ sulfuric acid plus $65 \mathrm{wt} \%$ distilled water to again avoid subtle commercial variations. The specimen was prepared by placing about $3 \mathrm{~cm}^{3}$ of the solution on the virgin surface and then heating it at $66^{\circ} \mathrm{C}$ for $24 \mathrm{~h}$ so that absorption occurred. The test results are presented in Fig. 14.8, which indicates that creep-rupture stress for battery acid splatter may be slightly lower than, but still comparable to, that for water with the long-term presoak. Since battery acid splatter is a feasible condition for automotive structural components, its minimum creep-rupture stress and maximum design allowable stress curves and equation are developed and presented in Fig. 14.8. Note that the curves and equation were developed based on ruptured data points excluding the two on-going points marked with arrows.

Low-frequency load cycling tests were conducted to simulate acceleration, curves, and rough roadway conditions. ${ }^{*}$ The previous study on the reference material indicated that motor vibration is less damaging than low-frequency load cycling and therefore can be represented by the low-frequency load cycling condition for design purposes. ${ }^{14}$ The minimum-to-maximum stress ratio $\left(\sigma_{\min } / \sigma_{\max }\right)$ was 0.5 , and the frequency was 30 cycles per minute. The test results are given in Fig. 14.9, which shows that the creep-rupture stresses under low-frequency cyclic loading are comparable to those for water with the long-term presoak. Therefore, the minimum creeprupture stress and the maximum design allowable stress curves and equation for water with

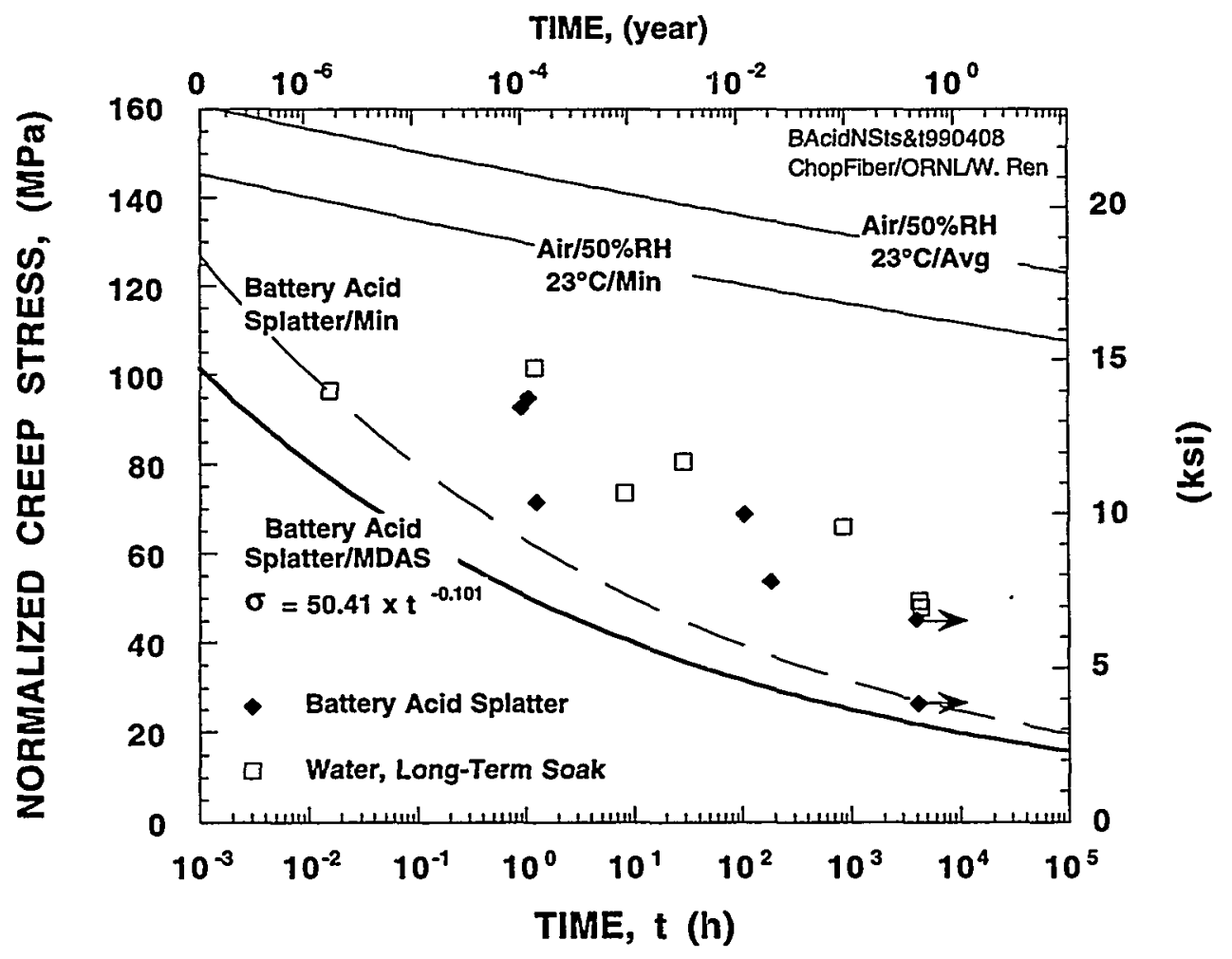

Fig. 14.8. Effect of battery acid splatter on creep rupture.

\footnotetext{
* The low-frequency load cycling is a creep-fatigue loading condition, where creep damage and fatigue damage are both developing.
} 
TIME, (year)

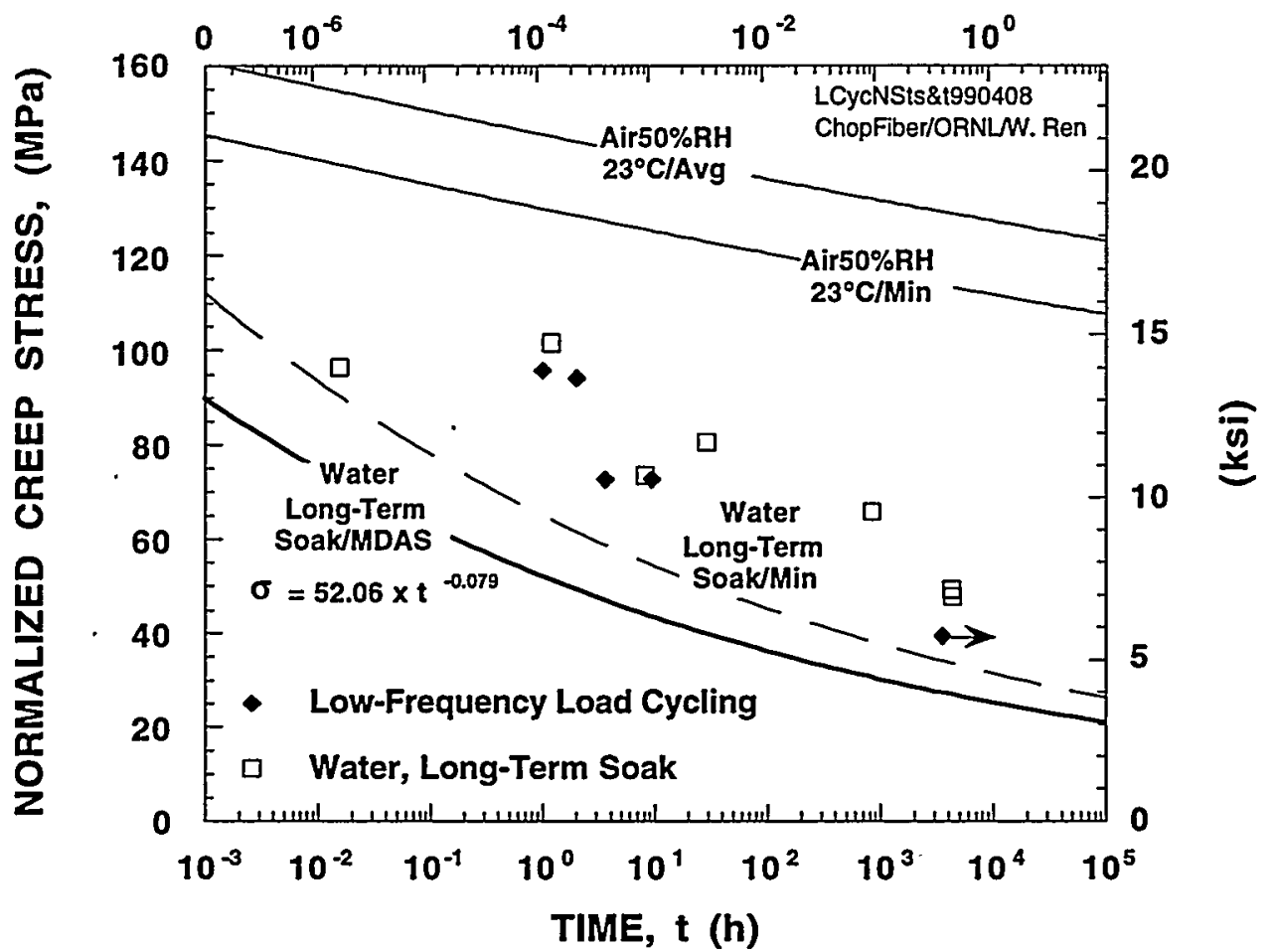

Fig. 14.9. Effect of low-frequency load cycling on creep rupture.

the long-term presoak are suggested for considering low-frequency load cycling effects in design. Here, as throughout this study, there may be synergisms (e.g., an interaction between water effects and load cycling effects).

The recommended maximum creep-rupture design allowable stresses for the above representative environments are calculated and listed in Table 14.2 for specific no-rupture time limits using Eq. (14.2) with the appropriate B and $m$ values.

Table 14.2. Maximum design allowable stresses in various environments for specific no-rupture time limits

\begin{tabular}{|c|c|c|c|c|c|c|c|c|c|c|}
\hline \multirow{3}{*}{ Environment } & \multicolumn{10}{|c|}{$\begin{array}{l}\text { Maximum design allowable stress } \\
(\mathrm{MPa})\end{array}$} \\
\hline & \multicolumn{4}{|c|}{ Hours } & \multicolumn{4}{|c|}{ Years } & \multicolumn{2}{|c|}{ Parameter } \\
\hline & 10 & 1000 & 3000 & 5000 & 1 & 5 & 10 & 15 & B & $\mathrm{m}$ \\
\hline Water $23^{\circ} \mathrm{C}$, short soak & 82.72 & 65.41 & 61.84 & 60.25 & 58.55 & & & & 93.03 & -0.051 \\
\hline $\begin{array}{c}\text { Water } 23^{\circ} \mathrm{C}, 1000-\mathrm{h} \\
\text { soak (estimated) }\end{array}$ & 75.28 & 59.52 & 56.27 & 54.83 & 53.28 & & & & 84.66 & -0.051 \\
\hline Water $23^{\circ} \mathrm{C}$, long soak & 43.40 & 30.17 & 27.66 & 26.56 & 25.41 & & & • & 52.06 & -0.079 \\
\hline Water $50^{\circ} \mathrm{C}$, long soak & 43.40 & 30.17 & 27.66 & 26.56 & & & & & 52.06 & -0.079 \\
\hline $\begin{array}{l}\text { Windshield washer } \\
\text { fluid }\end{array}$ & 82.72 & 65.41 & $\dot{6} 1.84$ & 60.25 & 58.55 & & & & 93.03 & -0.051 \\
\hline Battery acid splatter & 39.95 & 25.09 & 22.46 & 21.33 & 20.15 & 17.13 & 15.97 & 15.33 & 50.41 & -0.101 \\
\hline Load cycling & 43.40 & 30.17 & 27.66 & 26.56 & & & & & 52.06 & -0.079 \\
\hline
\end{tabular}




\subsection{COMPRESSIVE BEHAVIOR}

\subsubsection{Failure in Air with $50 \% \mathrm{RH}$ at Room Temperature}

Test results for compressive loading in air $/ 50 \% \mathrm{RH}$ at $23^{\circ} \mathrm{C}$ are presented in Fig. 14.10. The limited data suggest that creep-rupture behavior under compression is comparable to that under tension. Therefore, the minimum creep-rupture stress and maximum design allowable stress curves and equation for tension are recommended for compressive loading. The recommended maximum creep-rupture design allowable stresses for compressive loading in air/50\%RH at $23^{\circ} \mathrm{C}$ are calculated and listed in Table 14.3 for specific no-rupture time limits using Eq. (14.2) with the appropriate $B$ and $m$ values.

\subsubsection{Temperature Effects in Air}

Figure 14.11 shows how temperature combined with compression affects creep-rupture strength. The two solid lines at the top represent average and minimum stresses in the baseline condition, i.e., air $/ 50 \% \mathrm{RH}$ at $23^{\circ} \mathrm{C}$ under tension. Changing stress from tension to compression does not obviously affect the creep-rupture stress, as indicated by the filled triangles for compression at $23^{\circ} \mathrm{C}$. Increasing the temperature to $120^{\circ} \mathrm{C}$ under tension brings the stress below the minimum curve, as indicated by the crossed squares. Then changing the stress from tension to compression brings the stress significantly down to the filled circles. The combination of temperature and compressive loading may have induced matrix shear and fiber buckling mechanisms, which can greatly decrease creep-rupture strength.

TIME, (year)

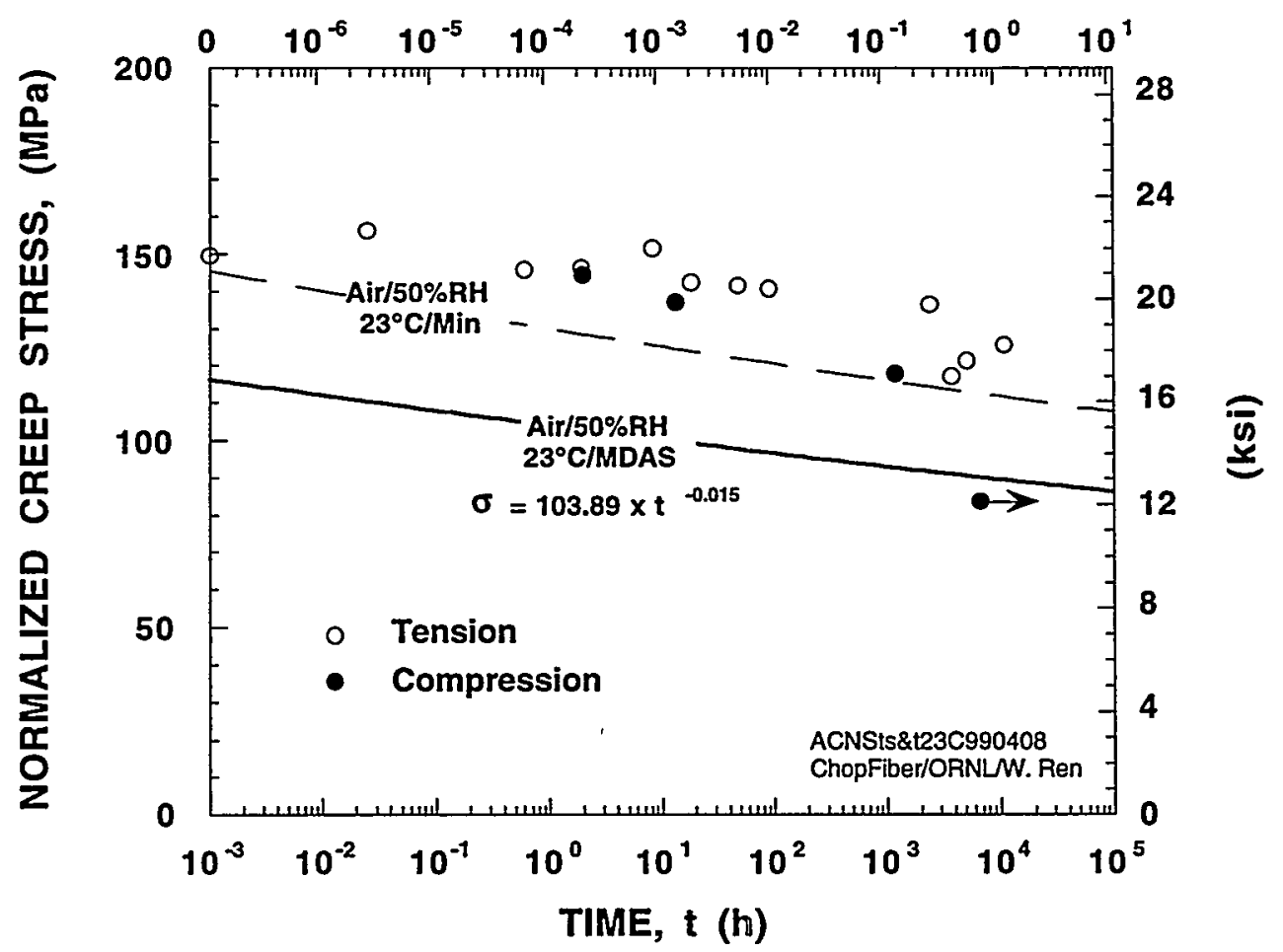

Fig. 14.10. Creep-rupture behavior under compression compared to tensile results. 
Table 14.3. Maximum design allowable stresses for compression in various environments for specific no-rupture time limits

\begin{tabular}{|c|c|c|c|c|c|c|c|c|c|c|}
\hline \multirow{3}{*}{ Condition } & \multicolumn{10}{|c|}{$\begin{array}{l}\text { Maximum design allowable stress } \\
(\mathrm{MPa})\end{array}$} \\
\hline & \multicolumn{4}{|c|}{ Hours } & \multicolumn{4}{|c|}{ Years } & \multicolumn{2}{|c|}{ Parameter } \\
\hline & 10 & 1000 & 3000 & 5000 & 1 & 5 & 10 & 15 & B & $\mathrm{m}$ \\
\hline Air $23^{\circ} \mathrm{C}$ & 100.36 & 93.66 & 92.13 & 91.43 & 90.66 & 88.50 & 87.59 & 87.06 & 103.89 & -0.015 \\
\hline Air $120^{\circ} \mathrm{C}$ & 25.52 & 12.97 & 11.03 & 10.24 & & & & & 35.8 & -0.147 \\
\hline $\begin{array}{c}\text { Water } 23^{\circ} \mathrm{C}, \\
\text { long soak }\end{array}$ & 43.40 & 30.17 & 27.66 & 26.56 & 25.41 & & & & 52.06 & -0.079 \\
\hline $\begin{array}{c}\text { Water } 50^{\circ} \mathrm{C}, \\
\text { long soak }\end{array}$ & 43.40 & 30.17 & 27.66 & 26.56 & & & & & 52.06 & -0.079 \\
\hline
\end{tabular}

TIME, (year)

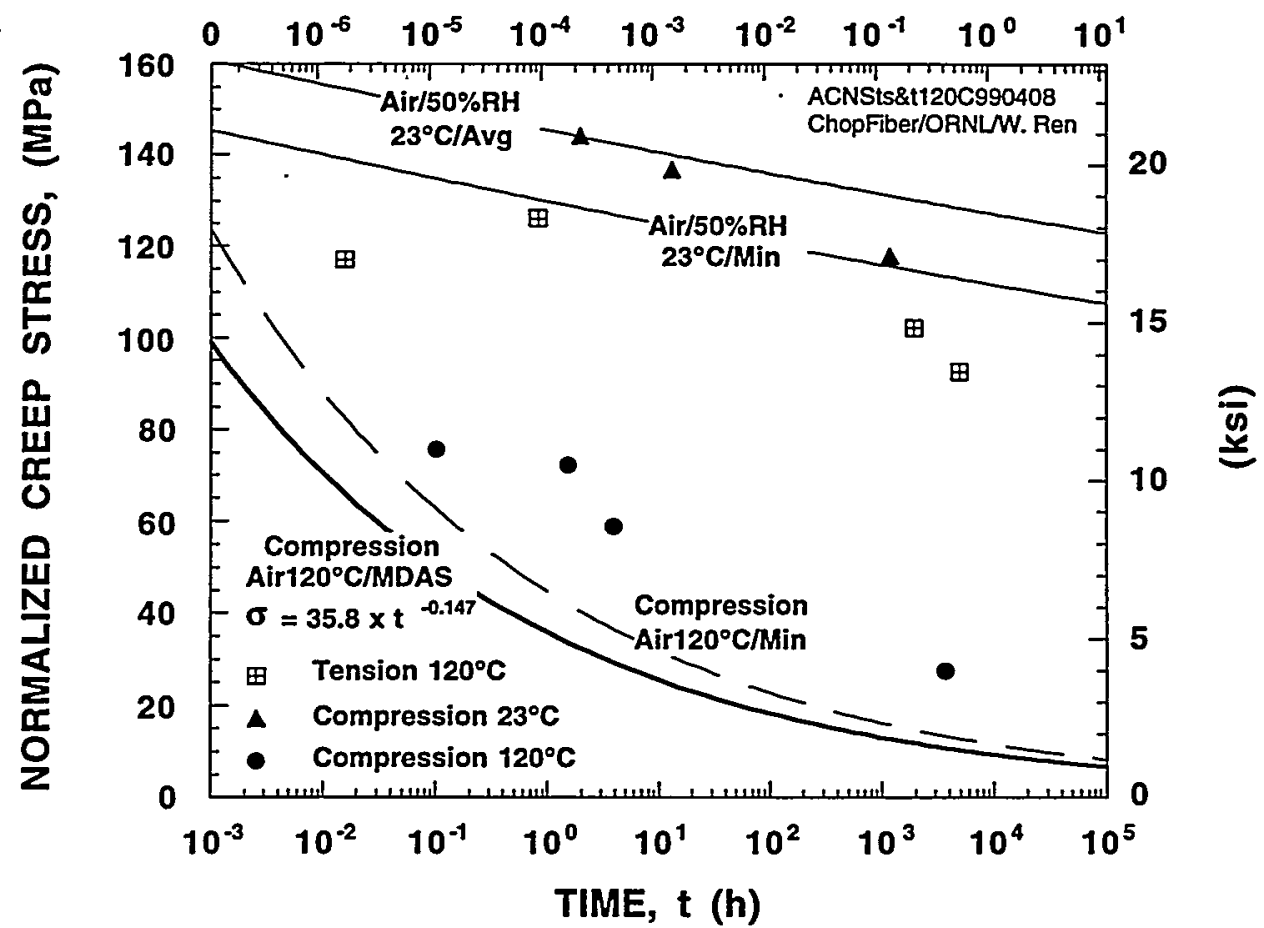

Fig. 14.11. In-air, $120^{\circ} \mathrm{C}$, creep-rupture behavior under compression compared to tensile results.

The minimum creep-rupture stress and maximum design allowable stress curves and the equation for air at $120^{\circ} \mathrm{C}$ under compression are given in Fig. 14.11. The recommended maximum creep-rupture design allowable stresses for compressive loading in air $/ 50 \% \mathrm{RH}$ at $120^{\circ} \mathrm{C}$ are calculated and listed in Table 14.3 for specific no-rupture time limits using Eq. (14.2) with the appropriate $B$ and $m$ values. 


\subsubsection{Environmental Effects}

The investigation of environmental effects under compression included water immersion during testing at 23 and $50^{\circ} \mathrm{C}$, both with long-term presoak at $50^{\circ} \mathrm{C}$ and battery acid splatter at $23^{\circ} \mathrm{C}$.

Test results for water immersion tests at $23^{\circ} \mathrm{C}$ under compression are given in Fig. 14.12. Obviously, the creep-rupture stresses under compression are comparable to those under tension. Therefore, the minimum creep-rupture stress and maximum design allowable stress curves and equation for tension are suggested for compression.

The effect of raising the water test temperature under compression is shown in Fig. 14.13, which indicates that compression at $50^{\circ} \mathrm{C}$ in distilled water slightly decreases creep-rupture stress. However, since all the data points are still bounded by the minimum creep-rupture stress curve for tension at $23^{\circ} \mathrm{C}$, and since a continuous compressive load in water at $50^{\circ} \mathrm{C}$ after a long-term presoak is an unlikely automotive service condition, the minimum creep-rupture stress and the maximum design allowable stress curves and equation for tension at $23^{\circ} \mathrm{C}$ are recommended.

Test results for battery acid compression are shown in Fig. 14.14. Contrary to the expectation, the creep-rupture stresses under compression are not lower but obviously higher than those under tension. Normally, creep-rupture stress is lower under compression than tension because of additional failure mechanisms such as matrix shearing and fiber buckling, and further stress

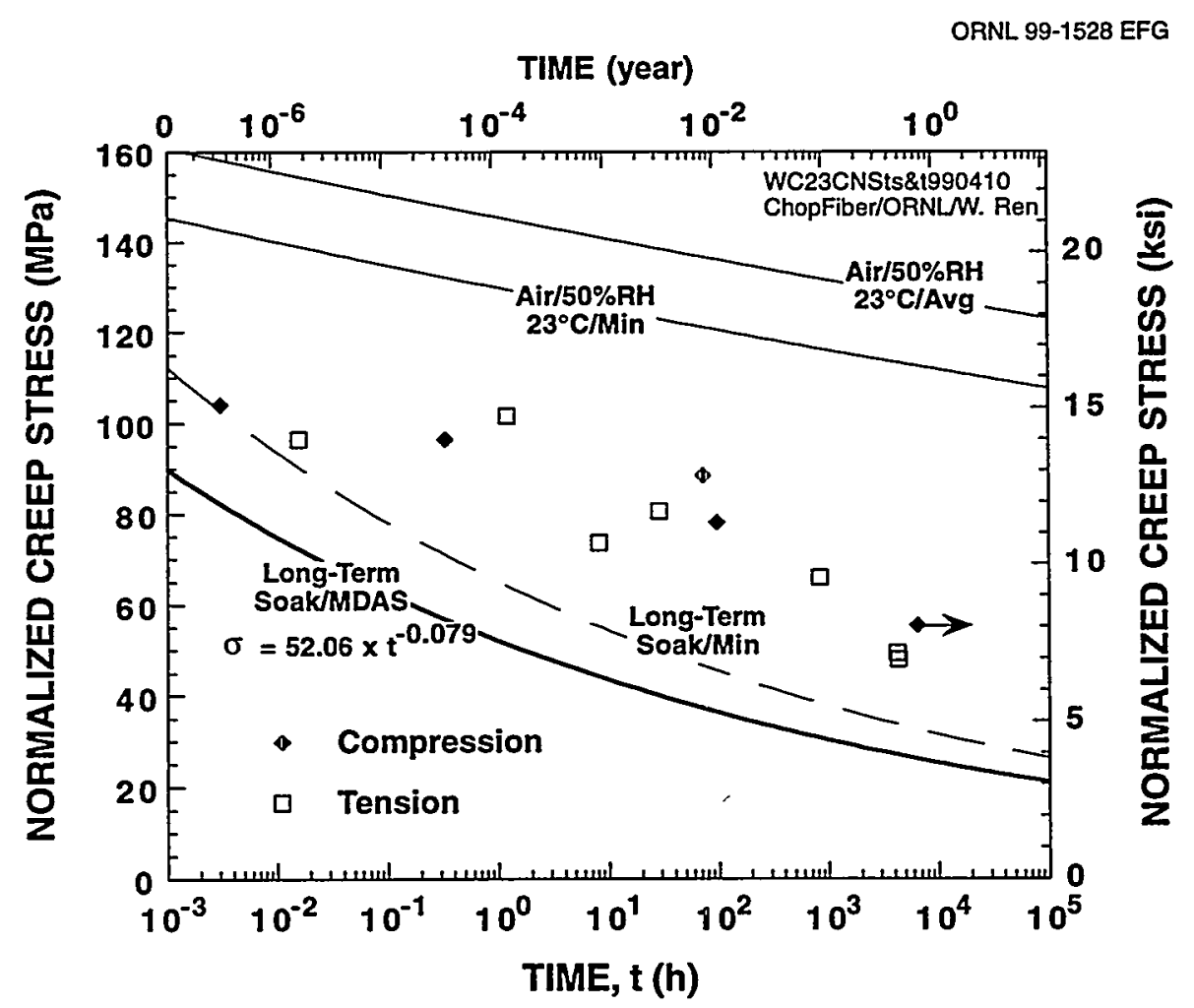

Fig. 14.12. Creep-rupture stress in water at $23^{\circ} \mathrm{C}$ under compression. The minimum creep-rupture and the maximum design allowable stress curves and equation for tension are suggested for compression. 
TIME (year)

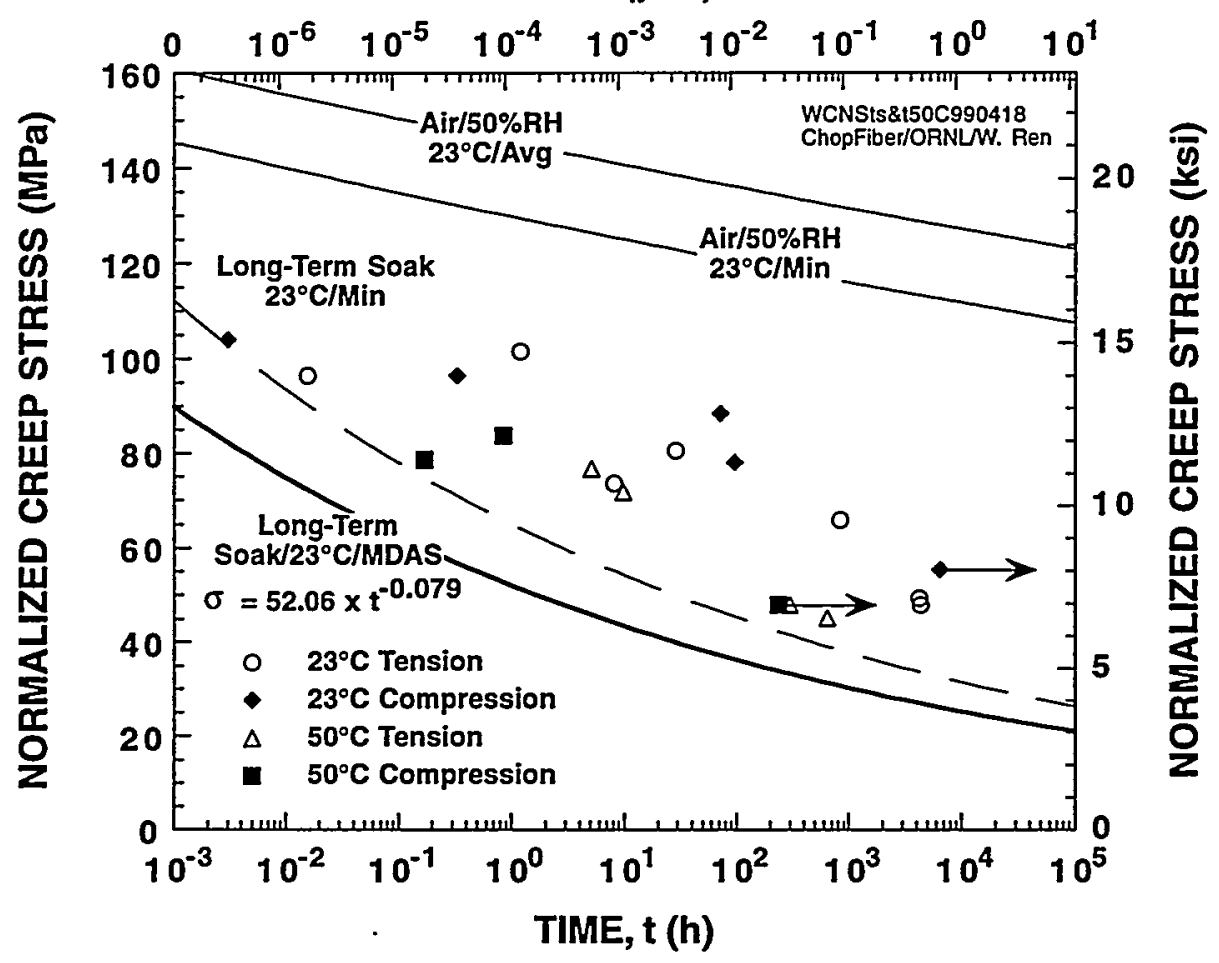

Fig. 14.13. Compression creep rupture at $50^{\circ} \mathrm{C}$ in distilled water. All the data points are still bounded by the minimum curve for tension at $23^{\circ} \mathrm{C}$.

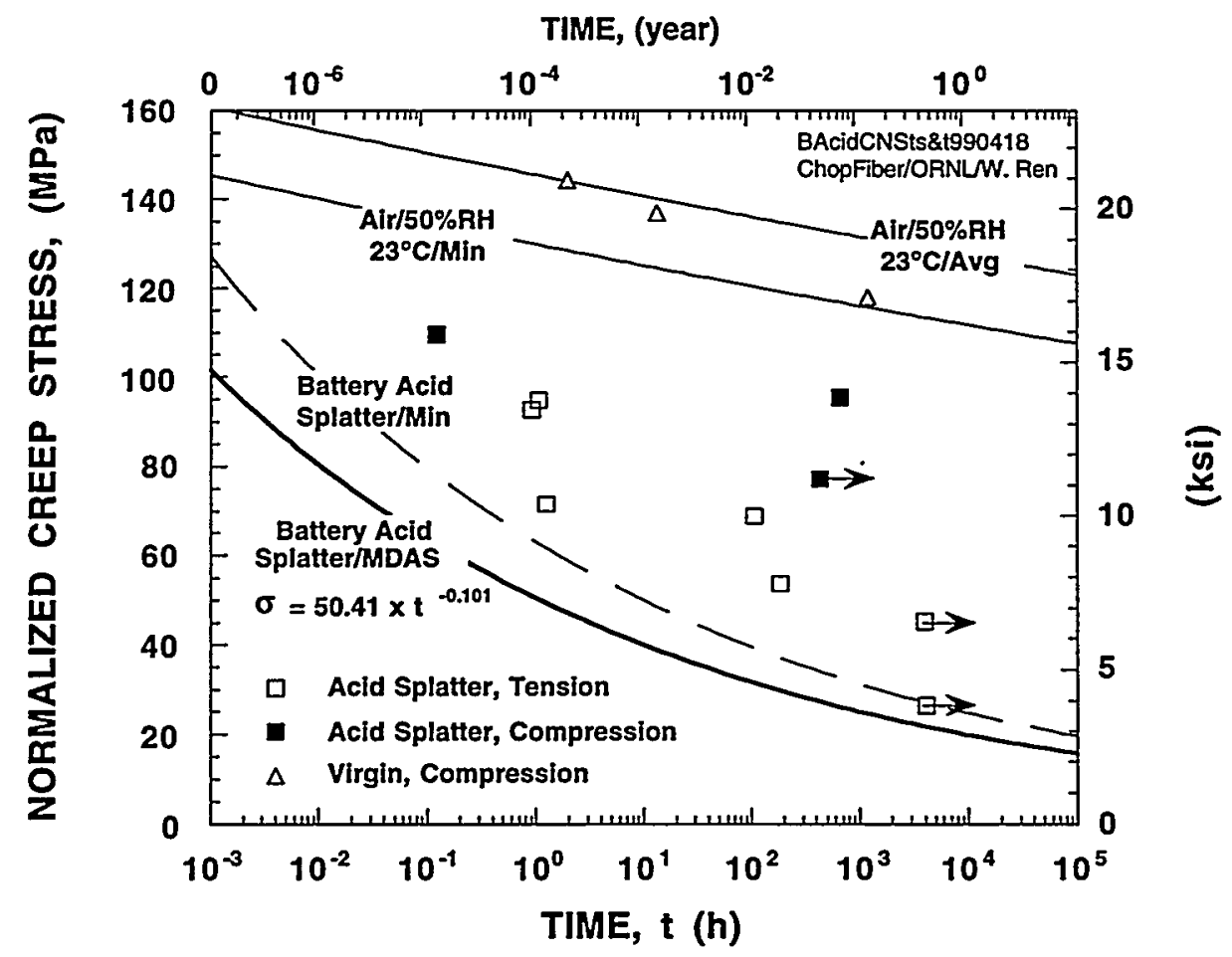

Fig. 14.14. Effect of battery acid splatter on creep rupture. 
degradation can be caused by the presence of corrosive liquid or moisture penetrating microcracks under compression. Analysis of the test process reveals that this abnormal behavior under compression in Fig. 14.14 was caused by changes in the specimen condition. Both specimens for tension and compression were prepared at the same time with the same procedure as previously described. The freshly prepared specimens were good absorbents of moisture. The surface of the freshly prepared specimens were always covered with a thin layer of corrosive liquid formed by the acid and moisture absorbed from the surrounding atmosphere. Under load, this corrosive liquid is believed to penetrate into microcracks of the specimen and thus lower the creeprupture stress. The tests under tension were conducted with freshly prepared specimens. Unfortunately, testing facilities for compressive loading did not become available until several months later when the specimens became completely dried. Without the presence of the corrosive liquid, creep-rupture stress obviously recovered under compression as indicated in Fig. 14.14. However, the damage of battery acid splatter to creep-rupture stress is still obvious when the compressive data are compared with the virgin material data in Fig. 14.14. It can be concluded that the most damaging time for battery acid is right after the splatter and absorption. As the material dries with the elapse of time, creep-rupture stress will partially recover.

The recommended maximum creep-rupture design allowable stresses, given as stress reduction factors, for the above representative environments are calculated and listed in Table 14.4 for specific no-rupture time limits using Eq. (14.2) with the appropriate B and $\mathrm{m}$ values. All the recommended maximum design allowable stress curves are compared in Fig. 14.15. Note the time limits for specific environments in Tables 14.1-14.3 are not presented in the figure due to limited space.

In addition to the maximum design allowable stresses given in Tables 14.1-14.3, stress reduction factors are also developed for convenient engineering design. The stress reduction factors were derived by dividing the stresses in Tables $14.1-14.3$ by the row for air/50\%RH at $23^{\circ} \mathrm{C}$ in Table 14.1 , i.e., the maximum design allowable stresses in air $/ 50 \% \mathrm{RH}$ at $23^{\circ} \mathrm{C}$ for specific no-rupture time. These stress reduction factors are listed in Table 14.4.

Table 14.4. Stress reduction factors in representative environments for specific no-rupture time limits

\begin{tabular}{|c|c|c|c|c|c|c|c|c|}
\hline \multirow{3}{*}{ Environment ${ }^{a}$} & \multicolumn{8}{|c|}{ Time } \\
\hline & \multicolumn{4}{|c|}{ Hours } & \multicolumn{4}{|c|}{ Years } \\
\hline & 10 & 1000 & 3000 & 5000 & 1 & 5 & 10 & 15 \\
\hline $\begin{array}{l}-40^{\circ} \mathrm{C} \text { air } / \mathrm{T}, 23^{\circ} \mathrm{C} \text { air } / \mathrm{T} \& \mathrm{C} \text {, and } \\
50^{\circ} \mathrm{C} \text { air } / \mathrm{T}\end{array}$ & 1.00 & 1.00 & 1.00 & 1.00 & 1.00 & 1.00 & 1.00 & 1.00 \\
\hline $120^{\circ} \mathrm{C}$ air/ $\mathrm{T}$ & 0.79 & 0.77 & 0.76 & 0.76 & & & & \\
\hline $\begin{array}{l}23^{\circ} \mathrm{C} \text { water, short soak } / \mathrm{T} \text {, and } \\
\text { windshield washer fluid } / \mathrm{T}\end{array}$ & 0.82 & 0.70 & 0.67 & 0.66 & 0.65 & & & \\
\hline $23^{\circ} \mathrm{C}$ water, $1000-\mathrm{h}$ soak $/ \mathrm{T}$ & 0.75 & 0.64 & 0.61 & 0.60 & 0.59 & & & \\
\hline $23^{\circ} \mathrm{C}$ water, long soak $/ \mathrm{T} \& \mathrm{C}$ & 0.43 & 0.32 & 0.30 & 0.29 & 0.28 & & & \\
\hline $\begin{array}{l}50^{\circ} \mathrm{C} \text { water, long soak } / \mathrm{T} \text {; load } \\
\text { cycling/T; and } 50^{\circ} \mathrm{C} \text { water, } \\
\text { long soak/C }\end{array}$ & 0.43 & 0.32 & 0.30 & 0.29 & & & & \\
\hline Battery acid splatter/T & 0.40 & 0.27 & 0.24 & 0.23 & 0.22 & 0.19 & 0.18 & 0.18 \\
\hline $120^{\circ} \mathrm{C}$ air $/ \mathrm{C}$ & 0.25 & 0.14 & 0.12 & 0.11 & & & & \\
\hline
\end{tabular}

$a_{\mathrm{T}}=$ tension, $\mathrm{C}=$ compression. 
TIME, (year)

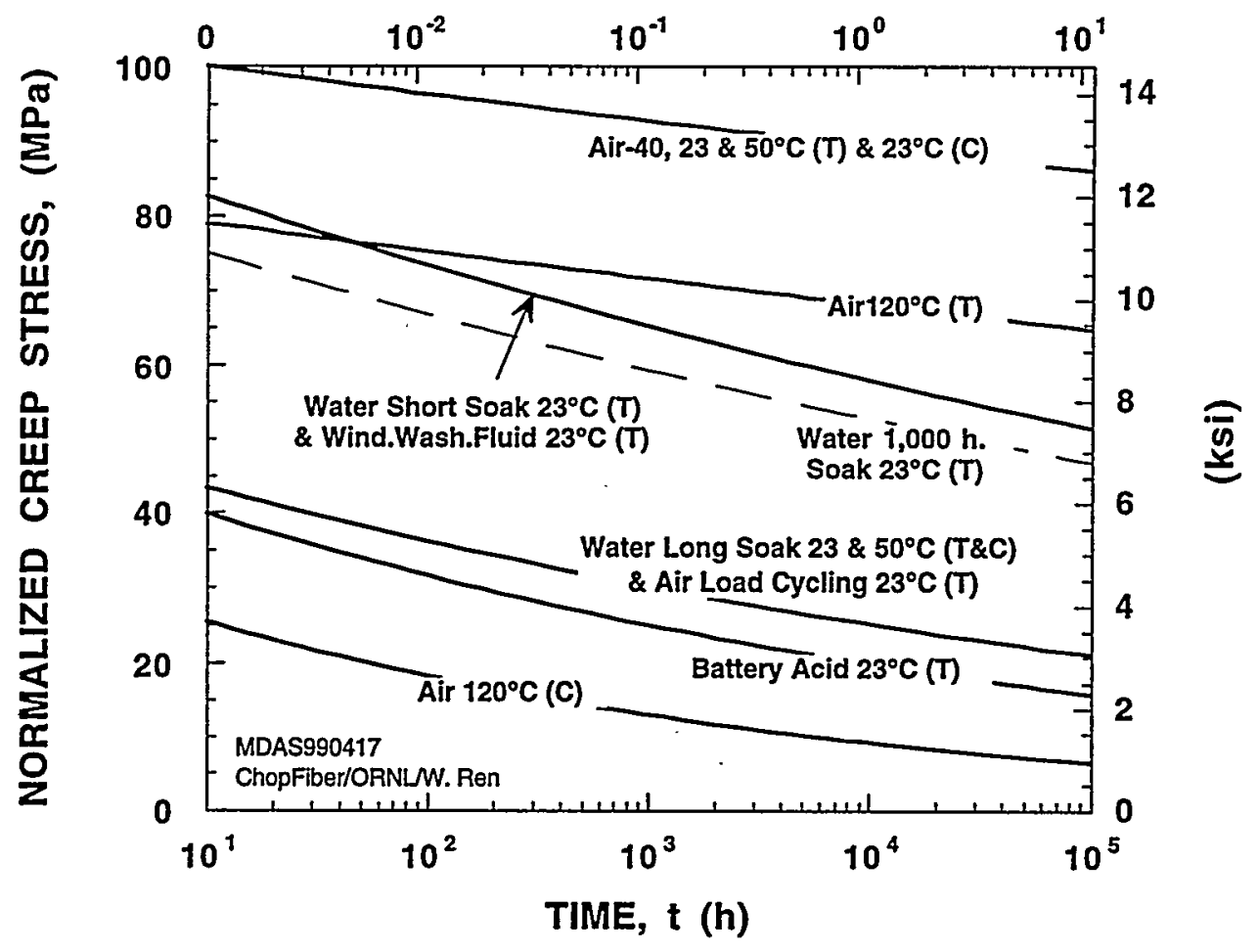

Fig. 14.15. Maximum design allowable stress curves in various simulated automotive environments. The dashed line is predicted.

\subsection{SUMMARY AND DISCUSSION}

For tensile loading, the design allowable stresses for various temperatures and times are given in Table 14.1. Table 14.4 shows, as creep-rupture stress reduction factors, the effects of various fluid conditions, temperature, and compressive loading on the basic room-temperature tensile allowable stresses. For the conditions examined, the reduction factors for tension and compression differed only in the $120^{\circ} \mathrm{C}$ air case. Recall from Chap. 8 that two fluid conditions have been adopted as practical bounding conditions:

1. Room-temperature water with a 1000-h presoak at room temperature.

2. Room-temperature windshield washer fluid with a $100-\mathrm{h}$ presoak at room temperature.

Of these two, Table 14.4 indicates the water to be most degrading to creep-rupture stress. The stress reduction factors for the water case are as follows:

\begin{tabular}{lll} 
Time & & $\begin{array}{c}\text { Reduction } \\
\text { factor }\end{array}$ \\
\cline { 1 - 1 } $10 \mathrm{~h}$ & & 0.75 \\
$1000 \mathrm{~h}$ & & 0.64 \\
$3000 \mathrm{~h}$ & & 0.61 \\
$5000 \mathrm{~h}$ & & 0.60 \\
1 year & & 0.59
\end{tabular}


Recall from Chap. 8 that the corresponding reduction factor for the UTS $(0 \mathrm{~h})$ is 0.91 , which is consistent with the above values.

Figure 14.16 compares the chopped fiber composite with the reference material studied in the previous investigation. ${ }^{1-2}$ The average creep-rupture stress for the chopped fiber composite is approximately $30 \mathrm{MPa}$ higher than that for the reference material in air with $50 \% \mathrm{RH}$ at $23^{\circ} \mathrm{C}$. Some selected environmental effects on creep-rupture stresses of the two materials are compared in Fig. 14.17 by their respective creep-rupture stress reduction factors. It should be pointed out that the reduction is relative to each material's own baseline stress, not the other's baseline stress. Obviously, the chopped-fiber composite is less vulnerable to environmental degradation than the reference material when creep-rupture stress is considered.

TIME, (year)

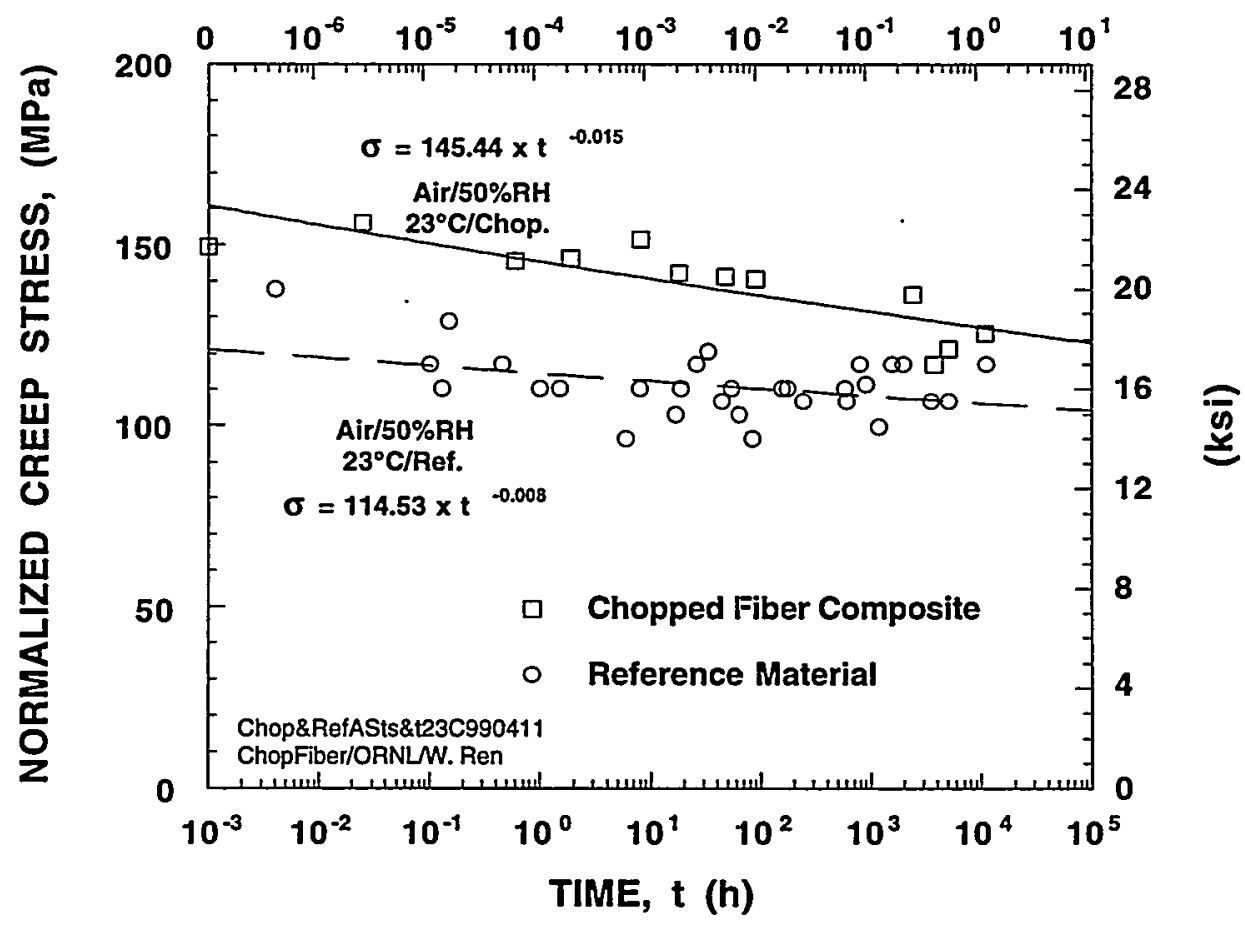

Fig. 14.16. Comparison between creep-rupture data for the chopped-fiber composite and data for the reference material for the baseline condition. 


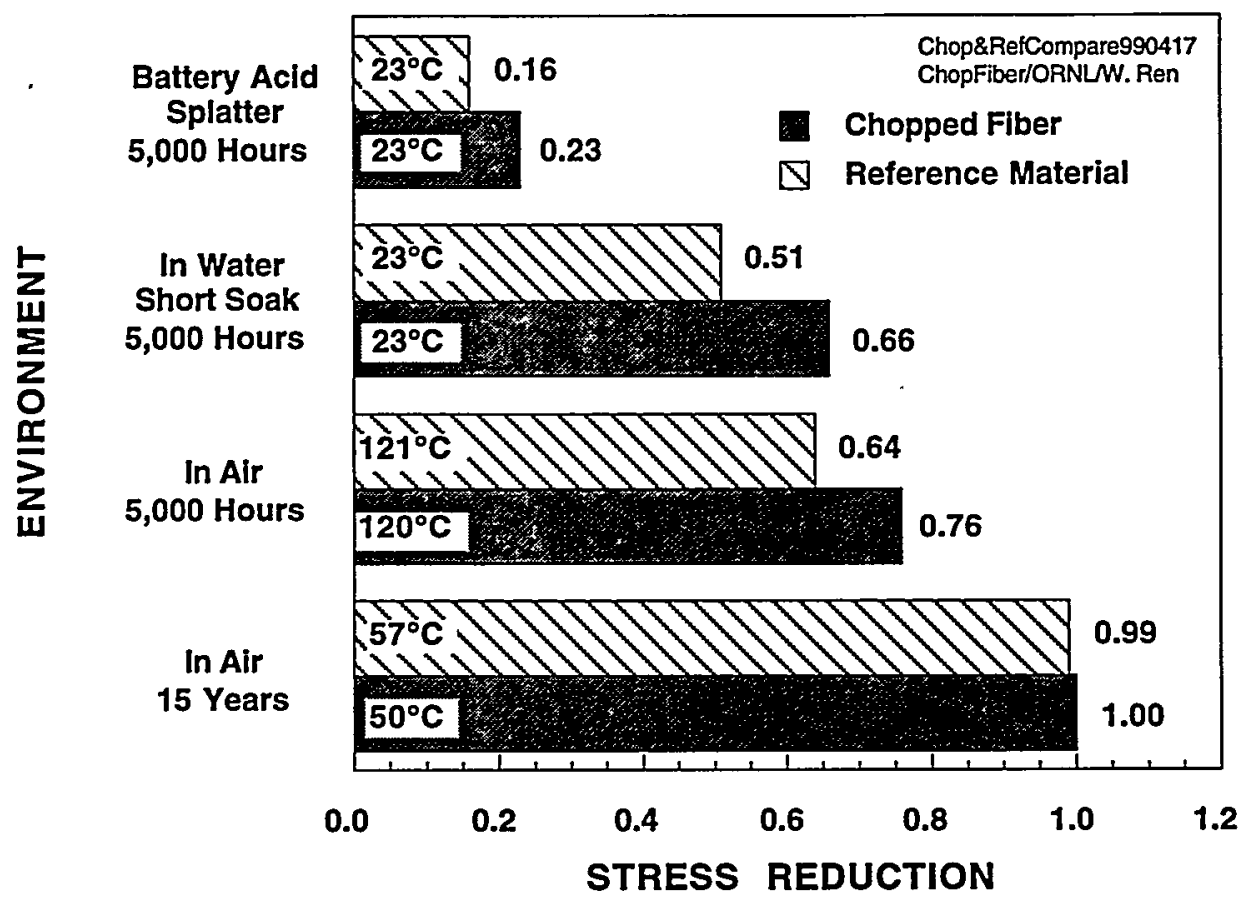

Fig. 14.17. Stress reduction for the chopped fiber and the reference material in the representative environments based on the respective maximum design allowable stresses in air/50\% RH. 


\title{
15. PRIOR LOAD EFFECTS
}

\author{
J. M. Corum, R. L. Battiste, W. Ren, and M. B. Ruggles
}

\subsection{INTRODUCTION}

The design rules in Ref. 1 for the reference CSM composite accounted for the effects of prior loadings on residual stiffness and strength. To quantify these effects for the chopped-fiber composite, a series of prior load effects studies were carried out. These addressed the following:

- effect of prior short-time static loads on stiffness:

- effects of prior fatigue cycles on stiffness, UTS, and creep-rupture strength; and

- effects of prior creep deformation on stiffness, UTS, and fatigue strength.

Each of these is discussed in the following sections.

\subsection{EFFECT OF PRIOR SHORT-TIME STATIC LOADS}

Subjecting a specimen to just a short-time tensile load can cause microstructural damage that is reflected in a loss in residual stiffness. To quantify this effect, several specimens from two different plaques were subjected to sequentially increasing loadings and then unloadings. After each unloading, the residual stiffness was measured. Six specimens from plaque B7 and four from plaque B10 were tested. In the case of the B7 specimens, loads of $14,27,41,54,68$, and $81 \%$ of the UTS were sequentially applied to each specimen. After each target load was reached, the specimen was unloaded, and the stiffness was checked. For the B10 specimens, the test history was modified to include additional stiffness checks for load levels of $10,12.5,15,17.5,20,22.5$, and $25 \%$ of the UTS. The average results for the two plaques are shown in Fig. 15.1. A quadratic fits the data fairly well.

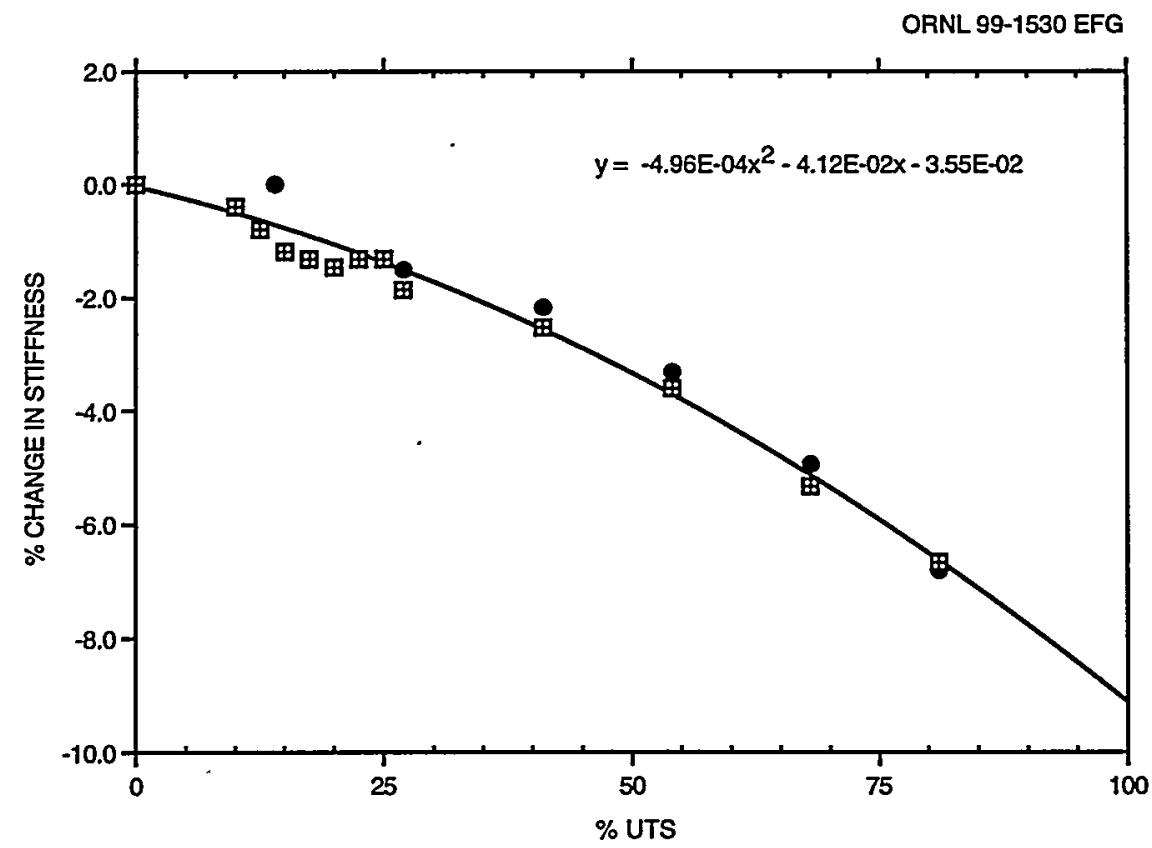

Fig. 15.1. Effect of prior short-time loads on stiffness. The circles are for plaque B7 tests, while the squares are for plaque B10 tests. 
In the case of the reference composite, a threshold of about $30 \%$ of the UTS was observed. Below this value prior loads resulted in no stiffness loss, presumably because no damage was produced. It is unclear from Fig. 15.1 whether or not a threshold exists for the chopped-fiber composite. If it does, it is considerably less than for the reference composite $(\sim 10$ vs $30 \%)$. However, the maximum reduction $(9.1 \%)$ is also less than for the reference composite $(13.1 \%)$.

For an allowable short-time stress value, $S_{0}$, of $99 \mathrm{MPa}$, which is $56 \%$ of the UTS, the stiffness reduction is 3.9\%. This is the value used in Part 1.

\subsection{EFFECT OF PRIOR FATIGUE CYCLES}

To quantify the effects of prior fatigue cycling, life fractions up to $\mathrm{n}_{\mathrm{N}} \mathrm{N}_{\mathrm{f}}=0.05$ were considered. With the additional fatigue strength reduction factor of 0.84 on cyclic stress recommended in Chap. 12, the allowable design life fraction is actually somewhat less than 0.05 .

The effect of prior cycling on residual stiffness was addressed in Chap. 12. Roomtemperature data presented in Fig. 12.7 showed stiffness reductions as high as $12 \%$ at $n / N_{\mathrm{f}}=$ 0.05 .

To evaluate the effect of prior cycling on subsequent UTS, 36 specimens from a single plaque, B6, were cycled to various life fractions and then tensile tested. Another six specimens were tensile tested with no prior cycling to provide a baseline UTS value for plaque B6. Fatigue tests $(R=0.1)$ were conducted at nominal maximum stress levels of 60,75 , and $100 \mathrm{MPa}$. Except for 6 of the 100-MPa tests, these were the actual applied stresses used in the tests. They were then converted to adjusted stresses (see Chap. 12), which were used to determine $\mathrm{N}_{\mathrm{f}}$ values from the plaque $\mathrm{B} 6$ baseline fatigue curve. This resulted in the life fractions being somewhat different from nominal target values. For six of the nominally $100-\mathrm{MPa}$ cyclic tests, the $100 \mathrm{MPa}$ was first adjusted. For these, the adjusted stresses were the applied stresses, in which case the resulting life fractions were 0.25 or 0.75 , as intended.

The results are plotted in Fig. 15.2. At first glance, these data appear to show little trend. However, if the 100-MPa points are ignored, the 60 - and $75-\mathrm{MPa}$ points are seen to be fairly self-consistent. There is a total of $18100-\mathrm{MPa}$ data points, and although they result in a curve-fit line that is fairly consistent with the other two lines, the scatter, especially at low $\mathrm{n}_{\mathbf{N}} \mathrm{N}_{\mathrm{f}}$ values, is large. Perhaps this is because so much damage is done on the initial loading to $100 \mathrm{MPa}$ that the subsequent fatigue effects are somewhat masked.

In Fig. 15.3, the curves in Fig. 15.2 have been translated vertically to pass through the origin, which they should. The curves are labeled with the nominal stress and the percentage of the plaque B6 UTS that the stress represents. The 75-MPa curve governs, and at a design life fraction of $\mathrm{n} / \mathrm{N}_{\mathrm{f}}=0.05$, the maximum strength loss is just $1.6 \%$. The corresponding value for the reference CSM composite was $1.5 \%$.

Similarly to the tests discussed above to determine the effects of prior fatigue on UTS, another series of tests was performed on plaque B31 specimens to determine the effects of 


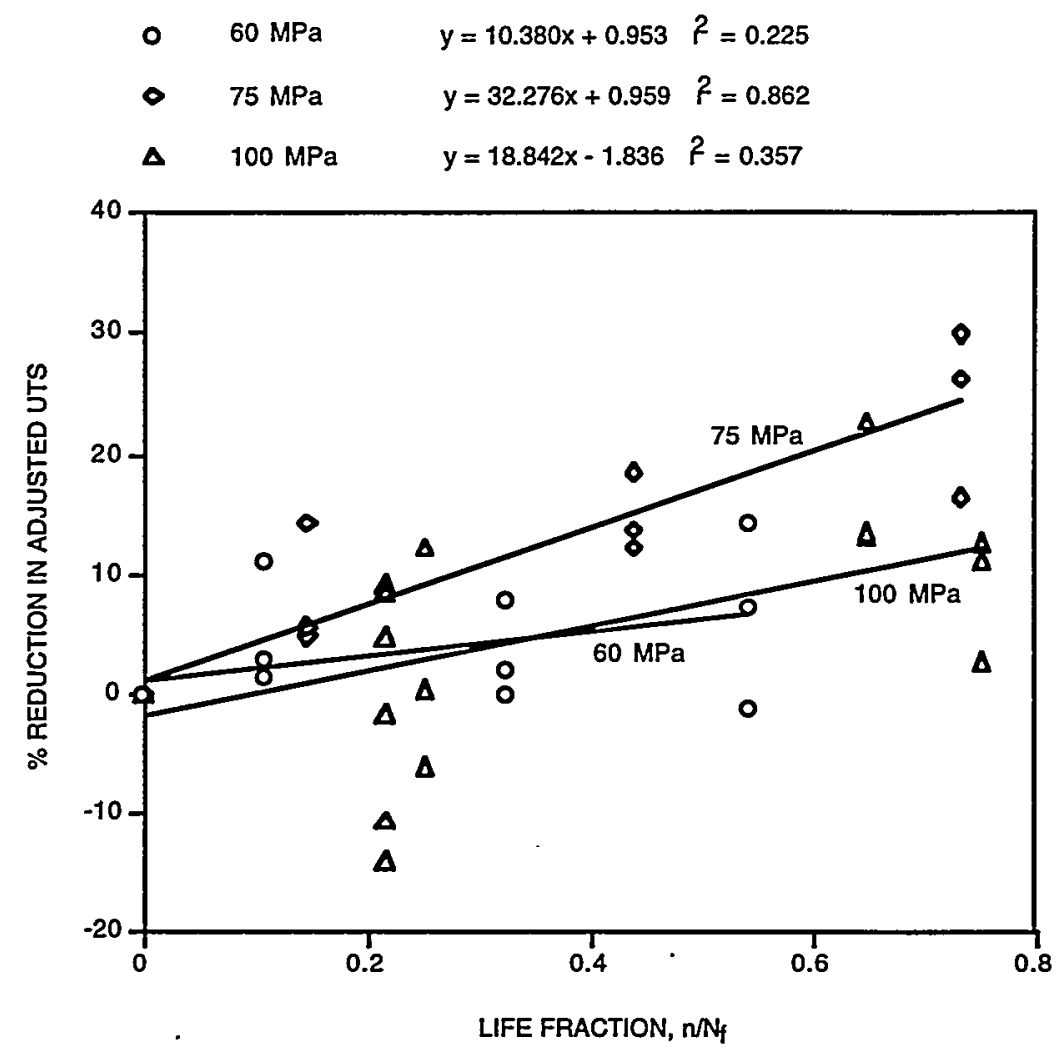

Fig. 15.2. Reduction in UTS produced by prior fatigue cycling to various fractions of the expected cyclic life.

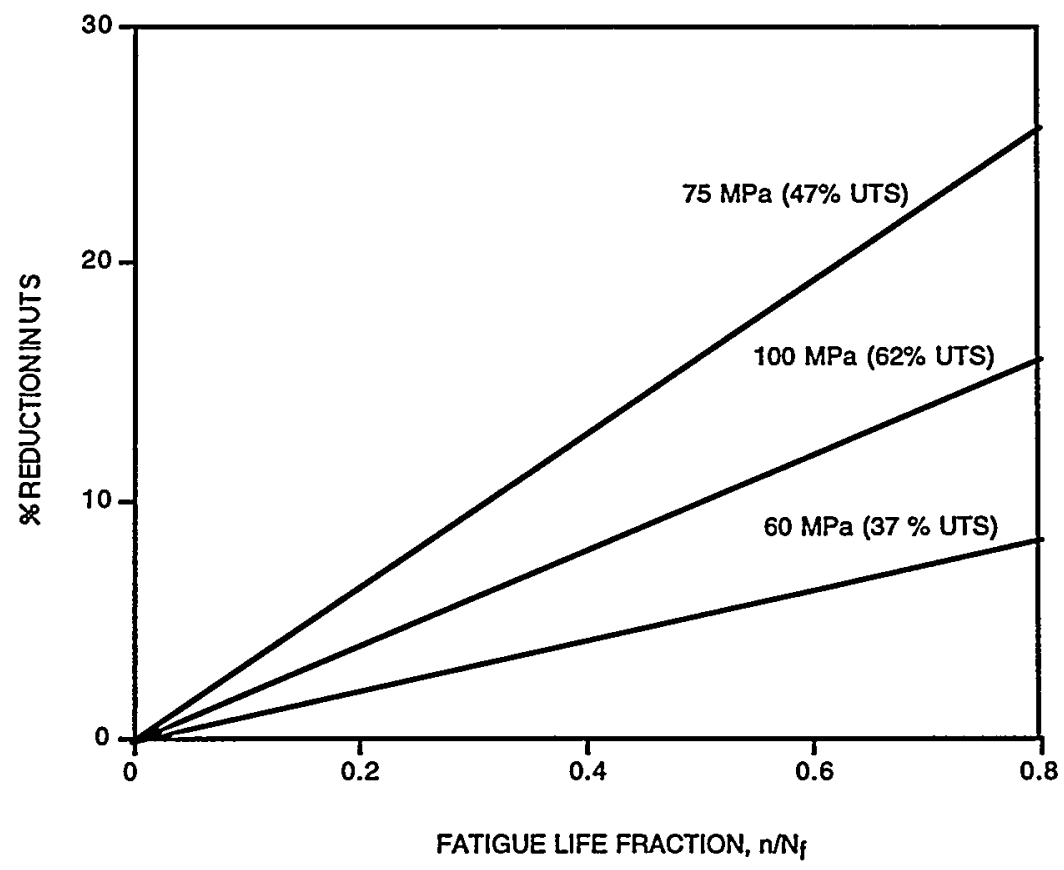

Fig. 15.3. Curves showing UTS reduction due to prior fatigue, shifted to pass through zero. The maximum reduction for $\mathrm{n}_{/} \mathrm{N}_{\mathrm{f}}=0.05$ is $1.6 \%$ (from the $75-\mathrm{MPa}$ curve). 
prior fatigue on creep-rupture strength. ${ }^{*}$ Six tests were performed, all at an adjusted stress level of $93 \mathrm{MPa}$ (the adjusted maximum cyclic fatigue stress was $93 \mathrm{MPa}$ in all cases, as was the adjusted creep stress). Three specimens were cycled to $\mathrm{n} / \mathrm{N}_{\mathrm{f}}=0.2$, and three were cycled to $\mathrm{n}_{/} \mathrm{N}_{\mathrm{f}}=0.6$.

The results are shown in Fig. 15.4. The creep-rupture lines for the two life fractions were assumed to be parallel to that for the as-received specimens. Interpolation between the three curves was used to estimate strength values for $\mathrm{n}_{\mathbf{N}} \mathrm{N}_{\mathrm{f}}=0.05$. Using these latter values, it was found that at $5000 \mathrm{~h}$ the creep-rupture strength reduction is $5.1 \%$. At 15 years, the reduction is $5.3 \%$. A value of $3 \%$ was used for the reference composite.

TIME, (year)

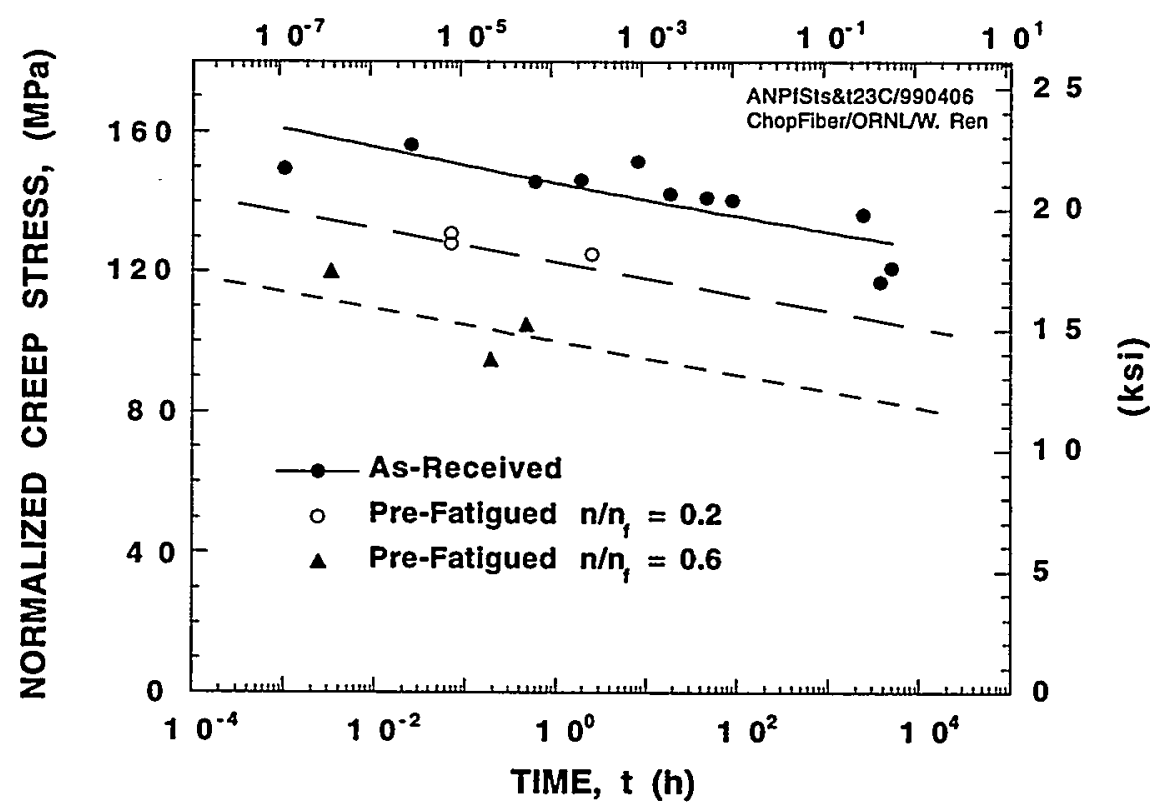

Fig. 15.4. Creep-rupture curves showing effect of prior fatigue cycling.

\subsection{EFFECT OF PRIOR CREEP DEFORMATION}

A small test series was carried out to assess the effects of prior creep on tensile and fatigue properties. Six specimens, three for subsequent tensile tests and three for subsequent fatigue tests, were precrept at an adjusted stress level of $93 \mathrm{MPa}(53 \%$ of the UTS). All of the specimens were from plaque B31. In all cases, the creep duration was that governed by the $0.8 \mathrm{~S}_{\mathrm{r}}$ design limit (the allowable design time corresponding to $93 \mathrm{MPa}$ being $80 \%$ of the minimum stress to produce rupture). This time was $1000 \mathrm{~h}$ (see Fig. 14.1).

The resulting average stiffness change from the three tensile tests was $-13.1 \%$, and the average UTS change was $-3.6 \%$. It can be seen from Fig. 15.1 that the stiffness loss due to the initial loading was $3.6 \%$; thus an almost $10 \%$ loss can be attributed to creep. In the case of

\footnotetext{
*Creep strains were not measured in these tests since similar tests on the reference composite indicated no effect on creep deformation.
} 
the reference composite, the stiffness loss was simply that due to just the initial loading; the UTS was unaffected.

The three fatigue tests were all run at a maximum adjusted stress of $93 \mathrm{MPa}$, the same value as used for the prior creep. The results are compared in Fig. 15.5 with B31 baseline results. As can be seen, there is no apparent effect of the prior creep on subsequent fatigue strength.

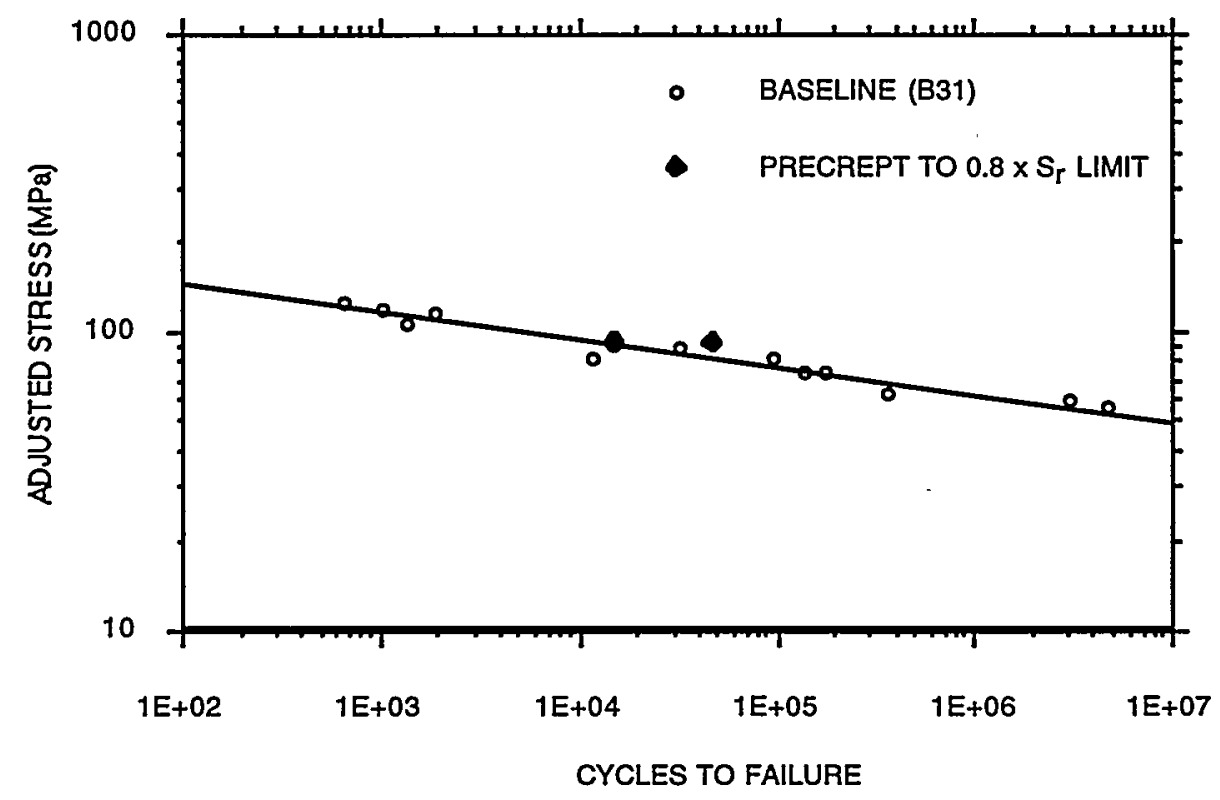

Fig. 15.5. Effect of prior creep on fatigue. The low-cycle precrept data point actually represents two nearly identical test results.

\subsection{SUMMARY AND DISCUSSION}

The various reductions that have been established in this chapter are summarized in Table 15.1. Corresponding reference composite reductions are shown in parenthesis.

The reductions shown in Table 15.1 for the chopped-fiber composite were factored into the rules of Part 1. A comparison between factors in Table 15.1 for the two composites indicates that, in general, the effects of prior loads appears to be somewhat higher in the chopped-fiber composite than in the reference CSM composite. 
Table 15.1. Summary of prior load effects

\begin{tabular}{|c|c|c|c|c|}
\hline \multirow{2}{*}{ Prior load } & \multicolumn{2}{|c|}{ Tensile } & \multirow{2}{*}{$\begin{array}{l}\text { Fatigue } \\
\text { strength }\end{array}$} & \multirow{2}{*}{$\begin{array}{l}\text { Creep-rupture } \\
\text { strength }\end{array}$} \\
\hline & $E$ & UTS & & \\
\hline $\begin{array}{l}\text { Short-time static to } S_{\circ} \\
\text { (56\% UTS) }\end{array}$ & $\begin{array}{c}-3.9 \\
(-4.5 \%)\end{array}$ & & & \\
\hline $\begin{array}{l}\text { Fatigue cycling to } \\
\mathrm{n} / \mathrm{N}_{\mathrm{f}}=0.05\end{array}$ & $\begin{array}{l}\leq 12 \% \\
(<10 \%)\end{array}$ & $\begin{array}{l}-1.6 \% \\
(-1.5 \%)\end{array}$ & & $\begin{array}{l}5.1 \text { to } 5.3 \% \text { for } \\
5000 \mathrm{~h} \text { to } 15 \text { year } \\
(-3.0 \%)\end{array}$ \\
\hline $\begin{array}{l}\text { Creep at } 53 \% \text { UTS to } 0.8 \\
S_{\mathrm{r}} \text { design limit }\end{array}$ & $\begin{array}{l}-13.1 \% \\
(0 \%)^{a}\end{array}$ & $\begin{array}{c}-3.6 \% \\
(0 \%)\end{array}$ & $\begin{array}{l}0 \% \\
(-)\end{array}$ & \\
\hline
\end{tabular}

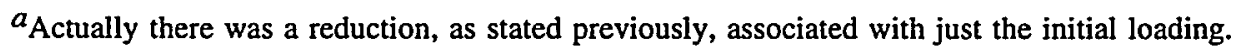




\title{
16. DAMAGE TOLERANCE
}

\author{
J. M. Corum, R. L. Battiste, and M. B. Ruggles
}

\subsection{INTRODUCTION}

The damage tolerance assessment procedure in Chap. 6 of Part 1 consisted of two parts: (1) demonstrating structural adequacy in the presence of a 6.4 -mm-diam hole in the worst possible location, and (2) determining the damage area and strength degradation for specified lowenergy impacts, such as roadway kickups, tool drops, and load drops in a pickup truck box. This chapter provides the background data and correlations for the latter.

Baseline impact damage area correlations were based on the results of tests in a pendulum impact facility and an air-gun facility, representing things like tool drops and roadway kickups, respectively. Specimens were the same in both cases-3.2-mm-thick by $229-\mathrm{mm}$-square plates. The facilities are described in Ref. 3. The specimens were clamped on 203-mm-diam circles and impacted at the center.

In addition to baseline tests, tests were performed to assess the effects of moisture. Also, brickdrop tests were performed to determine the ability of the baseline correlations to cover that event. Finally, impact specimens were cut into tensile, compression, or fatigue specimens that were tested to determine property degradation as a function of damage area. These tests and the results are presented in the following sections.

\subsection{IMPACT TESTS}

\subsubsection{Baseline Results}

Table 16.1 lists all of the pendulum and air-gun impact tests performed on the choppedfiber composite. In all cases, the pendulum impactor mass was $11.52 \mathrm{~kg}$ with a $12.7-\mathrm{mm}$-diam hemispherical impactor point. The air-gun projectile was a 12.7 -mm-diam steel cylinder with a hemispherical point. The projectile mass was $0.0227 \mathrm{~kg}$. The velocities in Table 16.1 were measured just prior to impact using a laser device. ${ }^{3}$ The forces, in the case of the pendulum tests, are peak values measured by a miniature load cell mounted behind the impactor point. Damage areas were determined from ultrasonic C-scans of the impacted plate specimens. Finally, the "property tests" column indicates the type of mechanical property test specimens cut from each impacted plate specimen.

Figure 16.1 shows the correlation between damage area and kinetic energy for the baseline data. Contrary to the reference CSM composite where damage area correlated with $\mathrm{m}^{0.564} \mathrm{v}$, where $\mathrm{m}$ is mass and $\mathrm{v}$ is velocity, kinetic energy, or $\mathrm{m}^{0.500} \mathrm{v}$, does a good job of bringing the two data sets together. This is illustrated in Fig. 16.2, where the individual correlations for the pendulum and air-gun data are compared to the overall correlation from Fig. 16.1.

For design assessment use, the design curve shown in Fig. 16.3 and used in Part 1 is recommended. The curve approximately represents the upper bound of the data. 
Table 16.1. Results of pendulum and air-gun tests on P4 chopped-glassfiber/Baydur 420 IMR composite

\begin{tabular}{|c|c|c|c|c|c|}
\hline $\begin{array}{l}\text { Specimen } \\
\text { number }\end{array}$ & $\begin{array}{c}\text { Property } \\
\text { tests }\end{array}$ & $\begin{array}{c}\text { Velocity } \\
(\mathrm{m} / \mathrm{s})\end{array}$ & $\begin{array}{c}\text { Energy } \\
\text { (J) }\end{array}$ & Force (N) & $\begin{array}{c}\text { C-Scan } \\
\text { damage area } \\
\left(\mathrm{mm}^{2}\right)\end{array}$ \\
\hline \multicolumn{6}{|c|}{$12.7 \mathrm{~mm} \mathrm{D}, 11.52 \mathrm{~kg},-$ baseline } \\
\hline $\mathrm{B} 22-1$ & Tensile & 1.00 & 5.8 & 1758 & 52 \\
\hline B22-2 & Tensile & 1.37 & 10.7 & 2567 & 103 \\
\hline B23-1 & Tensile & 1.72 & 17.0 & 3466 & 168 \\
\hline $\mathrm{B23-2}$ & Compression & 0.99 & 5.7 & 1758 & 65 \\
\hline B24-1 & Compression & 1.37 & 10.8 & 2641 & 136 \\
\hline $\mathrm{B24-2}$ & Compression & 1.71 & 16.8 & 3342 & 219 \\
\hline $\mathrm{B25-1}$ & Fatigue & 1.00 & 5.8 & 1758 & 52 \\
\hline $\mathrm{B} 25-2$ & Fatigue & 1.00 & 5.8 & 1791 & 39 \\
\hline B26-1 & Fatigue & 1.37 & 10.8 & 2525 & 148 \\
\hline$B 26-2$ & Fatigue & 1.37 & 10.7 & 2616 & 97 \\
\hline $\mathrm{B} 30-1$ & Tensile & 1.66 & 15.9 & 3153 & 116 \\
\hline $830-2$ & Compression & 2.16 & 27.0 & 3631 & 271 \\
\hline \multicolumn{6}{|c|}{ Water saturated } \\
\hline B27-1 & Tensile & 1.03 & 6.1 & 3631 & 65 \\
\hline B27-2 & Tensile & 1.38 & 11.0 & 2360 & 65 \\
\hline B28-1 & Tensile & 1.68 & 16.2 & 2781 & 258 \\
\hline$\overline{B 28-2}$ & Tensile & 1.93 & 21.4 & 2979 & $\overline{381}$ \\
\hline \multicolumn{6}{|c|}{ Impacted then water saturated } \\
\hline B29-1 & Tensile & 1.38 & 11.0 & 2649 & 123 \\
\hline B29-2 & Tensile & 1.29 & 9.6 & 2410 & 110 \\
\hline \multicolumn{6}{|c|}{ 1000h in room temperature water } \\
\hline B36-1 & None & 1.84 & 19.5 & 3524 & 192 \\
\hline $\mathrm{B36-2}$ & None & 1.46 & 12.3 & 3029 & 54 \\
\hline
\end{tabular}

\begin{tabular}{|c|c|c|c|c|}
\hline $\begin{array}{c}\text { Specimen } \\
\text { number }\end{array}$ & $\begin{array}{c}\text { Property } \\
\text { tests }\end{array}$ & $\begin{array}{l}\text { Velocity } \\
(\mathrm{m} / \mathrm{s})\end{array}$ & $\begin{array}{c}\text { Energy } \\
\text { (J) }\end{array}$ & $\begin{array}{c}\text { C-Scan } \\
\text { damage area } \\
\left(\mathrm{mm}^{2}\right)\end{array}$ \\
\hline \multicolumn{5}{|c|}{$12.7 \mathrm{~mm} \quad \mathrm{D}, 0.0227 \mathrm{~kg},-$ baseline } \\
\hline $\mathrm{B22-3}$ & Tensile & 30.84 & 10.8 & 161 \\
\hline$B 22-4$ & Tensile & 40.22 & 18.4 & 245 \\
\hline B23-3 & Tensile & 48.68 & 26.9 & 323 \\
\hline B23-4 & Compression & 30.82 & 10.8 & 142 \\
\hline B 24-3 & Compression & 40.26 & 18.4 & 194 \\
\hline $\mathrm{B} 24-4$ & Compression & 48.21 & 26.4 & 258 \\
\hline B 25-3 & Fatigue & 30.68 & 10.7 & 148 \\
\hline B25-4 & Fatique & 31.14 & 11.0 & 135 \\
\hline B26-3 & Fatique & 39.68 & 17.9 & 194 \\
\hline B26-4 & Fatique & 40.23 & 18.4 & 148 \\
\hline B 30:3 & Tensile & 53.74 & 32.8 & 129 \\
\hline B30-4 & Compression & 65.55 & 48.8 & 335 \\
\hline \multicolumn{5}{|c|}{ Water saturated } \\
\hline B27-3 & Tensile & 30.59 & 10.6 & 65 \\
\hline B27-4 & Tensile & 38.78 & 17.1 & 213 \\
\hline $\mathrm{B} 28-3$ & Tensile & 45.29 & 23.3 & 529 \\
\hline B28-4 & Tensile & 50.83 & 29.3 & 619 \\
\hline \multicolumn{5}{|c|}{ Impacted then water saturated } \\
\hline B29-3 & Tensile & 38.54 & 16.9 & 174 \\
\hline B29-4 & Tensile & 37.96 & 16.4 & 167 \\
\hline \multicolumn{5}{|c|}{$1000 \mathrm{~h}$ in room temperature water } \\
\hline B36-3 & None & 41.50 & 19.5 & 61 \\
\hline B36-4 & None & 31.40 & 11.2 & 39 \\
\hline
\end{tabular}




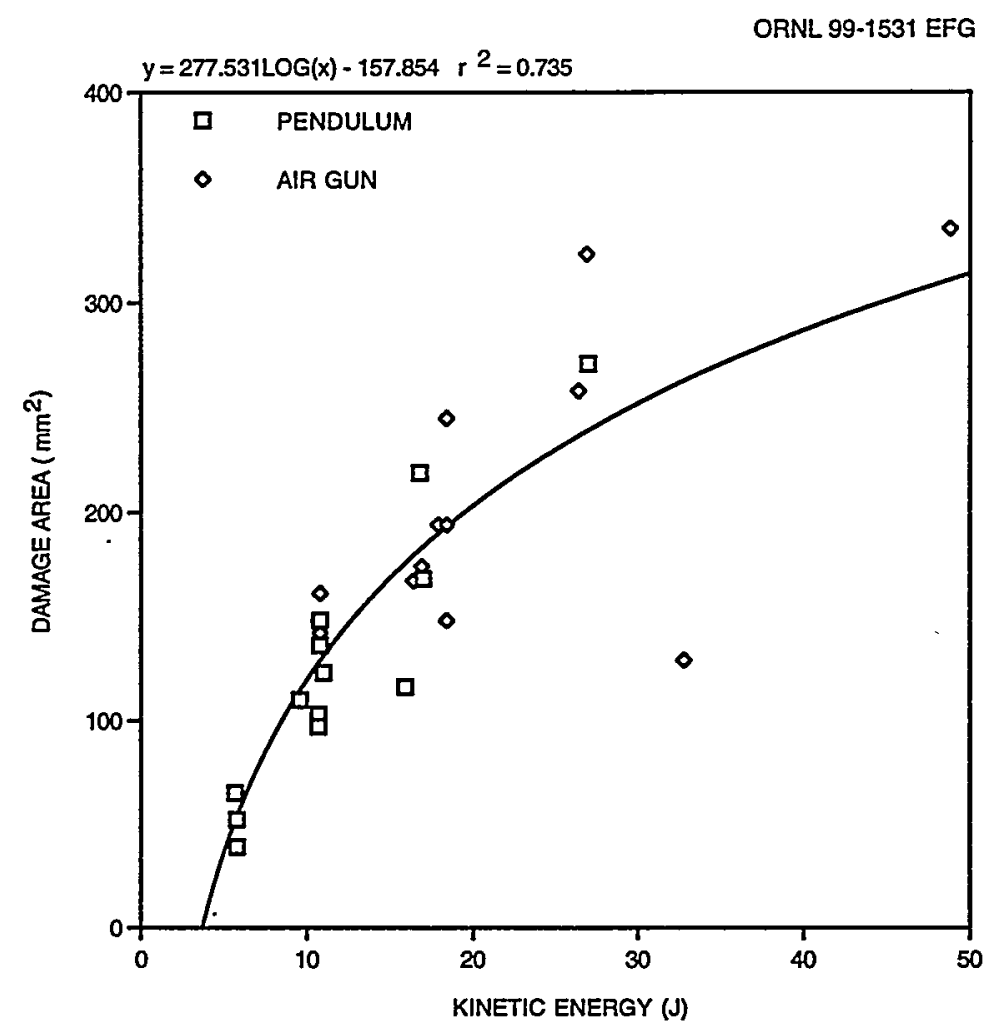

Fig. 16.1. Baseline impact damage vs kinetic energy correlation.

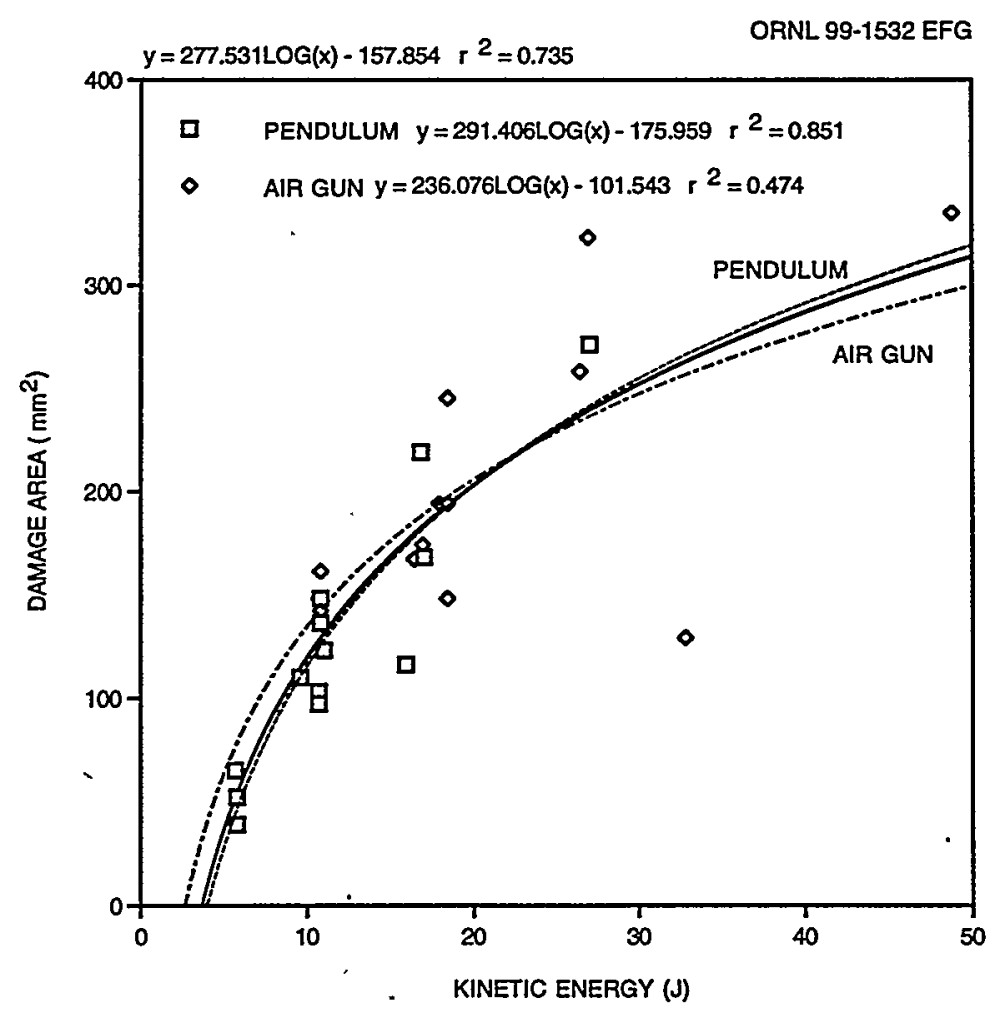

Fig. 16.2. Supporting baseline pendulum and air gun impact damage correlations. 


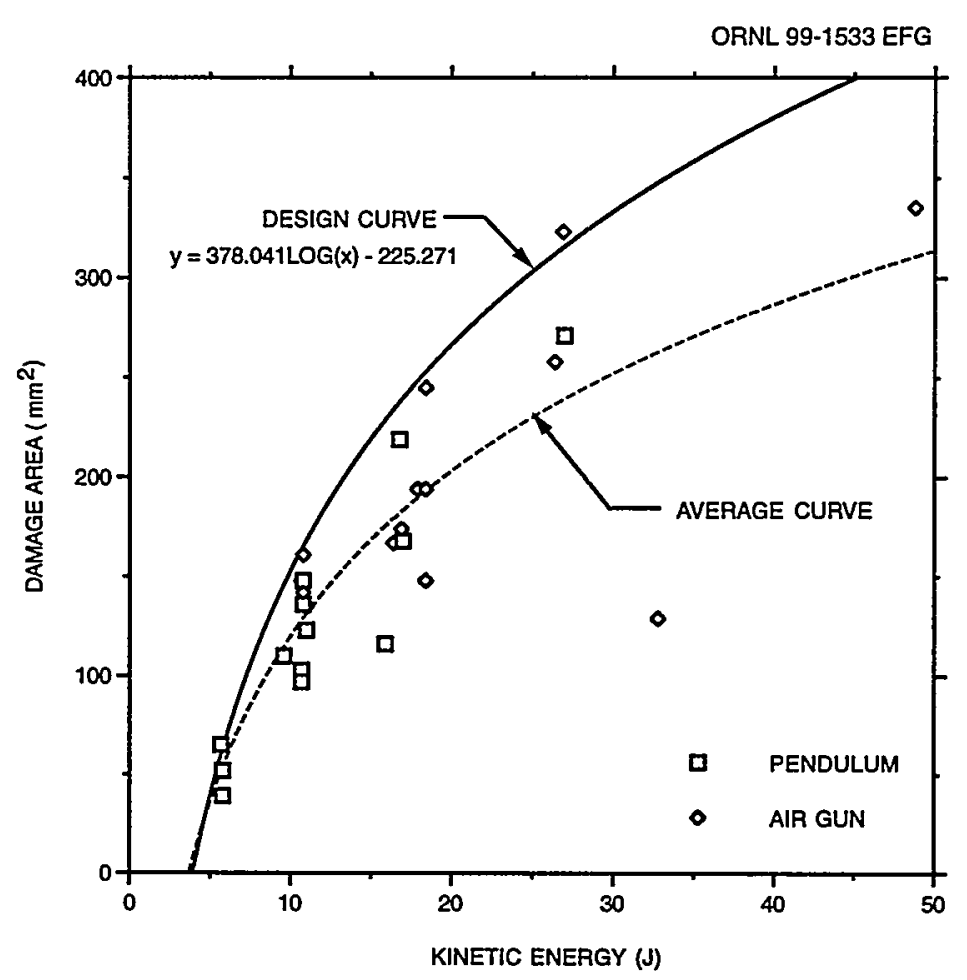

Fig. 16.3. Recommended "design" curve.

\subsubsection{Moisture Effects}

As shown in Table 16.1, three different moisture conditions were examined. In the first, eight specimens were tested that had been saturated by soaking in $50^{\circ} \mathrm{C}$ distilled water for 3 months. The specimens were removed from water and immediately tested. In the second group, four specimens were tested and then subjected to a 3-month soak in $50^{\circ} \mathrm{C}$ distilled water. The idea here was to see if damaged areas are particularly susceptible to moisture degradation as reflected by the resulting property degradation. The final moisture condition examined was the standard presoak in room-temperature distilled water for $1000 \mathrm{~h}$.

The water-saturated specimens $\left(3\right.$ months at $\left.50^{\circ} \mathrm{C}\right)$ exhibited major degradation in impact resistance, as shown in Fig. 16.4. As was mentioned in Chap. 8, specimens subjected to this presoak were somewhat damaged in the soaking, since material loss occurred. In addition, the impact specimens tended to blister on one side (the back side in the impact test ${ }^{*}$ ). The blistering appeared to be a debonding of the outer layer of matrix and is thought to be due to the veil or to binder gradients in the preform. In any event, the blisters appeared to interact with and aggravate the apparent impact damage, and this may be the source of much of the enhanced damage implied by the values reported in Fig. 16.4.

In contrast to the large effect of moisture shown in Fig. 16.4, the four specimens impacted after a presoak of $1000 \mathrm{~h}$ in room-temperature distilled water actually indicated an improvement in damage tolerance, as shown in Fig. 16.5. While this could be simply a reflection

*The specimens were consistently impacted on the side that exhibited the original ACC plaque number, which was the top of the plaque in the mold configuration. The back side of the impacted specimen thus corresponded to the bottom of the plaque, which contained the veil material (see Subsect. 1.2.2). 


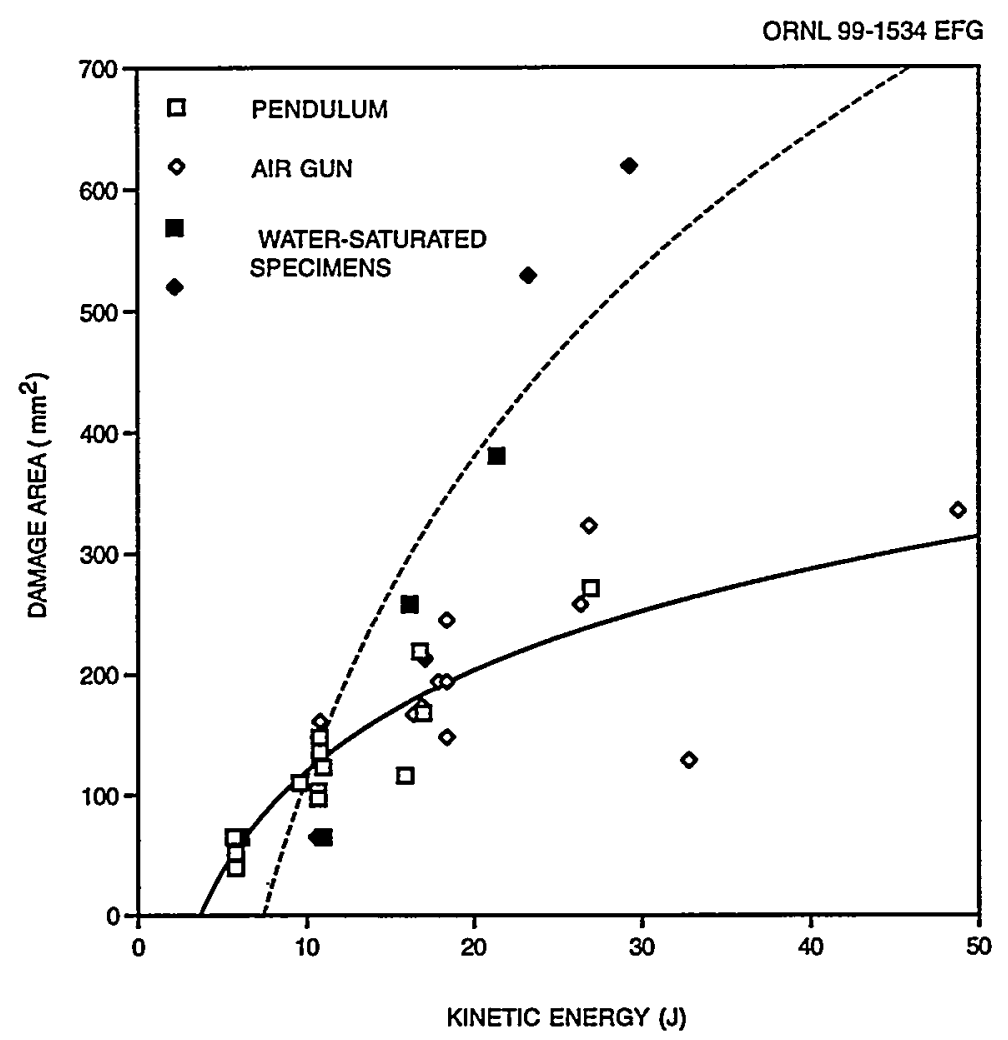

Fig. 16.4. Impact damage data for water-saturated specimens compared to baseline data and correlation.

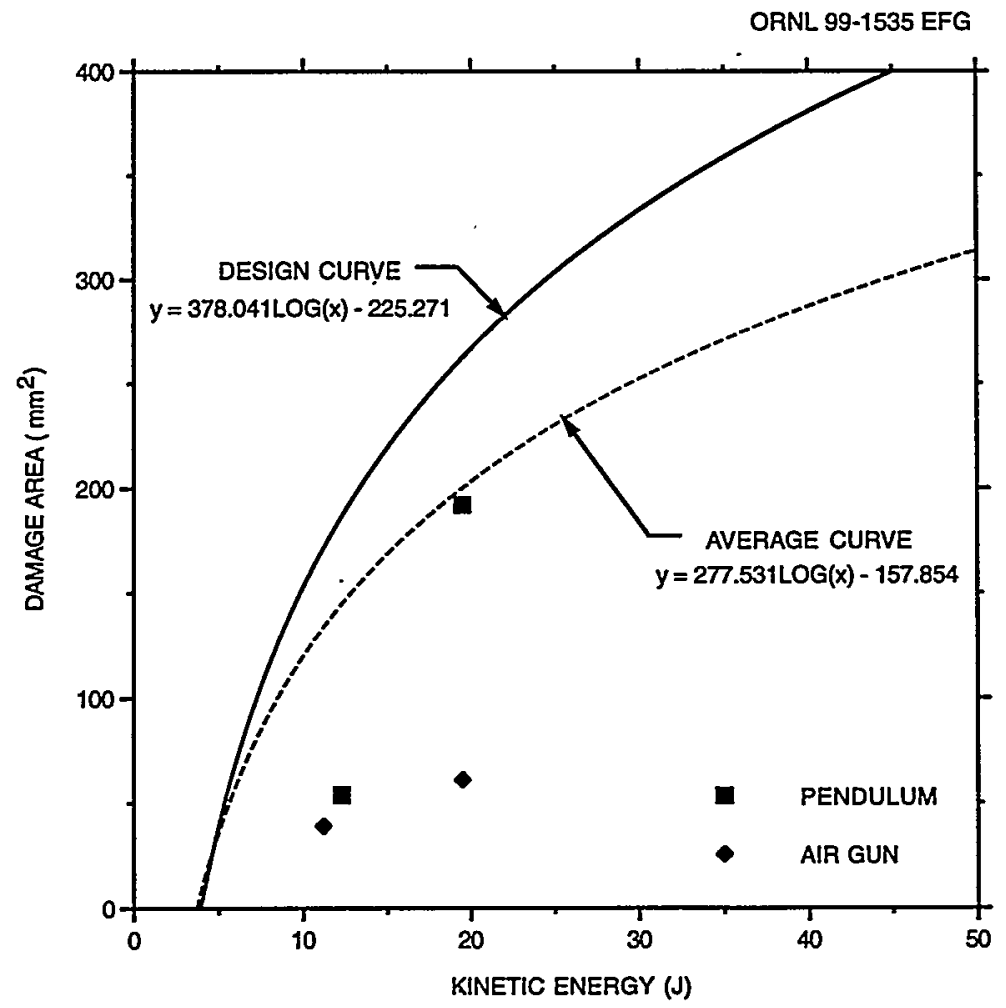

Fig. 16.5. Impact damage data for specimens soaked $1000 \mathrm{~h}$ in room-temperature distilled water compared to baseline correlation. 
of plaque variations, it is possible that the water plasticized the matrix somewhat, making it more flexible and less likely to craze and crack.

\subsubsection{Brick-Drop Tests}

The test results presented in the previous two subsections are all for smooth hemispherical steel impactor points. Brick drops, which are one of the loadings specified for the ACC Focal Project II pickup box design, provide an opportunity to determine if the results are applicable to impacts from more irregular objects.

Seven brick-drop tests were performed, as tabulated in Table 16.2. The bricks used had an average mass of $1.68 \mathrm{~kg}$. The bricks were dropped from heights of $2.4,2.1,1.8,1.5,1.2$, and $0.61 \mathrm{~m}(8,7,6,5,4,2 \mathrm{ft})$. They were dropped so that they hit on a corner with the center of gravity in line with the impact point. The same clamped specimen design as in the previous case was used, and the bricks hit near the center of the plates.

Figures 16.6-16.8 are photographs of the backside of specimens impacted from 2.4, 1.8, and $1.6 \mathrm{~m}$. In all cases, the damage was localized and does not appear to differ significantly from that produced in the pendulum and air-gun tests. Figure 16.9 compares damage areas produced by the brick drops with the average and design correlations from the pendulum and air-gun tests. With two exceptions, the brick drop points are below the average of the pendulum and air-gun data. The design curve bounds all but one point—the drop from $2.4 \mathrm{~m}$.

Table 16.2. Results of brick-drop tests

BRICK DROP TESTS
\begin{tabular}{|c|c|r|r|r|}
\hline $\begin{array}{c}\text { Specimen } \\
\text { number }\end{array}$ & $\begin{array}{c}\text { Property } \\
\text { tests }\end{array}$ & $\begin{array}{c}\text { Velocity } \\
(\mathrm{m} / \mathrm{s})\end{array}$ & $\begin{array}{c}\text { Energy } \\
(\mathrm{J})\end{array}$ & $\begin{array}{c}\text { C-Scan } \\
\text { damage area } \\
\left(\mathrm{mm}^{2}\right)\end{array}$ \\
\hline B33-1 & None & 6.92 & 39.8 & 471 \\
\hline B33-2 & None & 5.99 & 29.8 & 234 \\
\hline B33-3 & None & 4.89 & 20.2 & 101 \\
\hline B33-4 & None & 5.99 & 30.1 & 328 \\
\hline B35-1 & None & 6.46 & 35.0 & 223 \\
\hline B35-2 & None & 5.45 & 24.7 & 230 \\
\hline B35-3 & None & 3.46 & 10.1 & 54 \\
\hline
\end{tabular}

\subsection{DEGRADATION OF PROPERTIES}

As was indicated in Table 16.1, the baseline impact specimens were cut into either tensile, compression, or fatigue test specimens. Saturated moisture specimens were cut into tensile specimens. In all cases, five specimens were cut from each impact specimen, as shown in Fig. 16.10. The center specimen was centered on the damage area. The outer four specimens did not contain damage, and their results were averaged to obtain reference values against which the results from the center specimens were evaluated. All specimens were $25.4 \mathrm{~mm}$ wide.

All of the fatigue tests $(R=0.1)$ were performed at a single maximum stress level of $100 \mathrm{MPa}$, which corresponds to a 10,000 cycle life in undamaged material. It was assumed that the fatigue curves for impact-damaged specimens would be parallel to those of the undamaged 


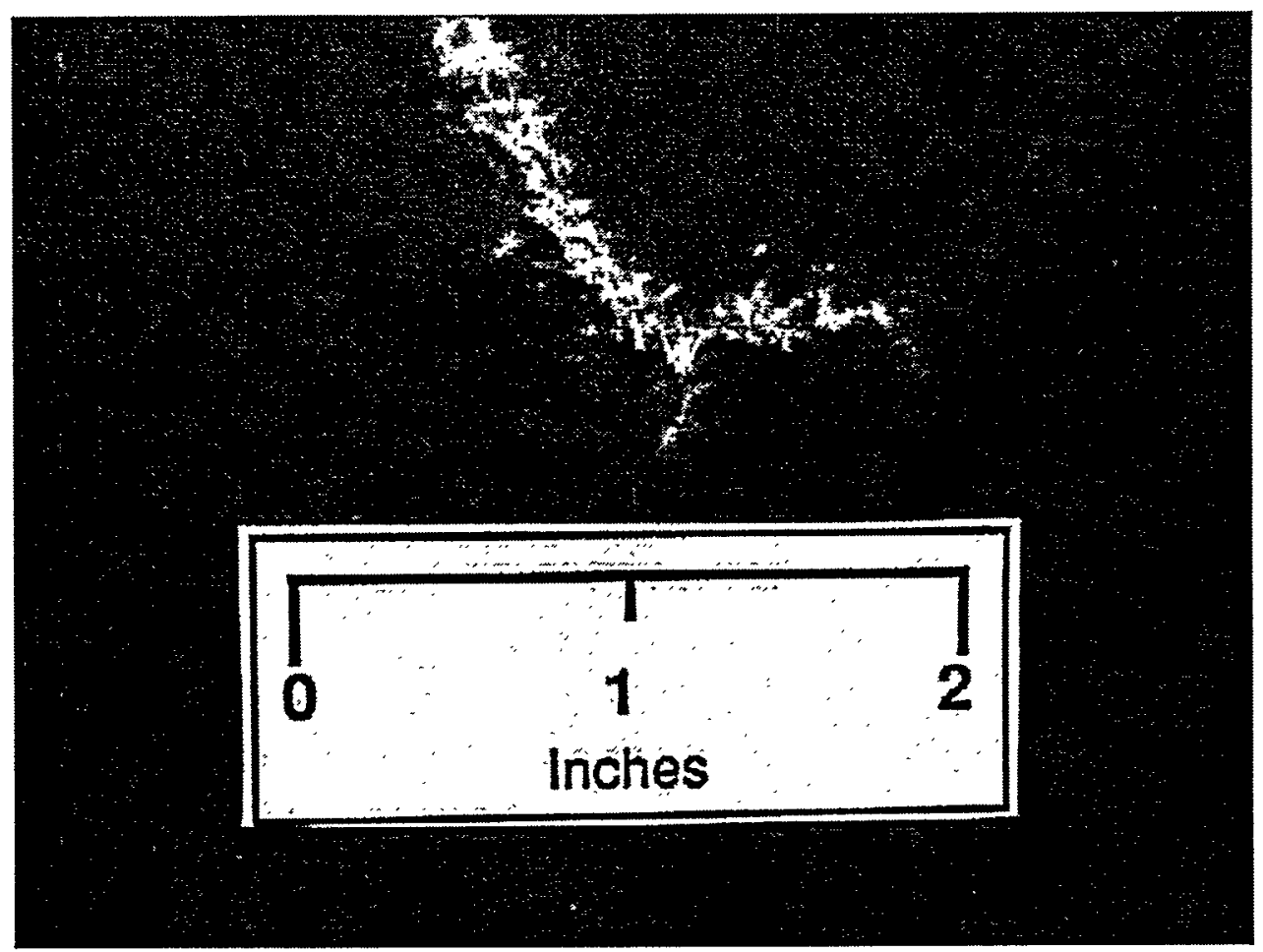

Fig. 16.6. Back side of specimen showing damage produced by 2.4-m (8-ft) brick drop.

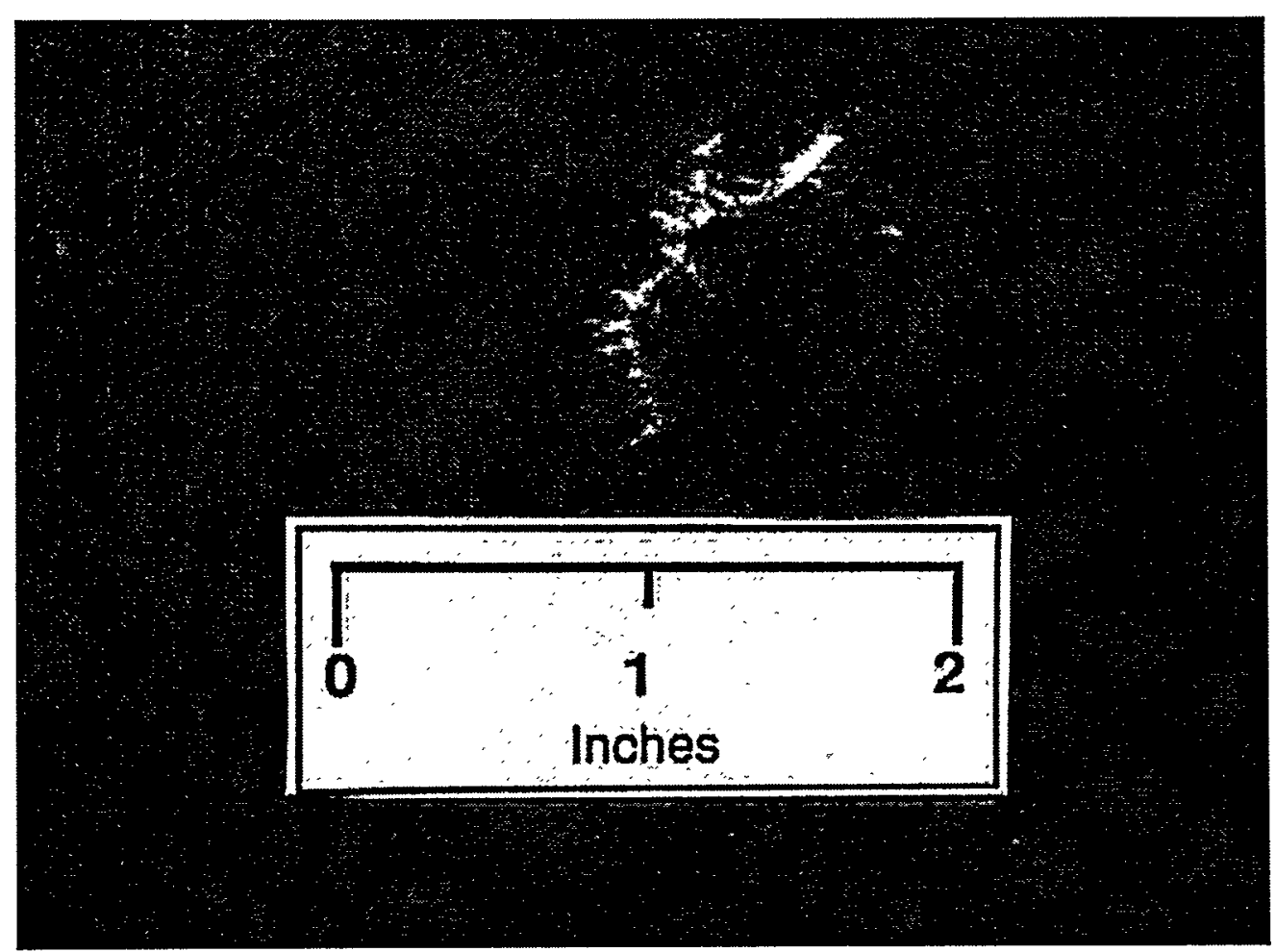

Fig. 16.7. Back side of specimen showing damage produced by $1.8-\mathrm{m}$ (6-ft) brick drop. 


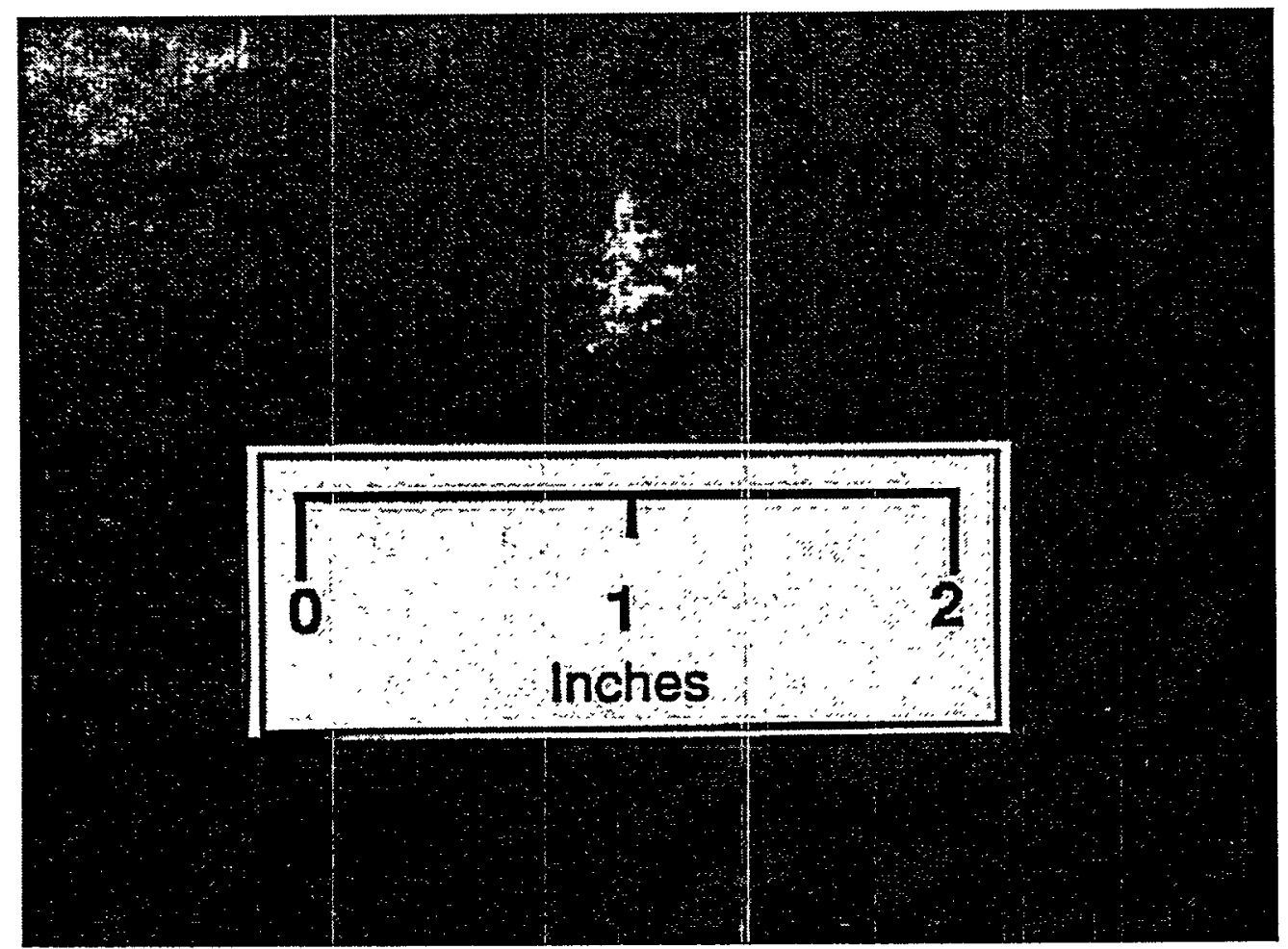
drop.

Fig. 16.8. Back side of specimen showing damage produced by $1.2-\mathrm{m}$ (4-ft) brick

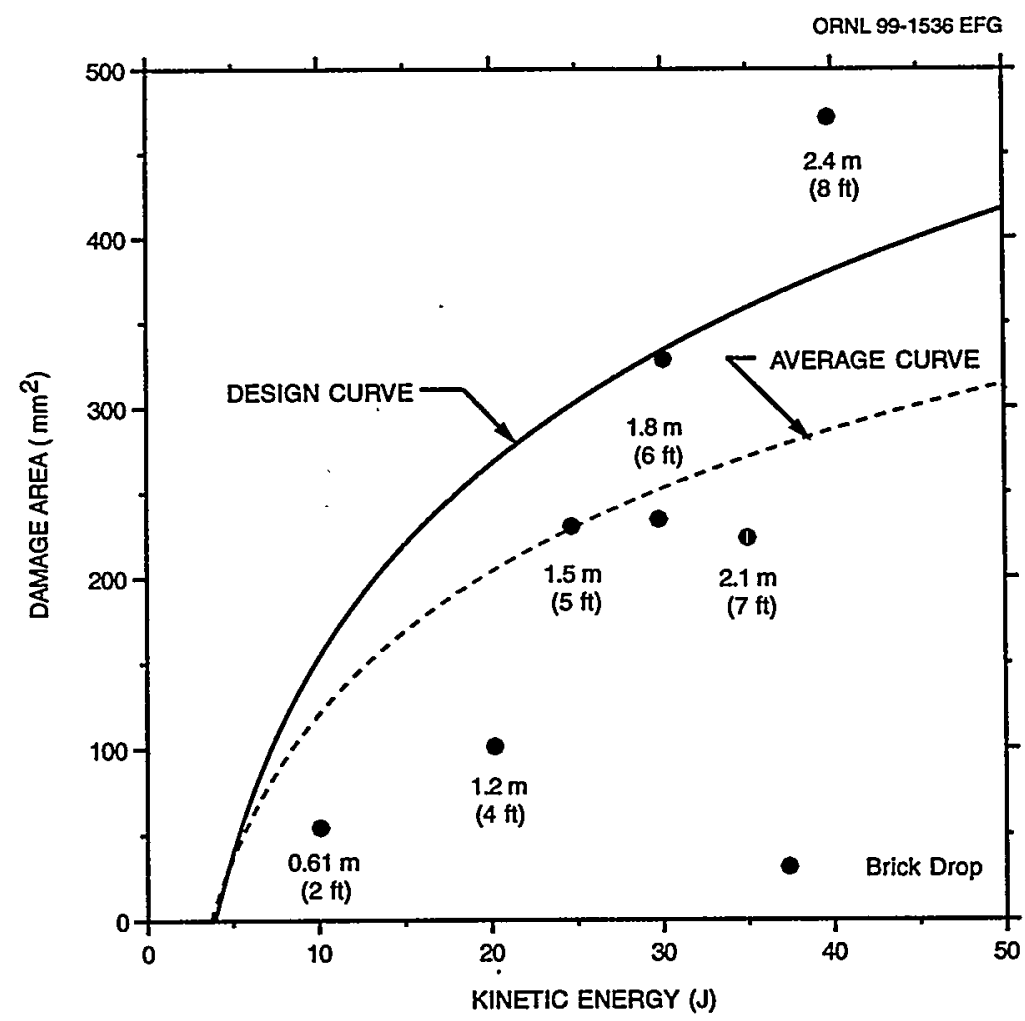

Fig. 16.9. Impact damage data for specimens subjected to brick drops compared to baseline correlation and to design curve. 


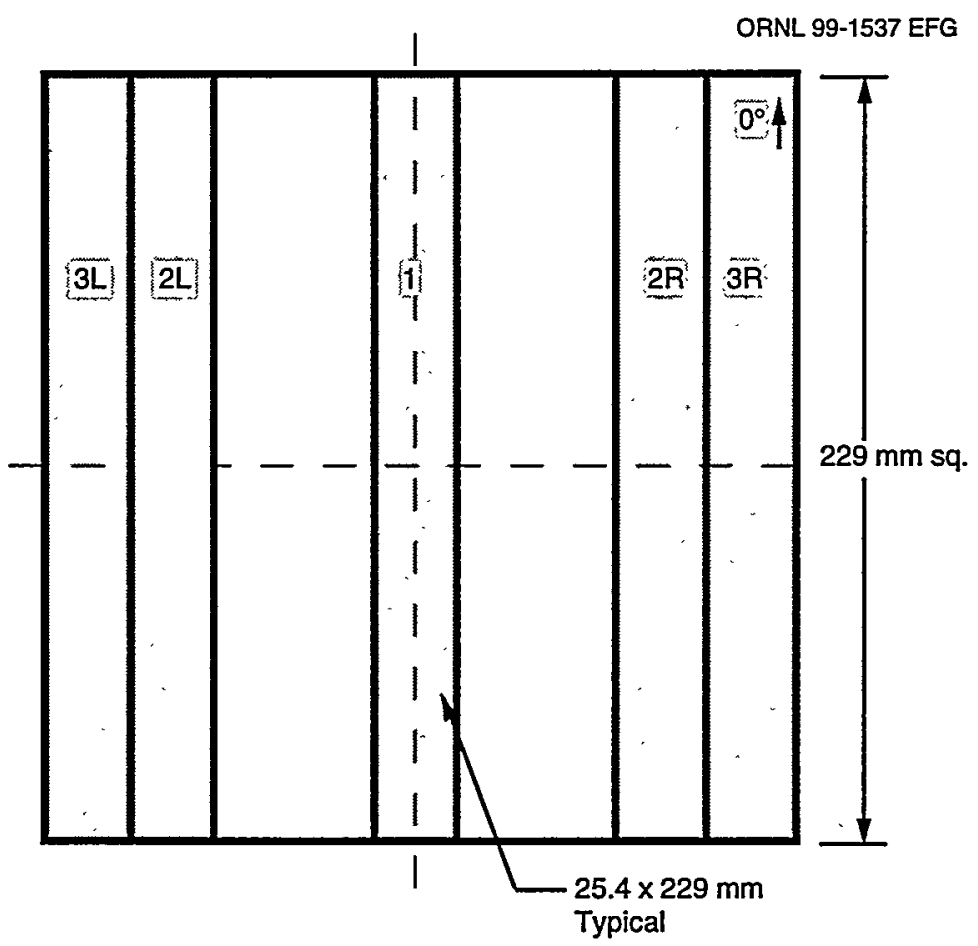

Fig. 16.10. Cutting plan used for obtaining tensile and fatigue specimens from impact specimens.

specimens. On this basis, the results of the 100-MPa tests were used to estimate the fatigue strength at $10^{6}$ cycles.

The results from the baseline specimens are shown in Fig. 16.11, where the relative strength (the strength from the center specimen relative to the average of that from the outer four) is shown as a function of damage area. Surprisingly, the trends in this figure are opposite to those found from similar tests of the reference composite. ${ }^{2}$ Tension and fatigue strengths appear to be unaffected by the damage, whereas compression strength is significantly affected. The latter is akin to the behavior of true laminants. This is understandable since failed mechanical property specimens of the chopped-fiber composite often exhibit "delaminations" between fiber layers in the vicinity of the failure surface.

In the case of the reference composite, tensile strength was most degraded by impact damage, followed by fatigue strength. Compressive strength was least degraded. Again, this is consistent with the fact that delaminations or splitting between fiber layers was rarely observed in the case of the CSM reference composite.

Also, none of the impacted chopped-fiber specimens from which tensile and fatigue specimens came appeared to have a significant number of broken fibers in the damage area (two of those from which compression specimens came did). This may explain the lack of an effect on tensile and fatigue strengths. In contrast, the reference CSM composite impacted specimens appeared to have more distinct cracks and broken fibers.

Figure 16.12 isolates the compressive strength points in Fig. 16.11 and compares them with the straight line correlation suggested for design use in Chap. 6 of Part 1. It is interesting to 


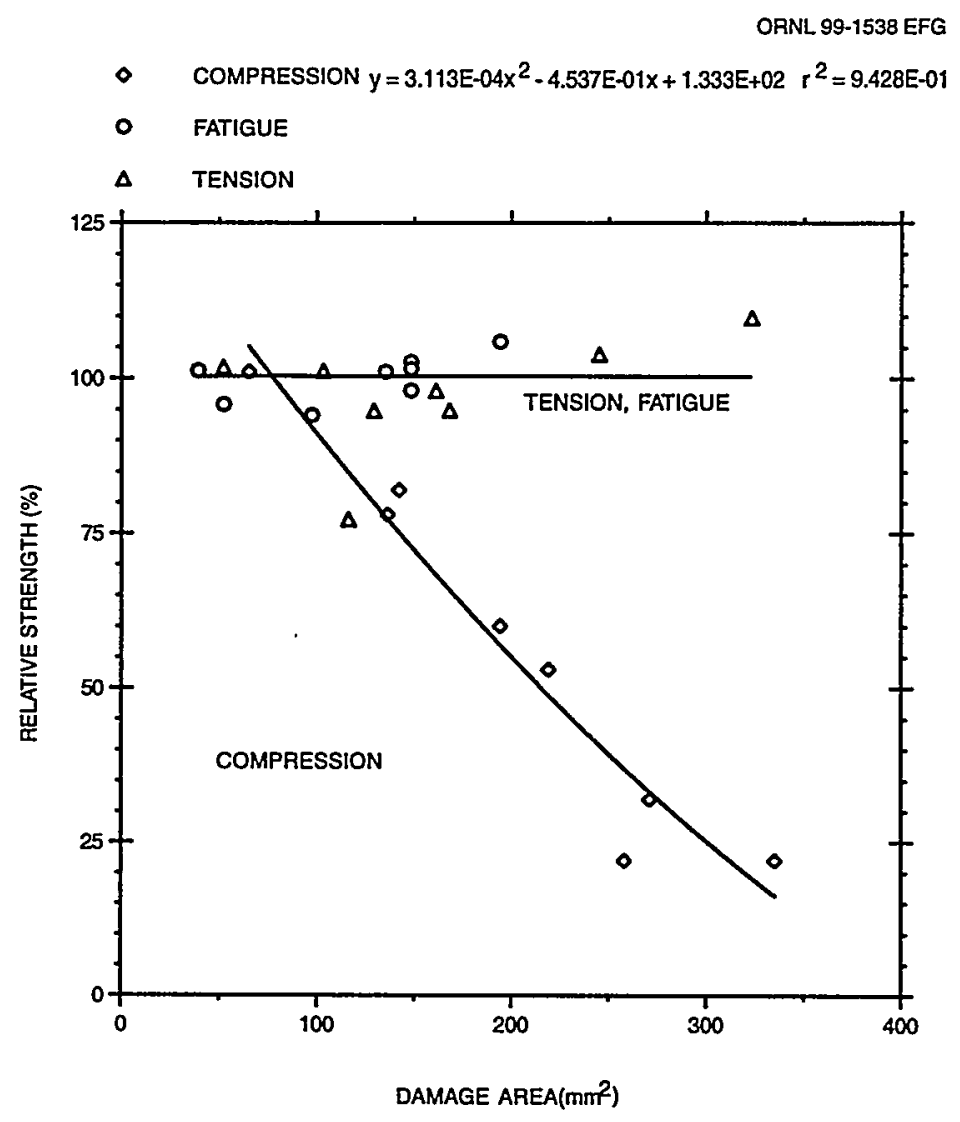

Fig. 16.11. Relative residual strengths of specimens containing the damage area vs the damage area. The fatigue strength reduction corresponds to any cyclic life.

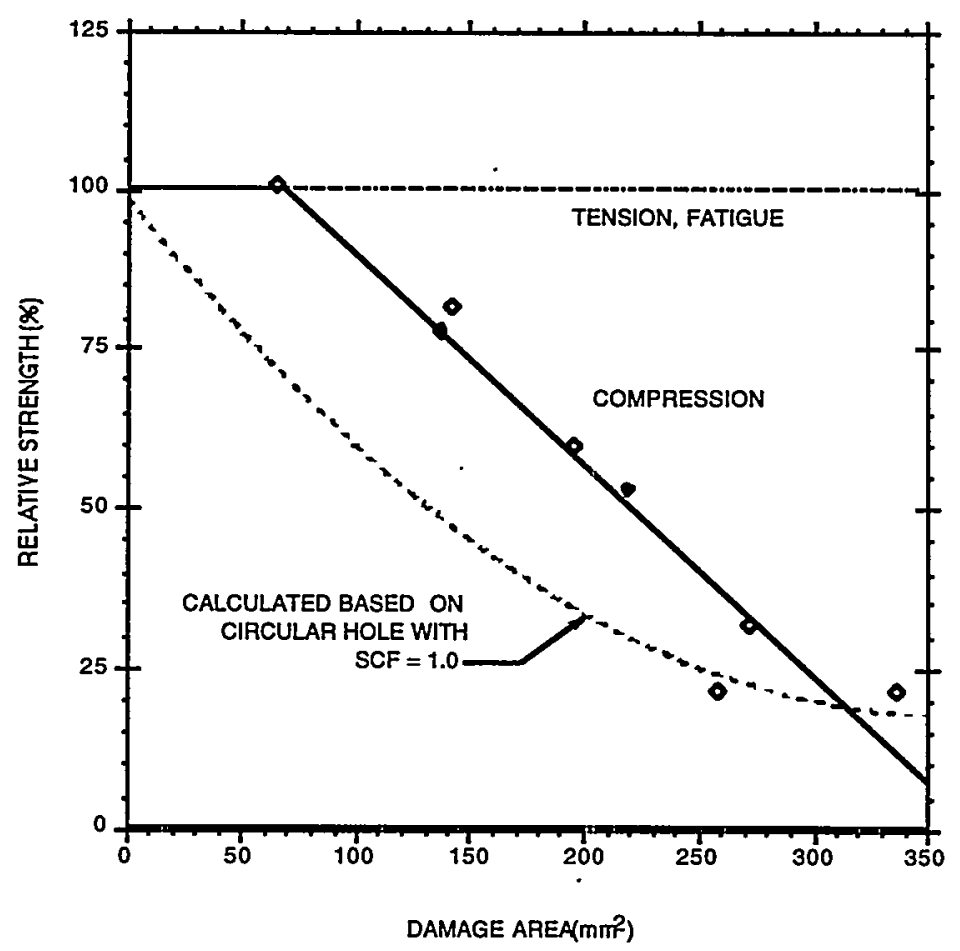

Fig. 16.12. Comparison of compressive failure points with calculated effect of equivalent circular holes. 
compare the compressive failure points with the calculated strength of 25.4-mm-wide specimens with circular holes. That prediction is included in Fig. 6.12. It is based on the assumption that the SCF is 1.0, i.e., failure occurs when the average stress at the minimum area reaches the ultimate compressive strength of the material. Over most of the damage area range, the assumption of an equivalent circular hole provides a lower bound to the expected strength degradation; i.e., an impact damage area does have some inherent strength in compression. The inherent strength is not nearly as large as in tension, however, where it is postulated that the unbroken fibers still carry the load.

Figure 16.13 is the same as Fig. 16.11 except for the addition of tensile strength reduction points for two saturated moisture conditions:

1. saturated prior to impact testing, and

2. impact tested and then saturated.

As previously discussed, blistering that interacted with impact damage in the case of the presoaked specimens may be responsible for the data scatter in that case. Otherwise, even this extreme moisture condition appears to have only a moderate effect on residual strength.

As was pointed out in Ref. 2, these relative properties are pseudoproperties. Clearly, they depend on specimen width, at least in the case of compression.

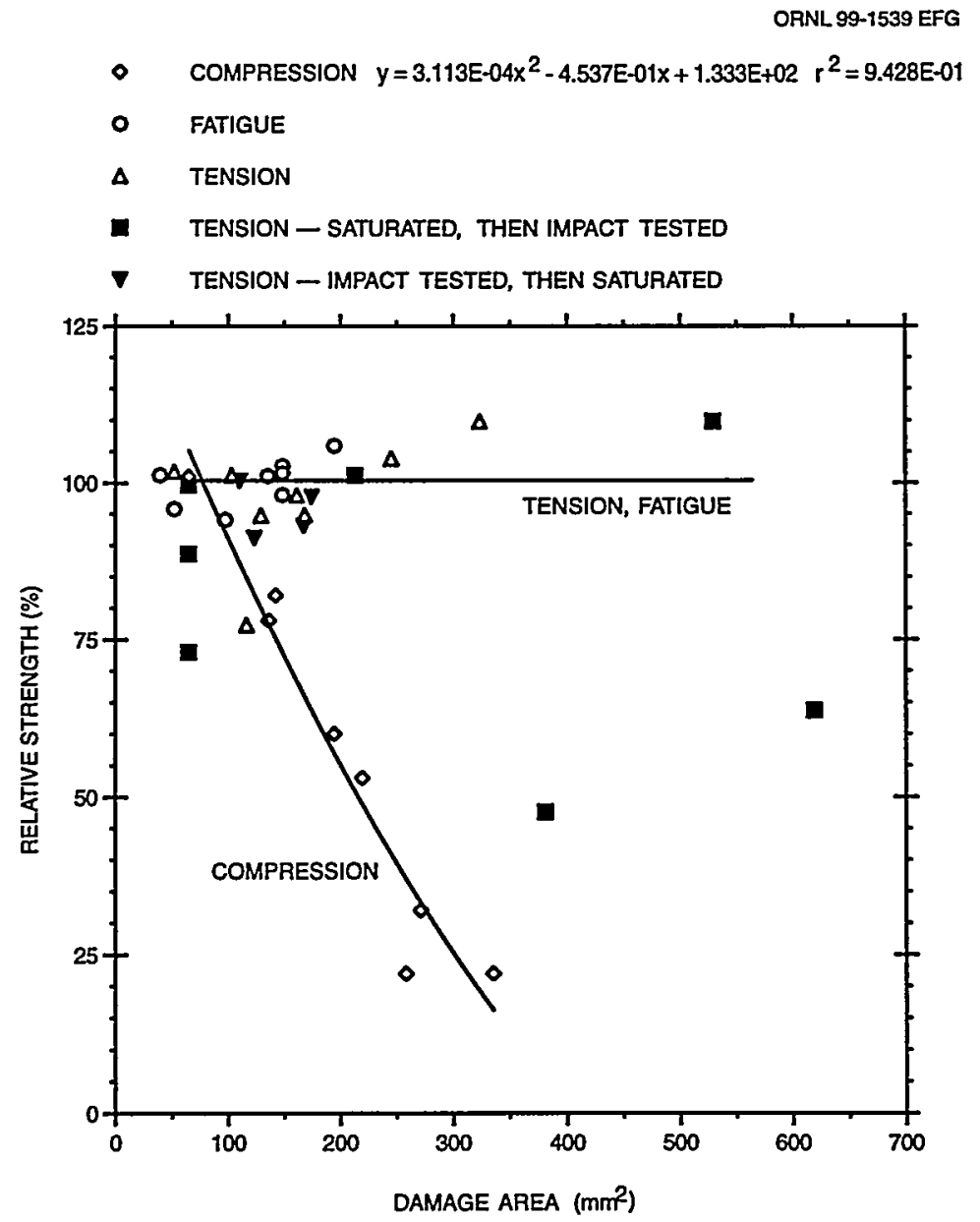

Fig. 16.13. Moisture effect on relative residual tensile strength. 


\subsection{SUMMARY AND DISCUSSION}

Based on the results of 24 baseline impact tests (12 pendulum and 12 air gun), it was found that impact damage in the Baydur $420 \mathrm{IMR} / \mathrm{P} 4$ chopped-fiber composite is of the same magnitude as in the reference CSM composite. In contrast with the reference composite, however, the damage area in the chopped-fiber composite correlates well with the kinetic energy of the impactor.

While water-saturated specimens (presoaked 3 months in distilled water at $50^{\circ} \mathrm{C}$ ) were significantly more susceptible to impact damage, the standard $1000 \mathrm{~h}$ in room-temperature distilled water presoak actually improved impact resistance. This is attributed to the plastisizing effect of water on the matrix. Blistering caused by the long $50^{\circ} \mathrm{C}$ presoak probably added to the apparent impact damage in those specimens. It is concluded that realistic moisture exposure conditions should have no adverse effect on impact damage. Thus, the design curve derived from the baseline correlation should be applicable.

Seven brick-drop tests were performed. With a couple of exceptions, all of the damage areas were below that predicted by the average correlation from the baseline pendulum and airgun tests. The design curve bounded all of the brick-drop data except for the highest drop (from $2.4 \mathrm{~m}$ ). For moderate drops, the baseline design curve is adequate.

Baseline impact specimens were subsequently cut into either tension, compression, or fatigue specimens. These specimens were tested to establish the strength degradation due to the impact damage. The compressive strength was significantly degraded, while tensile strength and tensile fatigue strength were essentially unaffected. This is consistent with the observations that (1) the chopped-fiber composite is more prone to delaminations and splitting between fiber layers than the reference composite and (2) impact damage in the chopped-fiber composite seemed to be less likely to produce broken fibers than in the reference composite. Tensile- and fatigue-strength degradation were greater than compressive strength degradation in the reference composite.

Although the impact specimens that had been subjected to the standard moisture presoak of $1000 \mathrm{~h}$ in room-temperature water were not cut into mechanical property specimens, it is not expected that this condition would further degrade residual strength. 


\section{REFERENCES}

1. J. M. Corum et al., Durability-Based Design Criteria for an Automotive Structural Composite: Part 1. Design Rules, ORNL-6930, Lockheed Martin Energy Research Corp., Oak Ridge National Laboratory, February 1998.

2 J. M. Corum et al., Durability-Based Design Criteria for an Automotive Structural Composite: Part 2. Background Data and Models, ORNL-6931, Lockheed Martin Energy Research Corp., Oak Ridge National Laboratory, February 1998.

3. J. M. Corum, R. L. Battiste, W. Ren, and M. B. Ruggles, Recommended Minimum Test Requirements and Test Methods for Assessing Durability of Random-Glass-Fiber Composites, ORNL-6953, Lockheed Martin Energy Research Corp., Oak Ridge National Laboratory, June 1999.

4. M. Elahi and Y. J. Weitsman, On the Mechanical Response of P4 Chopped Glass/Urethane Resin Composite: Data and Model, ORNL-6955, Lockheed Martin Energy Research Corp., Oak Ridge National Laboratory, October 1999.

5 Military Handbook Polymer Matrix Composites, Volume 1: Guidelines, MIL-HDBK17-1D, U.S. Department of Defense, February 1994.

6. J. M. Whitney and R. J. Nuismer, "Stress Fracture Criteria for Laminated Composites Containing Stress Concentrations," J. Composite Materials 8, 253-265 (July 1974).

7. ASTM Standard D 2584-68, Standard Test Method for Ignition Loss of Cured Reinforced Resins, American Society for Testing and Materials.

8. ASTM Standard D 3410, Standard Test Method for Compressive Properties of Unidirectional or Crossply Fiber-Resin Composites, American Society for Testing and Materials.

9. ASTM Standard D 2344, Standard Test Method for Apparent Interlaminar shear Strength of Parallel Fiber Composites by Short Beam Method, American Society for Testing and Materials.

10. R. E. Peterson, Stress Concentration Factors, John Wiley and Sons, New York, p. $111,1974$.

11. M. J. Owen and T. R. Smith, "Some fatigue properties of chopped-strandmat/polyester resin laminates," Plastics and Polymers, 33-44 (February 1968).

12. A. F. Johnson, Engineering Design Properties of GPR, The British Plastics Federation, London.

13. A. Conle and J. P. Ingall, "Effects of Mean Stress on the Fatigue of Composite Materials," J. of Composite Technology and Research 7:1, 3-11 (Spring 1985).

14. W. Ren and C. R. Brinkman, "Creep and Creep Rupture Behavior of a Continuous Strand, Swirl Mat Reinforced Polymer Composite in Automotive Environments," Proceedings of International Composites Expo '98, Nashville, Tennessee, January 19-21, 1998. 
17-2 


\section{ACKNOWLEDGEMENT}

The authors wish to express their gratitude to W. K. Kahl and Y. J. Weitsman for their painstaking and thorough reviews of the manuscript. Their many comments and suggestions have resulted in an improved document. Also, thanks are extended to R. A. Fortner who typed and composed the document. 
ORNL/TM-1999/182

\section{INTERNAL DISTRIBUTION}

\author{
1. R. L. Battiste \\ 2. R. G. Bowman \\ 3. C. R. Brinkman \\ 4-13. J. M. Corum \\ 14. W. G. Craddick \\ 15. S. Deng \\ 16. M. Elahi \\ 17. D. L. Erdman \\ 18. J. G. Hansen \\ 19. W. K. Kahl \\ 20. L. D. Klett
}

21. R. E. Norris

22. M. B. Ruggles

23. J. M. Starbuck

24. P. A. Sklad

25. C. D. Warren

26. Y. J. Weitsman

27. G. T. Yahr

28. S. Simunovic

29. R. E. Ziegler

30. ORNL Laboratory Records-RC

31-32. ORNL Laboratory Records-OSTI

\section{EXTERNAL DISTRIBUTION}

33. R. A. Bergen, MSX International, 255 Rex Boulevard, Auburn Hills, Michigan 48326.

34. K. Fielder, The Dow Chemical Company, 2301 N. Brazosport Blvd., B1608, Freeport, Texas 77541-3257.

35. R. B. Freeman, The Budd Company, 1515 Atlantic Boulevard, Auburn Hills, Michigan 48326.

36. R. Gjerde, Textron Automotive Company, 100 Brady Road, Americus, Georgia 31709.

37-65. E. M. Hagerman, Automotive Composite Consortium, General Motors, 30500 Mound Road, I-6, Box 9055, Warren, Michigan 48090-9055.

66. J. M. Henshaw, Department of Mechanical Engineering, The University of Tulsa, 600 S. College Avenue, Tulsa, Oklahoma 74104-3189.

67. G. A. Holmes, National Institute of Standards and Technology, Bldg. 224, Room B116, MS: Room B108, Gaithersburg, Maryland 20899.

68. D. Kossak, Cambridge Industries, 29333 Stephenson Highway, Madison Heights, Michigan 48071.

69. F. G. Krautz, Vetrotex Certainteed, 4515 Allendale Road, Wichita Falls, Texas 76310-2199.

70. K. Liechti, Engineering Mechanics Research Laboratory, Department of Aerospace Engineering and Engineering Mechanics, The University of Texas at Austin, Austin, Texas 78712 .

71. G. R. Miesel; Ashland Chemical Company, 900 Wilshire Drive, Suite 100, Troy, Michigan 48084.

72. L. M. Ojanen, Decona International, 50 Casmir Court, Concord, Ontario, Canada L4K 4J5.

73. D. Oplinger, AAR-431, FAA William J. Hughes Technical Center, Atlantic City International Airport, New Jersey 08405.

74. W. Ren, AFRL/MLLN, 2230 Tenth St., Bldg. 655, Room 23, WPAFB, OH 454337817.

75. T. A. Reinhart, The University of Dayton Research Institute, 300 College Park Drive, Dayton, Ohio 45469-0130.

76. G. Sandgren, Owens Corning Science \& Technology Centre, 2790 Columbus Road, Route 16, Granville, Ohio 43023-1200.

77. C. R. Schultheisg, National Institute of Standards and Technology, Building 224, Room A209, Gaithersburg, Maryland 20899. 
78. T. D. Seagrave, Bayer Corporation, 100 Bayer Road, Pittsburgh, Pennsylvania 15205.

79. L. V. Smith, Washington State University, School of Mechanics and Materials Engineering, Pullman, Washington 99164-2920.

80-83. J. A. Carpenter, U.S. Department of Energy, 1000 Independence Avenue, SW, Washington, DC 20588.

84. P. G. Patil, U.S. Department of Energy, 1000 Independence Avenue, SW, Washington, DC 20588.

85. M. Rowlins, U.S. Department of Energy, Oak Ridge Site Office, Oak Ridge, Tennessee 37831.

86. J. Russell, U.S. Department of Energy, 1000 Independence Avenue, SW, Washington, DC 20588. 